\title{
Homogeneous Metal Catalysis for Conversion between Aromatic and Saturated Compounds
}

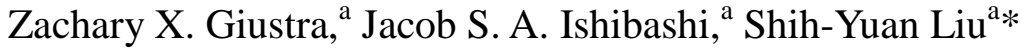 \\ ${ }^{a}$ Merkert Chemistry Center, Department of Chemistry, Boston College \\ 2609 Beacon Street, Chestnut Hill, MA 02467 USA \\ *shihyuan.liu@bc.edu
}

\begin{abstract}
In the past few decades, homogeneous catalysis of arene and heteroarene reduction has grown into a mature research field. In particular, hydrogenation of heteroaromatic systems facilitates rapid access to many classes of fine chemicals and pharmaceutically relevant compounds. In this review, we discuss the advancements made in the field of homogeneous metal-catalyzed arene and heteroarene hydrogenation from its early beginnings to the present day. We also review homogeneous catalysts for the reverse dehydrogenation of cyclic saturated species back to their aromatic counterparts, as well as single-catalyst systems capable of performing reversible hydrogenationdehydrogenation reactions.
\end{abstract}

Keywords: Homogeneous catalysis, Arene hydrogenation, Mechanistic studies, First-row transition metals

1. Introduction ${ }^{1}$

${ }^{1}$ Abbreviations

acac, acetylacetonate; ASE, aromatic stabilization energy; BArF, tetrakis[3,5bis(trifluoromethyl)phenyl]borate, BINAP, 2,2'-bis(diphenylphosphino)-1,1'-binaphthyl; BIPHEP, 2,2'-bis(diphenylphosphino)-1,1'-biphenyl; bipy, 2,2'-bipyridine; cod, 1,5cyclooctadiene; coe, cyclooctene; $\mathrm{Cp}^{*}$, 1,2,3,4,5-pentamethylcyclopentadienyl; DCE, 1,2dichloroethane; DIOP, 4,5-bis(diphenylphosphinomethyl)-2,2-dimethyl-1,3-dioxolane; DMAD, dimethyl acetylenedicarboxylate; dppe, 1,2-bis(diphenylphosphino)ethane; EtFerroTANE, 1,1'-bis(2,4-diethylphosphotano)ferrocene; MorPhos, (3,5-dioxa-4-phosphacyclohepta[2,1-a;3,4-a']dinaphthalen-4-yl)morpholine; MP²-SEGPHOS, 5,5'-bis(2,5dimethyl-1H-phosphol-1-yl)-4,4'-bibenzo[d][1,3]dioxole; PhTRAP, 2,2"bis[(diphenylphosphino)ethyl]-1,1"-biferrocene; PipPhos, (3,5-dioxa-4-phosphacyclohepta[2,1-a;3,4-a']dinaphthalen-4-yl)piperidine; RSE, resonance stabilization energy; SEGPHOS, 5,5'-bis(diphenylphosphinyl)-4,4'-bibenzo[d][1,3]dioxole; SynPhos, $\left[(5,6),\left(5^{\prime}, 6^{\prime}\right)\right.$-bis(ethylenedioxy)biphenyl-2,2'-diyl]bis(diphenylphosphine); TBAI, tetra(n-butyl)ammonium iodide; TBE, tert-butylethylene; TFE, 2,2,2-trifluoroethanol; TfOH, triflic acid; THQ, 1,2,3,4-tetrahydroquinoline; TOF, turnover frequency; TON, turnover number; Tp, tris(pyrazolyl)borate; triphos, 1,1,1-tris(diphenylphosphinomethyl)ethane; TsDPEN, $N$-( $p$-toluenesulfonyl)-1,2-diphenylethylenediamine; $\mathrm{C}_{3}{ }^{*}$-TunePhos, $(6,8$ dimethyl-7,8-dihydro-6H-dibenzo[f,h][1,5]dioxonine-1,13-diyl)bis(diphenylphosphine) 


\subsection{Scope}

The main contents of this review comprise studies of homogeneous metal catalysts for the reduction of arenes and heteroarenes to cycloalkanes and saturated heterocycles respectively. The extent of literature surveyed ranges from the early entries of the 1970s to the present day. A separate section also details catalysts developed for achieving the reverse transformation, i.e. dehydrogenation of cycloalkanes and saturated heterocycles back to their aromatic counterparts. A fifth, final section highlights single-catalyst systems designed to effect reversible hydrogenation-dehydrogenation of various $N$ heterocycles.

Homogeneous catalysis of enantioselective heteroaromatic ${ }^{2}$ hydrogenation has already been extensively reviewed by Zhou [1-3] and others [4-6], and thus will only be treated sparingly herein. Examples of molecular catalysts affixed to solid supports are not included in this review, as significant uncertainty exists regarding the nature of the active species in these systems [7]. Soluble metal nanoclusters active in arene hydrogenation [8] are also excluded.

\subsection{Homogeneous versus heterogeneous catalysis}

\subsubsection{Distinctions}

Categorization of metal-based catalysts as either homogeneous or heterogeneous has classically been based on the apparent solubility or insolubility of the species in question. In 1985, however, Schwartz [9] proposed adoption of a more relevant criterion: the nature of the material's catalytically active sites. Specifically, this classification scheme identifies homogeneous and heterogeneous catalysts as those operating via active sites of identical or diverse composition respectively, irrespective of their solubility profiles. By such an evaluation, soluble metal colloids and nanoclusters for example would still be considered heterogeneous, while insoluble zeolites would nonetheless be designated as homogeneous [10].

A more precise set of definitions notwithstanding, unambiguous determination of a catalyst's homogeneous or heterogeneous nature remains a particularly challenging experimental task to this day. Many of the early methods devised to probe this property, including the oft-used mercury poisoning test, have been demonstrated potentially ineffective when applied individually. ${ }^{3}$ In an effort to overcome these deficiencies, Finke [10] assembled a suite of analytical techniques designed for effective general use when

${ }^{2}$ To the best of our knowledge, only three examples of this transformation have been reported for an all-carbon aromatic unit. The substrates in each case have consisted of fused bicycles only; see Section 3.5 for details.

${ }^{3}$ For further details on the strengths and weaknesses of these tests, see: J. A. Widegren, R. G. Finke, J. Mol. Catal. A 198 (2003) 317. 
rigorously applied in toto. Specifically, these consist of TEM characterization of all isolated metal-containing species, kinetic studies, quantitative catalyst poisoning experiments, and other mechanistic experiments as required to rationalize all the observed reaction phenomena.

Following this protocol, Finke has elucidated the true nature of a number of purportedly homogeneous arene hydrogenation catalysts [11-13]. Among those investigated, $\left[\mathrm{Cp}^{\star} \mathrm{RhCl}_{2}\right]_{2}$ (originally reported by Maitlis [14]) presented a particularly complex case [13]. For although Finke found benzene hydrogenation to actually proceed via a heterogeneous active species, ${ }^{4}$ cyclohexene hydrogenation did in fact appear to operate through a homogeneous species (Scheme 1). Finke attributed the differing behavior to the reaction conditions: under the more strongly reducing conditions required for benzene hydrogenation, discrete precatalysts such as $\left[\mathrm{Cp}^{\star} \mathrm{RhCl}_{2}\right]_{2}$ are more likely to degenerate into heterogeneous metal $(0)$ colloids and nanoclusters. ${ }^{5}$

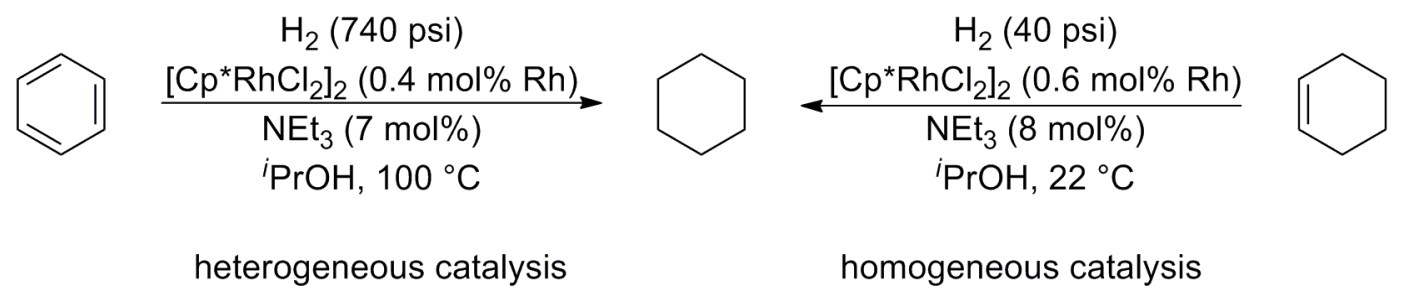

Scheme 1. Heterogeneous hydrogenation of benzene (left) and homogeneous hydrogenation of cyclohexene (right) using the same catalyst precursor $\left[\mathrm{Cp}^{\star} \mathrm{RhCl}_{2}\right]_{2}$.

Such a thorough examination as in the above studies has not been performed for many of the catalytic systems featured in this review. We have chosen, however, to err on the side of inclusivity. Readers are also encouraged to refer to Dyson's 2003 review [7] for more in-depth treatment of the debate concerning those arene hydrogenation catalysts whose homogeneous or heterogeneous nature remains in question.

\subsubsection{Advantages and disadvantages}

The greater robustness of heterogeneous catalysts vis-à-vis their homogeneous counterparts often renders use of the former more practical under the frequently forcing conditions required for either arene hydrogenation or cycloalkane dehydrogenation. Nevertheless, homogeneous catalysts can still afford a number of advantages within these

\footnotetext{
${ }^{4}$ This species was later identified as subnanometer $\mathrm{Rh}_{4}$ clusters of the general form $\mathrm{Rh}_{4}\left(\mathrm{Cp}^{*}\right)_{a} \mathrm{Cl}_{b} \mathrm{H}_{c}(\bar{a}=2.4, \bar{b}=4)$. For further details, see: E. Bayram, J. C. Linehan, J. L. Fulton, J. A. S. Roberts, N. K. Szymczak, T. D. Smurthwaite, S. Özkar, M. Balasubramanian, R. G. Finke, J. Am. Chem. Soc. 133 (2011) 18889 and E. Bayram, R. G. Finke, ACS Catal. 2 (2012) 1967.

${ }^{5}$ Páez has reported a similar dependence on reaction conditions for the tungsten-based hydrogenation catalyst $\mathrm{W}(\mathrm{CO})_{3}\left(\mathrm{CH}_{3} \mathrm{CN}\right)(\mathrm{TPPMS})_{2}(\mathrm{TPPMS}=\operatorname{sodium}(3-$ sulfonatophenyl)diphenylphosphine). Specifically, the catalyst exhibits heterogeneous behavior at $\mathrm{pH}<6$, but homogeneous reactivity at $\mathrm{pH}>6$. For further details, see: $\mathrm{P}$. Baricelli, G. Morfes, D. E. Páez, J. Mol. Catal. A 176 (2001) 1.
} 
contexts. In particular, by providing a singular, often mononuclear active site, homogeneous metal catalysts are generally regarded as more amenable to mechanistic investigations [15]. ${ }^{6}$ Indeed, the homogeneous hydrogenation reactions of nitrogen- and sulfur-containing heteroarenes have been studied as partial models of industrial scale hydrodenitrogenation [16] and hydrodesulfurization [17,18] fuel refinement processes. In contrast, mechanistic models of heterogeneous reactions are often complicated by the need to account for the catalyst's amorphous, nanoscale structure as well as additional surface-related processes, e.g. substrate adsorption and desorption, absent from homogeneous systems. ${ }^{7}$

The greater structural complexity of some heterogeneous catalysts can also complicate their modification for use in enantioselective reactions [19,20]. While such systems have been reported, their current scope is predominantly limited to hydrogenation of activated ketones [21]. For those few examples of heterogeneous catalyzed asymmetric hydrogenation of heteroarenes, high levels of enantioselectivity were only achieved by substitution of the substrate with a chiral auxiliary (see Zhou's 2012 review [2] for examples).

By comparison, the generation of enantioselective homogeneous catalysts typically requires the straightforward and predictable combination of a metal-containing precursor with a chiral ligand. Families of such applicable ligands are available in such abundance and with such tuneability $[19,22]$ that effective homogeneous metal catalysts have been developed for a broad range of asymmetric transformations, including heteroarene hydrogenation. While only a few classes of chiral ligands are actually available in industrial scale quantities [23], a number of major industrial enantioselective reactions are nevertheless performed using homogeneous catalysts. For example, the key step in the production of the widely-used herbicide $(S)$-metolachlor involves hydrogenation of an imine precursor catalyzed by a highly active Ir-xyliphos complex (Scheme 2$)^{8}$ [24].

\footnotetext{
${ }^{6}$ Although, as Sánchez-Delgado rightly cautions, developing a full and accurate description of a reaction mechanism can still prove challenging even for homogeneous systems.

${ }^{7}$ For representative examples of kinetic models used for heterogeneous dehydrogenation reactions of cycloalkanes, see: F. Alhumaidan, D. Cresswell, A. Garforth, Energy Fuels 25 (2011) 4217. For discussion of the difficulties in computational modeling of heterogeneous metal-catalyzed reactions, see: W. Liu, A. Tkatchenko, M. Scheffler, Acc. Chem. Res. 47 (2014) 3369.

${ }^{8}$ For ease of comparison, pressure values are shown both in the originally reported units and in [psi], rounded to the nearest five.
} 


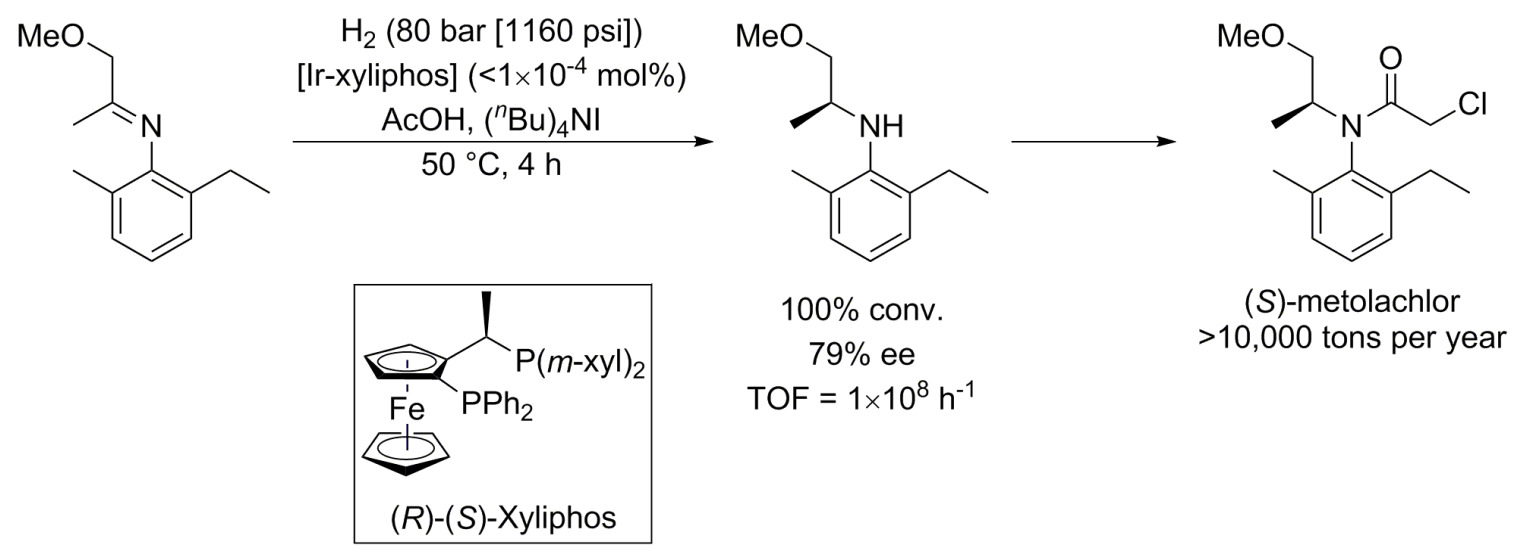

Scheme 2. Asymmetric imine hydrogenation by an Ir-xyliphos catalyst used in production of $(S)$-metolachlor by Ciba-Geigy (now Solvias).

\subsection{General substrate reactivity trends}

In a pair of studies conducted in 1936, Kistiakowsky measured the heat of hydrogenation of cyclohexene [25] and of 1,3-cyclohexadiene and benzene [26]. As is well known, these now classic experiments revealed the $\Delta \mathrm{H}$ for complete hydrogenation of the $\mathrm{C}=\mathrm{C}$ bonds in benzene $(-49 \mathrm{kcal} / \mathrm{mol})$ was significantly less than the sum of the $\Delta \mathrm{H}$ for an equivalent number of cyclohexene $\mathrm{C}=\mathrm{C}$ bonds $(3 \times[-28 \mathrm{kcal} / \mathrm{mol}])$, even when accounting for the calculated resonance stabilization energy (RSE) of 1,3-cyclohexadiene (1.8 kcal/mol; Fig. 1) [27]. The observed difference ( $29 \mathrm{kcal} / \mathrm{mol})$ is now recognized as a manifestation of the additional stability uniquely afforded by aromaticity. This aromatic stabilization energy (ASE) contributes to the greater resistance exhibited by monocyclic arenes to hydrogenation under conditions otherwise effective for equivalent acyclic polyenes. Furthermore, for polycyclic arenes, partial hydrogenation that leaves at least one aromatic subunit intact is usually favored over complete saturation; while the former process preserves some measure of the starting ASE in the product, the latter eliminates this stabilization entirely [8].

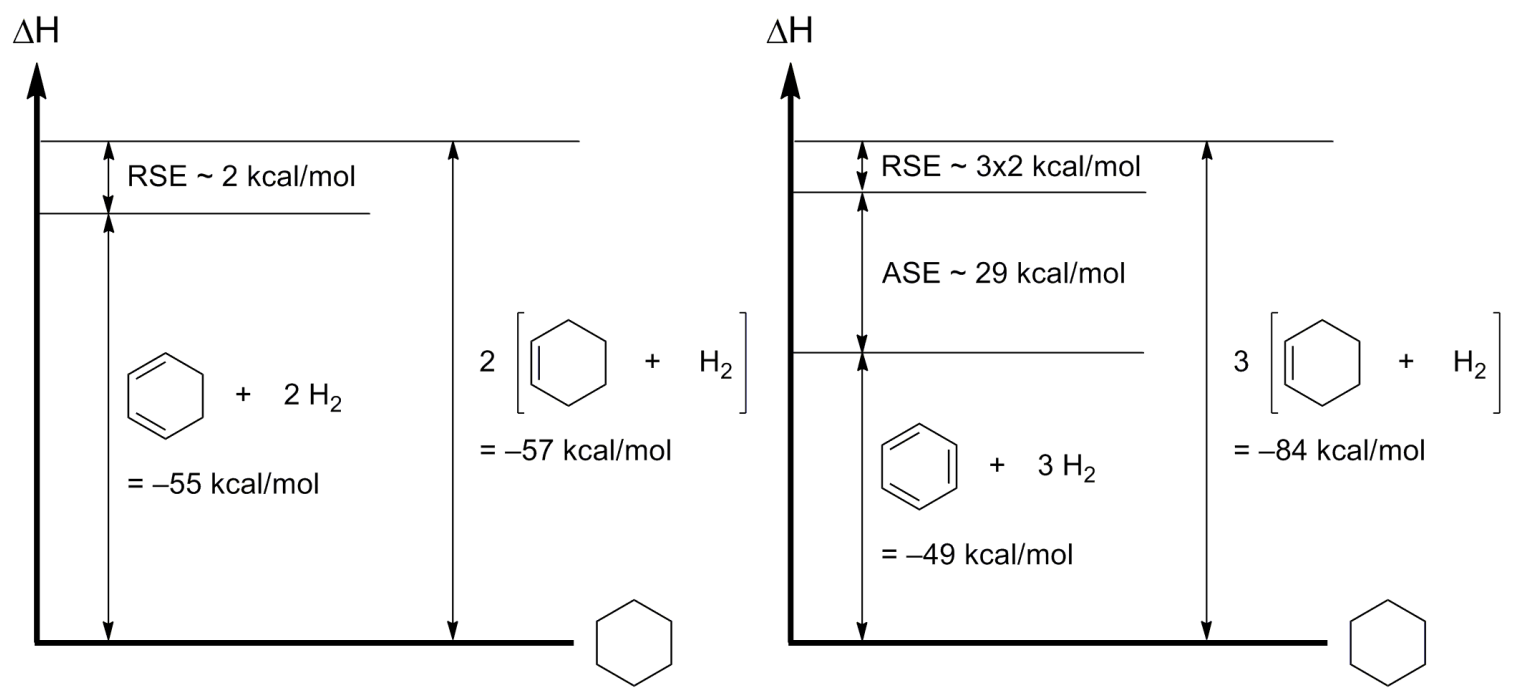

Fig. 1. Comparison of the measured heat of hydrogenation of 1,3-cyclohexadiene (left) 
and benzene (right) with that of cyclohexene.

These trends typically hold for heteroarenes as well. As the ASE values of monocyclic heteroarenes are lower than that of benzene [28-31], they commonly undergo hydrogenation more readily than their all-carbon counterparts. Additionally, in mixed polycyclic systems, e.g. quinoline, lower ASE, coupled with the propensity for heteroatoms to strongly coordinate to a metal catalyst [2], generally results in regioselective hydrogenation of the heterocyclic ring.

Aromatization also provides a net driving force for the dehydrogenation of the corresponding saturated cyclic compounds. The energetic requirements for dehydrogenation of $N$-heterocycles are overall less demanding than those of cycloalkanes [32]. DFT calculations performed by Eisenstein and Crabtree [33] predict the replacement of cycloalkane $\mathrm{CH}_{2}$ units with $\mathrm{NH}$ groups reduces the resulting compound's enthalpy of dehydrogenation (Scheme 3). The authors attribute this effect in part to the greater lability of $\mathrm{N}-\mathrm{H}$ and adjacent $\mathrm{C}-\mathrm{H}$ bonds relative to $\mathrm{C}-\mathrm{H}$ bonds in an all-carbon chain. The effect also appears to be additive, although only for certain positional arrangements of the additional NH groups, e.g. those shown in Scheme 3 [33,34].<smiles>C1CCCCC1</smiles><smiles></smiles>

$\Delta \mathrm{H}=+53 \mathrm{kcal} / \mathrm{mol}$<smiles>C1CCNCC1</smiles>

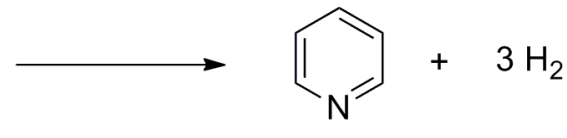

$$
\Delta \mathrm{H}=+48 \mathrm{kcal} / \mathrm{mol}
$$<smiles>C1CNCNC1</smiles>

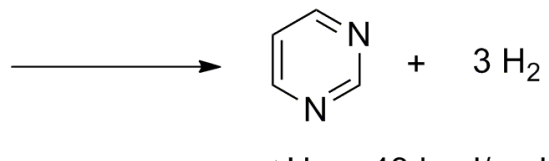

$$
\Delta \mathrm{H}=+43 \mathrm{kcal} / \mathrm{mol}
$$<smiles>C1CCC(C2NCNCN2)CC1</smiles>

Scheme 3. Calculated (B3PW91/aug-cc-pVDZ) enthalpies of dehydrogenation (kcal/mol substrate) for cyclohexane and a series of six-membered $N$-heterocycles.

2. Heterocycle hydrogenation

\subsection{Iridium}

\subsubsection{Neutral complexes}




\subsubsection{Mechanistic studies}

In one of the first examples of asymmetric quinoline hydrogenation, Zhou [35] prepared chiral iridium catalysts in situ by combination of $[\operatorname{Ir}(\operatorname{cod}) \mathrm{Cl}]_{2}$ with the chiral bisphosphine $(R)$-MeO-BIPHEP (Scheme 4). ${ }^{9}$ Notably, the presence of $\mathrm{I}_{2}$ proved essential for catalyst activity. Later mechanistic investigations by Zhou and Li [36] suggested oxidative addition of $\mathrm{I}_{2}$ to a monomeric bisphosphine complex (1) forms a catalytically active diiodo-Ir(III) species (Compound 2; Scheme 5). $\sigma$-Bond metathesis with $\mathrm{H}_{2}$ to generate 3 by loss of $\mathrm{HI}$ then affords entry into the catalytic cycle.
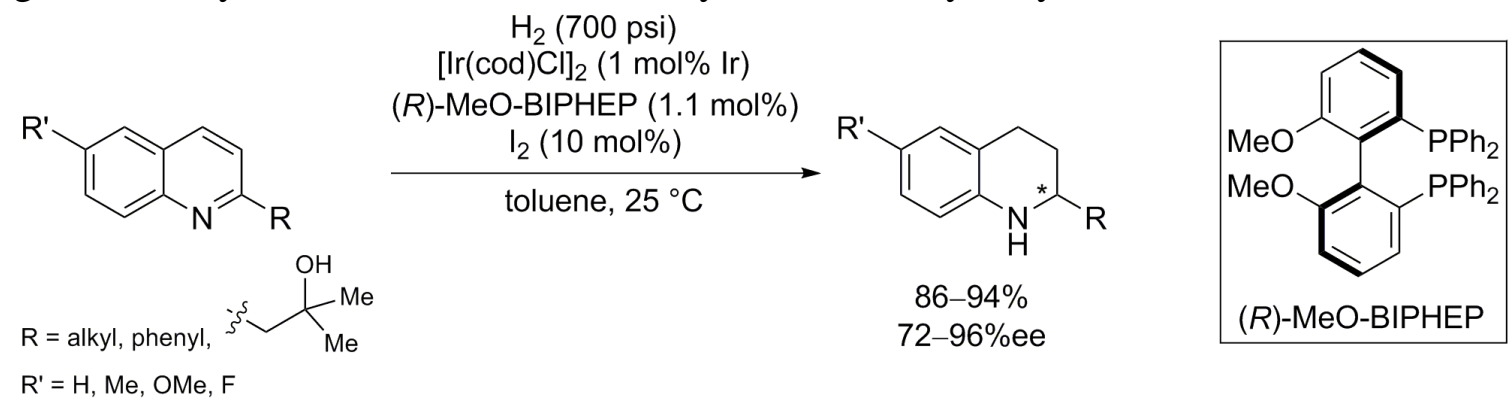

Scheme 4. Asymmetric hydrogenation of quinolines catalyzed by $[\operatorname{Ir}(\operatorname{cod}) \mathrm{Cl}]_{2}$ in the presence of $(R)-\mathrm{MeO}-\mathrm{BIPHEP}$.
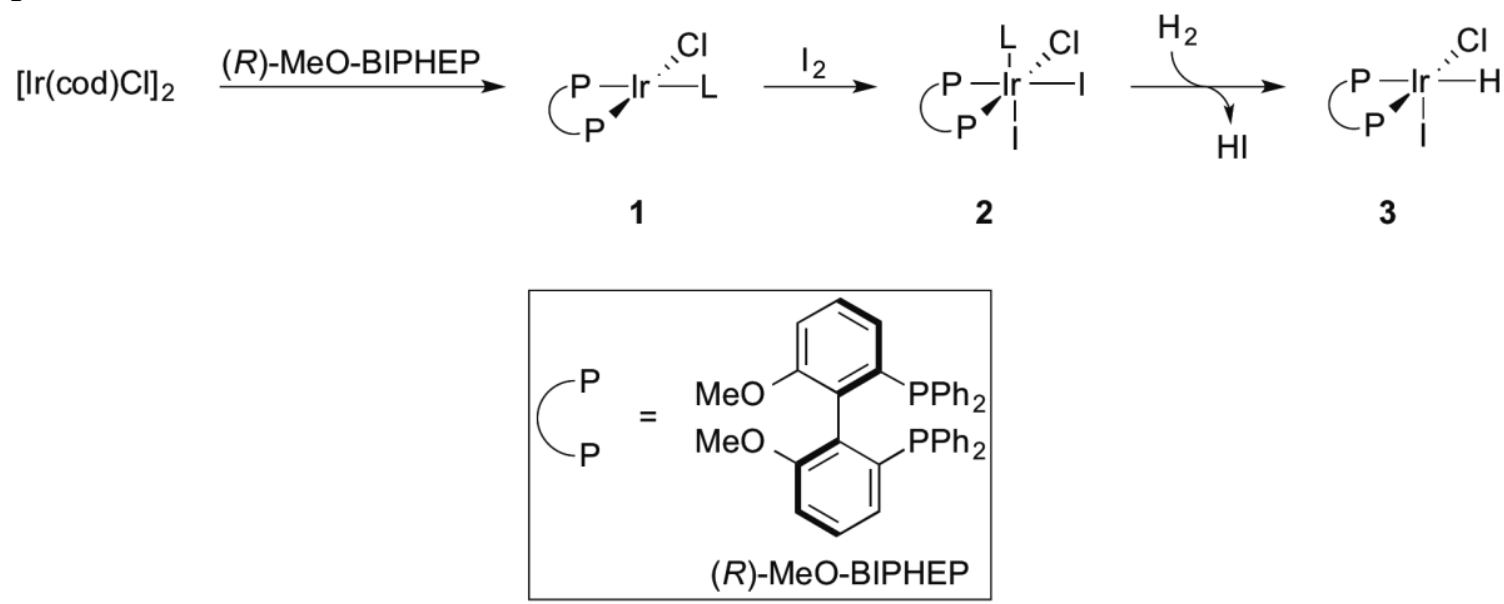

Scheme 5. Proposed pathway for formation of 3 from $[\operatorname{Ir}(\operatorname{cod}) \mathrm{Cl}]_{2}$.

As shown in Scheme 6, upon association of the substrate to complex 3, 1,4hydride addition forms a coordinatively unsaturated $\eta^{1}-\mathrm{N}$ complex. Heterolytic activation of $\mathrm{H}_{2}$ across the $\mathrm{Ir}-\mathrm{N}$ bond then leads to substrate dissociation and isomerization to a 3,4dihydro intermediate (4; steps iii-v). Coordination of $\mathbf{4}$ to regenerated $\mathbf{3}$ subsequently facilitates reduction of the remaining $\mathrm{C}(2)=\mathrm{N}$ bond. The authors favor 1,2-hydride addition at this stage of the catalytic cycle rather than step ii on the basis of computations (B3LYP/6-311++ $\mathrm{G}^{* *}$ ): the calculated $\Delta \mathrm{G}$ for net 1,4-addition of $\mathrm{H}_{2}$ to 2-methylquinoline

\footnotetext{
${ }^{9}$ By judicious choice of other bisphosphine ligands, Maj and Agbossou-Niedercorn later expanded Zhou's original substrate scope to include quinolines substituted at the 2position by esters and $-\mathrm{CH}_{2} \mathrm{NBoc}_{2}$ and $-\mathrm{CH}_{2} \mathrm{Br}$ groups; for further details, see A. M. Maj, I. Suisse, C. Hardouin, F. Agbossou-Niedercorn, Tetrahedron 69 (2013) 9322.
} 
$(+6.8 \mathrm{kcal} / \mathrm{mol})$ was significantly lower than that of 1,2 -addition $(+11.1 \mathrm{kcal} / \mathrm{mol})$. Additionally, enamine $\mathbf{5}$ was synthesized and isolated as a model for $\mathbf{4}$ and was found to undergo hydrogenation with the same enantioselectivity as the corresponding quinoline (Scheme 7).

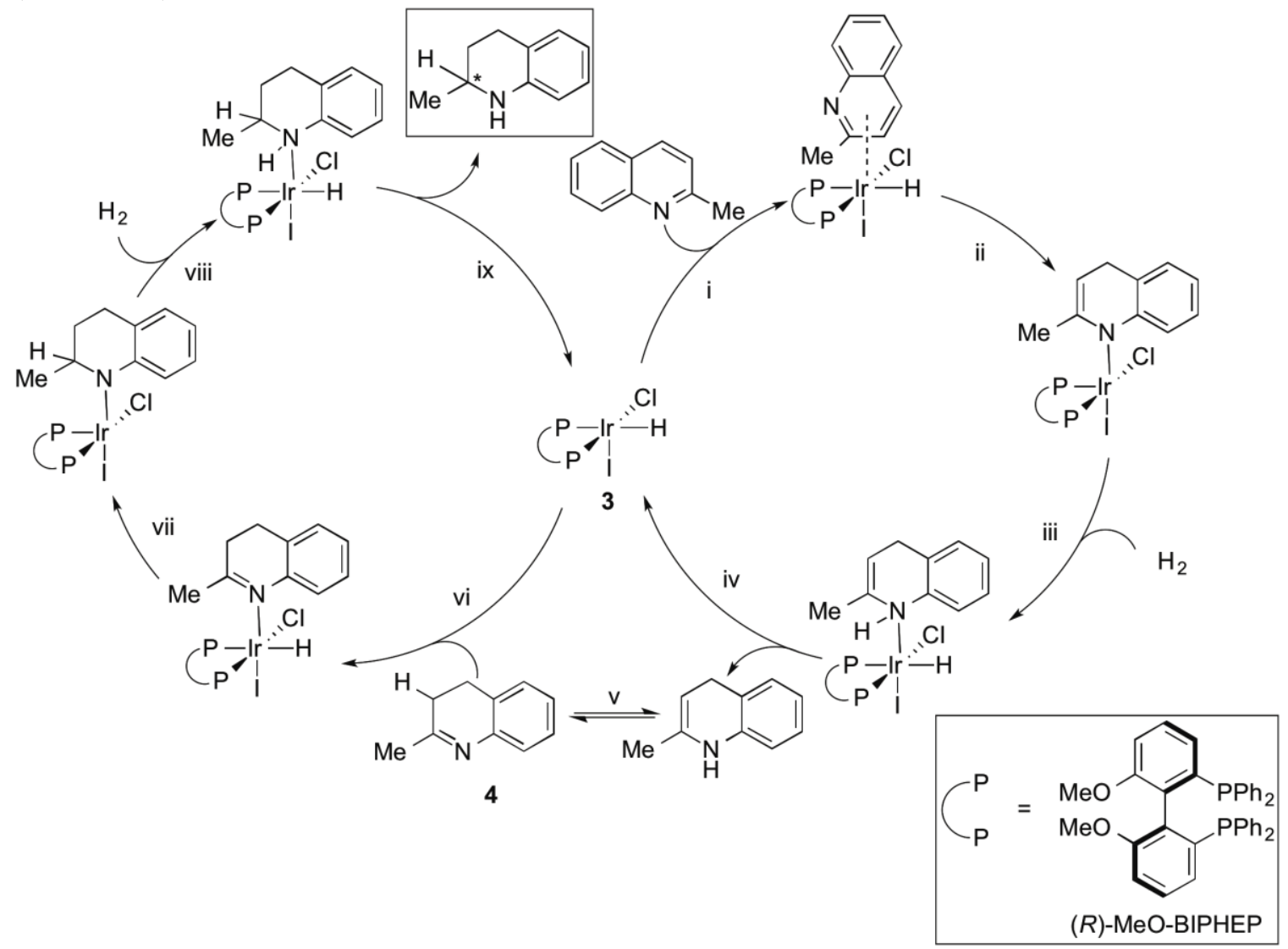

Scheme 6. Proposed catalytic cycle for asymmetric hydrogenation of quinolines starting with 3 (shown for 2-methylquinoline).

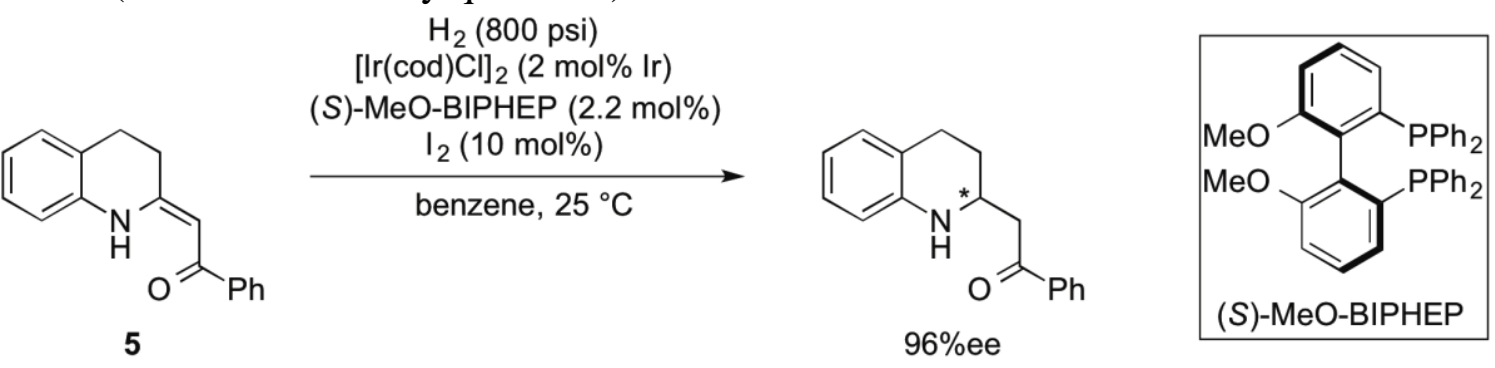

Scheme 7. Asymmetric hydrogenation of $\mathbf{5}$ as a model for 3,4-dihydroquinoline intermediates.

\subsubsection{Asymmetric hydrogenation}

In 2012, Zhou [37] reported the asymmetric hydrogenation of 1,2-disubstituted pyridinium bromides in good to excellent yields and enantioselectivity (Scheme 8). Pyridinium salts are attractive hydrogenation substrates because they avoid the potential catalyst deactivation that can occur with strongly coordinating, free pyridines. 
Furthermore, hydrogenation of $N$-functionalized pyridinium salts can directly afford the saturated piperidine homologues without the need to perform a separate carbon-nitrogen bond forming reaction. In this particular case, 2-(isopropoxycarbonyl)benzyl was required as the $N$-substituent to act as a directing group for the catalyst in combination with the chiral bisphosphine ligand $(R)$-SynPhos. The lowest reactivity and selectivity arose from ortho-substitution of the pyridinium ring with an isopropyl group, indicating a significant steric effect on reaction efficacy.
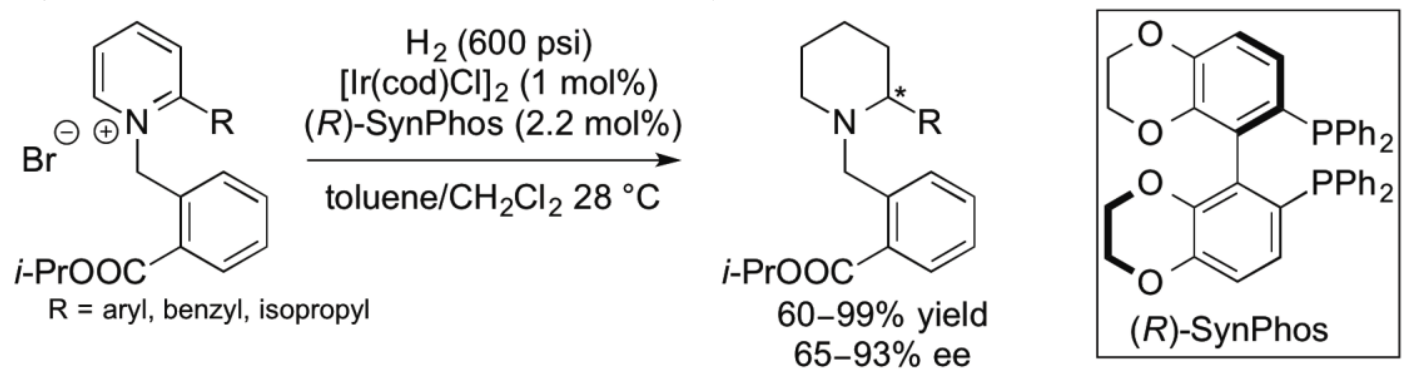

Scheme 8. Asymmetric hydrogenation of pyridinium salts using $[\operatorname{Ir}(\operatorname{cod}) \mathrm{Cl}]_{2}$ as a precatalyst and $(R)$-SynPhos.

Zhou also employed the Ir/SynPhos system in the asymmetric hydrogenation of 3,4-disubstituted isoquinolines [38] (Scheme 9, top). Use of the related $\left(R_{\mathrm{ax}}, S, S\right)-\mathrm{C}_{3}{ }^{*}-$ TunePhos ligand also facilitated enantioselective reduction of 1,2-disubstituted isoquinolinium salts [39] (Scheme 9, bottom). As with the pyridinium salts, $N$ substitution by a 2-(isopropoxycarbonyl)benzyl group typically afforded the highest enantioselectivity. Control experiments revealed that neutral 1,2-dihydroisoquinolines were not hydrogenated under the reaction conditions, suggesting that the reactive intermediates in the catalytic cycle are likely charged, protonated species.
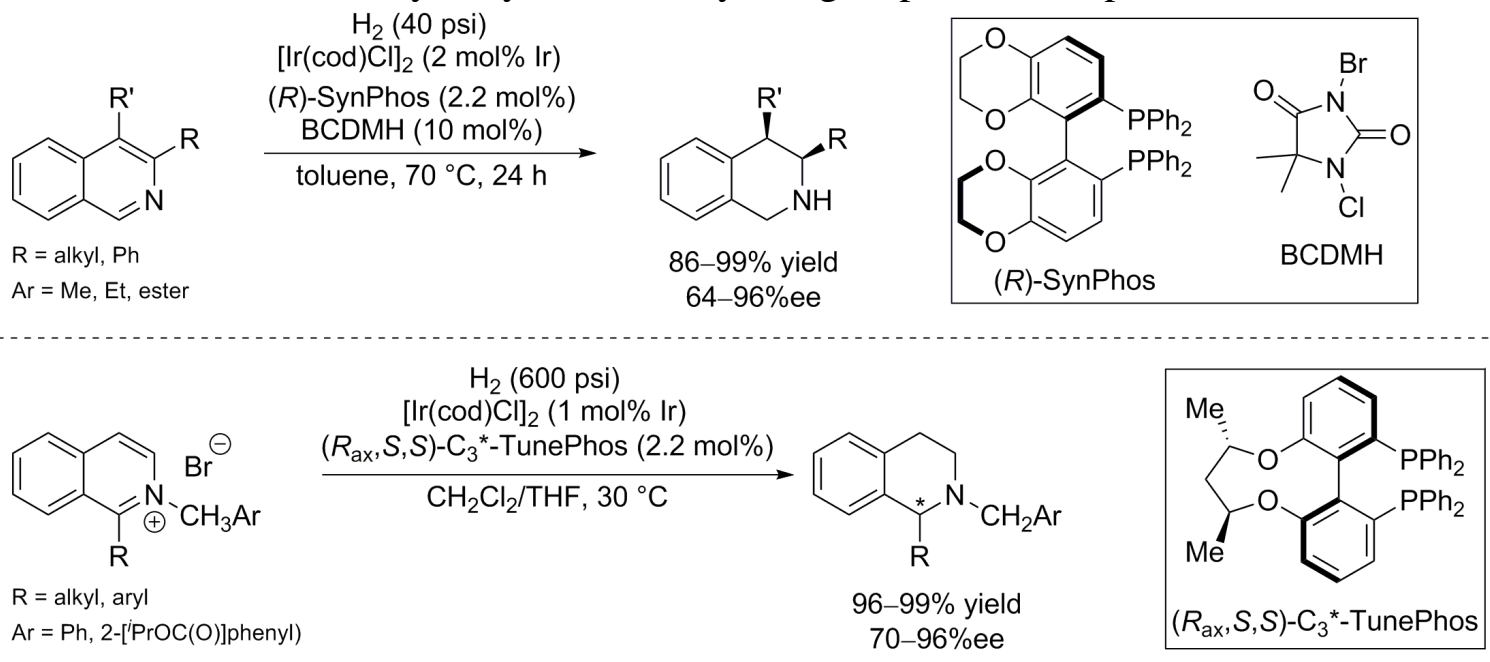

Scheme 9. Asymmetric hydrogenation of 3,4-disubstituted isoquinolines (top) and 1,2disubstituted isoquinolinium salts (bottom). (BCDMH $=1$-bromo-3-chloro-5,5dimethylhydantoin)

In an effort to circumvent the need for a stoichiometric auxiliary such as the 2(isopropoxycarbonyl)benzyl group, Chen and Zhang [40] screened a library of 240 chiral phosphine ligands in the hydrogenation of $N$-benzyl-2-phenylpyridinium bromide 
(Scheme 10, top). The screening revealed phosphole-based ( $R$ )-MP ${ }^{2}$-SEGPHOS to afford the highest yields and enantioselectivity. The optimized reaction conditions proved generally applicable for a range of $\mathrm{N}$-benzyl-2-arylpyridinium salts and also allowed for variation of the $N$-substituent (Scheme 10, bottom). The authors attribute this increased versatility in part to the rigid chiral environment afforded by the phosphole groups on $(R)$-MP ${ }^{2}$-SEGPHOS. The authors also found (by measure of infrared $\mathrm{CO}$ stretching frequencies) dimethyl-substituted phospholes are more electron-donating than either alkyl- or aryl-substituted phosphines; in their screening efforts, increased ligand electrondonating ability had appeared to correlate with improved enantioselectivity.
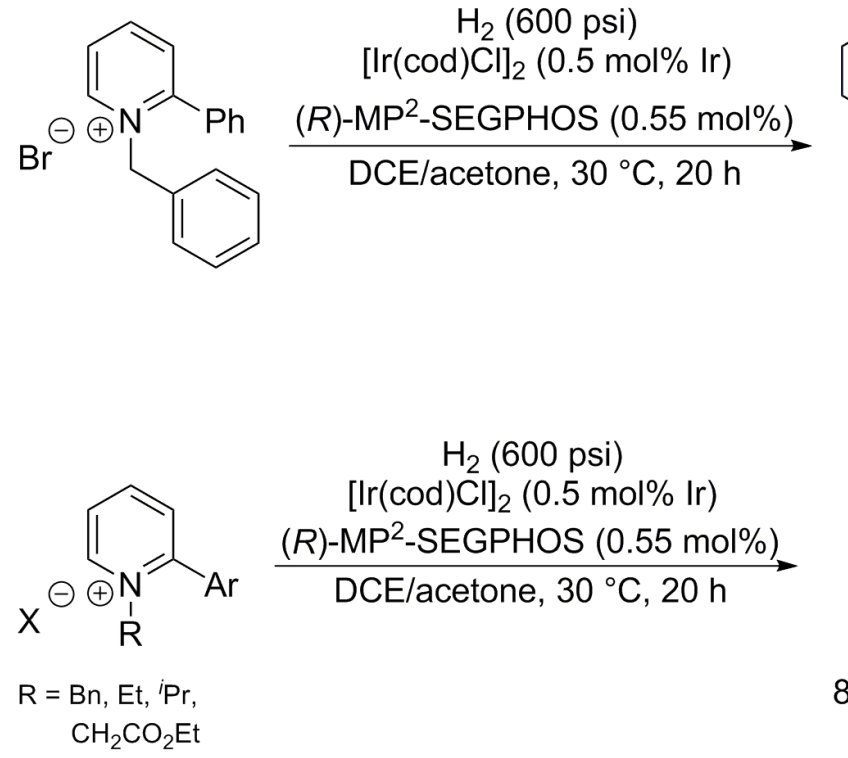<smiles>c1ccc(CN2CCCCC2c2ccccc2)cc1</smiles>

$97 \%$ yield $96 \%$ ee<smiles>[R]N1CCCCC1Br</smiles>

$82-99 \%$ yield 90-96\% ee

Scheme 10. Asymmetric hydrogenation of $N$-substituted 2-arylpyridinium salts using $\left[\operatorname{Ir}(\operatorname{cod}) \mathrm{Cl}_{2}\right.$ as a precatalyst and $(R)-\mathrm{MP}^{2}$-SEGPHOS.

In 2013, Dragan, McWilliams, and Miller [41] used $[\operatorname{Ir}(\operatorname{cod}) \mathrm{Cl}]_{2}$ and the chiral phosphoramidite $(S)$-MorPhos to enantioselectively hydrogenate the quinolinium core of a precursor to the potential anti-psychotic agent Vabicaserin (Scheme 11). Addition of $\mathrm{P}\left({ }^{t} \mathrm{Bu}\right)_{3}$ and $\mathrm{LiCl}$ were found to improve catalyst activity and enantioselectivity respectively. Following hydrogenation, tosyl deprotection and recrystallization afforded Vabicaserin in $>99 \%$ ee.
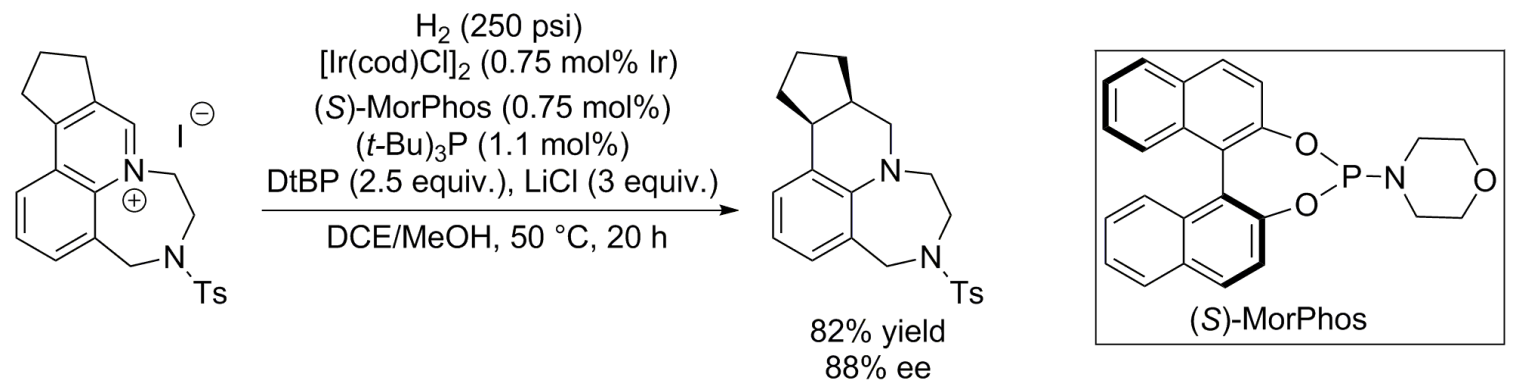

Scheme 11. Asymmetric hydrogenation of an advanced intermediate in the synthesis of Vabicaserin. (DtBP = 2,6-di-t-butylpyridine)

Using the structurally similar P-OP ligand, Vidal-Ferran [42] was able to 
hydrogenate free indoles with good enantioselectivity in acidic media (Scheme 12). Use of the DOWEX 50WX8 resin allowed for the recovery and recycling of the acidifying agent up to two times without loss of enantioselectivity.

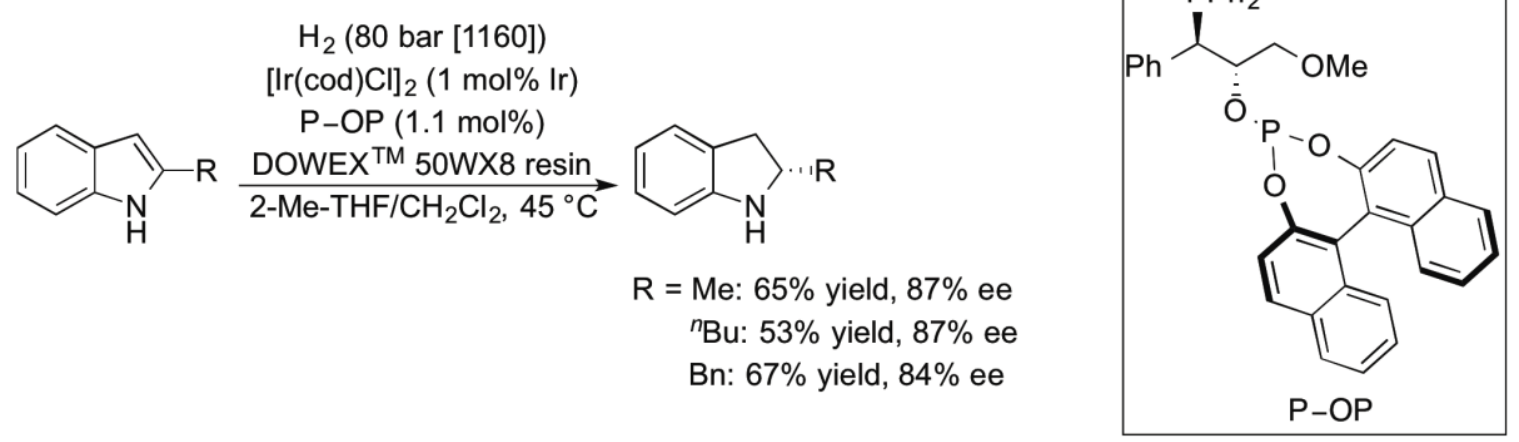

Scheme 12. Asymmetric hydrogenation of free indoles using $[\operatorname{Ir}(\operatorname{cod}) \mathrm{Cl}]_{2}$ as a precatalyst and a $\mathrm{P}-\mathrm{OP}$ ligand.

In 2014, Zhou [43] asymmetrically hydrogenated the 6-membered ring of $N$ benzyl-pyrrolo[1,2-a]pyrazinium salts (Scheme 13). Use of $\left(R_{\mathrm{ax}}, S, S\right)-\mathrm{C}_{3}{ }^{*}$-TunePhos effected the most efficient and stereoselective hydrogenation without loss of the $N$-benzyl protecting group. The presence of cesium carbonate proved necessary to prevent racemization of the stereocenter by the $\mathrm{HBr}$ produced in the reaction. Zhou subsequently removed the $N$-benzyl group via conventional hydrogenolysis with minimal erosion of ee.
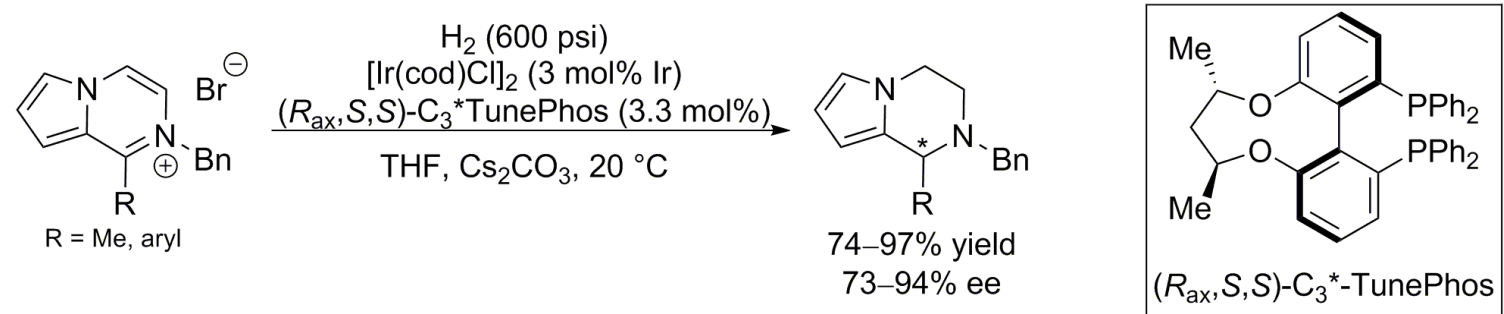

Scheme 13. Asymmetric hydrogenation of pyrrolopyrazinium salts using $[\operatorname{Ir}(\operatorname{cod}) \mathrm{Cl}]_{2}$ as a precatalyst and TunePhos.

Most recently, Kuwano [44] reported the asymmetric partial hydrogenation of pyrimidines using $[\operatorname{Ir}(\operatorname{cod}) \mathrm{Cl}]_{2}$ and the Josiphos ligand $(R)-(S)-\mathrm{Ph}_{2} \mathrm{PF}-\mathrm{P}\left({ }^{t} \mathrm{Bu}\right)_{2}(\mathrm{Scheme}$ $14)$. Addition of the Lewis acid $\mathrm{Yb}(\mathrm{OTf})_{3}$ was found to enhance both the yield and the stereoselectivity of the reaction. The authors postulate the Lewis acid activates the substrate in a manner similar to $N$-alkylation of pyridines and quinolines to form the corresponding salts that are reactive toward hydrogenation.

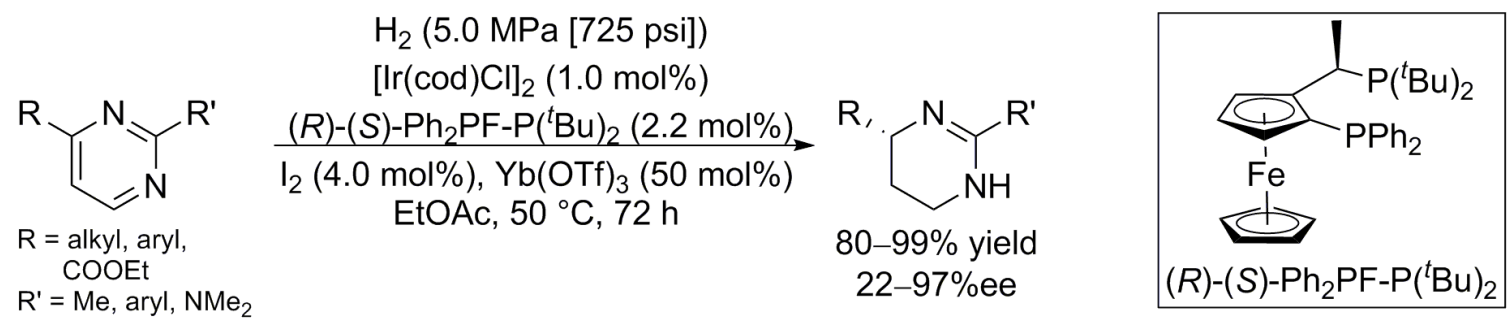

Scheme 14. Asymmetric partial hydrogenation of pyrimidines using $[\operatorname{Ir}(\operatorname{cod}) \mathrm{Cl}]_{2}$ as a precatalyst and $(R)-(S)-\mathrm{Ph}_{2} \mathrm{PF}-\mathrm{P}\left({ }^{t} \mathrm{Bu}\right)_{2}$. 


\subsubsection{Transfer hydrogenation}

In 2004, Fujita and Yamaguchi [45] hydrogenated quinolines using isopropanol as the hydrogen source and $\left[\mathrm{Cp}^{*} \mathrm{IrCl}_{2}\right]_{2}$ as the transfer catalyst. They found it necessary to also add a Brønsted acid such as triflic or perchloric acid in order to protonate the quinoline substrate and thereby activate it for hydrogenation. 1,2-Dihydroquinoline, however, underwent hydrogenation in the absence of acid; free 1,2-dihydroquinoline or a related tautomer thus appears to serve as a reactive intermediate.

The authors' proposed catalytic cycle is shown in Scheme 15. Cleavage of the iridium dimer by isopropanol, followed by deprotonation and $\beta$-hydride elimination (steps $i$ and ii) affords the $\operatorname{Ir}(\mathrm{III})$ monohydride 6 . This species reacts with the protonated quinoline substrate by 1,2-hydride addition, before being intercepted by another unit of isopropanol to regenerate $\mathbf{6}$ (steps iv and v). The exact mechanism by which $\mathbf{6}$ then further reduces the dihydroquinoline intermediate remain unelucidated, but possibly involves Ir $-\mathrm{H}$ addition across the $\mathrm{C}(3)=\mathrm{C}(4)$ bond, followed by protonolysis.

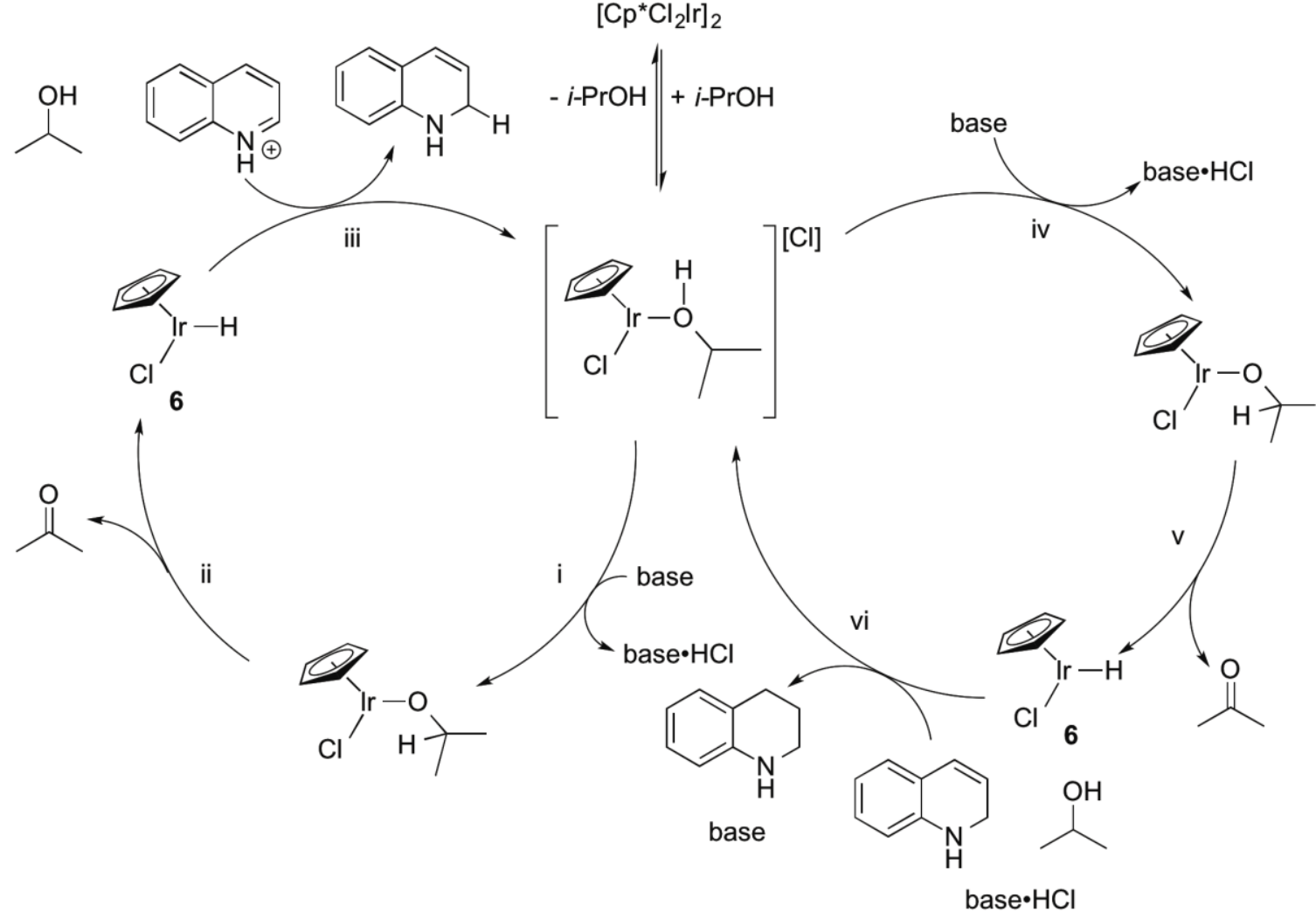

Scheme 15. Proposed catalytic cycle for transfer hydrogenation of quinoline catalyzed by $\left[\mathrm{Cp}^{\star} \mathrm{IrCl}_{2}\right]_{2}$.

Zhou [46] reported enantioselective transfer hydrogenation of quinolines using methyl Hantzsch esters as the hydrogen source (Scheme 16). The use of non-polar solvents produced high yields but poor enantioselectivity, while the opposite was observed with coordinating solvents. Optimal results were achieved with a mixed solvent 
of toluene/dioxane (2:1).

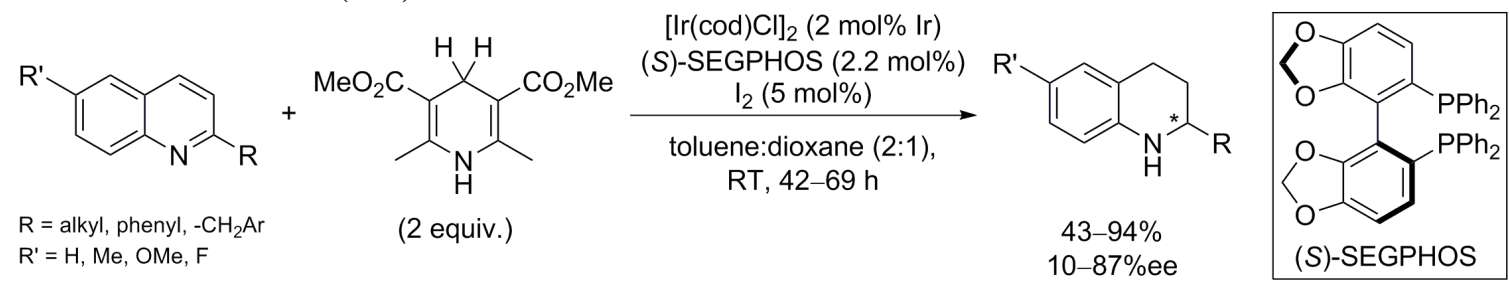

Scheme 16. Asymmetric transfer hydrogenation of quinolines using Hantzsch esters as the hydrogen source.

$\mathrm{Xu}$, Fan, and Xiao [47] achieved transfer hydrogenation of quinoxalines using $\left[\mathrm{Cp}^{\star} \mathrm{IrCl}_{2}\right]_{2}$ and a bidentate amino-sulfonamide ligand with formic acid as the hydrogen source (Scheme 17). The highest initial rate of conversion was observed for a reaction medium of $\mathrm{pH}=5.5$, with lower rates observed at both higher and lower $\mathrm{pH}$. Furthermore, the $\mathrm{pH}$ was found to increase as the reaction progressed due to consumption of acid. By increasing the concentration (and thus the buffer capacity) of the acetic acid/sodium acetate buffer from 2.0 M to 5.0 M, the overall reaction rate was increased. Based on these observations, the authors concluded that the quinoxaline substrate must be protonated for hydride transfer from the catalyst to occur. Above the optimal $\mathrm{pH}$, substrate protonation is limited, but if the reaction conditions are too acidic, catalyst activity is also deleteriously affected [48]. The substrate scope included quinoxalines substituted by alkyl, aryl, and even alkenyl groups, although the latter two required longer reaction times to obtain high yields. Asymmetric transfer hydrogenation was attempted using a chiral diamine ligand, but only modest ( $40 \%$ ee) enantioselectivity was observed.
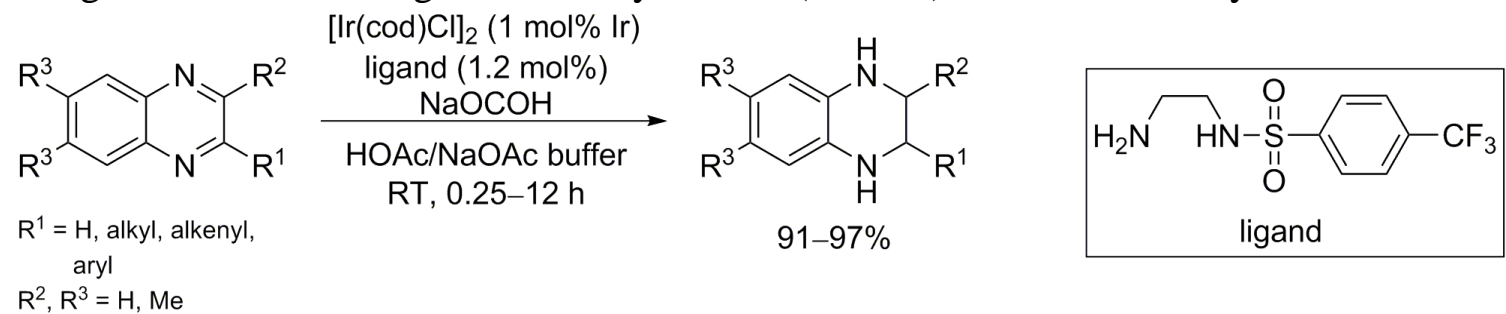

Scheme 17. Transfer hydrogenation of quinoxalines using formic acid as the hydrogen source.

\subsubsection{Cationic complexes}

In 2011, Eisenstein and Crabtree [49] developed a cationic iridium catalyst (7; Fig. 2 , left) for the hydrogenation of quinolines under one atmosphere of hydrogen (Scheme 18). The low hydrogen pressure required with this catalyst contrasts with the higher pressures typically required for heteroaromatic reduction. The system tolerates halosubstitution on the carbocyclic ring, although these substrates required elevated (5 atm [75 psi]) hydrogen pressure. 

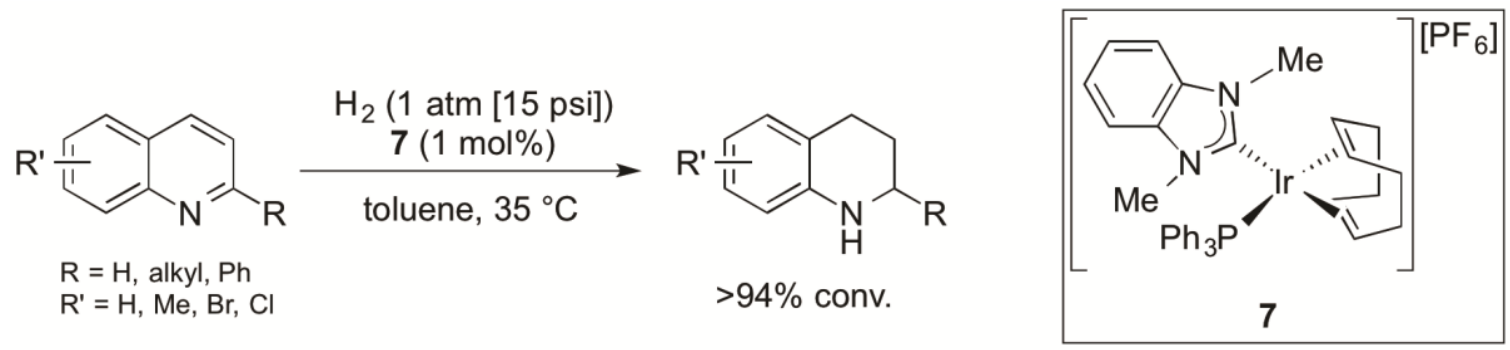

Scheme 18. Hydrogenation of quinolines catalyzed by 7 .
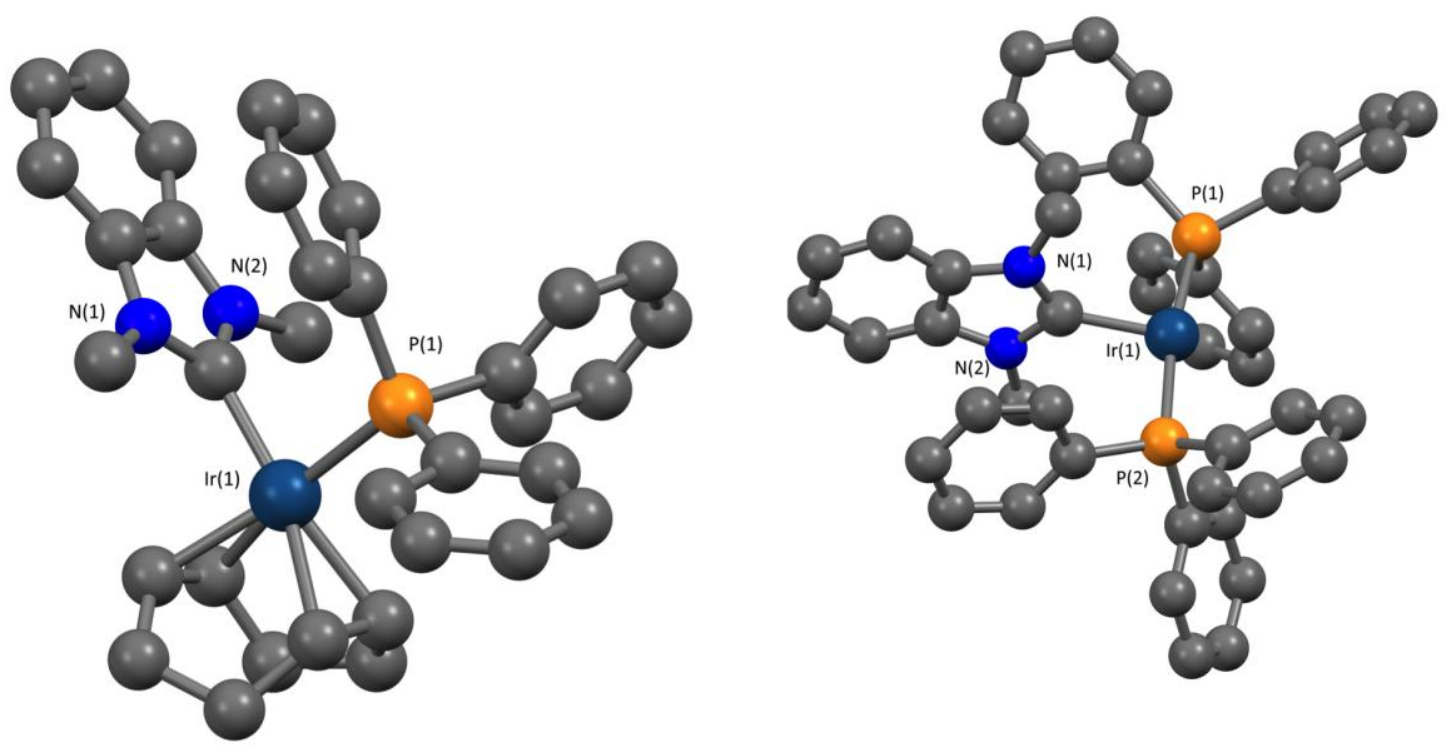

Fig. 2. Ball-and-stick representations of $\mathbf{7}$ (left) and $\mathbf{8}$ (right) generated with the program Mercury using crystallographic data made available in the Supporting Information of Ref. 49. $\mathrm{PF}_{6}$ counteranions and hydrogen atoms are omitted for clarity.

The related bisphosphine iridium dihydride $\mathbf{8}$ (Fig. 2, right) was also found active for quinoline hydrogenation and was subsequently employed in empirical and computational studies to probe the catalytic cycle (Scheme 19). Hydrogen first adds to 8 to form $\sigma$-complex 9. Step-wise, outer-sphere protonation and hydride addition to the substrate then forms a 1,2-dihydro intermediate, which upon isomerization, can undergo further reduction to the final product (steps iv and $v$ ). 


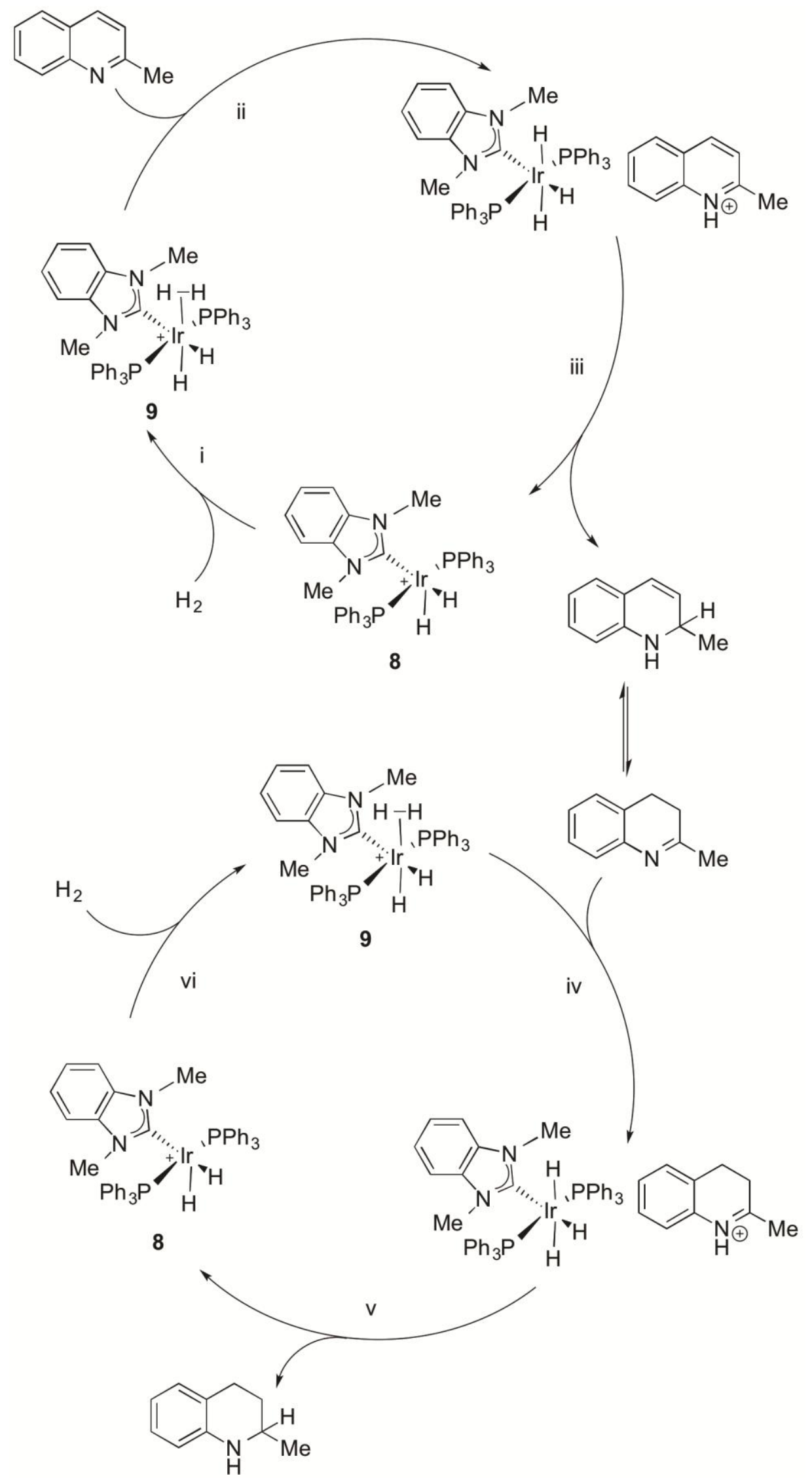


Scheme 19. Eisenstein and Crabtree's proposed mechanism for quinoline hydrogenation

\subsubsection{Mechanistic studies}

In 1993, Sánchez-Delgado and Bianchini [50] isolated and characterized a series of bis- $\eta^{1}$-S-ligated cationic iridium dihydride complexes formed from the addition of excess $S$-heterocycle to $\left[\operatorname{Ir}(\operatorname{cod})\left(\mathrm{PPh}_{3}\right)_{2}\right]\left[\mathrm{PF}_{6}\right]$ in the presence of $\mathrm{H}_{2}$ (Scheme 20). X-ray diffraction analysis of the complexes derived from thiophene $(\mathbf{1 0})$ and tetrahydrothiophene (11) revealed both to adopt a distorted octahedral geometry, with the phosphine ligands occupying the axial positions, and the $S$-heterocycle and hydride ligands mutually cis in the equatorial plane (Fig. 3). When $\mathbf{1 0}$ was briefly heated to $80^{\circ} \mathrm{C}$, the monohydride $\eta^{4}-\mathrm{SC}_{3}$ complex $\mathbf{1 2}$ formed through dissociation of a thiophene ligand followed by a stereospecific endo hydride migration (Scheme 21) [51]. Further reduction of the $\eta^{4}$-thioallyl ligand in $\mathbf{1 2}$ to ultimately form $\mathbf{1 1}$ was proposed to proceed selectively through a bis- $\eta^{1}$-S-2,3-dihydrothiophene complex (13). Indeed, exposure of independently synthesized $\mathbf{1 3}$ to a hydrogen atmosphere resulted in formation of $\mathbf{1 1}$, whereas the related 2,5-dihydrothiophene complex 14 proved unreactive under identical conditions.

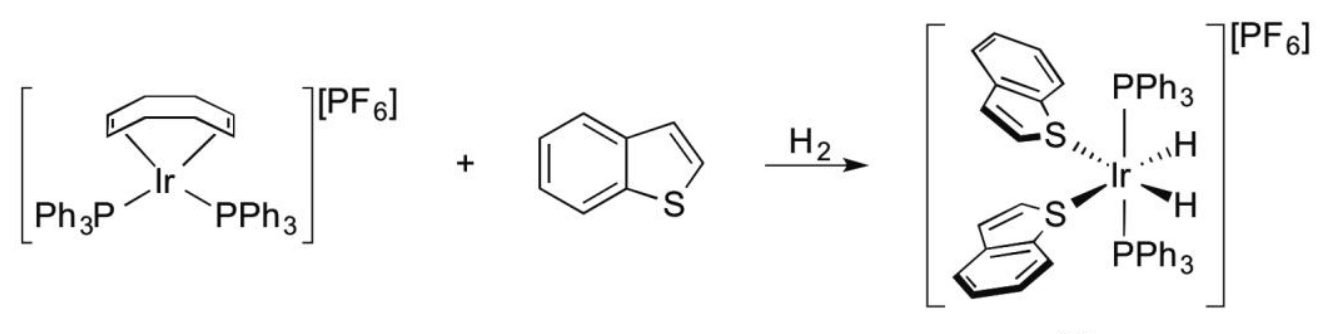

15

Scheme 20. Addition of $S$-heterocycles to $\left[\operatorname{Ir}(\operatorname{cod})\left(\mathrm{PPh}_{3}\right)_{2}\right]\left[\mathrm{PF}_{6}\right]$ in the presence of $\mathrm{H}_{2}$ (shown for benzothiophene). 

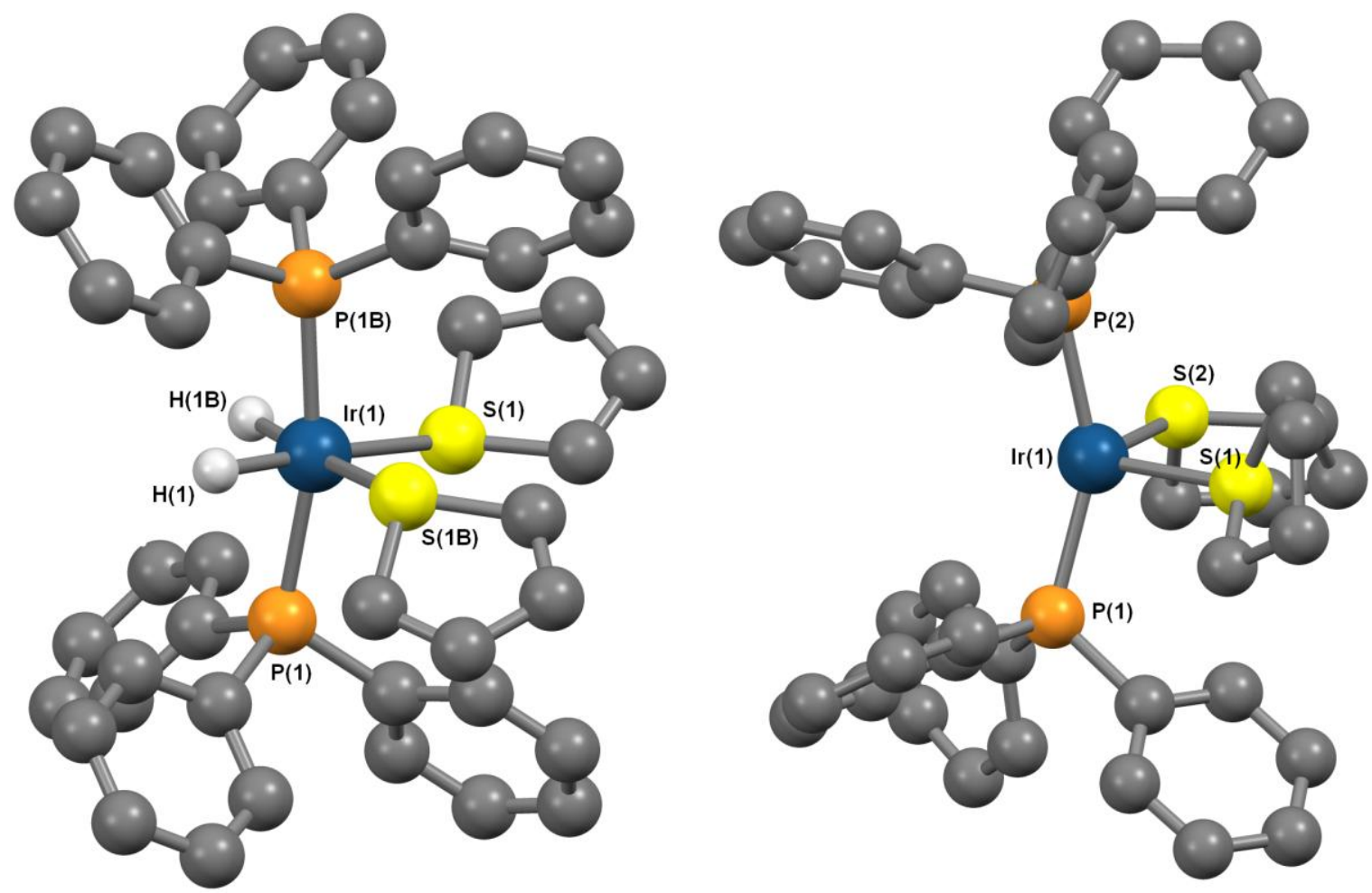

Fig. 3. Ball-and-stick representation of $\mathbf{1 0}$ (left) and $\mathbf{1 1}$ (right) generated with the program Mercury using crystallographic data retrieved from the Cambridge Crystal Structure Database (Refcodes HAKLEK and HAKLIO respectively); structural information originally provided in Ref. 50. $\mathrm{PF}_{6}$ counteranion, dichloromethane solvate, and ligand hydrogen atoms are omitted for clarity. The metal hydride ligands could not be located for 11.

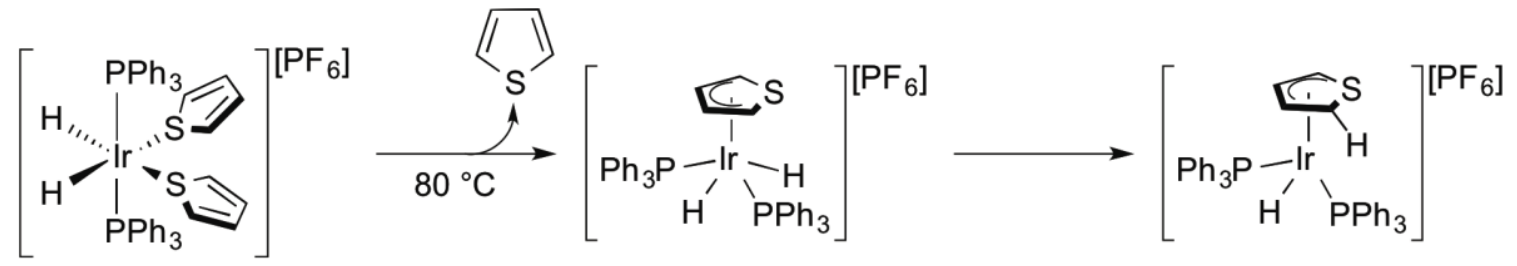

10
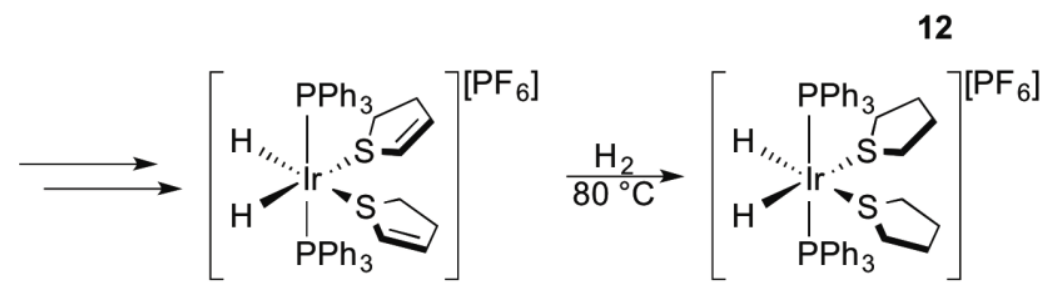

12

13

11

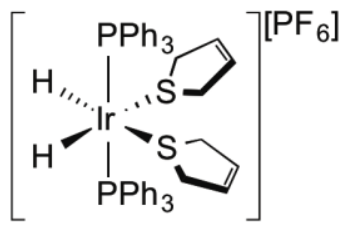

$\frac{\mathrm{H}_{2}}{80^{\circ} \mathrm{C}}$ no reaction 
Scheme 21. Proposed pathway for formation of $\mathbf{1 1}$ from $\mathbf{1 0 .}$

While the above system could not be rendered catalytic due to total product inhibition, Sánchez-Delgado [52] found $\left[\operatorname{Ir}(\operatorname{cod})\left(\mathrm{PPh}_{3}\right)_{2}\right]\left[\mathrm{PF}_{6}\right]^{10}$ readily catalyzed the hydrogenation of benzothiophene in a non-coordinating solvent such as 1,2dichloroethane. ${ }^{11}$ Kinetic analysis of the reaction using $\mathbf{1 5}$ (previously isolated in the 1993 study; vide supra) as the precatalyst yielded the following rate law:

$$
\frac{d[\mathrm{DHBT}]}{d t}=k_{\mathrm{cat}}[\mathrm{Ir}]\left[\mathrm{H}_{2}\right]
$$

Additional stoichiometric experiments with 15 led to isolation of 16 (Fig. 4) after an extended exposure to $\mathrm{H}_{2}$. Notably, this latter complex itself was catalytically inert and also resistant to ligand exchange with excess benzothiophene; as such, it appears to constitute the end-point of a catalyst deactivation pathway.

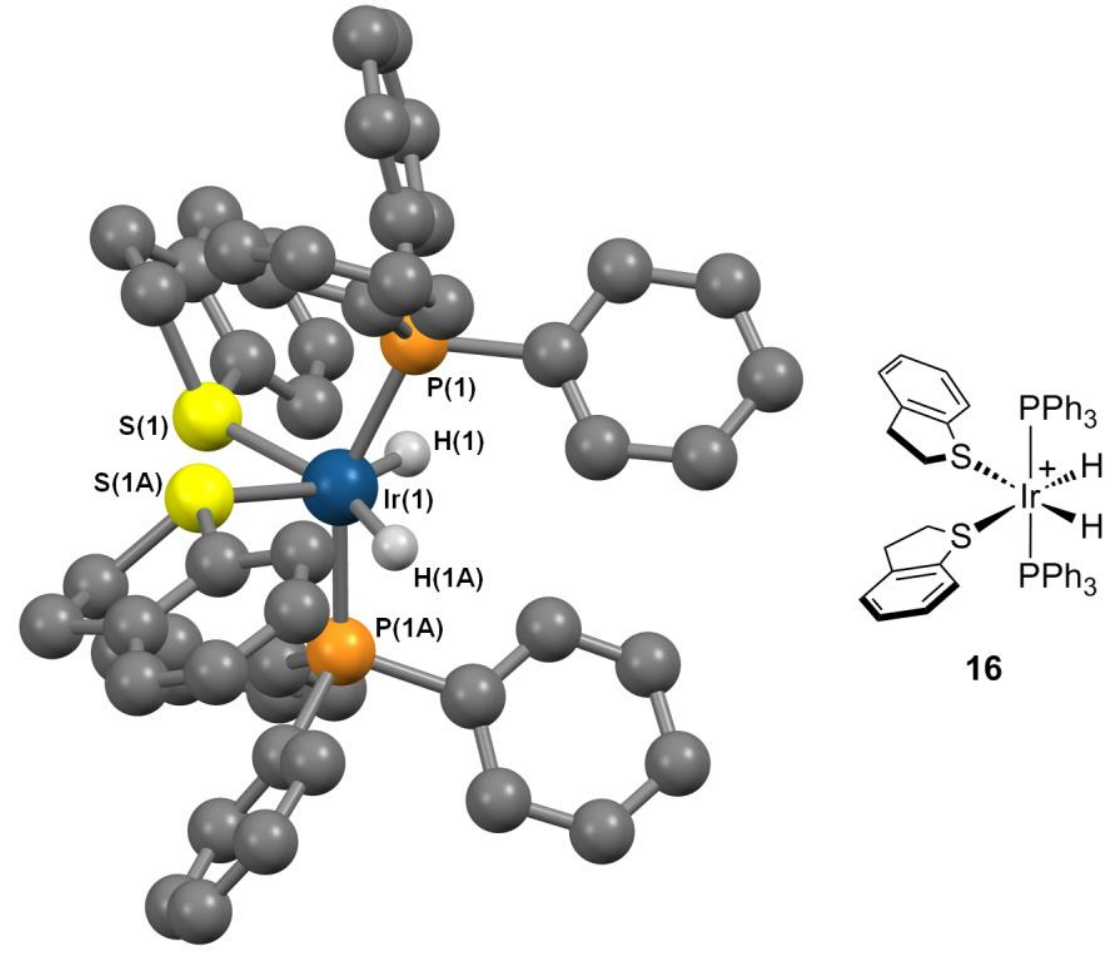

Fig. 4. Ball-and-stick representation of 16 generated with the program Mercury using crystallographic data retrieved from the Cambridge Crystal Structure Database (Refcode RUPHOZ); structural information originally provided in Ref. 52. $\mathrm{PF}_{6}$ counteranion and ligand hydrogen atoms are omitted for clarity.

\footnotetext{
${ }^{10}$ A previous study had already found $\left[\mathrm{Rh}(\operatorname{cod})\left(\mathrm{PPh}_{3}\right)_{2}\right]\left[\mathrm{PF}_{6}\right]$ active for this transformation. A detailed, semi-empirical mechanistic analysis at the time suggested a catalytic cycle highly similar to that later proposed for iridium. Unlike the iridium system, however, none of the proposed rhodium intermediates could be isolated. For further details, see: R. A. Sánchez-Delgado, V. Herrera, L. Rincón, A. Andriollo, G. Martín, Organometallics 13 (1994) 553.

${ }^{11}$ No catalytic activity was observed in 2-methoxyethanol even at $125^{\circ} \mathrm{C}$.
} 
Based on these results, Sánchez-Delgado proposed 15 first enters the catalytic cycle by loss of a benzothiophene ligand to form $\mathbf{1 7}$ (Scheme 22). A hapticity shift from $\eta^{1}-\mathrm{S}$ to $\eta^{2}-\mathrm{C}_{2}$ then facilitates the reaction's rate-determining step: hydride addition to the $\mathrm{C}(2)=\mathrm{C}(3)$ bond. ${ }^{12}$ Reductive elimination then affords $\eta^{1}-\mathrm{S}-1,2$-dihydrobenzothiopheneligated 18, which can undergo successive ligand exchange with another unit of benzothiophene and oxidative addition to $\mathrm{H}_{2}$ to reform $\mathbf{1 7}$ and close the catalytic cycle. Generation of $\mathbf{1 6}$ results from an off-cycle process involving interception of $\mathbf{1 8}$ by a free molecule of 1,2-dihydrobenzothiophene instead of substrate.

${ }^{12}$ The depicted regioselectivity for insertion specifically at $\mathrm{C}(3)$ is based purely on the Sánchez-Delgado's computational analyses. 


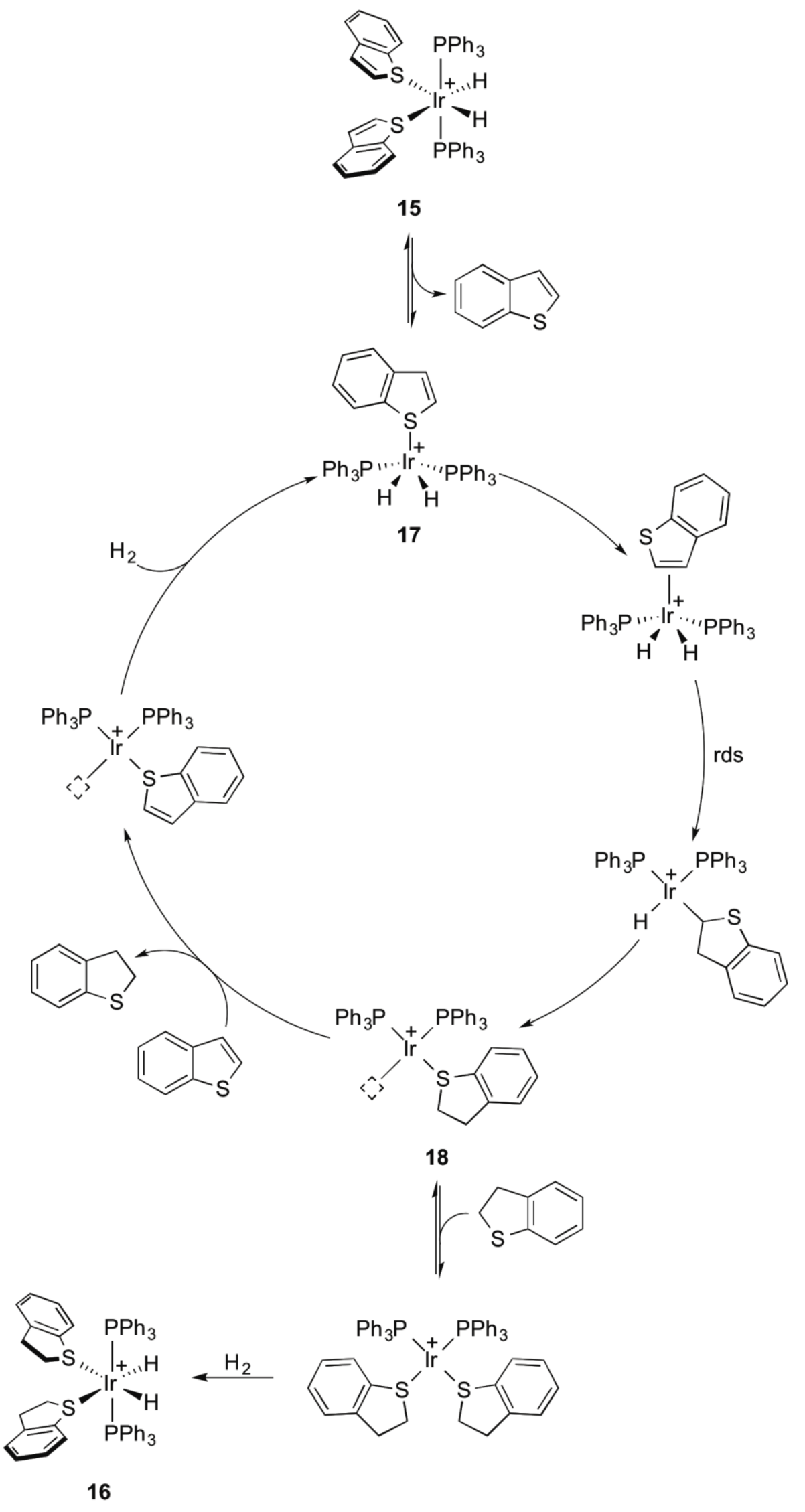


Scheme 22. Proposed catalytic cycle for hydrogenation of benzothiophene catalyzed by 15. Counteranions omitted for clarity.

\subsubsection{Asymmetric hydrogenation}

In 2012, Ohshima, Mashima, and Ratovelomanana-Vidal [53] enantioselectively hydrogenated quinoxalines using a cationic, dinuclear iridium(III) precatalyst (19) bearing fluorinated SEGPHOS-based ligands (Scheme 23, top). The authors discovered a pronounced effect on enantioselectivity with regard to the nature of the catalyst's innerand outer-sphere halides. The use of the all-chloride complex gave $>99 \%$ conversion and $92 \%$ ee for the hydrogenation of 2-methylquinoxaline, but when iodides, bromides or hexafluorophosphates were used, the enantioselectivity decreased (48-87\% ee). This dependence led the authors to postulate the dimer precatalyst initially cleaves to form two equivalent, neutral iridium complexes. These then catalyze addition of hydrogen to the substrate in an out-sphere fashion similar to that proposed by Eisenstein and Crabtree (see Section 2.1.2).

Mashima later demonstrated 19 could diastereoselectively hydrogenate 2,6disubstituted pyridinium salts [54] (Scheme 23, middle) and also 1,3-disubstituted isoquinolinium hydrochloride salts enantioselectively (bottom) [55].
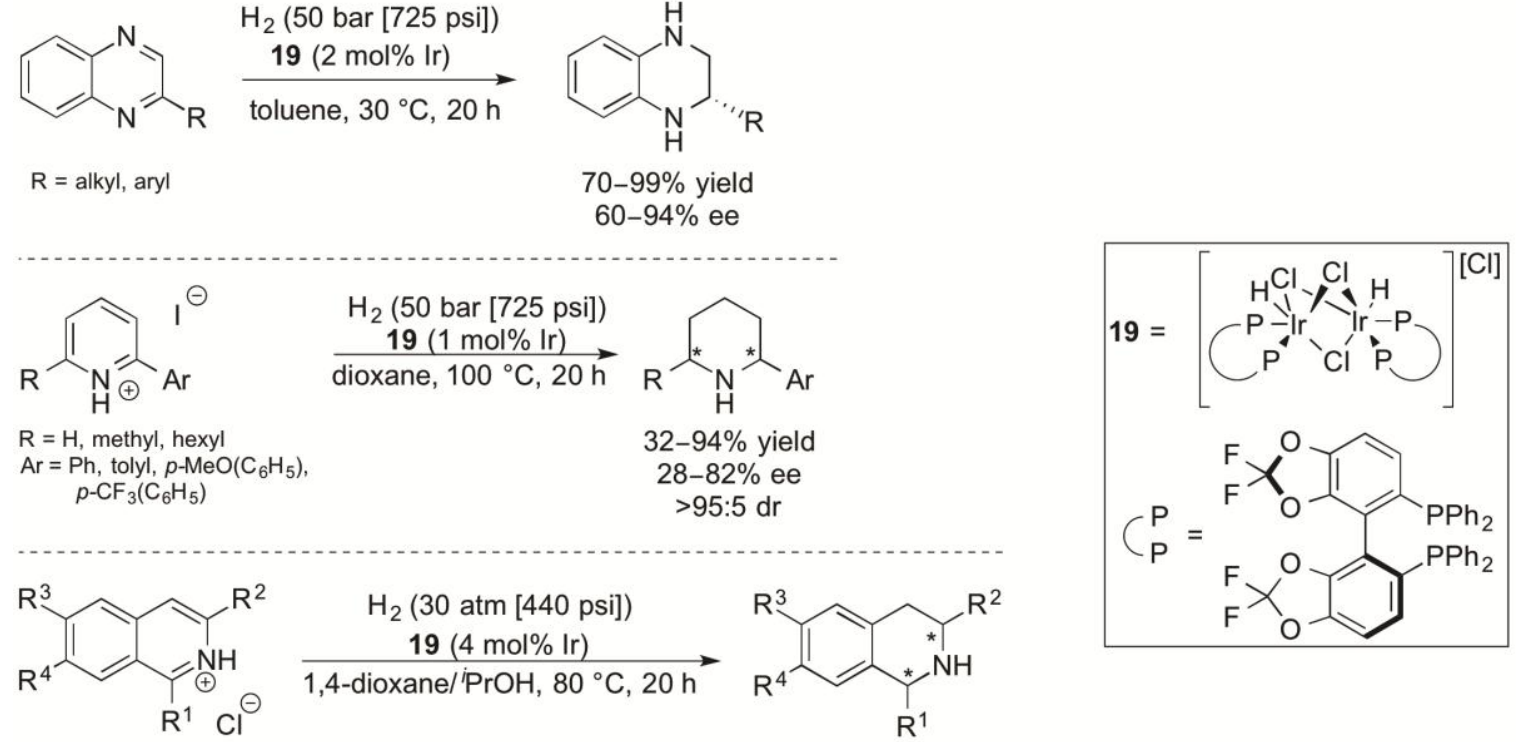

$\mathrm{R}^{1}=c-\mathrm{Hex}$, aryl

$\mathrm{R}^{2}=n-\mathrm{Hex}$, aryl

$56-93 \%$ yield

$\mathrm{R}^{3}=\mathrm{H}, \mathrm{Me}, \mathrm{F}$

$\mathrm{R}^{4}=\mathrm{H}, \mathrm{OMe}, \mathrm{F}$

91-98\% ee

Scheme 23. Asymmetric hydrogenation of quinoxalines (top), pyridinium salts (middle), and isoquinolinium hydrochlorides (bottom) catalyzed by 19.

Lyubimov [56] enantioselectively hydrogenated unprotected 2-methylindole using a cationic iridium catalyst supported by BINOL-based chiral phosphite ligand 20 (Scheme 24). For this system, full conversion and $80 \%$ ee were the optimized results. Lyubimov was also able to hydrogenate quinolines and quinolinium hydrochloride salts, with the latter yielding better results (conversion up to $80 \%$ and enantioselectivity up to 
$65 \%$ ee) [57].

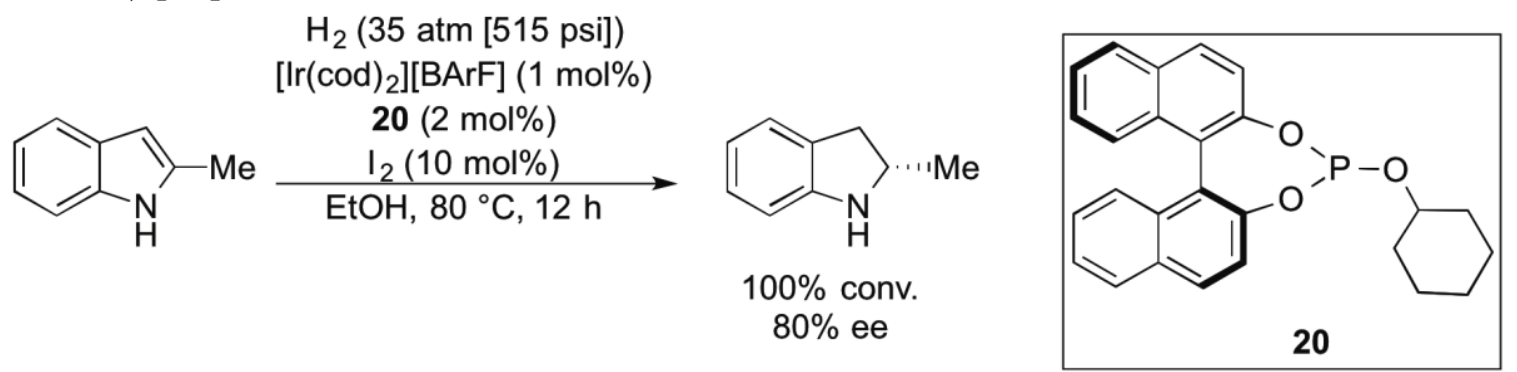

Scheme 24. Asymmetric hydrogenation of 2-methylindole using $\left[\operatorname{Ir}(\operatorname{cod})_{2}\right][\mathrm{BArF}]$ as a precatalyst and $\mathbf{2 0}$ as a chiral ligand.

Recently, Pfaltz [58] reported asymmetric hydrogenation of furans and benzofurans with chiral iridium catalyst 21 (Scheme 25). For furans, although both alkyl and aryl substitution were well-tolerated at the 3-position, at the 2-position, only alkyl and electron-deficient aryl substituents were supported; 2-phenylfuran and 2-( $p$ methoxyphenyl)furan for example were unreactive. 2,4-Disubstituted furans also gave poor yields and poor enantioselectivity. The addition of 2,2,2-trifluoroethanol proved beneficial for some difficult substrates such as 3-(n-octyl)furan. Pfaltz postulated that addition of the fluorinated alcohol improved reactivity by disrupting the hydrogen bonding between the substrate and the dichloromethane solvent. For benzofurans, 2-alkyl and even 2-alkenyl substitution gave excellent yields and stereoselectivity, while 2-aryl substitution rendered the substrate inert to hydrogenation. Notably, this catalytic system was used in a formal synthesis of thespesone, a natural product.

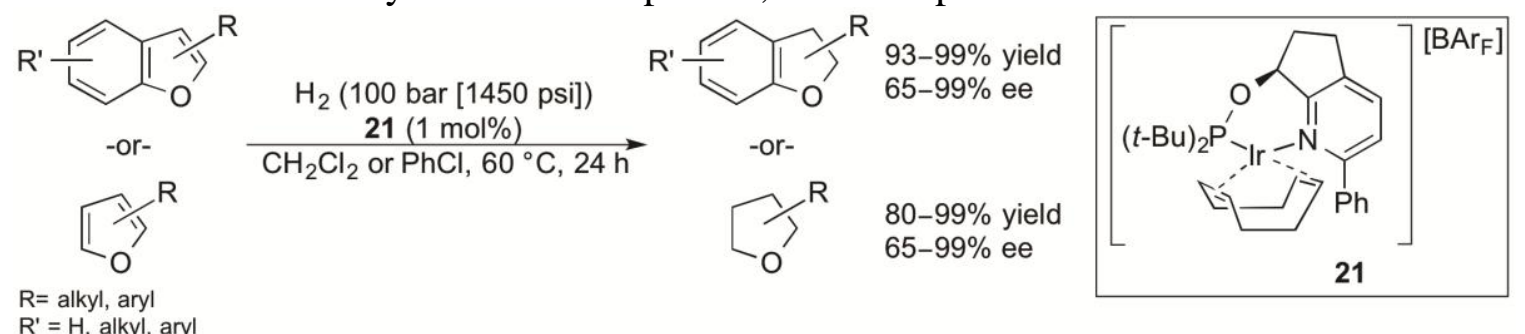

Notable Examples
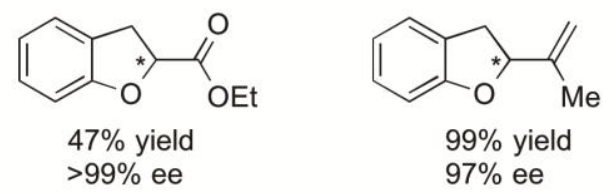

Scheme 25. Asymmetric hydrogenation of benzofurans and furans catalyzed by 21.

\subsubsection{Transfer hydrogenation}

Crabtree [59] found the NHC-ligated cationic iridium complex 22 selectively active in the transfer hydrogenation of pyrazine to piperazine (Scheme 26). While 22 also promoted the hydrogenation of quinoline in more moderate yields (67\%), it proved completely inactive with other $N$-heterocycles, including isoquinoline, acridine, and indole. 


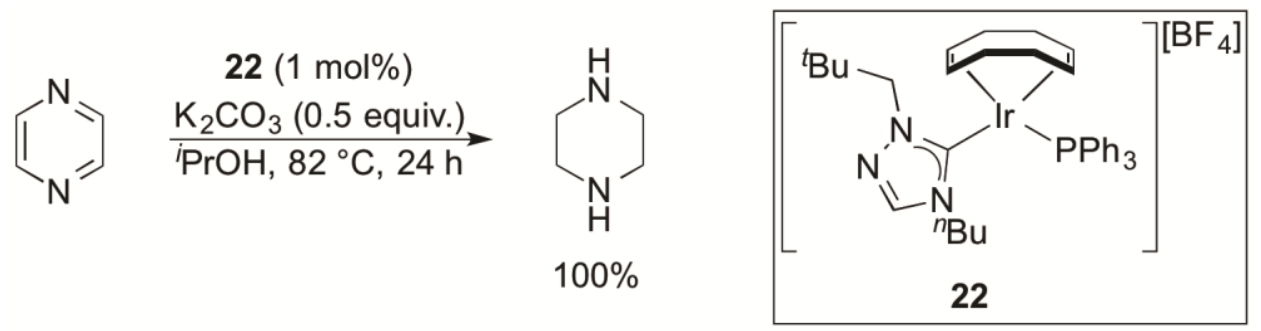

Scheme 26. Transfer hydrogenation of pyrazine catalyzed by $\mathbf{2 2}$.

\subsection{Rhodium}

\subsubsection{Neutral complexes}

In 1984, Fish [60] reported $\mathrm{RhCl}\left(\mathrm{PPh}_{3}\right)_{3}$ (Wilkinson's catalyst) to catalyze the hydrogenation of various polycyclic heteroaromatic compounds. A comparison of relative reaction rates revealed a combination of steric and electronic influences on substrate reactivity, with reduction of phenanthridine proving the most facile, while that of 7,8benzoquinoline the least so (Fig. 5). A subsequent study [61] using the ruthenium(II) analogue $\mathrm{RuCl}_{2}\left(\mathrm{PPh}_{3}\right)_{3}$ produced a similar trend. The ruthenium catalyst, however, also afforded higher absolute reaction rates, except in the case of benzothiophene.<smiles>c1ccc2c3c(ccc2c1)CCCN3</smiles>

$k_{\text {rel }}$<smiles>c1ccc2c3c(ccc2c1)NCCC3</smiles>

0.38<smiles>c1ccc2c(c1)CCCN2</smiles>

1.0<smiles>c1ccc2c(c1)CCS2</smiles>

1.5

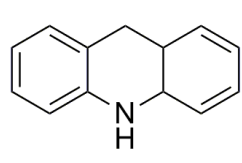

2.7<smiles>c1ccc2c(c1)CNc1ccccc1-2</smiles>

$>76$

Fig. 5. Relative rates of product formation from hydrogenation of heterocycles catalyzed by $\mathrm{RhCl}\left(\mathrm{PPh}_{3}\right)_{3}$. Conditions: $10 \mathrm{~mol} \%$ catalyst, $310 \mathrm{psi}_{2}$, benzene, $85{ }^{\circ} \mathrm{C}$.

Neutral rhodium complexes have also been generated in situ to catalyze heterocycle hydrogenation. Murata [62] found addition of $(S, S)$-DIOP and $\mathrm{KBH}_{4}$ to $\left[\mathrm{RhCl}(\mathrm{CO})_{2}\right]_{2}$ produced an active catalyst for the reduction of quinoxaline at room temperature (Scheme 27). Despite the use of a chiral ligand, hydrogenation of 2-methylquinoxaline yielded essentially racemic product. More recently, Ito [63] reported the combination of $\mathrm{Rh}(\mathrm{acac})(\mathrm{cod})$ and $\mathrm{PPh}_{3}$ to catalyze hydrogenation of variously substituted indoles and select other heterocycles (Scheme 28). Both the aforementioned systems presumably operate through a $\mathrm{Rh}(\mathrm{I})$ monohydride species.

$$
\begin{gathered}
\mathrm{H}_{2}\left(7 \mathrm{~kg} \mathrm{~cm}^{-2}[100 \mathrm{psi}]\right) \\
{\left[\mathrm{RhCl}(\mathrm{CO})_{2}\right]_{2} \text { (4 mol\% Rh) }}
\end{gathered}
$$<smiles>[R]c1cnc2ccccc2n1</smiles>

$(S, S)$-DIOP $(4 \mathrm{~mol} \%)$
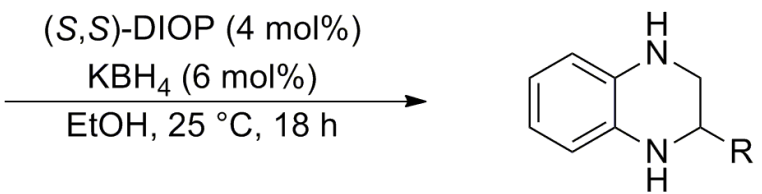

$$
\begin{gathered}
\mathrm{R}=\mathrm{H}: 81 \% \text { GC yield } \\
\text { Me: } 84 \% \text { GC yield, } \\
2 \% \text { ee }
\end{gathered}
$$

Scheme 27. Hydrogenation of quinoxaline and 2-methylquinoxaline catalyzed by 
$\left[\mathrm{RhCl}(\mathrm{CO})_{2}\right]_{2}$ in the presence of $(S, S)$-DIOP and $\mathrm{KBH}_{4}$.

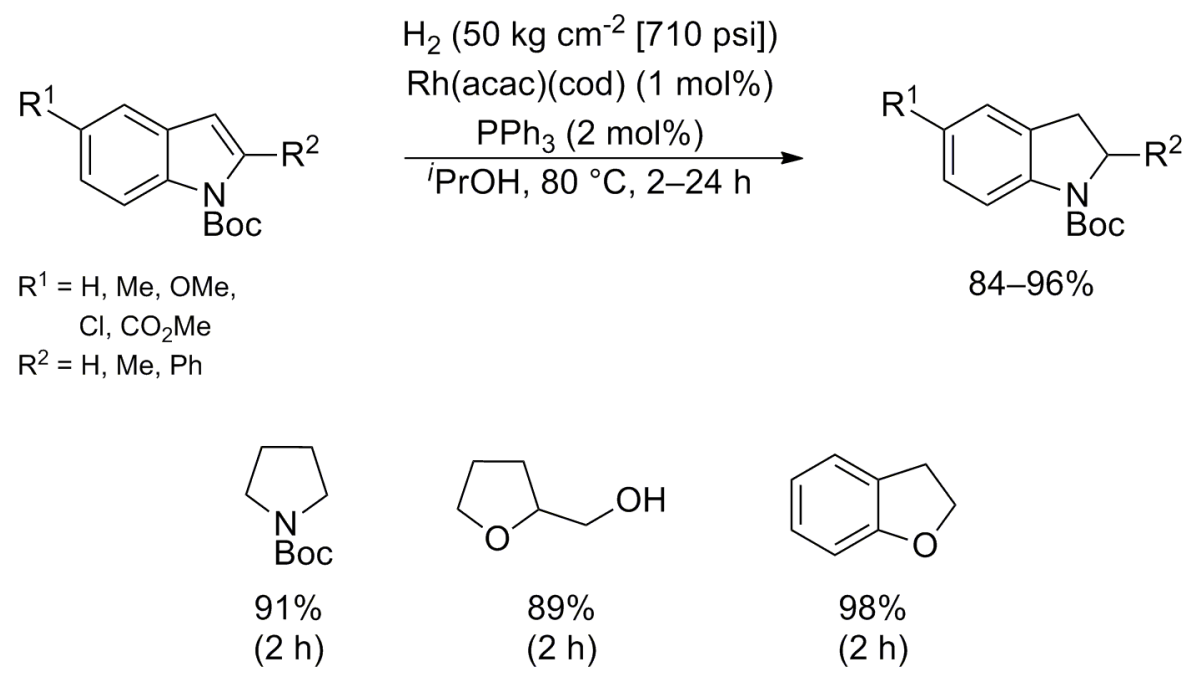

Scheme 28. Hydrogenation of indoles and other heterocycles catalyzed by $\mathrm{Rh}(\mathrm{acac})(\mathrm{cod})$ in the presence of $\mathrm{PPh}_{3}$.

In addition to phosphine-based ligand systems, López-Linares [64] found sodium tris(pyrazolyl)borate $(\mathrm{NaTp})$ an effective support for a $[\mathrm{RhCl}(\mathrm{cod})]_{2}$ precatalyst in the hydrogenation of quinoline (Scheme 29). Venanzi [65] had previously demonstrated the addition of $\mathrm{NaTp}$ to $[\mathrm{RhCl}(\mathrm{cod})]_{2}$ formed the monomeric $\mathrm{TpRh}(\mathrm{cod})$ (23; Scheme 30). Based on observations by Sánchez-Delgado with cationic 34 (see Section 2.2.2.1, Scheme 32), López-Linares proposed $\mathbf{2 3}$ reacts further in the presence of quinoline to form the bis- $N$-ligated complex $\mathbf{2 4}$ as the catalytically active species.

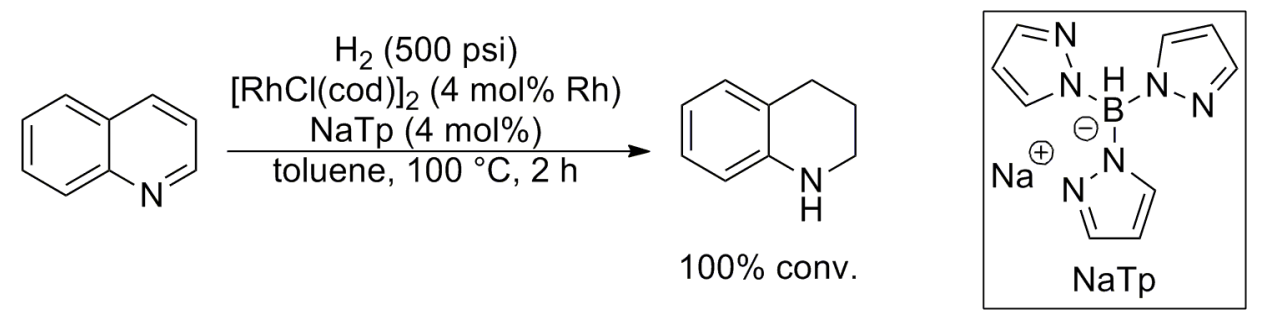

Scheme 29. Hydrogenation of quinoline catalyzed by $[\mathrm{RhCl}(\operatorname{cod})]_{2}$ in the presence of NaTp. 


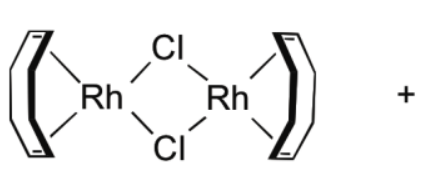

2<smiles></smiles>

$\mathrm{NaTp}$

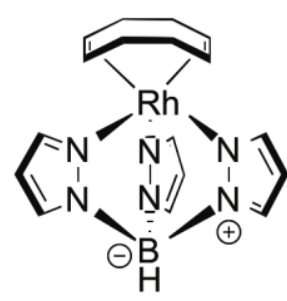

23

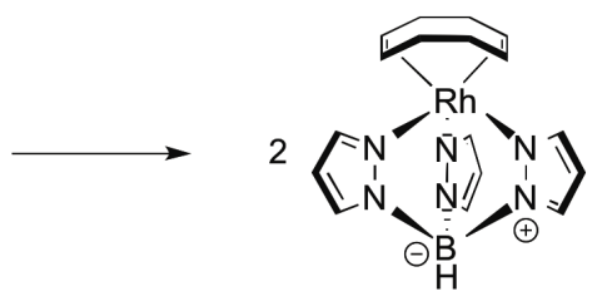

23

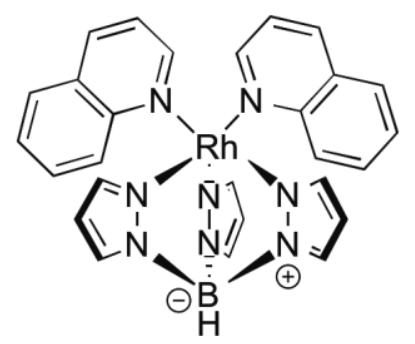

24

Scheme 30. Proposed formation of $\mathbf{2 4}$ starting from $[\mathrm{RhCl}(\operatorname{cod})]_{2}$.

Upon extensive ligand and condition screening, Xiao [48] reported $\mathrm{Cp}^{\star} \mathrm{RhCl}(\mathrm{TsDPEN})$ complexes (25) to catalyze the asymmetric transfer hydrogenation of 2 -substituted quinolines (Scheme 31). The reaction required an $\mathrm{AcOH} / \mathrm{NaOAc}$ buffer to maintain $\mathrm{pH}=4-5$; such acidic conditions supported sufficient concentrations of the substrates' activated quinolinium formate form to achieve high levels of conversion. Wills [66] also found this reaction to proceed in a 5:2 formic acid:triethylamine methanolic solution via the rhodium and ruthenium tethered-TsDPEN catalysts $\mathbf{2 6}$ and 27 (Scheme 32). While 27 generally afforded greater activity, 26 typically demonstrated higher levels of enantioselectivity. Notably, this catalytic system proved ineffective with other $N$ heterocycles, including 1-methylisoquinoline, 2-phenylpyridine, and quinoxaline.

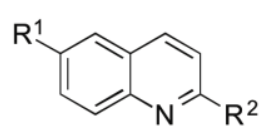

$\mathrm{R}^{1}=\mathrm{H}, \mathrm{Me}, \mathrm{F}$,

$\mathrm{Cl}, \mathrm{Br}, \mathrm{OMe}$

$\mathrm{R}^{2}=\mathrm{Me}, 1^{\circ}, 2^{\circ}$,

$3^{\circ}$ alkyl
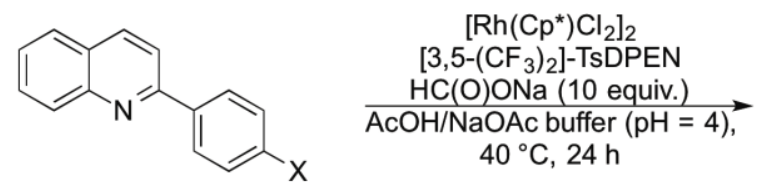
$\mathrm{HC}(\mathrm{O}) \mathrm{ONa}$ (10 equiv.) $\overrightarrow{\mathrm{AcOH} / \mathrm{NaOAc} \text { buffer }(\mathrm{pH}=5),}$ $40{ }^{\circ} \mathrm{C}, 6-24 \mathrm{~h}$<smiles>[R1]c1ccc2c(c1)CCC([R2])N2</smiles>

$80-97 \%$ yield $91-98 \%$ ee

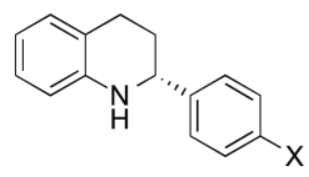

$\mathrm{X}=\mathrm{H}: 96 \%$ yield, $90 \%$ ee OMe: $95 \%$ yield, $90 \%$ ee F: $93 \%$ yield, $89 \%$ ee

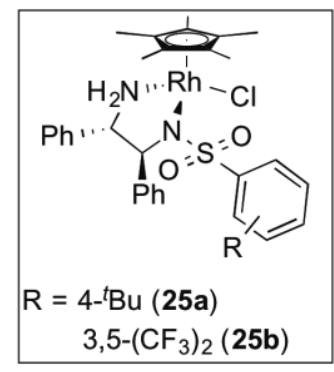
Scheme 31. Asymmetric transfer hydrogenation of 2-alkyl (top) and 2-aryl (bottom)
quinolines catalyzed by pre-formed $\mathrm{Cp}^{*} \mathrm{RhCl}(\mathrm{TsDPEN})$ complex 25a and in situ generated $\mathbf{2 5 b}$ respectively. 


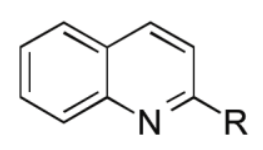

$\mathrm{R}=\mathrm{Me}, 1^{\circ}$ alkyl, $\mathrm{Ph}$

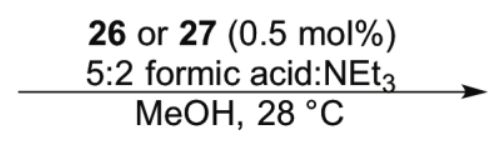

26: $30-68 \%$ conv.

$81-94 \%$ ee

27: $68-96 \%$ conv.

$41-73 \%$ ee

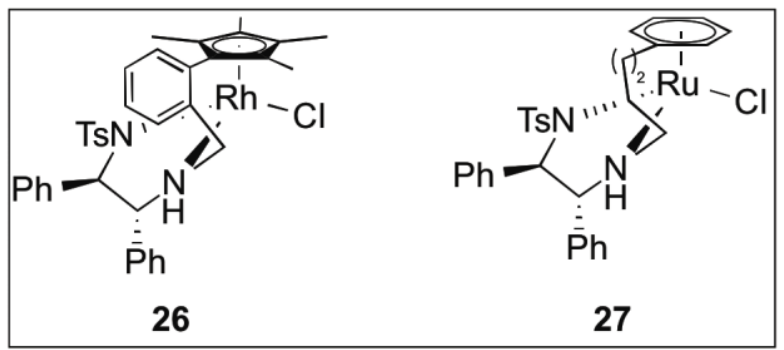

Scheme 32. Asymmetric transfer hydrogenation of 2-substituted quinolines catalyzed by tethered-TsDPEN $\mathrm{Rh}$ and $\mathrm{Ru}$ complexes $\mathbf{2 6}$ and 27 (generated in situ from the corresponding dimeric precursors).

\subsubsection{Cationic complexes}

\subsubsection{Mechanistic studies}

In 1988, Fish [67] analyzed the binding modes of various quinoline derivatives with the dicationic rhodium species $\left[\mathrm{Cp}^{\star} \mathrm{Rh}\left(\mathrm{CH}_{3} \mathrm{CN}\right)_{2}\right]\left[\mathrm{BF}_{4}\right]_{2}(\mathbf{2 8})$ by ${ }^{13} \mathrm{C} \mathrm{NMR}$. Quinoline and isoquinoline formed the mono- and tris- $\eta^{1}-\mathrm{N}$-ligated complexes 29 and $\mathbf{3 0}$ respectively (Fig. 6). 1,2,3,4-Tetrahydroquinoline, however, formed an $\eta^{6}-\mathrm{C}_{6}$ complex (31), possibly due to increased electron density in the remaining aromatic ring. The influence of steric effects was demonstrated by 2-methylquinoline, which formed an approximately 1:1 mixture of $\eta^{1}-\mathrm{N}$ - and $\eta^{6}-\mathrm{C}_{6}$-coordinated species ( 32 and 33 respectively). Later hydrogenation studies also found 2-methylquinoline reacted at approximately half the initial rate of unsubstituted quinoline itself (Fig. 7) [68,69]. Among all the substrates examined, 7,8-benzoquinoline proved the most reactive (TOF $=40 \mathrm{~h}^{-1}$ ), and 2methylpyridine and $N$-methylindole the least so (TOF $<1 \mathrm{~h}^{-1}$ ). 


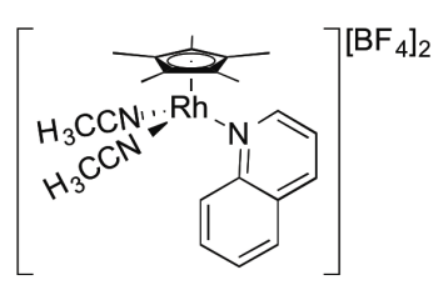

29

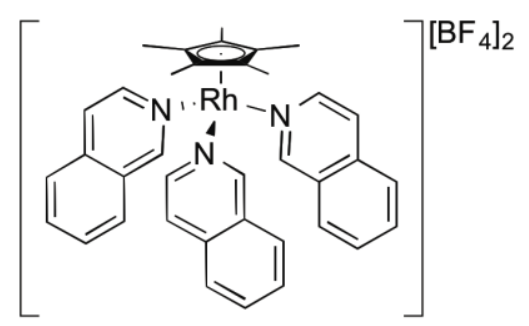

30

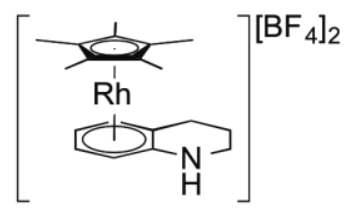

31

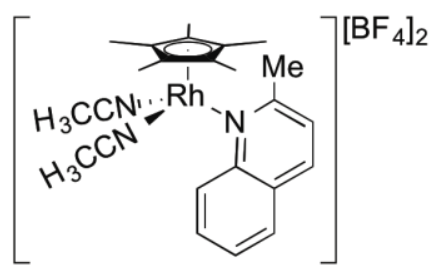

32

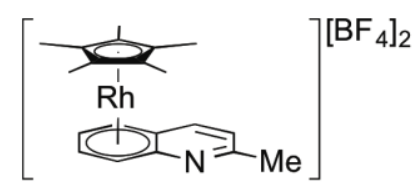

33

Fig. 6. Complexes formed between $\left[\mathrm{Cp}^{\star} \mathrm{Rh}\left(\mathrm{CH}_{3} \mathrm{CN}\right)_{2}\right]\left(\mathrm{BF}_{4}\right)_{2}$ and various quinoline derivatives.<smiles>CC1CCCCN1</smiles>

$k_{\text {rel }}$

0.03<smiles>c1ccc2c3c(ccc2c1)NCCC3</smiles>

$k_{\text {rel }}$<smiles>CN1CCc2ccccc21</smiles>

0.03<smiles>c1ccc2c(c1)CCO2</smiles>

0.09<smiles>c1ccc2c(c1)CCS2</smiles>

0.19<smiles>CC1CCc2ccccc2N1</smiles>

0.47<smiles>c1ccc2c(c1)CCCN2</smiles>

1.0<smiles>C1=CC2Cc3ccccc3NC2C=C1</smiles>

1.28<smiles>c1ccc2c3c(ccc2c1)CCCN3</smiles>

11

Fig. 7. Relative rates of product formation from hydrogenation of heterocycles catalyzed by $\left[\mathrm{Cp}^{*} \mathrm{Rh}\left(\mathrm{CH}_{3} \mathrm{CN}\right)_{2}\right]\left[\mathrm{BF}_{4}\right]_{2}$. Conditions: 5 mol\% catalyst, $500 \mathrm{psi}_{2}, \mathrm{CH}_{2} \mathrm{Cl}_{2}, 40{ }^{\circ} \mathrm{C}$.

In a comparison of different catalysts for quinoline and benzothiophene hydrogenation, Sánchez-Delgado [70] found [Rh(cod) $\left.\left(\mathrm{PPh}_{3}\right)_{2}\right]\left[\mathrm{PF}_{6}\right](\mathbf{3 4})$ produced the greatest initial rates for both substrates (Scheme 33). A subsequent kinetic study of quinoline hydrogenation yielded the following rate law [71]:

$$
\frac{d[\mathrm{THQ}]}{d t}=k_{\text {cat }}[\mathrm{Rh}]\left[\mathrm{H}_{2}\right]^{2}
$$

Efforts to determine the active rhodium species found that under the conditions for hydrogenation, quinoline displaced the two phosphine ligands from 34 to form 35 (Scheme 34). The latter species was also isolated from catalytic hydrogenation reactions as the only rhodium-containing compound, and in separate experiments, demonstrated activity comparable to 34 . 


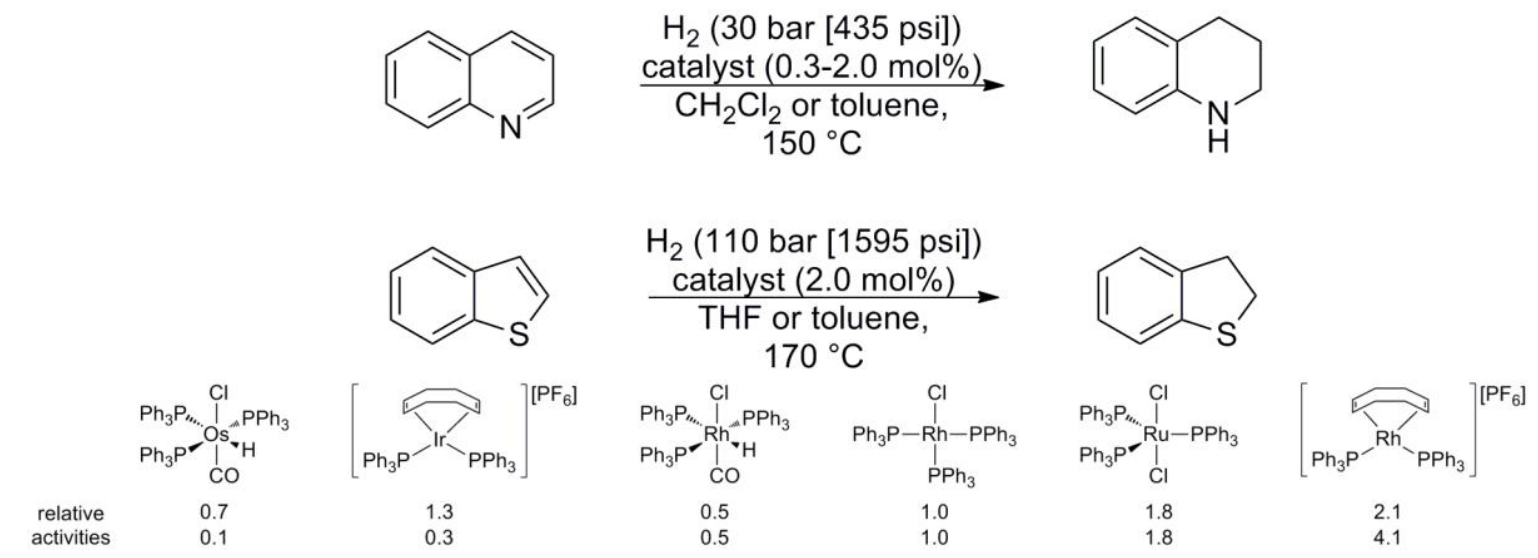

Scheme 33. Relative activities of hydrogenation of quinoline (top) and benzothiophene (bottom) catalyzed by various complexes.<smiles>CC(C)C[Pb]1(P(c2ccccc2)c2ccccc2)C=CCC1</smiles>

34<smiles>c1ccc2ncccc2c1</smiles>

50 equiv.

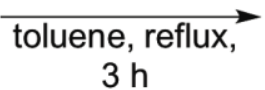

$3 \mathrm{~h}$<smiles></smiles>

35

$90 \%$

Scheme 34. Formation of $\mathbf{3 5}$ from 34 under hydrogenation conditions.

Based on these results, Sánchez-Delgado proposed the catalytic cycle shown in Scheme 35. Starting from 35, oxidative addition to $\mathrm{H}_{2}$ is followed by reduction of the $\mathrm{C}(2)=\mathrm{N}$ bond. A shift from $\eta^{1}-\mathrm{N}$ - to $\eta^{2}-\mathrm{C}_{2}$-coordination then facilitates hydrogenation of the $\mathrm{C}(3)=\mathrm{C}(4)$ bond. Assignment of this latter process as the rate-determining step accords with the observed rate law and the observation that 1,2-dihydroquinoline reacts at the same rate as quinoline itself. In contrast to the findings by Fish [67], the 1,2,3,4tetrahydroquinoline product did not appear to ligate $\mathbf{3 4}$ or 35. Thus, Sánchez-Delgado proposed the formation of the coordinatively unsaturated species $\mathbf{3 7}$ following product release. Closure of the catalytic cycle then occurs through the favored $\eta^{1}-\mathrm{N}$-coordination of a new unit of substrate. 


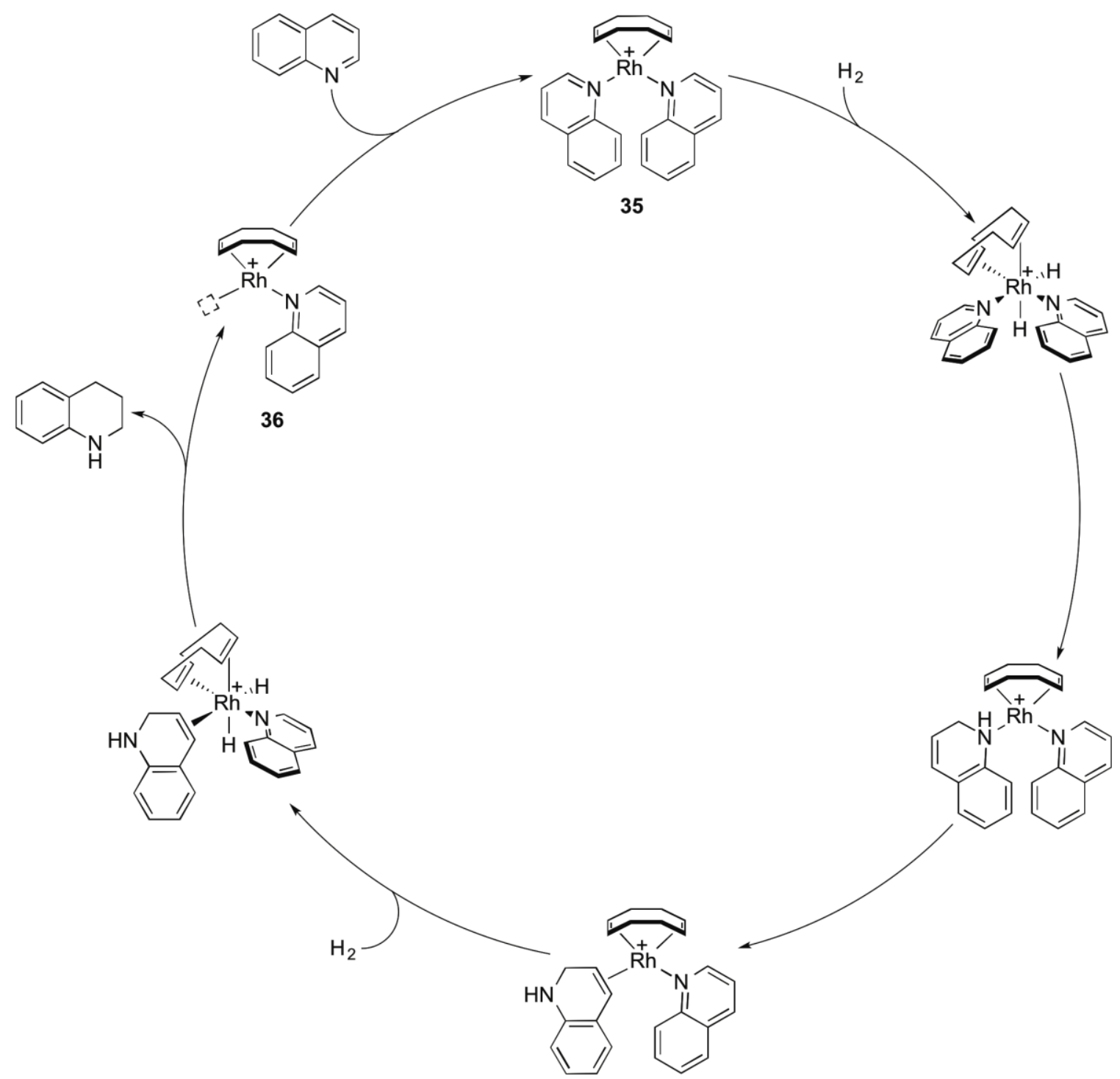

Scheme 35. Proposed catalytic cycle for hydrogenation of quinoline catalyzed by 35 . Counteranions omitted for clarity.

Bianchini [72] also investigated the hydrogenation of quinoline by a cationic rhodium species, specifically using $\left[\mathrm{Rh}(\mathrm{DMAD})(\right.$ triphos) $]\left[\mathrm{PF}_{6}\right](37)$ as a precatalyst. NMR analysis at room temperature under a hydrogen atmosphere in the presence of $\leq 70$ $\mathrm{mM}$ quinoline revealed 37 to form predominantly the dihydride 38 (Scheme 36). (At higher temperatures or quinoline concentrations, the bis- $N$-ligated complex 39 was detected in increasing amounts over time.) Both $\mathbf{3 7}$ and $\mathbf{3 8}$ catalyzed reduction of quinoline to 1,2,3,4-tetrahydroquinoline, with $\mathbf{3 8}$ actually displaying greater activity at $40{ }^{\circ} \mathrm{C}$ (Scheme 37). Significantly, no partially reduced 1,2- or 1,4-dihydro products were detected in these reactions. Indeed, the separate hydrogenation of 1,2-dihydroquinoline with 37 was found to proceed approximately eight times faster than that of quinoline itself, a result that contrasts with that reported by Sánchez-Delgado with 35 (vide supra). 


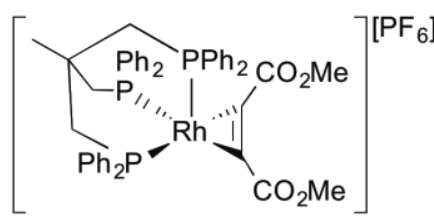

37

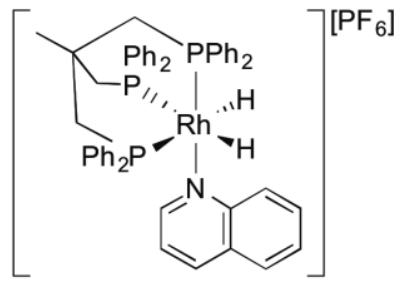

38
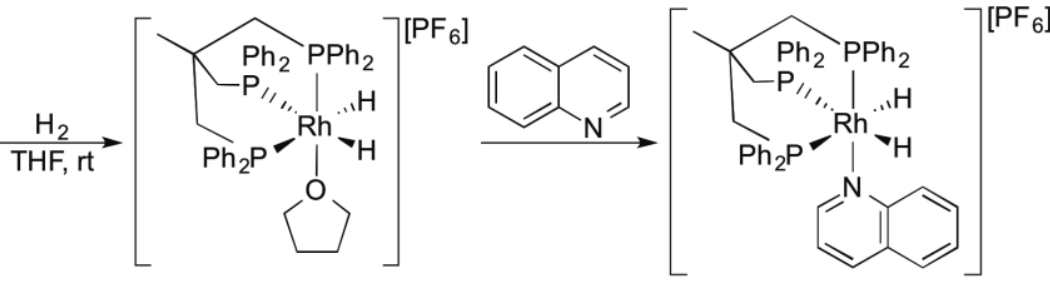

38

Scheme 36. Formation of $\mathbf{3 8}$ and 39 from 37.

$\mathrm{H}_{2}$ (30 bar [435 psi]) 37 or $38(1 \mathrm{~mol} \%)$ THF, $40^{\circ} \mathrm{C}, 1 \mathrm{~h}$

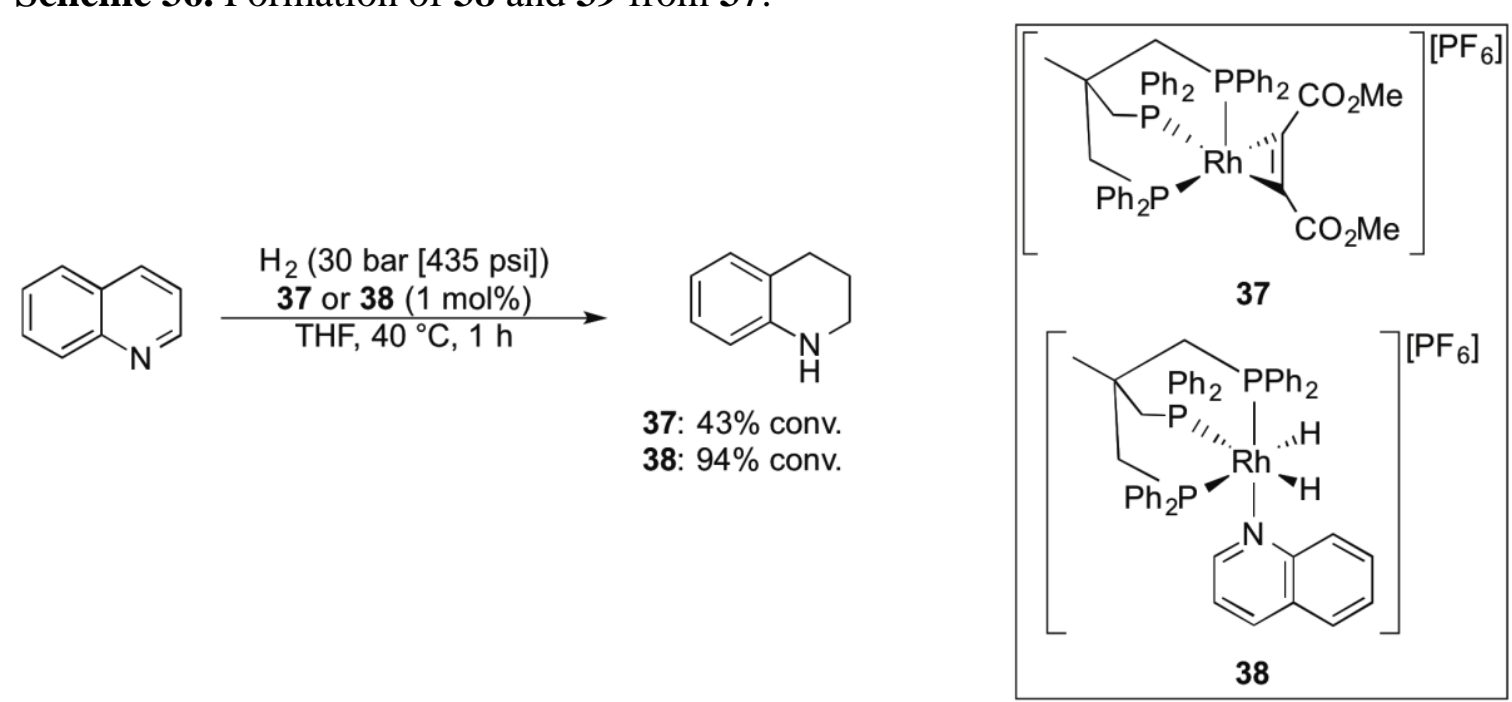

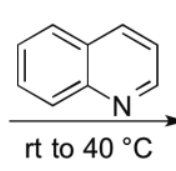

(1)

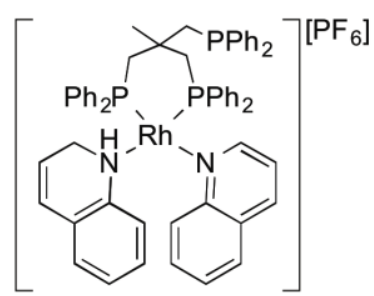

39

Scheme 37. Hydrogenation of quinoline catalyzed by either $\mathbf{3 7}$ or $\mathbf{3 8 .}$

Reduction with $\mathrm{D}_{2}$ led to deuterium incorporation at $\mathrm{C}(2)$ of both the substrate and product, suggesting reversibility of $\mathrm{C}=\mathrm{N}$ bond hydrogenation (Scheme 38). Notably, Fish had previously observed a similar result with 28 [68]. In contrast to Fish's other findings [69], however, Bianchini observed only cis deuteration at C(3) and C(4), indicative of irreversible $\mathrm{C}=\mathrm{C}$ bond hydrogenation.<smiles>O=Cc1ccc2ccccc2n1</smiles>

$$
\begin{aligned}
& \mathrm{D}_{2}(15 \mathrm{bar}[220 \mathrm{psi}]) \\
& \frac{37(1 \mathrm{~mol} \%)}{\mathrm{THF}, 60^{\circ} \mathrm{C}}
\end{aligned}
$$<smiles>[2H]C1Nc2ccccc2C([2H])C1([2H])[2H]</smiles>

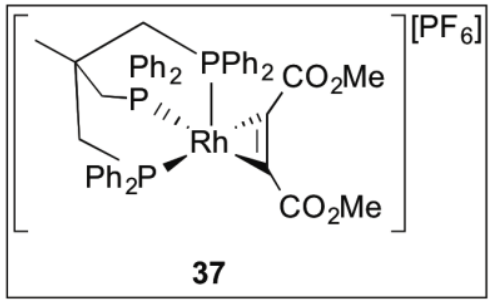

Scheme 38. Deuterium-labeling of quinoline reduction by 37 with $\mathrm{D}_{2}$.

Based on the above mechanistic probes, Bianchini proposed a catalytic cycle highly 
reminiscent of that previously put forth by Sánchez-Delgado, with the tridentate triphos taking the place of the 1,5-cyclooctadiene and quinoline ligands (Scheme 39). Unlike Sánchez-Delgado, however, Bianchini designated hydride addition to the $\mathrm{C}(2)=\mathrm{N}$ bond as the rate-determining step. This assignment was supported by kinetic analyses that yielded first order dependencies on catalyst, hydrogen, and quinoline concentrations under typical reaction conditions.

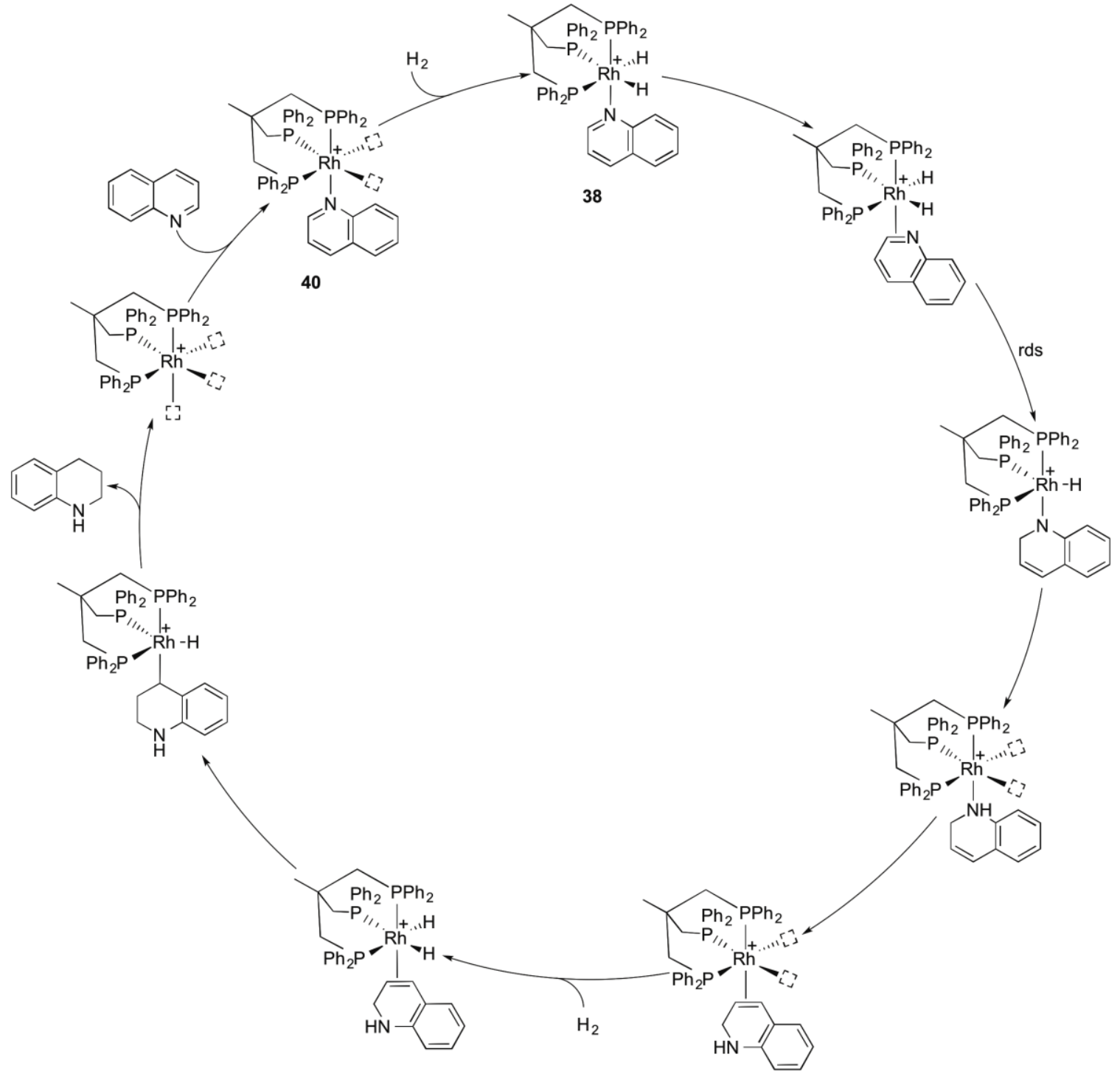

Scheme 39. Proposed catalytic cycle for hydrogenation of quinoline catalyzed by 38 . Counteranions omitted for clarity.

In addition to quinoline, Bianchini [73] also employed 37 in the hydrogenation of indole to indoline (Scheme 40). ${ }^{13}$ The authors attribute the need for a large excess of triflic acid to the requisite protonation of the indole substrate to facilitate $\eta^{2}-(\mathrm{C}=\mathrm{N})$

${ }^{13}$ The same study also reported the use of the related ruthenium complex $\left[\mathrm{Ru}\left(\mathrm{CH}_{3} \mathrm{CN}\right)_{3} \text { triphos][OTf }\right]_{2}$ to effect this transformation under similar conditions, but the product yields thus obtained were generally lower than with $\mathbf{3 7}$ 
coordination to the catalyst (Scheme 41). ${ }^{14}$ Under acidic conditions in the presence of $\mathrm{H}_{2}$, 37 had been previously shown to form a mixture of the neutral and cationic species $\mathbf{4 1}$ and 42 respectively (Scheme 42) [72]. Although no indole-rhodium or indoline-rhodium species were observed by in situ NMR, the disappearance of signals for $\mathbf{4 1}$ and $\mathbf{4 2}$ upon substrate addition nonetheless implies their presence in the reaction. Based on these findings, the authors proposed the catalytic cycle shown in Scheme 41. A measured zeroorder rate dependence on hydrogen pressure suggests either hydride addition to $\mathrm{C}(2)$ of the coordinated $\mathrm{C}=\mathrm{N}$ bond or product release from the catalyst acts as the ratedetermining step.
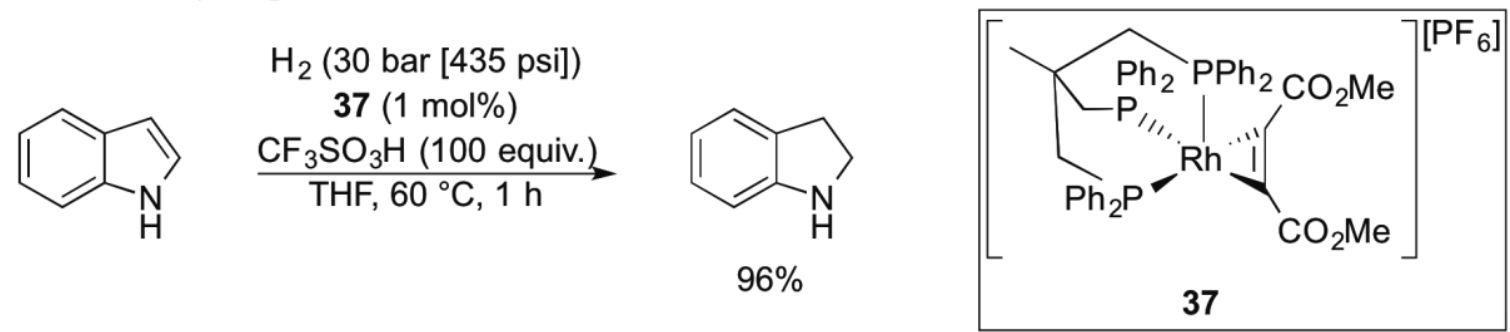

Scheme 40. Hydrogenation of indole catalyzed by 37 .

\footnotetext{
${ }^{14}$ Significant resonance delocalization of the nitrogen lone pair in neutral indole largely prevents $\eta^{1}-\mathrm{N}-$ metal bonding, typically resulting in $\eta^{6}-\mathrm{C}_{6}$-coordination occurring instead. For examples with various metals, see: C. White, S. J. Thompson, P. M. Maitlis, J. Chem. Soc., Dalton Trans. (1977) 1654 and S. Chen, V. Carperos, B. Noll, R. J. Swope, M. R. DuBois, Organometallics 14 (1995) 1221.
} 


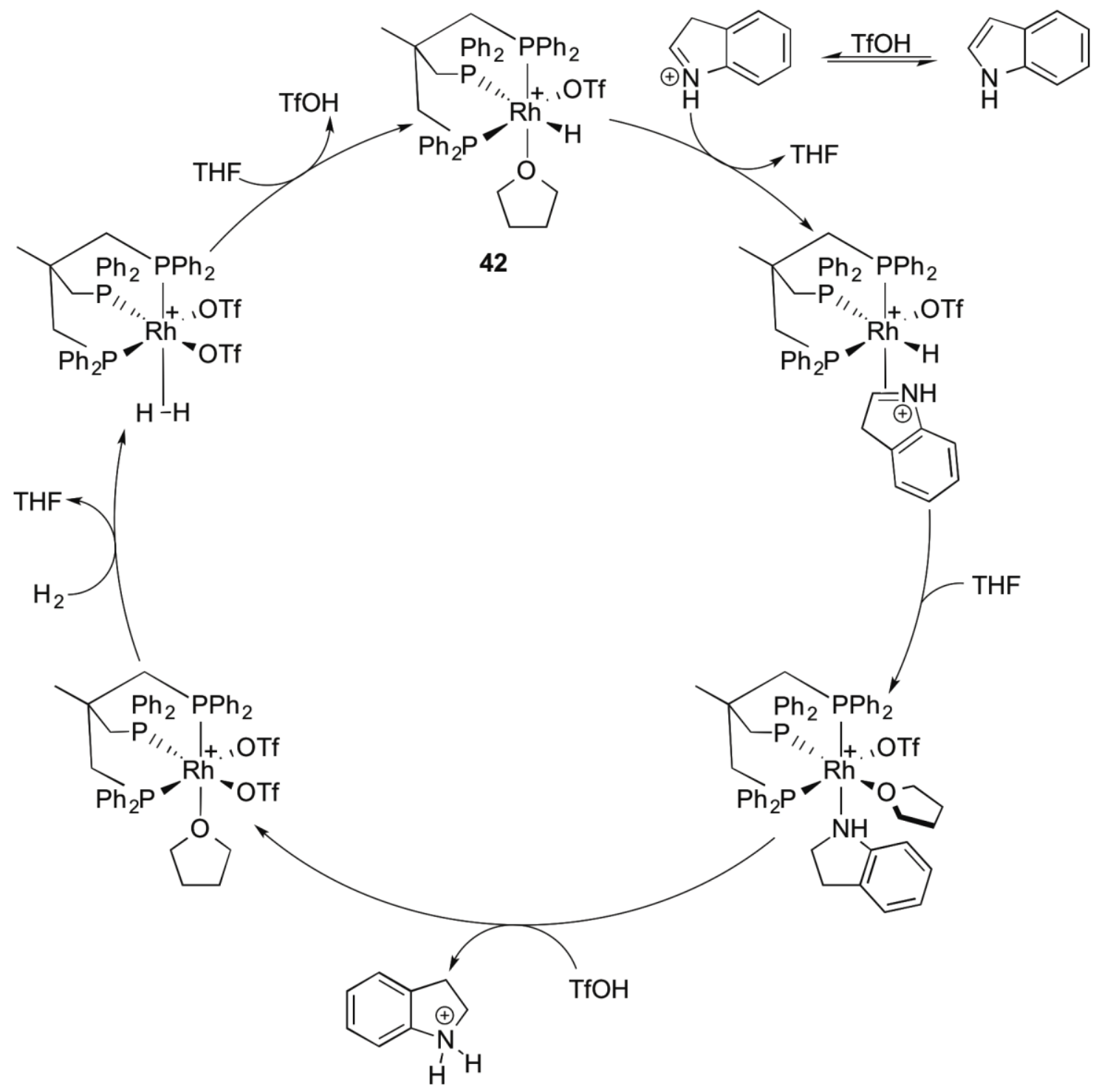

Scheme 41. Proposed catalytic cycle for hydrogenation of indole starting with $\mathbf{4 1}$. Counteranions omitted for clarity.

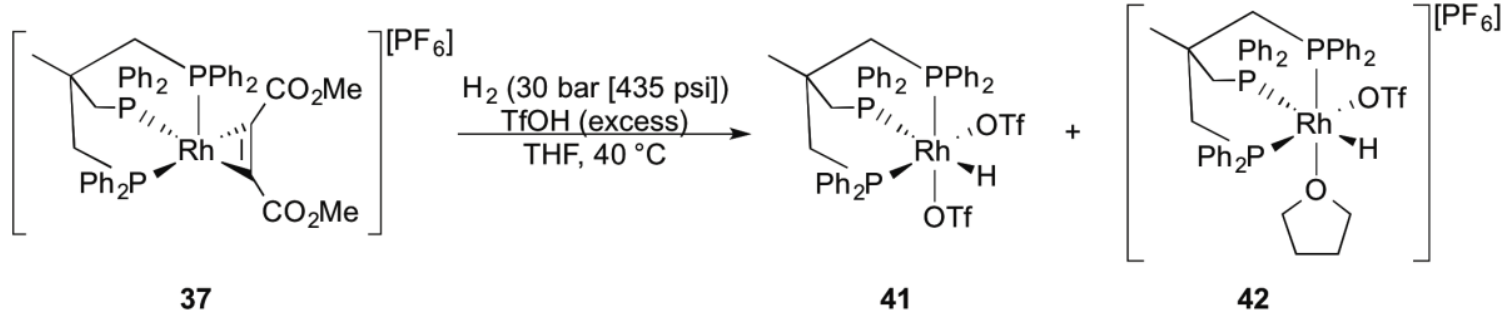

Scheme 42. Formation of 41 and 42 from 37 under acidic conditions in the presence of $\mathrm{H}_{2}$.

Rosales [74] later demonstrated the in situ generation of catalytically active species similar to 38 by addition of triphos to neutral rhodium and iridium dimers of the form $\left[\mathrm{MCl}(\mathrm{coe})_{2}\right]_{2}(\mathrm{M}=\mathrm{Rh}, \mathrm{Ir})$. In a comparison of activity with catalysts formed with monodentate $\left(\mathrm{PPh}_{3}\right)$ and bidentate (dppe) ligands, the Rh-triphos catalyst produced the 
greatest initial rates for quinoline hydrogenation (Scheme 43). For acridine, however, Irdppe proved the most active combination.

\begin{tabular}{|c|c|c|c|c|c|c|c|}
\hline \multirow[b]{2}{*}{ M } & \multirow[b]{2}{*}{ ligand } & \multicolumn{4}{|c|}{$\begin{array}{c}\mathrm{H}_{2}(4 \text { atm }[59 \mathrm{psi}]) \\
{\left[\mathrm{MCl}(\text { coe })_{2}\right]_{2}(1 \mathrm{~mol} \% \mathrm{M})} \\
\text { ligand }(n \mathrm{~mol} \%) \\
\text { xylene }, 130^{\circ} \mathrm{C}\end{array}$} & \multirow[b]{2}{*}{$n$} & \multirow[b]{2}{*}{ initial rate $\left(10^{6} \mathrm{M} \mathrm{s}^{-1}\right)$} \\
\hline & & $n$ & initial rate $\left(10^{6} \mathrm{M} \mathrm{s}^{-1}\right)$ & M & ligand & & \\
\hline \multirow[t]{5}{*}{$\mathrm{Rh}$} & \multirow[t]{2}{*}{$\mathrm{PPh}_{3}$} & 2 & $2.17 \pm 0.01$ & $\operatorname{Ir}$ & $\mathrm{PPh}_{3}$ & 2 & $0.21 \pm 0.01$ \\
\hline & & 3 & $2.32 \pm 0.03$ & & & 3 & $0.20 \pm 0.01$ \\
\hline & dppe & 1 & $8.54 \pm 0.20$ & & dppe & 1 & $0.33 \pm 0.01$ \\
\hline & triphos & 1 & $11.60 \pm 1.00$ & & triphos & 1 & $0.54 \pm 0.02$ \\
\hline & & & \multicolumn{3}{|c|}{$\begin{array}{c}\mathrm{H}_{2}(4 \mathrm{~atm}[59 \mathrm{psi}]) \\
{\left[\begin{array}{c}\left.\mathrm{MCl}(\mathrm{coe})_{2}\right]_{2}(1 \mathrm{~mol} \% \mathrm{M}) \\
\text { ligand }(n \%)\end{array}\right.} \\
\underset{\text { xylene }, 130{ }^{\circ} \mathrm{C}}{\longrightarrow}\end{array}$} & & $\mathrm{H}$ \\
\hline M & ligand & $n$ & initial rate $\left(10^{5} \mathrm{M} \mathrm{s}^{-1}\right)$ & M & ligand & $n$ & initial rate $\left(10^{5} \mathrm{M} \mathrm{s}^{-1}\right)$ \\
\hline \multirow[t]{4}{*}{$\mathrm{Rh}$} & \multirow[t]{2}{*}{$\mathrm{PPh}_{3}$} & 2 & $1.01 \pm 0.02$ & Ir & $\mathrm{PPh}_{3}$ & 2 & $1.67 \pm 0.02$ \\
\hline & & 3 & $1.43 \pm 0.01$ & & & 3 & $1.04 \pm 0.01$ \\
\hline & dppe & 1 & $2.50 \pm 0.05$ & & dppe & 1 & $3.78 \pm 0.20$ \\
\hline & triphos & 1 & $1.87 \pm 0.06$ & & triphos & 1 & $3.09 \pm 0.03$ \\
\hline
\end{tabular}

Scheme 43. Initial rates of hydrogenation of quinoline (top) and acridine (bottom) using various Rh- and Ir-based catalysts.

Notably, when $\left[\mathrm{IrCl}(\mathrm{coe})_{2}\right]_{2}$ was used as the precatalyst, the iridium analogue of $\mathbf{3 8}$ was recovered from the quinoline reactions [74]. Rosales thus proposed that reaction of $\left[\mathrm{MCl}(\mathrm{coe})_{2}\right](\mathrm{M}=\mathrm{Rh}, \mathrm{Ir})$ with quinoline and triphos initially forms the bis-quinolineligated complex 43 (Scheme 44, top) [75]. Loss of a quinoline ligand to generate the coordinatively unsaturated $\mathbf{4 4}$ (see Scheme 39) then facilitates entry into the catalytic cycle. Separate kinetic measurements revealed a fractional reaction order with respect to hydrogen ( $n=1.86$ for rhodium, 1.38 for iridium), leading Rosales to identify the second oxidative addition to $\mathrm{H}_{2}$ in the catalytic cycle $(\mathbf{4 0} \rightarrow \mathbf{3 8}$ in Scheme 39$)$ as the ratedetermining step. ${ }^{15}$

${ }^{15}$ A similar study with the related $\left[\mathrm{RhCl}(\mathrm{coe})_{2}\right]_{2}$-dppe system also found the second oxidative addition to $\mathrm{H}_{2}$ as most likely rate-limiting. In this case, [Rh(quinoline) $\left(\kappa^{2}-\right.$ dppe $)\left(\kappa^{1}\right.$-dppe $\left.)\right]^{+}$was proposed as the catalytically active species. For further details, see: M. Rosales, L. J. Bastidas, B. González, R. Vallejo, P. J. Baricelli, Catal. Lett. 141 (2011) 1305. 
$\left[\mathrm{MCl}(\mathrm{coe})_{2}\right]_{2}+{ }_{4} \longrightarrow$

43

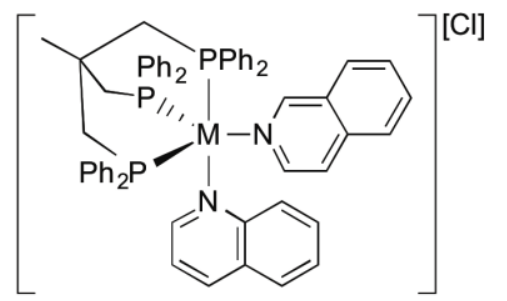

43

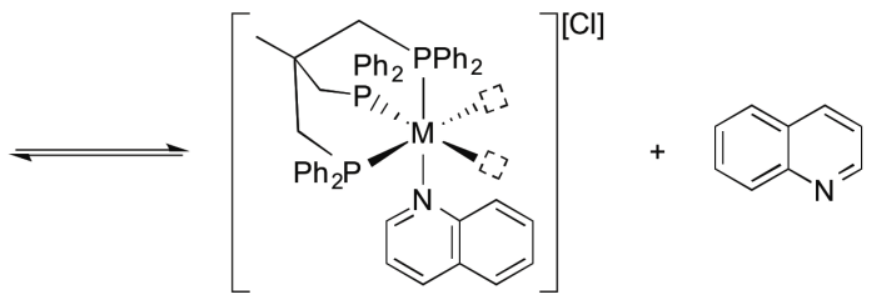

44

Scheme 44. Proposed generation of active catalytic species 44 from $\left[\mathrm{MCl}(\mathrm{coe})_{2}\right]_{2}(\mathrm{M}=$ $\mathrm{Rh}, \mathrm{Ir})$ precatalysts.

\subsubsection{Asymmetric hydrogenation}

A number of cationic rhodium precatalysts have been used in combination with chiral ligands to effect enantioselective hydrogenation of various heterocycles. In an early study by Studer [76], [Rh(nbd $\left.)_{2}\right]\left[\mathrm{BF}_{4}\right]$ was found to act as an effective precatalyst for the hydrogenation of picolinic acid and its ethyl ester (Scheme 45); the use of chiral ligands $(R)-(S)-\mathrm{Cy}_{2} \mathrm{PF}-\mathrm{PPh}_{2}$ or BINAP respectively led to modest enantioselectivity ( $25 \%$ ee). While the reaction conditions also hydrogenated 2 -substituted furans in high yields, the products were essentially racemic (Scheme 46). Higher levels of enantioselectivity in furan hydrogenation were reported by Albert [77] through the use of $[\mathrm{Rh}(\mathrm{cod})($ ligand $)]\left[\mathrm{BF}_{4}\right]$ (ligand $=2,3$-bis$[(2 R, 5 R)$-2,5-di-isopropylphospholano]benzo[ $b]$ thiophene), although only for the particular 2,5-disubstituted substrate 45 (Scheme 47).<smiles>O=C(O)c1ccccn1</smiles>

$$
\begin{gathered}
\mathrm{H}_{2}(60 \text { bar }[870 \mathrm{psi}]) \\
{\left[\mathrm{Rh}(\mathrm{nbd})_{2}\right]\left[\mathrm{BF}_{4}\right](5 \mathrm{~mol} \%)} \\
\frac{(R)-\mathrm{Cy} \mathrm{y}_{2} \mathrm{PF}-\mathrm{PPh}_{2}(5 \mathrm{~mol} \%)}{\mathrm{MeOH}, 60{ }^{\circ} \mathrm{C}, 20 \mathrm{~h}} \\
100 \% \text { yield } \\
25 \% \text { ee }
\end{gathered}
$$
$\mathrm{H}_{2}$ (60 bar [870 psi])<smiles>CCOC(=O)c1ccccn1</smiles>
$\left[\mathrm{Rh}(\mathrm{nbd})_{2}\right]\left[\mathrm{BF}_{4}\right](5 \mathrm{~mol} \%)$ $\underset{\mathrm{BINAP}, 60^{\circ} \mathrm{C}, 20 \mathrm{~h}}{\mathrm{BtOl}}$<smiles>CCOC(=O)C1CCCCN1</smiles>
$96 \%$ yield, $25 \%$ ee 
Scheme 45. Asymmetric hydrogenation of picolinic acid and its ethyl ester using $\left[\mathrm{Rh}(\mathrm{nbd})_{2}\right]\left[\mathrm{BF}_{4}\right]$ as a precatalyst.

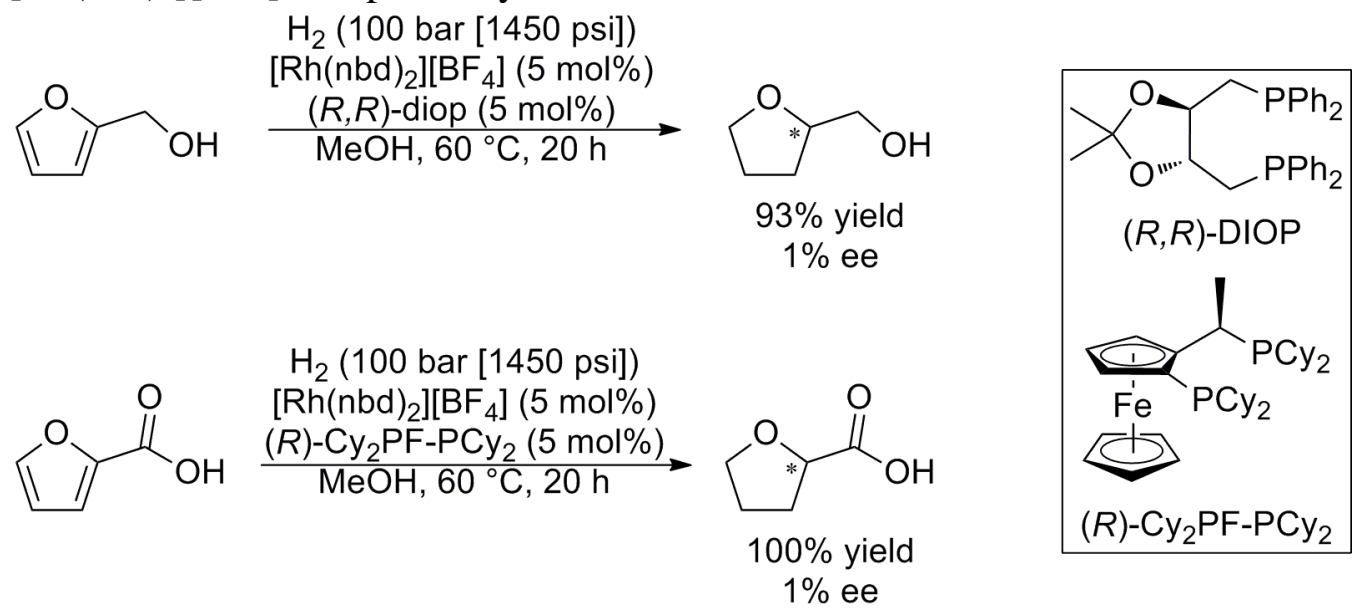

Scheme 46. Attempted asymmetric hydrogenation of 2-substituted furans using $\left[\mathrm{Rh}(\mathrm{nbd})_{2}\right]\left[\mathrm{BF}_{4}\right]$ as a precatalyst.
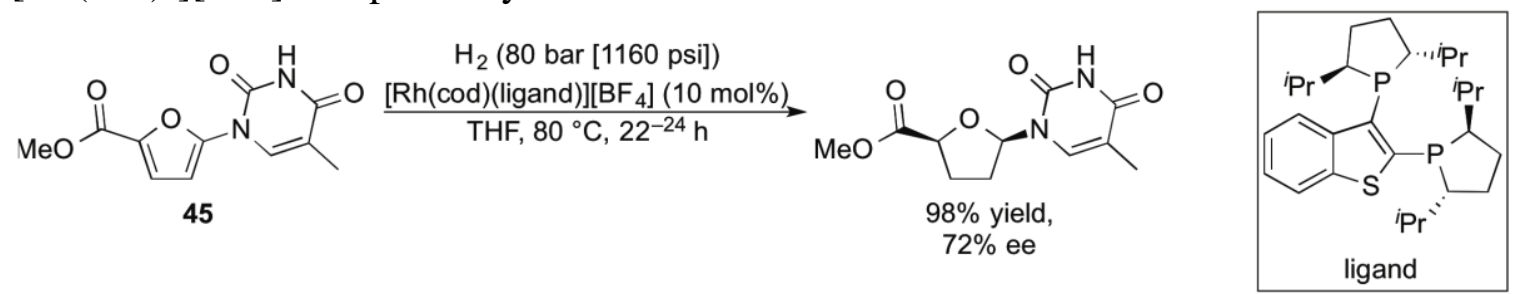

Scheme 47. Asymmetric hydrogenation of 2,5-disubstituted furan 45 catalyzed by $[\mathrm{Rh}(\operatorname{cod})($ ligand $)]\left[\mathrm{BF}_{4}\right] \quad$ (ligand $=2,3$-bis $[(2 R, 5 R)-2,5$-di-isopropylphospholano]benzo $[b]$ thiophene).

Kuwano and Ito $[78,79]$ reported the combination of $\left[\mathrm{Rh}(\mathrm{nbd})_{2}\right]\left[\mathrm{SbF}_{6}\right]$ and the bisphosphine ligand $(S, S)-(R, R)$-PhTRAP catalyzed highly enantioselective hydrogenation of 2- and 3-substituted indoles (Scheme 48). Notably, a catalytic amount of base was required to achieve any reactivity or selectivity. The choice of the nitrogen protecting group also proved critical, with only $N$-acyl or $N$-sulfonyl substitution effective for 2- and 3-substituted indoles respectively. Minnaard, Feringa, and de Vries [80] observed similar sensitivities with a $\left[\mathrm{Rh}(\operatorname{cod})_{2}\right]\left[\mathrm{BF}_{4}\right]$-phosphoramidite system for hydrogenation of methyl $N$-acetylindole-2-carboxylate (Scheme 49). 


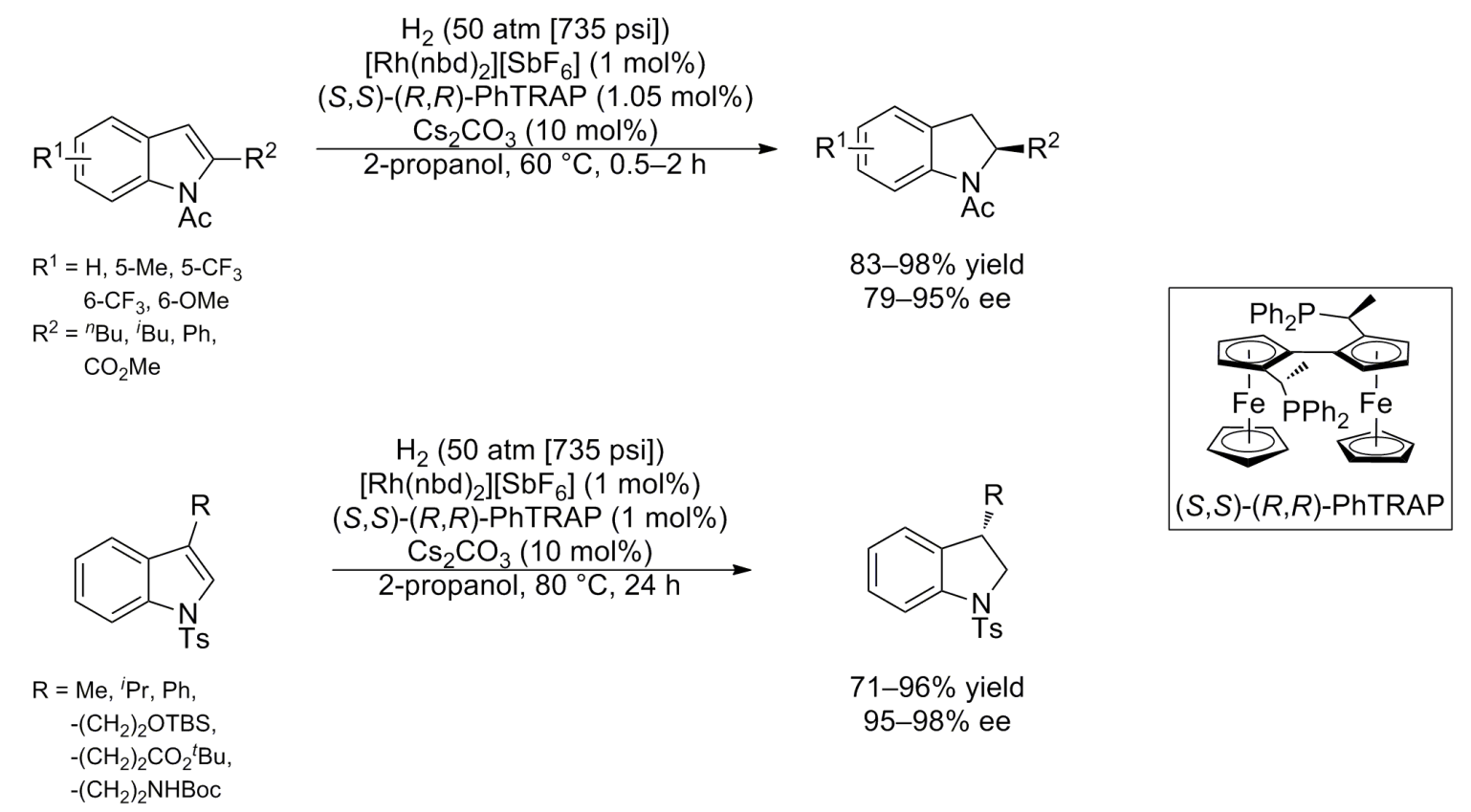

Scheme 48. Asymmetric hydrogenation of 2- and 3-substituted indoles using $\left[\mathrm{Rh}(\mathrm{nbd})_{2}\right]\left[\mathrm{SbF}_{6}\right]$ as a precatalyst and $(S, S)-(R, R)-\mathrm{PhTRAP}$ as a chiral ligand.

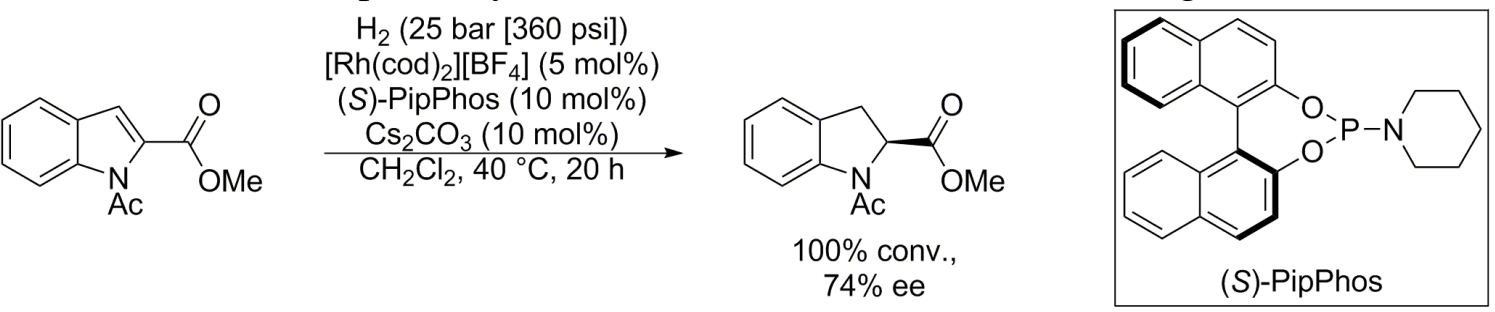

Scheme 49. Asymmetric hydrogenation of methyl $\mathrm{N}$-acetylindole-2-carboxylate using $\left[\mathrm{Rh}(\mathrm{cod})_{2}\right]\left[\mathrm{BF}_{4}\right]$ as a precatalyst and $(S)$-PipPhos as a chiral ligand.

Most recently, Yamashita [81] has reported a high yielding asymmetric hydrogenation of substituted benzofuran 46 using $\left[\mathrm{Rh}(\operatorname{cod})_{2}\right][\mathrm{OTf}]$ and $(S, S)$-EtFerroTANE (Scheme 50). Notably, methylation of the 6-hydroxyl group did not appear to affect the reaction much; esterification of the free acid group, however, resulted in a significant loss of both reactivity and selectivity.
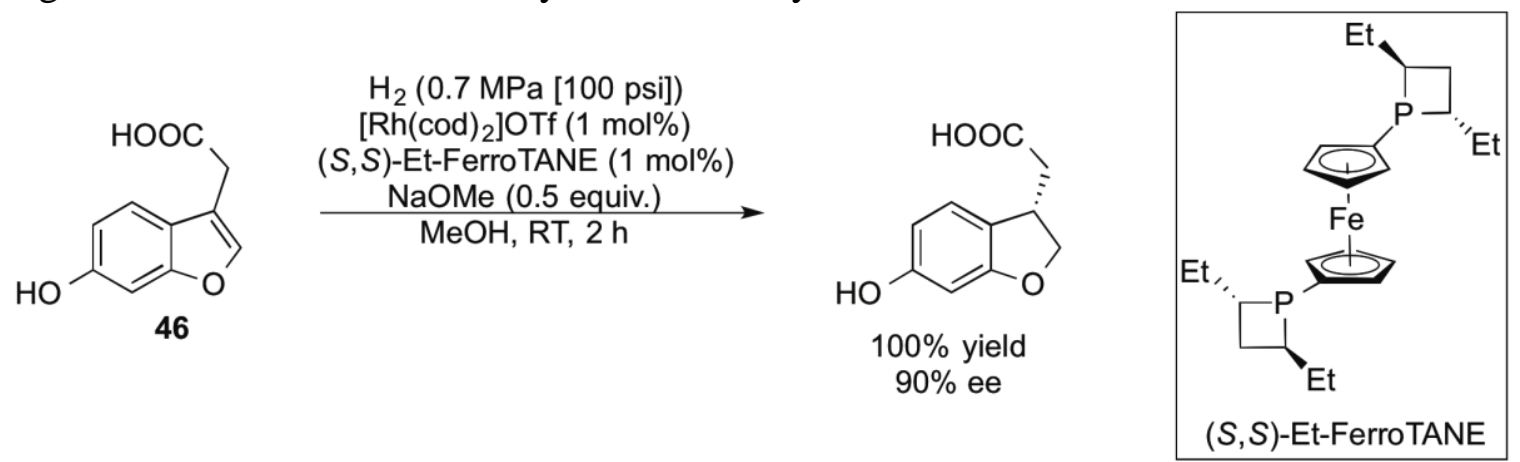

Scheme 50. Asymmetric hydrogenation of $\mathbf{4 6}$ using $\left[\mathrm{Rh}(\mathrm{cod})_{2}\right][\mathrm{OTf}]$ as a precatalyst and $(S, S)$-Et-FerroTANE as a chiral ligand. 


\subsubsection{Transfer hydrogenation}

In 2006, Frediani [82] demonstrated pre-activation of cis-[Rh(bipy $\left.)_{2} \mathrm{Cl}_{2}\right][\mathrm{Cl}] \cdot 2 \mathrm{H}_{2} \mathrm{O}$ (47) with $\mathrm{NaOH}$ to generate an effective catalyst for transfer hydrogenation of quinoline and pyridine (Scheme 51). In accordance with a previous study by Miller [83], Frediani proposed alkaline treatment of $\mathbf{4 7}$ initially results in formation of the cationic species $\left[\mathrm{Rh}(\text { bipy })_{2}\right]^{+}\left(\mathbf{4 8}\right.$; Scheme 52). Coordination of ${ }^{i} \mathrm{PrOH}$ and subsequent hydride migration then facilitates entry into the catalytic cycle as the monohydride 49. Notably, when quinoline reduction was performed under a hydrogen atmosphere, a significant increase in tetrahydro product yield was observed (Scheme 51). The authors attribute this apparent improvement in catalyst performance to the operation of an additional hydrogenation pathway involving traditional activation of molecular $\mathrm{H}_{2}$.

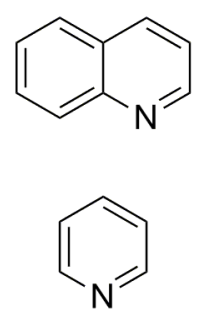

$$
\begin{gathered}
\begin{array}{c}
\text { cis- }\left[\mathrm{Rh}(\text { bipy })_{2} \mathrm{Cl}_{2}\right][\mathrm{Cl}] \cdot 2 \mathrm{H}_{2} \mathrm{O} \\
(1 \mathrm{~mol} \%, \text { pre-activated })
\end{array} \\
\left.\underset{\mathrm{N}_{2} \text { or } \mathrm{H}_{2}\left(1 \mathrm{MPa}, 110{ }^{\circ} \mathrm{C}, 3 \mathrm{~h},\right.}{\longrightarrow}[145 \mathrm{psi}]\right)
\end{gathered}
$$<smiles>c1ccc2c(c1)CCCN2</smiles>

$46 \%$ under $\mathrm{N}_{2}$ $81 \%$ under $\mathrm{H}_{2}$<smiles>C1CCNCC1</smiles>

$51 \%$ under $\mathrm{N}_{2}$

Scheme 51. Transfer hydrogenation of quinoline and pyridine catalyzed by pre-activated cis- $\left[\mathrm{Rh}(\text { bipy })_{2} \mathrm{Cl}_{2}\right][\mathrm{Cl}] \cdot 2 \mathrm{H}_{2} \mathrm{O}$. Preactivation conditions: $0.0125 \mathrm{M} \mathrm{NaOH},{ }^{i} \mathrm{PrOH}, 80{ }^{\circ} \mathrm{C}, 3$ h, $\mathrm{N}_{2}$ (1 MPa [145 psi]). 

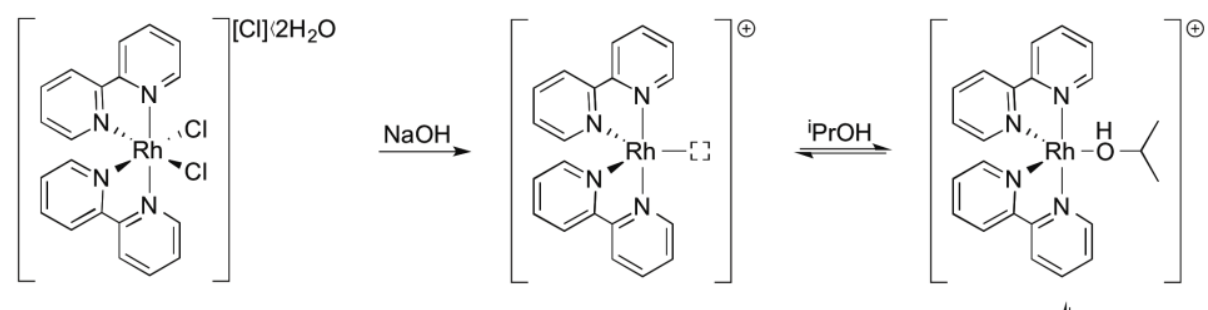

47

48
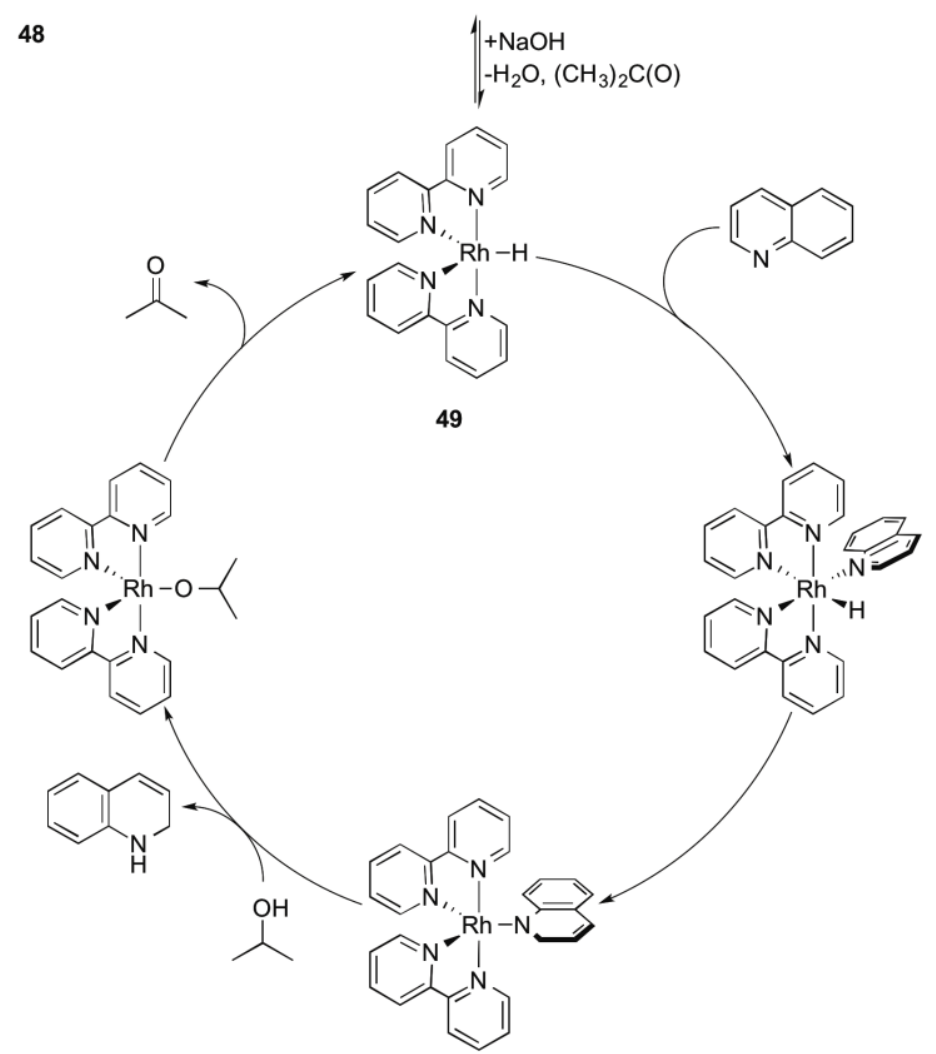

Scheme 52. Proposed formation of 49 from $c i s-\left[\mathrm{Rh}(\text { bipy })_{2} \mathrm{Cl}_{2}\right][\mathrm{Cl}] \cdot 2 \mathrm{H}_{2} \mathrm{O}$ and catalytic cycle for first net addition of hydrogen to quinoline.

\subsubsection{Hydrosilylation}

In 2008, Crabtree [59] reported the reductive hydrosilylation of a series of $\mathrm{N}$ heterocycles catalyzed by $\left[\mathrm{Rh}(\mathrm{cod})\left(\mathrm{PPh}_{3}\right)_{2}\right]\left[\mathrm{PF}_{6}\right](\mathbf{5 0} ;$ Scheme 53$)$. Notably, with the specific use of $\mathrm{H}_{3} \mathrm{SiPh}$, quinoline was selectively reduced to 1,2-dihydroquinoline, while isoquinoline was fully reduced to the tetrahydro product instead. No $N$-silylated intermediates were ever observed; the authors presume such species, if formed at all, must be rapidly hydrolyzed in situ by trace amounts of water. Control experiments also revealed 50 to catalyze the disproportionation of $\mathrm{H}_{3} \mathrm{SiPh}$ into $\mathrm{H}_{2} \mathrm{SiPh}_{2}$ and $\mathrm{SiH}_{4}$, with the latter most likely serving as the active reductant for the reaction. 
<smiles>[R]c1ccc2ccccc2n1</smiles>

$\mathrm{R}=\mathrm{H}, \mathrm{Me}$<smiles>c1ccc2c(c1)CCNC2</smiles>

$87 \%$

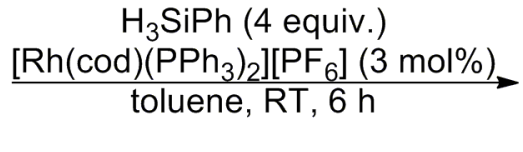<smiles>[R]C1C=Cc2ccccc2N1</smiles>

$>95 \%$<smiles>C1=CC2Cc3ccccc3NC2C=C1</smiles>

$93 \%$<smiles>c1ccc2c(c1)CCN2</smiles>

$82 \%$

Scheme 53. Reductive hydrosilylation of quinoline and other $N$-heterocycles catalyzed by $\left[\mathrm{Rh}(\mathrm{cod})\left(\mathrm{PPh}_{3}\right)_{2}\right]\left[\mathrm{PF}_{6}\right] \mathbf{5 0}$. Reaction time $=12 \mathrm{~h}$ for isoquinoline, acridine, and indole.

\subsubsection{Anionic complexes}

Xiao [48] previously found the asymmetric transfer hydrogenation of 2-substituted quinolines proceeded with high levels of enantioselectivity under conditions in which the substrates are most likely protonated (see Section 2.2.1). Attempts to perform the reaction with $N$-methyl-2-methylquinolinium iodide (51), however, only resulted in high yield of nearly racemic product (Scheme 54, top) [84]. Notably, un-ligated $\left[\mathrm{Rh}\left(\mathrm{Cp}^{\star}\right) \mathrm{Cl}_{2}\right]_{2}$ also gave similarly high conversion for 51, but not for neutral 2-methylquinoline.
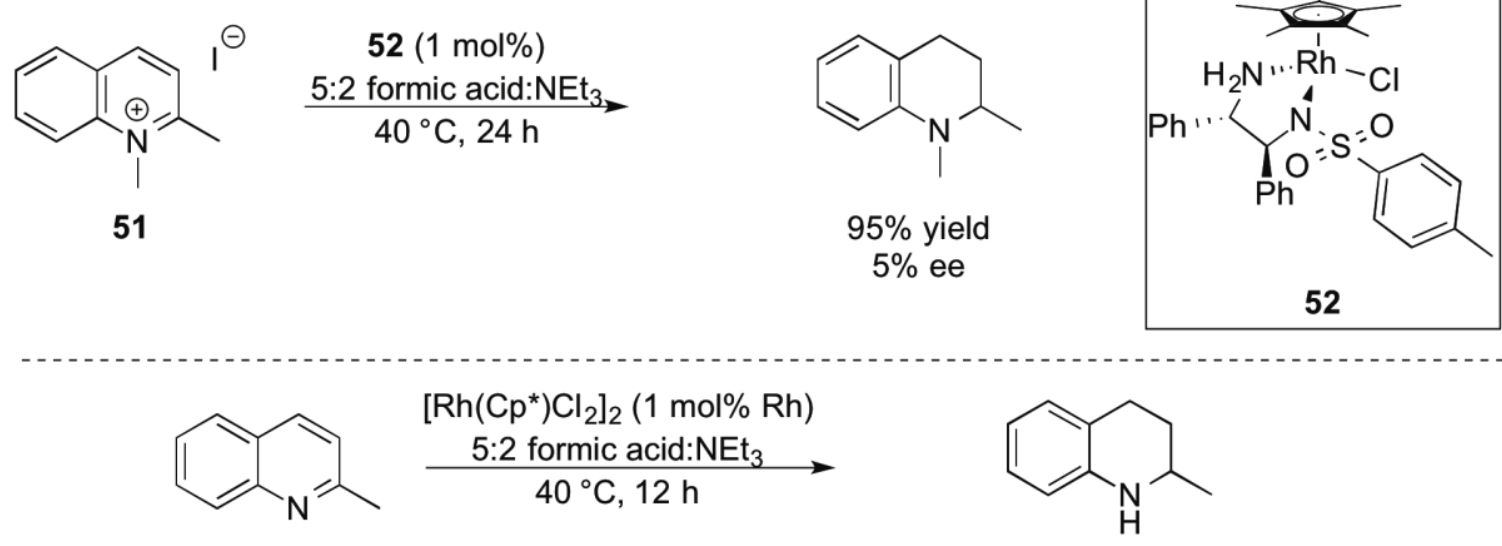

no [I]: $6 \%$ conv. $100 \%$ TBAl: $100 \%$ conv. $20 \% \mathrm{KI}(0.01 \% \mathrm{Rh}): 100 \%$ conv.

Scheme 54. Attempted asymmetric transfer hydrogenation of $N$-methyl-2methylquinolinium iodide with $\mathbf{5 2}$ (top) and transfer hydrogenation of 2-methylquinoline catalyzed by $\left[\mathrm{Rh}\left(\mathrm{Cp}^{*}\right) \mathrm{Cl}_{2}\right]_{2}$ with and without iodide additives (bottom).

Based on these results, the authors proposed the iodide counteranion of $\mathbf{5 1}$ displaces either the TsDPEN or $\mathrm{Cl}$ ligands to form a highly active anionic triiodo-Rh species (53). Indeed, addition of either TBAI or KI to the formerly ineffective reactions of 2methylquinoline with $\left[\mathrm{Rh}\left(\mathrm{Cp}^{*}\right) \mathrm{Cl}_{2}\right]_{2}$ resulted in complete conversion within $15 \mathrm{~h}$ (Scheme 54 , bottom). Loadings of KI above $20 \mathrm{~mol} \%$, however, appeared to increasingly inhibit the reaction, suggesting $\mathbf{5 3}$ is in equilibrium with a precursor (formate complex 54) to the 
active catalytic species (monohydride 55) (Scheme 55). Isotope labeling studies using formic acid- $d_{1}$ found deuterium incorporation at $\mathrm{C}(2)$ and $\mathrm{C}(4)$, leading the authors to favor a 1,4-hydride addition mechanism: initial hydride insertion from $\mathbf{5 5}$ occurs at $\mathrm{C}(4)$ to form an enamine. This intermediate isomerizes to an iminium and a second hydride insertion occurs at $\mathrm{C}(2)$ to form the final tetrahydro product.

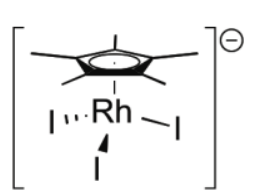

53

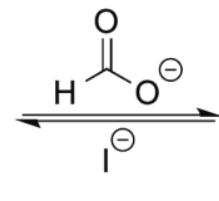

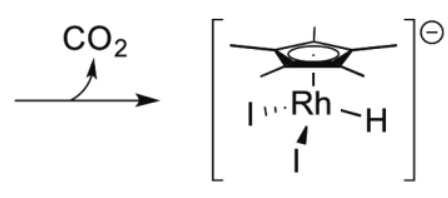

55<smiles>CC1=CCc2ccccc2N1</smiles>

55

54<smiles>CC1=CCc2ccccc2N1</smiles><smiles>CCCCCC(=O)O</smiles><smiles>CC1=Nc2ccccc2CC1</smiles><smiles>CCCCC=O</smiles><smiles>CC1=C(C)Nc2ccccc2CC1</smiles>

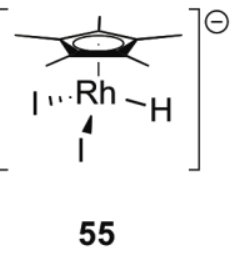<smiles>CC1=CCc2ccccc2N1</smiles>

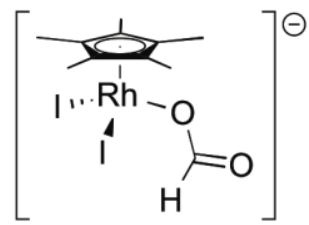

54

Scheme 55. Proposed mechanistic pathway for transfer hydrogenation of 2methylquinoline starting from $\mathbf{5 3}$.

In addition to a range of other 2-substituted quinolines, the Rh-iodide catalytic system also proved effective for reduction of a number of isoquinolines and quinoxalines (Scheme 56). As expected for these more challenging transfer hydrogenation substrates, somewhat higher catalyst loadings were required $(0.2 \mathrm{~mol} \%$ and $0.02 \mathrm{~mol} \% \mathrm{Rh}$ respectively), but high yields could still be obtained in reaction times comparable to those of the quinoline series. 

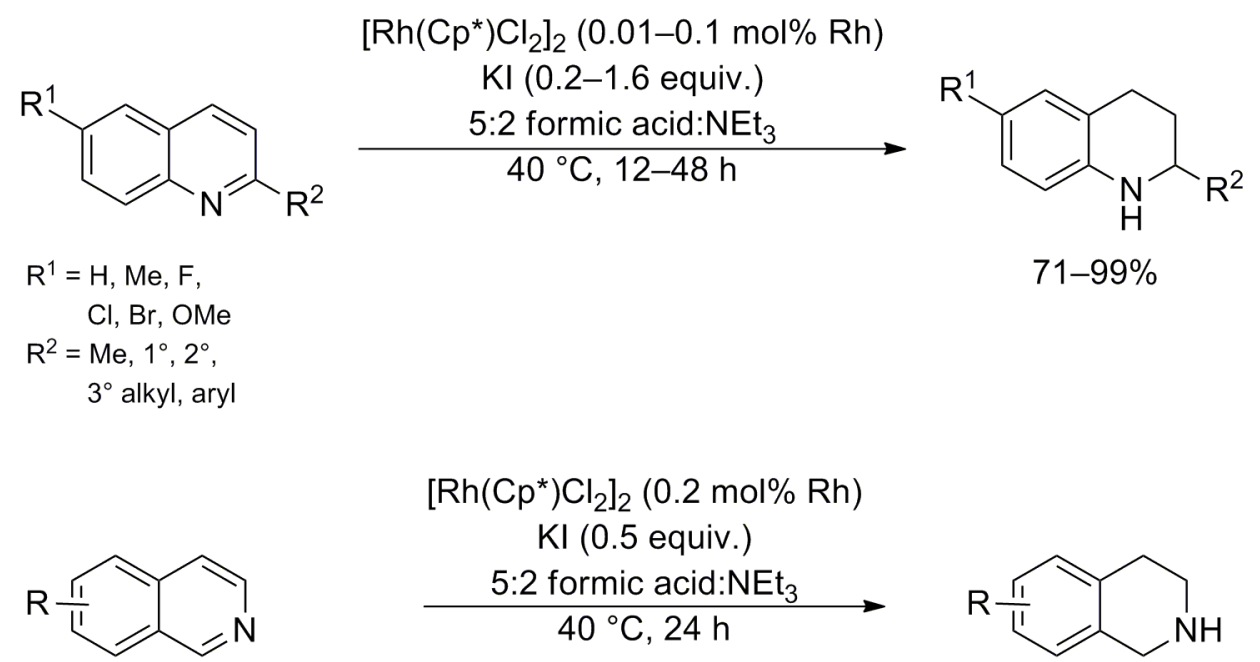

$\mathrm{R}=\underset{6-\mathrm{Me}}{\mathrm{H}, 1-\mathrm{Me}, 3-\mathrm{Me},}$<smiles>[R][R]1ccc2nccnc2c1</smiles>
$\left[\mathrm{Rh}\left(\mathrm{Cp}^{\star}\right) \mathrm{Cl}_{2}\right]_{2}(0.02 \mathrm{~mol} \% \mathrm{Rh})$
$\mathrm{KI}(0.5$ equiv.)
5:2 formic acid: $\mathrm{NEt}_{3} \rightarrow$<smiles>[R][X]1ccc2c(c1)CNCC2</smiles>

$83-95 \%$

$\mathrm{R}=\mathrm{H}, 2-\mathrm{Me}, 5-\mathrm{Me}$, 6-Me<smiles>[R][X]c1ccc2c(c1)NCCN2</smiles>

$86-99 \%$

Scheme 56. Transfer hydrogenation of quinolines, isoquinolines, and quinoxalines catalyzed by $\left[\mathrm{Rh}\left(\mathrm{Cp}^{*}\right) \mathrm{Cl}_{2}\right]_{2}$ in the presence of $\mathrm{KI}$.

\subsection{Ruthenium}

In an early study of ruthenium catalysts for aromatic reduction, Fish [85] found $\mathrm{RuCl}_{2}(\mathrm{CO})_{2}\left(\mathrm{PPh}_{3}\right)_{3}$ effective in the hydrogenation of quinoline and 5,6- and 7,8benzoquinoline (Scheme 57); with the addition of $0.2 \mathrm{M} \mathrm{KOH}$, acridine could also be quantitatively reduced to 9,10 -dihydroacridine. 


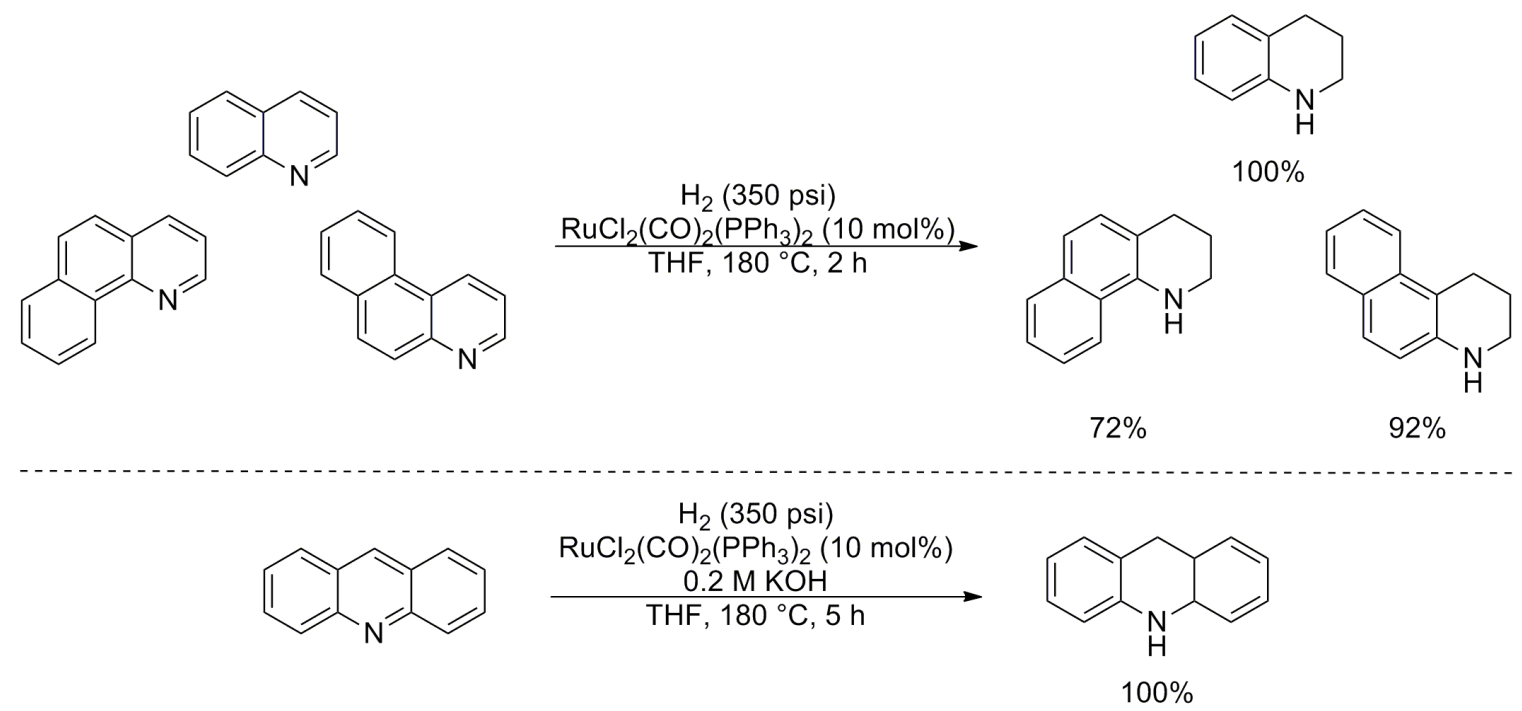

Scheme 57. Hydrogenation of various $N$-heterocycles catalyzed by $\mathrm{RuCl}_{2}(\mathrm{CO})_{2}\left(\mathrm{PPh}_{3}\right)_{3}$.

Frediani [86] used a closely related catalyst system, $\mathrm{RuH}_{2}\left(\mathrm{PPh}_{3}\right)_{4}$, to hydrogenate quinoline, isoquinoline, and even pyridine to some extent. Reactivity was found to trend with substrate basicity, with quinolines being the most reactive, followed by isoquinolines and then pyridines. Minor steric encumbrance, i.e. methyl substitution, inhibited reaction progress. In the case of quinoline, both 1,2,3,4- and 5,6,7,8-tetrahydroquinoline were observed in the reaction mixture, in addition to perhydrogenated quinoline (Scheme 58). Hydrogenation of 1,2,3,4-tetrahydroquinoline did not produce the perhydrogenated species after 3 hours reaction time, but 5,6,7,8-tetrahydroquinoline gave $7.5 \%$ conversion to the perhydrogenated product under identical conditions. The authors thus concluded that the perhydrogenated species can only be obtained if the carbocyclic ring is hydrogenated first.

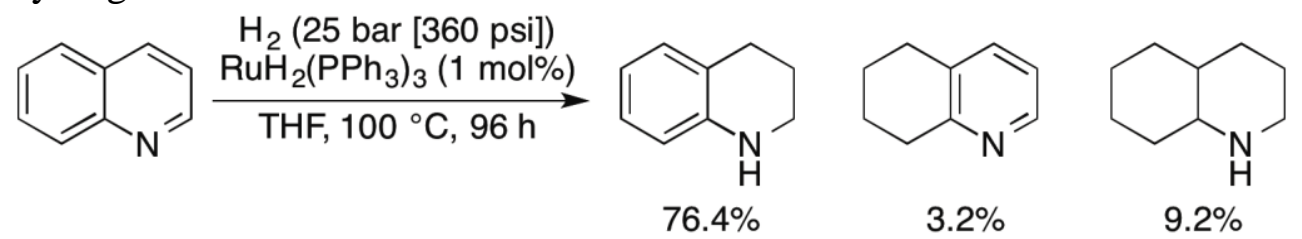

Scheme 58. Hydrogenation of quinoline catalyzed by $\mathrm{RuH}_{2}\left(\mathrm{PPh}_{3}\right)_{3}$

\subsubsection{Mechanistic studies}

In 2005, Rosales [87] reported a kinetic analysis of the hydrogenation of quinoline using the cationic ruthenium precatalyst $\left[\mathrm{RuH}(\mathrm{CO})\left(\mathrm{CH}_{3} \mathrm{CN}\right)_{2}\left(\mathrm{PPh}_{3}\right)_{2}\right]\left[\mathrm{BF}_{4}\right](\mathbf{5 6})$. The reaction was found to be first order in $\mathbf{5 6}$ concentration and second order in hydrogen concentration at low pressures. An inverse first order dependence on tetrahydroquinoline concentration was also observed, while addition of acetonitrile in equimolar amounts relative to quinoline completely inhibited the reaction. Additionally, the $\eta^{1}$-N-quinolineligated complex $\mathbf{5 7}$ was isolated from catalytic reactions and subsequently demonstrated activity comparable to that of $\mathbf{5 6}$.

Based on these results and later computational work [88], Rosales proposed the 
catalytic cycle shown in Scheme 59. First, quinoline displaces the $\mathrm{CH}_{3} \mathrm{CN}$ ligand trans to the hydride in $\mathbf{5 6}$ to form $\mathbf{5 7}$, which then isomerizes to $\mathbf{5 8}$ to enter the catalytic cycle. Hydride migration to $\mathrm{C}(2)$ followed by heterolytic ${ }^{16} \mathrm{H}_{2}$ activation then forms the $\eta^{1}-\mathrm{N}$ 1,2-dihydroquinoline-ligated complex 59. A subsequent hapticity shift to $\eta^{2}-\mathrm{C}(2)$ then facilitates hydrogenation of the remaining $\mathrm{C}(3)=\mathrm{C}(4)$ bond. Product-substrate exchange then closes the catalytic cycle.

\footnotetext{
${ }^{16}$ This mode of activation differs from that proposed by Sánchez-Delgado for related cationic rhodium systems (see Section 2.2.2.1), wherein oxidative addition to $\mathrm{H}_{2}$ is believed to predominate. Heterolytic activation is likely favored in the case of $\mathbf{5 6}$ to avoid formation of species with more than 18 electrons.
} 


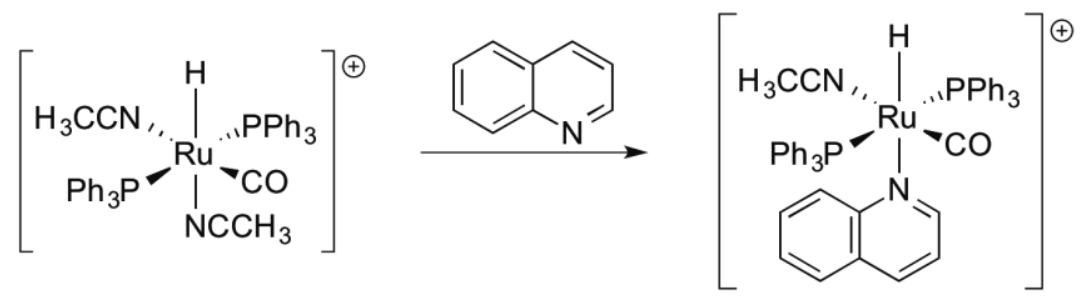

56

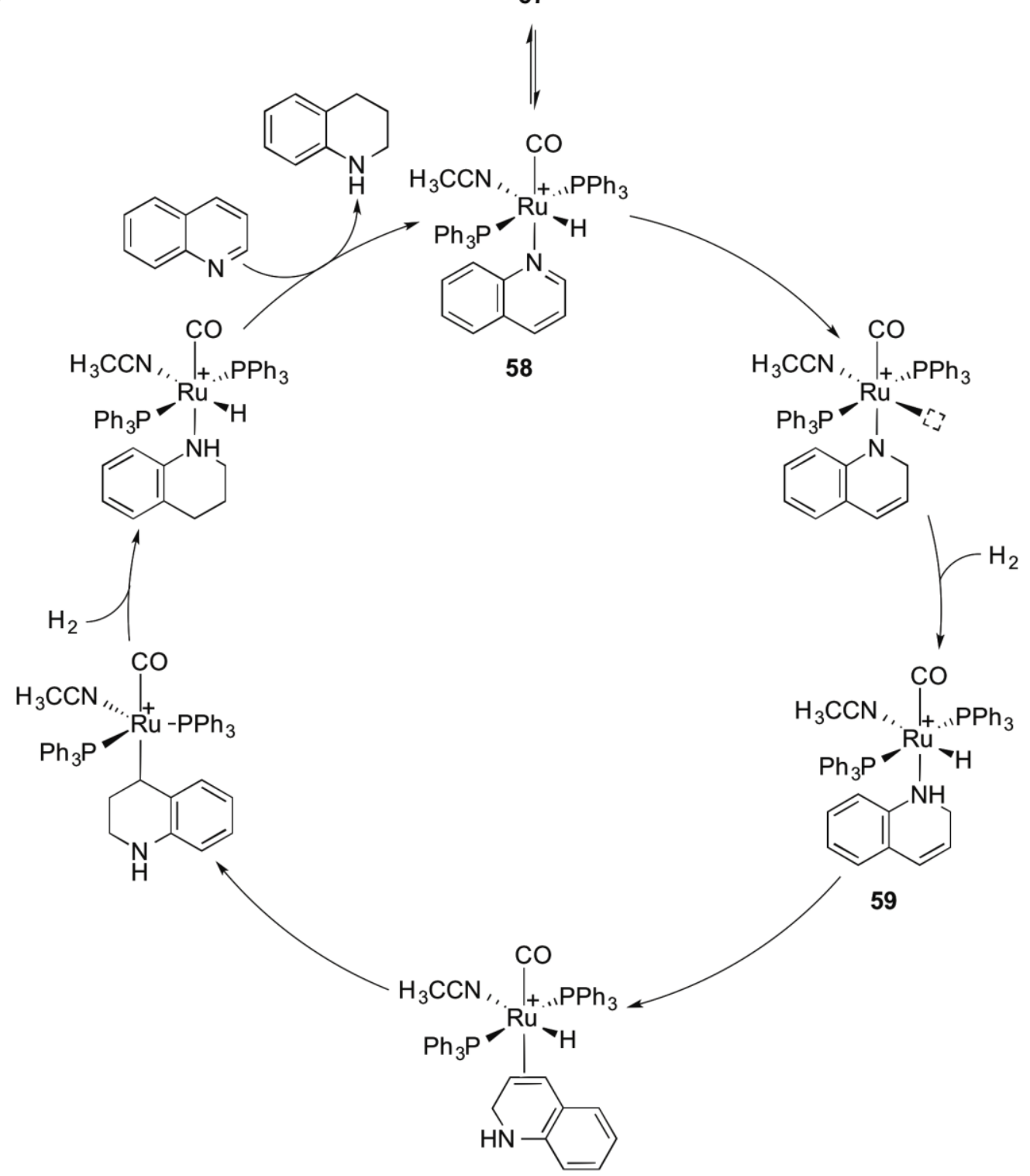

Scheme 59. Proposed catalytic cycle for quinoline hydrogenation catalyzed by $\mathbf{5 6}$. Counteranions omitted for clarity.

Additional kinetic studies [89] appeared to indicate the above hydrogenation mechanism is generally operative for other $N$-heterocycles such as isoquinoline and 5,6and 7,8-benzoquinoline. ${ }^{17}$ In the case of acridine, heterolytic activation of $\mathrm{H}_{2}$ by the $\eta^{1}-\mathrm{N}-$

${ }^{17}$ Evidence for the same mechanism was also found using the osmium analogue of $\mathbf{5 8}$; 
acridine-ligated analogue of $\mathbf{5 6}$ (compound 60) was proposed to directly form the 9,10dihydro product as the rate-determining step (Scheme 60).

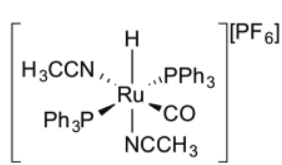

57
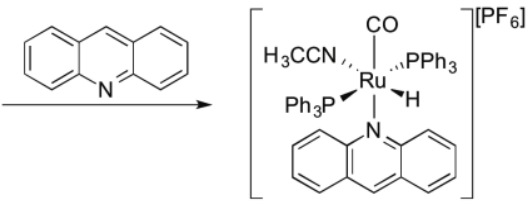

60

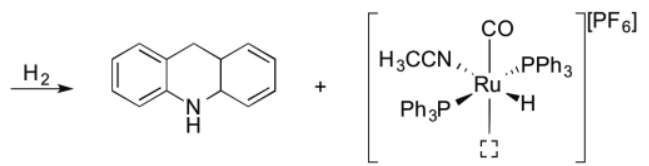

Scheme 60. Proposed mechanistic pathway for hydrogenation of acridine catalyzed by $\mathbf{6 0}$.

\subsubsection{Asymmetric hydrogenation}

In 2012, Glorius [90] demonstrated efficient Ru-NHC-catalyzed enantioselective hydrogenation of thiophenes and benzothiophenes (Scheme 61, top). ${ }^{18}$ Hydrogenation of monosubstituted thiophenes gave racemic product, but 2,5-disubstituted thiophenes gave enantiomeric ratios as high as 97:3. For benzothiophenes, bulky 2-substitution such as isobutyl or benzyl led to poor reactivity in comparison with that observed for smaller substituents such as $n$-butyl or $n$-decyl; excellent enantioselectivity (>96\% ee), however, was observed in all cases.

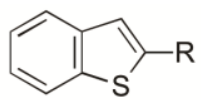

$\mathrm{R}=$ alkyl<smiles>[R]c1ccc([R])s1</smiles>

$\mathrm{R}=\mathrm{Me}, \mathrm{Et}$

$\mathrm{R}^{\prime}=\mathrm{Ph}$, electron-poor aryl
$\mathrm{H}_{2}$ (90 bar [1305 psi])

[Ru(cod)(2-methylallyl) 2 ] (5 mol\%) $\mathrm{NHC}$ precursor $(11 \mathrm{~mol} \%)$ KO'Bu, $n$-hexane, RT, $18 \mathrm{~h}$

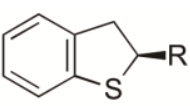

$63-98 \%$ yield 96-98\% ee

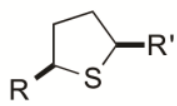

$55-99 \%$ yield rac- $94 \%$ ee cis-only

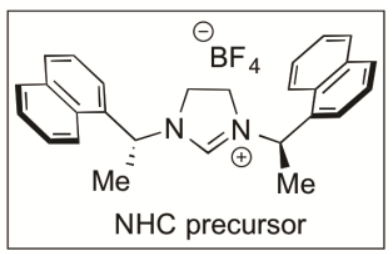

$\mathrm{NHC}$ precursor

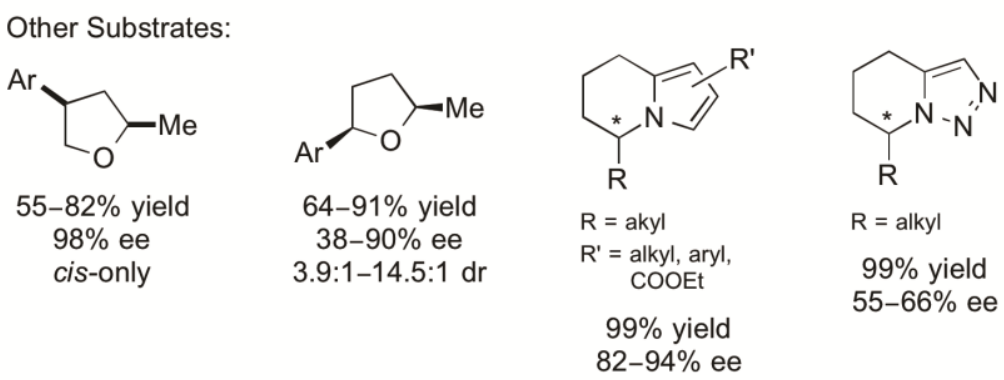

Scheme 61. Asymmetric hydrogenation of benzothiophenes and thiophenes (top) and other heterocycles (bottom) using a Ru-NHC catalyst.

Using the same Ru-NHC system, Glorius also hydrogenated 2,4- and 2,5disubstituted furans [91] and indolizidines and benzotriazoles [92] in moderate to high enantioselectivity (Scheme 61, bottom). Modification of the NHC ligand to feature an

see: M. Rosales, F. Arrieta, J. Castillo, A. González, J. Navarro, R. Vallejo, Stud. Surf. Sci. Catal. 130 (2000) 3357.

18 The catalyst system also hydrogenated both unsubstituted thiophene and benzothiophene in $>99$ yield. 
unsaturated backbone additionally facilitated asymmetric hydrogenation of 2-substituted benzofurans (Scheme 62) [93]. In all cases, the Ru-NHC catalyst is chemoselective for heteroarenes over fused and monocyclic aryl groups. Additionally, while the catalyst proved active for hydrogenation of the $\mathrm{C}(2)=\mathrm{C}(3)$ bond in 3-methylindene, the reaction proceeded with low enantioselectivity (16\% ee) [94]. Glorius thus postulated that a coordinating heteroatom is required to induce stereoselectivity.
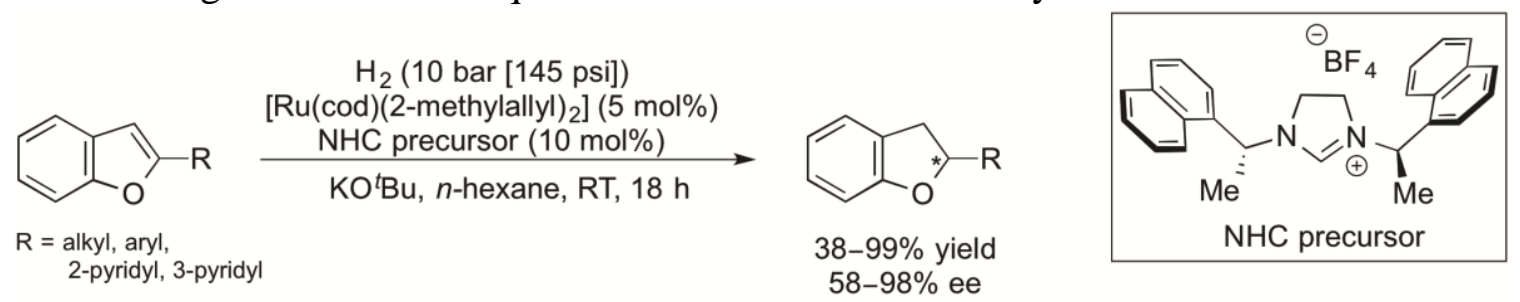

Scheme 62. Asymmetric hydrogenation of 2-substituted benzofurans using a Ru-NHC catalyst.

Fan and Chan [95] showed that Noyori-type hydrogenation catalysts such as $\mathbf{6 1}$ could be employed at room temperature in methanol or ionic liquids to efficiently catalyze hydrogenation of 2-substituted quinolines (Scheme 63). The organic products could be extracted directly from the ionic liquid via hexane wash, leaving the catalyst behind for further use. This recycling process could be repeated up to six times before the conversion dropped from $100 \%$ to $88 \%$, with enantioselectivity remaining high through eight runs. Further study showed that a variety of polar protic and aprotic solvents could be used, though relatively nonpolar solvents such as methylene chloride, ether, and toluene gave lower conversions [96]. Free alcohol functionality on the substrate was tolerated, in addition to some non-conjugated olefins, but carboxylic acids and esters stifled reactivity completely. Large groups such as phenyl in the 2-position did not slow reactivity but eroded enantioselectivity to $50 \%$ ee. Also, by using less coordinating anions in the ionic liquid, the hydrogenation reaction was accelerated [97], implying lability of the $\mathrm{Ru}-\mathrm{OTf}$ bond. By extending reaction time to 24 hours, the catalyst loading could be decreased to $0.1 \mathrm{~mol} \%$.<smiles>[R]c1ccc2ccccc2n1</smiles>

$\mathrm{R}=$ alkyl,<smiles>CCC(C)(C)O</smiles>

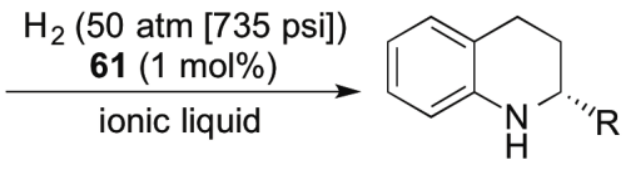

$92-97 \%$ yield 97-99\% ee

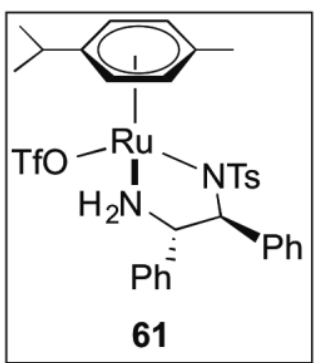

61

Scheme 63. Asymmetric hydrogenation of quinolines catalyzed by Noyori-type catalyst 61.

When employed in carbonyl hydrogenation, Noyori-type catalysts typically transfer hydrides and protons in a concerted fashion [98]. A ruthenium hydride complex derived from 61 by replacement of the OTf ligand does not, however, react with 2methylquinoline. Fan, Chan, and $\mathrm{Yu}$ [96] thus have proposed that quinoline hydrogenation by $\mathbf{6 1}$ proceeds through a different mechanism. The substrate must first be 
activated by protonation by the in situ generated $\sigma$-complex 62 (Scheme 64, step i). 1,4Hydride addition then produces a neutral enamine intermediate. Isomerization to the imine then affords re-entry into the catalytic cycle (step iv), with 1,2-hydride addition affording the final product (step $\mathrm{v}$ ). 


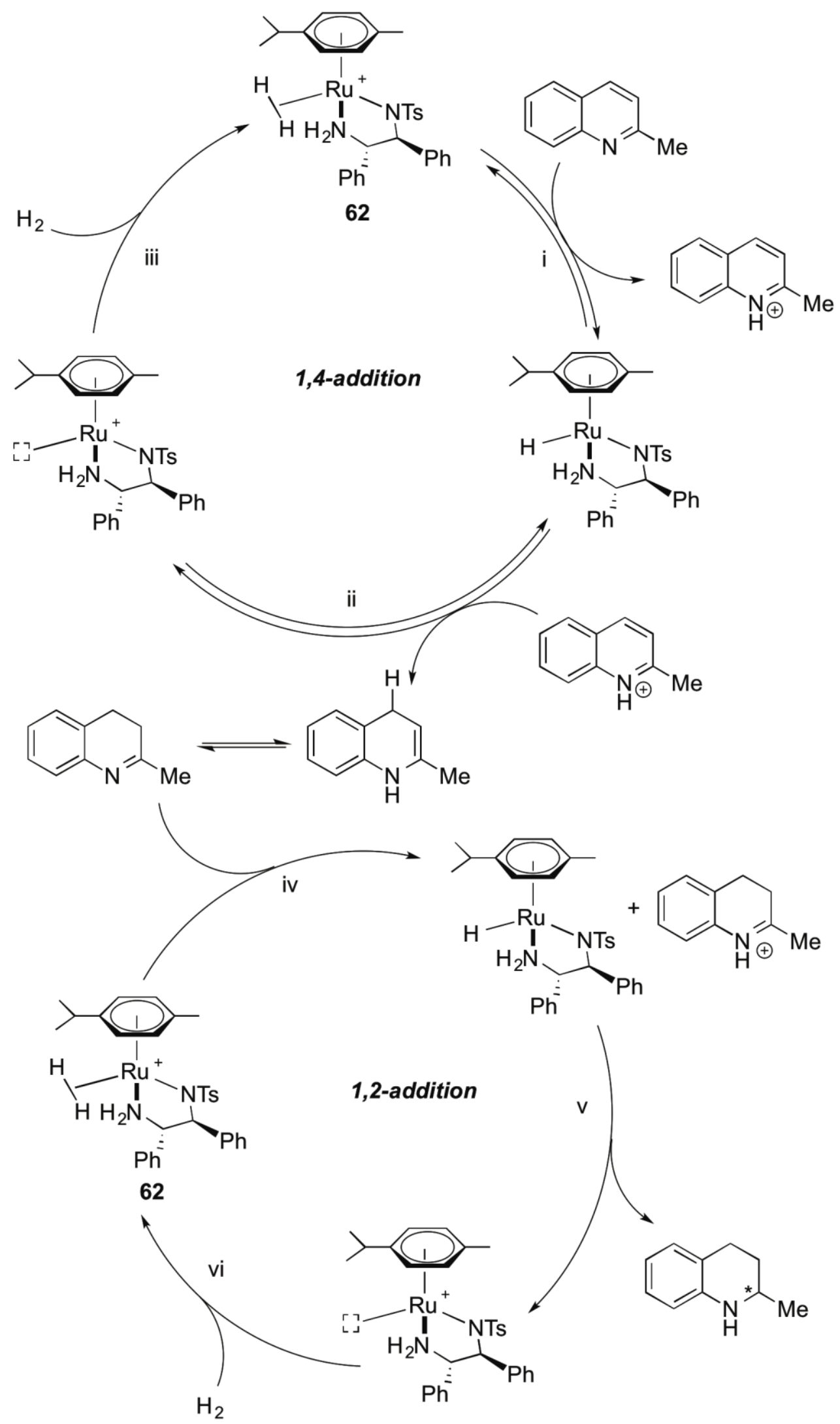

Scheme 64. Proposed catalytic cycle for asymmetric quinoline hydrogenation using 
Noyori-type catalysts.

Fan [99] also hydrogenated substituted quinoxalines using the related catalysts $\mathbf{6 3}$ and 64 in organic solvent to achieve excellent enantioselectivity in all cases (Scheme 65). The diastereoselectivity for the latter class of substrates, however, varied considerably, especially with fluoro- and chloro-substitution at the 6-position.<smiles>[R]c1cc2nc([R])c([R])nc2cc1[R]</smiles>

$R^{1}=$ alkyl, styryl

$\mathrm{R}^{2}=\mathrm{H}, \mathrm{Me}, \mathrm{Et}$

$\mathrm{R}^{3}=\mathrm{H}, \mathrm{Me}, \mathrm{F}, \mathrm{Cl}$

$\mathrm{R}^{4}=\mathrm{H}, \mathrm{Me}$

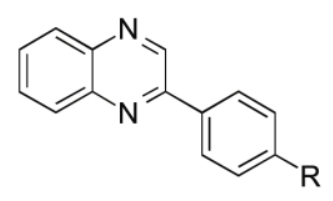

$\mathrm{R}=\mathrm{H}$, halogen, OMe

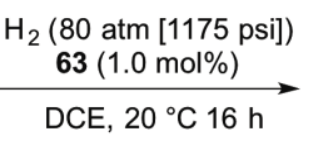

DCE, $20^{\circ} \mathrm{C} 16 \mathrm{~h}$<smiles>[R]C1=C([R])Nc2cc([R3])c([R4])cc2N1</smiles>

90-98\% yield

95-99\% ee

69:31-86:14 dr
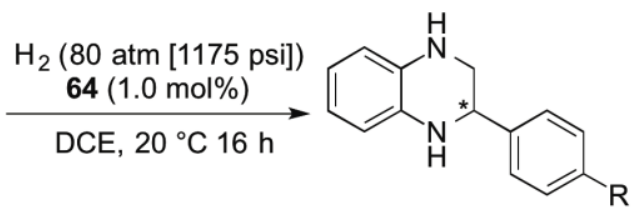

90-95\% yield 94-96\% ee
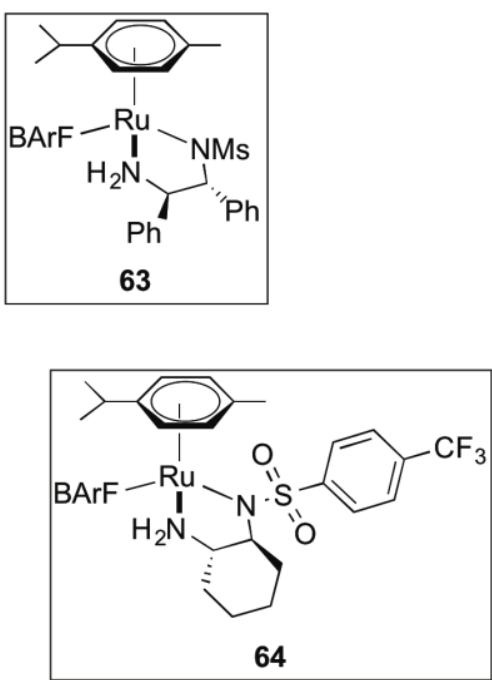

Scheme 65. Asymmetric hydrogenation of quinoxalines catalyzed by 63 and 64 .

Using the $(R, R)$-enantiomer of $\mathbf{6 1}$, Fan [100] enantioselectively hydrogenated the heterocyclic portions of 2,9-disubstituted 1,10-phenanthrolines (Scheme 66). By following different reaction protocols, either the tetrahydro or octrahydro product could be obtained selectively. Notably, the catalyst exhibited complete control of stereoselectivity, as the existing stereocenter of an optically active tetrahydrophenanthroline (65) did not appear to affect the selectivity of the second reduction when either catalyst enantiomer was used (Scheme 67).

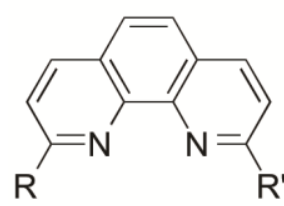

$\mathrm{R}=\mathrm{H}$, alkyl, $\mathrm{Ph}$

$\mathrm{R}^{\prime}=$ alkyl, $\mathrm{Ph}$

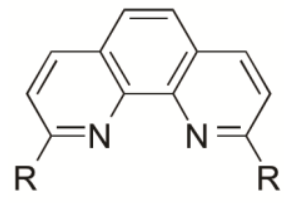

$\mathrm{R}=$ alkyl
1. $\mathrm{H}_{2}$ (50 atm $[735 \mathrm{psi}]$ ) $(R, R)-61(1.0 \mathrm{~mol} \%)$ $\mathrm{MeOH}, 25^{\circ} \mathrm{C}, 12 \mathrm{~h}$ 2. Air exposure, $12 \mathrm{~h}$ $\mathrm{R}^{\prime}$

$\mathrm{H}_{2}$ (50 atm [735 psi])

$(R, R)-61(2.0 \mathrm{~mol} \%)$ $\mathrm{MeOH}, 25^{\circ} \mathrm{C}, 12-24 \mathrm{~h}$

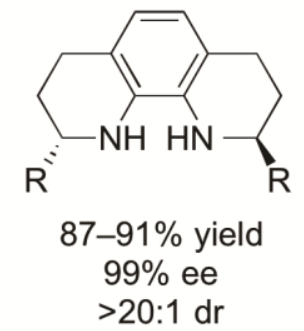

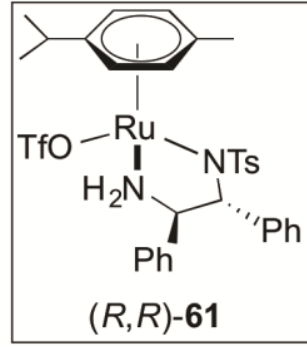

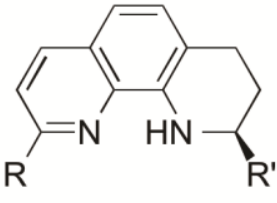

$40-100 \%$ yield 95->99\% ee

$>20: 1 d r$

Scheme 66. Asymmetric hydrogenation of 1,10-phenanthrolines catalyzed by $(R, R)-61$. 


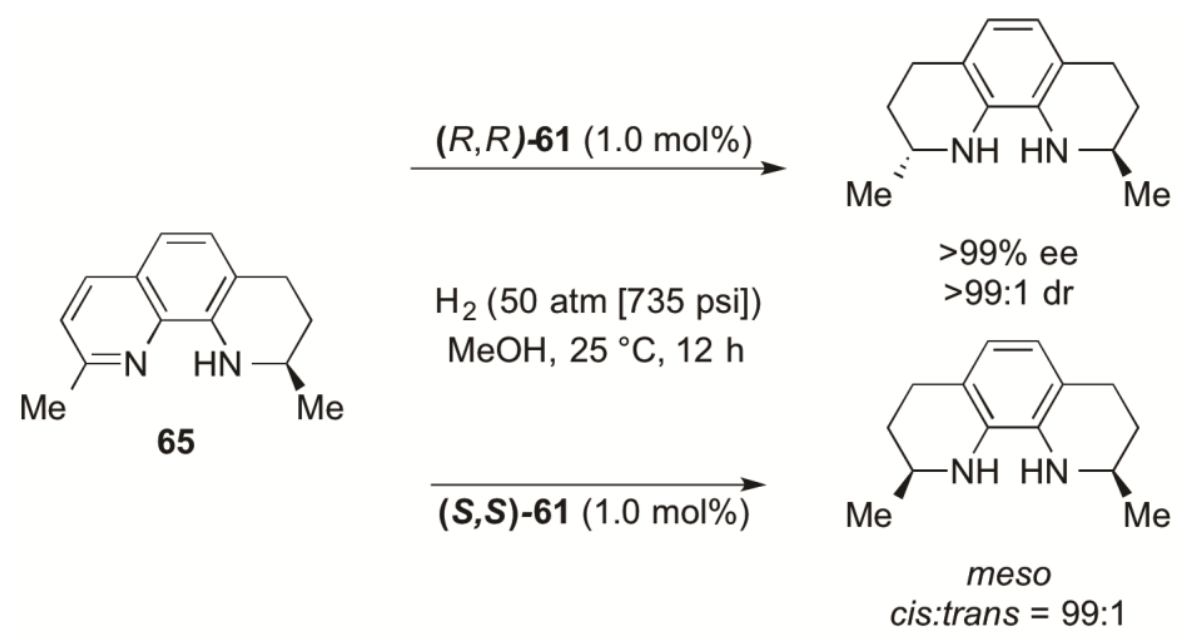

Scheme 67. Catalyst-controlled enantio- and diastereoselective hydrogenation of tetrahydrophenanthroline $\mathbf{6 5}$.

Recently, Fan [101] reported the asymmetric hydrogenation of 2,6-disubstituted 1,5-naphthyridines to form pyridyl-fused piperidines (Scheme 68, top). In case of unsymmetric, 2,6-diaryl-substituted substrates, hydrogenation occurred on the more electron-rich heterocyclic ring; no selectivity was observed when two different alkyl groups were present at the 2- and 6-positions. To obtain perhydrogenated products, Fan used a second heterogeneous platinum-catalyzed diastereoselective hydrogenation to reduce the remaining pyridyl ring (Scheme 68, bottom).
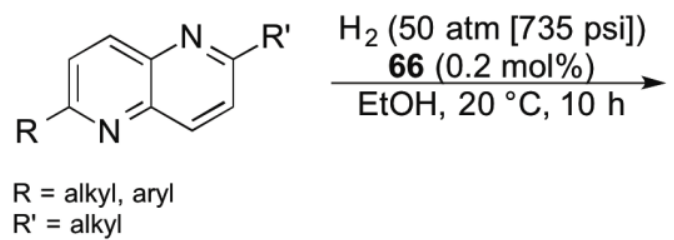

$\mathrm{R}^{\prime}$ = alkyl<smiles>[R]c1ccc2c(n1)CCC([R])N2</smiles>

$45-95 \%$ yield $89-99 \%$ ee

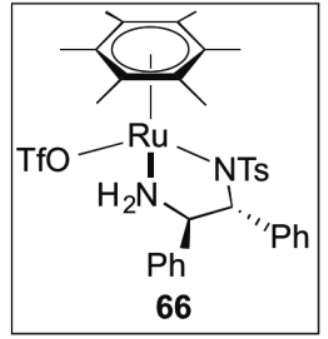

$$
\begin{gathered}
\mathrm{H}_{2}(50 \mathrm{~atm}[735 \mathrm{psi}]) \\
(R, R)-61(2.0 \mathrm{~mol} \%)
\end{gathered}
$$

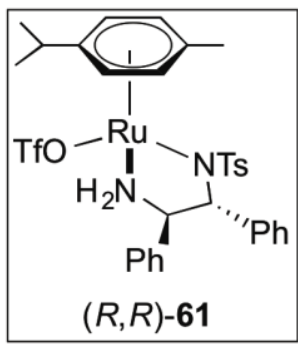<smiles>Cc1ccc2c(n1)CCC([18OH])N2</smiles> 
Scheme 68. Catalyst-controlled enantioselective hydrogenation of 1,5-naphthyridines (top) and subsequent substrate-controlled diastereoselective hydrogenation (bottom).

In 2008, Kuwano [102] reported a rare example of asymmetric hydrogenation of $\mathrm{N}$-Boc-protected pyrrole derivatives using a ruthenium precatalyst and a ferrocene-based PhTRAP ligand (Scheme 69). Kuwano postulated that hydrogenation of the pyrrole's double bonds occurs sequentially: the less hindered first and the more hindered second. For 2,3,5-substituted pyrroles, enantioselective hydrogenation of the $\mathrm{C}(4)=\mathrm{C}(5)$ bond sets a stereocenter that subsequently controls all further hydrogenation to yield the all-syn diastereomer product.

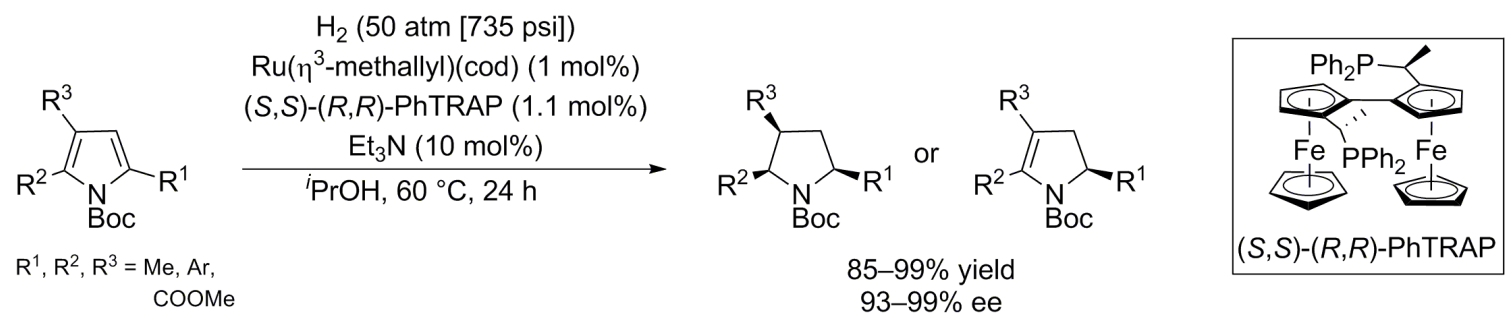

Scheme 69. Asymmetric hydrogenation of $N$-Boc-pyrroles.

\subsection{Other metals}

\subsubsection{Cerium}

Recently, Perrin, Eisenstein, and Andersen [103] reported the addition of pyridine to $\left(1,2,4-\left(\mathrm{Me}_{3} \mathrm{C}\right)_{3} \mathrm{C}_{5} \mathrm{H}_{2}\right)_{2} \mathrm{CeH}\left([\mathrm{Ce}]^{\prime} \mathrm{H}\right)[104]$ to form an $\eta^{2}$-(2-pyridyl) cerium complex (67; Scheme 70$)$. When placed under a hydrogen atmosphere, 67 slowly converted to a mixture of the corresponding trihydropyridyl (68) and piperidyl (69) complexes (Scheme 71 , top). These latter species were also independently synthesized and characterized by X-ray crystallography (Fig. 8).

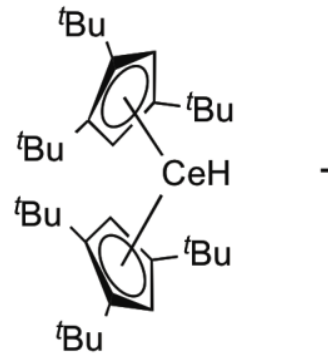

[Ce]'H

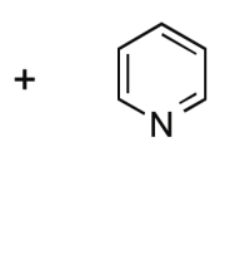

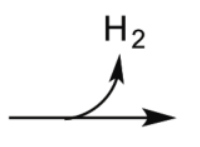

Bu

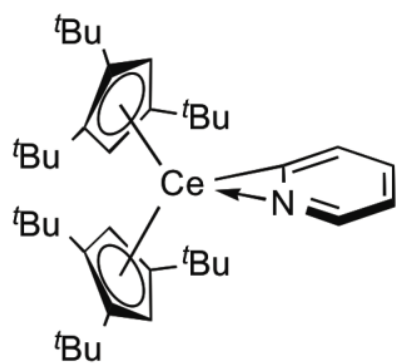

67

Scheme 70. Formation of $\eta^{2}$-(2-pyridyl) cerium complex 67 by addition of pyridine to $[\mathbf{C e}]^{\prime} \mathbf{H}$. 

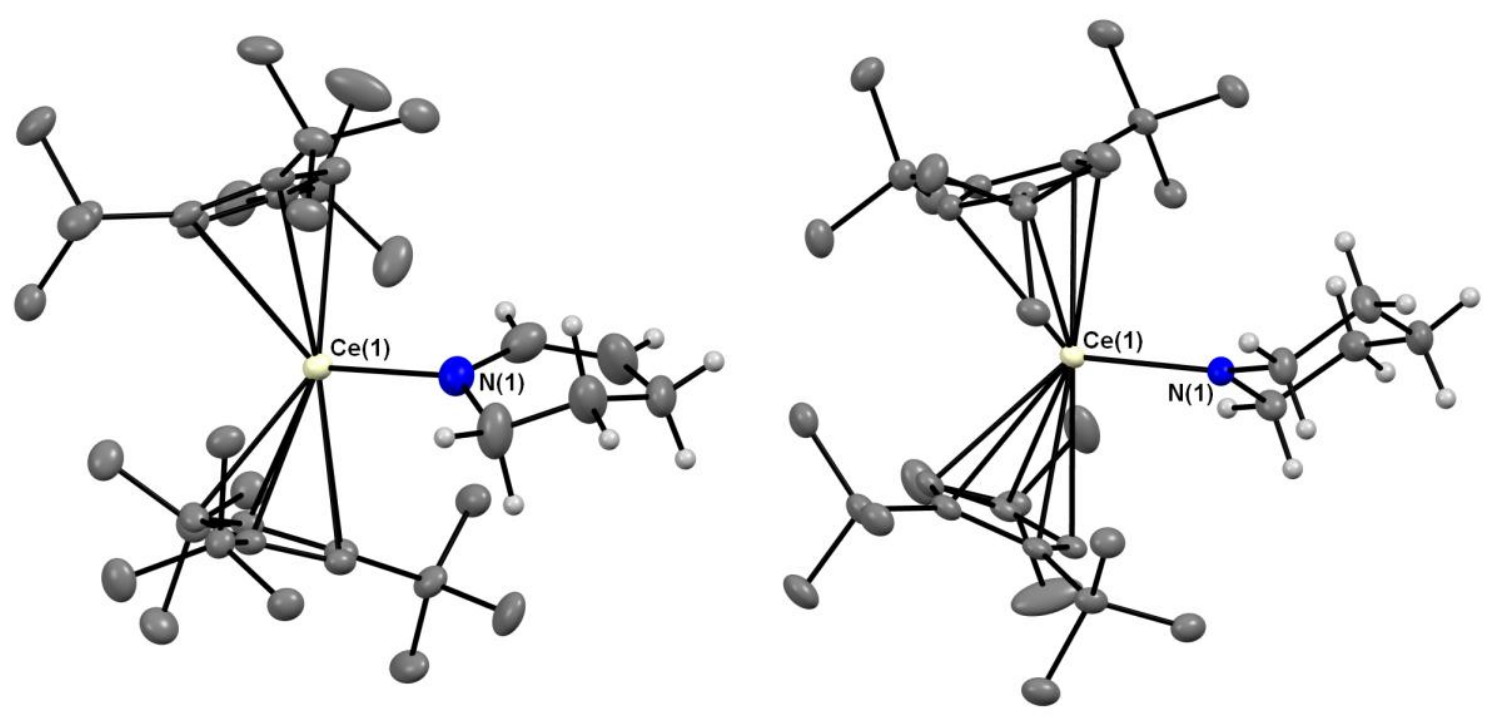

Fig. 8. ORTEP drawing of 68 (left) and 69 (right) generated with the program Mercury using crystallographic data made available in the Supporting Information of Ref. 103. Cp' ligand hydrogen atoms are omitted for clarity.

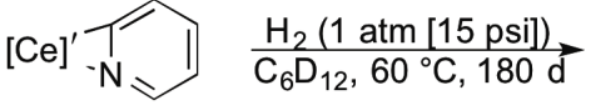

67

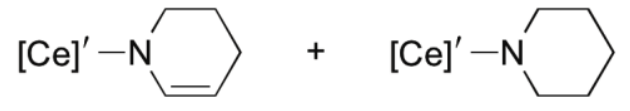

68
$\mathrm{H}_{2}$ (1 atm [15 psi])<smiles></smiles>

67

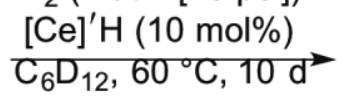

$\mathrm{C}_{6} \mathrm{D}_{12}, 60^{\circ} \mathrm{C}, 10 \mathrm{~d}^{\mathrm{T}}$<smiles>C1=CN([Al]2CCCCC2)[GeH]C1</smiles>

68

$$
\text { 68:69 }=6: 1
$$<smiles>[GeH2]N1CCCCC1</smiles>

69

Scheme 71. Hydrogenation of $\mathbf{6 7}$ in the absence (top) and presence (bottom) of [Ce]'H.

The presence of $10 \mathrm{~mol} \%$ additional [Ce]'H greatly increased the rate of 67 hydrogenation (Scheme 71, bottom), leading the authors to propose the simultaneous involvement of two [Ce]' units in the later stages of the reaction. Detailed DFT calculations at the B3PW91 level of theory supported this hypothesis; Scheme 72 shows the most energetically favorable of the computed reaction pathways. Following initial hydrogenolysis of the $\mathrm{C}-\mathrm{Ce}$ bond in 67 to form [Ce]'H-pyridine adduct 70, intramolecular hydride migration reduces the pyridine $\mathrm{C}=\mathrm{N}$ bond. Reduction of the remaining $\mathrm{C}=\mathrm{C}$ bonds occurs via successive intermolecular hydride additions by $[\mathrm{Ce}]^{\prime} \mathrm{H}$ (Scheme 72, steps iii and v) and subsequent hydrogenolysis of the resulting $\mathrm{C}-\mathrm{Ce}$ bonds (steps iv and vi). These latter processes are thus catalytic in $[\mathrm{Ce}]^{\prime} \mathrm{H}$. The exchange of free pyridine with the $N$-piperidyl group of 69 to reform 67 closes a potential cycle for the overall reaction. 


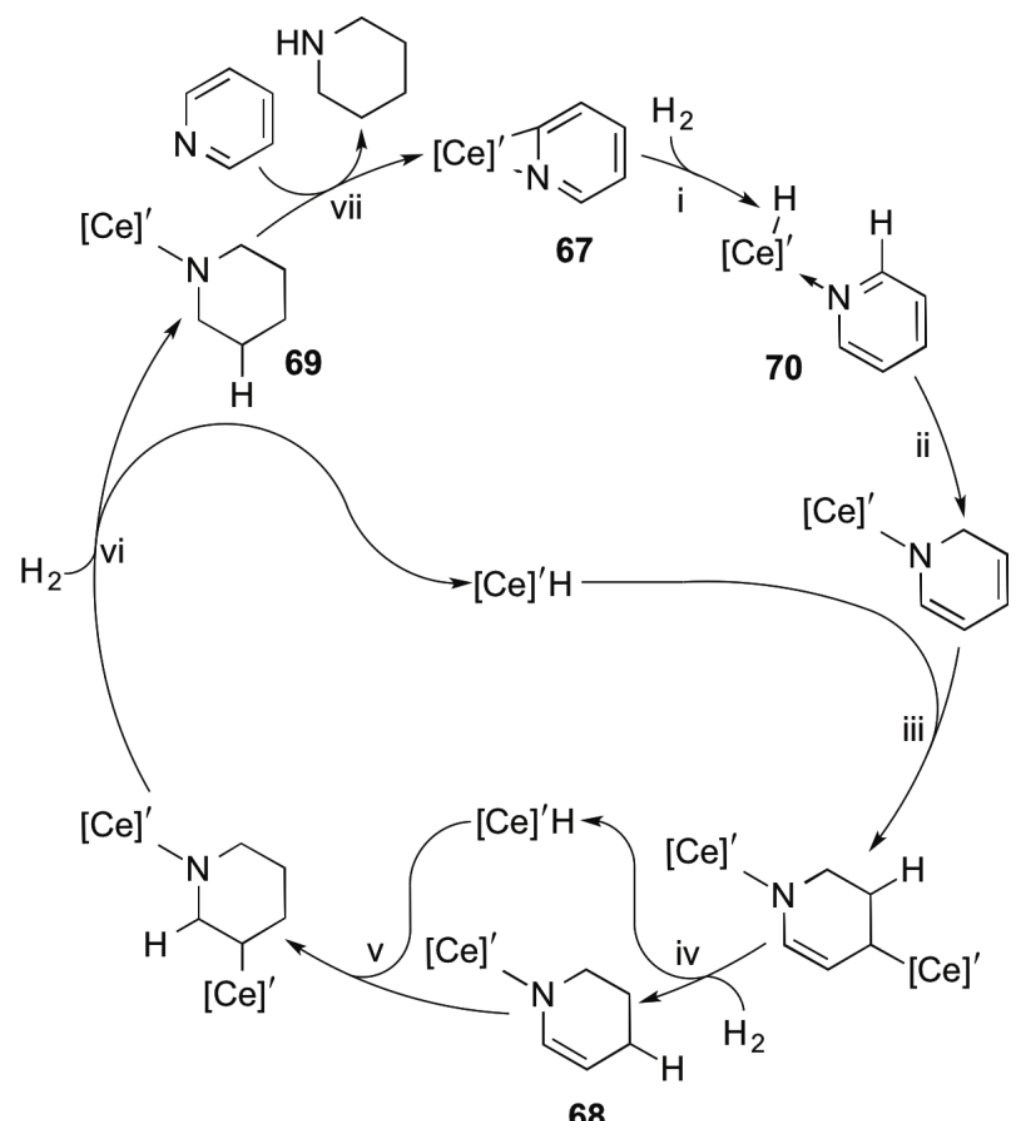

68

Scheme 72. Proposed reaction cycle for hydrogenation of 67 to 69 based on DFT (B3PW91) calculations.

\subsubsection{Cobalt}

Under an atmosphere of syngas $\left(\mathrm{H}_{2} / \mathrm{CO}\right)$, Fish found $\mathrm{Co}_{2}(\mathrm{CO})_{6}\left(\mathrm{PPh}_{3}\right)_{2}$ catalyzed the hydrogenation of acridine and quinoline to 9,10-dihydroacridine and 1,2,3,4tetrahydroquinoline respectively (Scheme 73) [82]. ${ }^{19}$ Kispert [105] was also able to reduce quinoline with a Ziegler-type $\mathrm{Co}(\text { stearate })_{2} \bullet \mathrm{AlEt}_{3}$ catalyst at room temperature (Scheme 74). In contrast, reaction with isoquinoline only occurred at elevated temperatures $\left(90^{\circ} \mathrm{C}\right)$. Notably, the presence of chloride or nitro substituents on the substrates appeared to completely deactivate the catalyst, resulting only in recovery of starting material.

\footnotetext{
${ }^{19}$ Under the same conditions, $\mathrm{Mn}_{2}(\mathrm{CO})_{8}\left(\mathrm{P}^{n} \mathrm{Bu}_{3}\right)_{2}$ also hydrogenated acridine with the same selectivity.
} 
<smiles>c1ccc2nc3ccccc3cc2c1</smiles><smiles>c1ccc2ncccc2c1</smiles><smiles>C1=CC2Cc3ccccc3NC2C=C1</smiles>

$100 \%$

(GC yield)<smiles>c1ccc2c(c1)CCCN2</smiles>

$70 \%$

(GC yield)

Scheme 73. Hydrogenation of $N$-heterocycles catalyzed by $\mathrm{Co}_{2}(\mathrm{CO})_{6}\left(\mathrm{PPh}_{3}\right)_{2}$ under syngas.
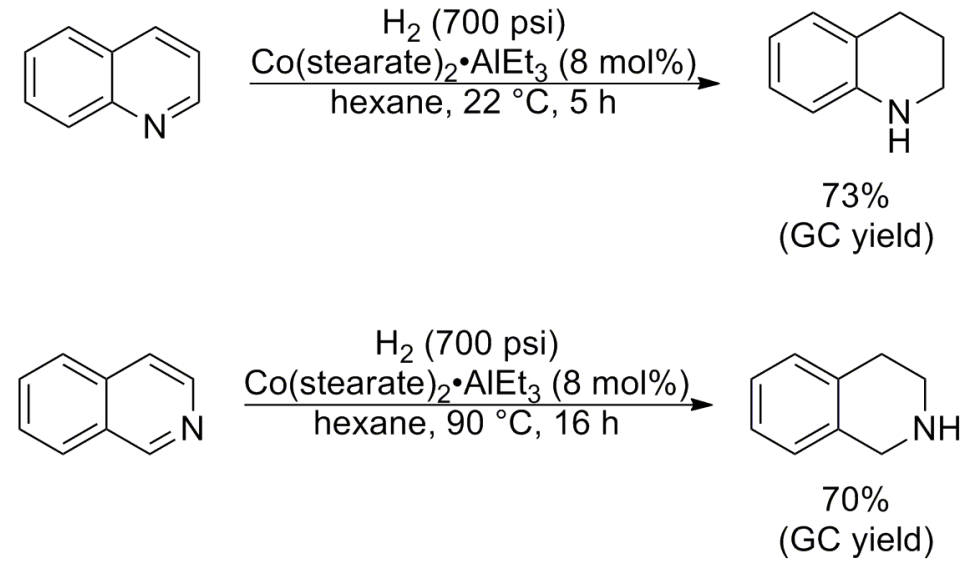

Scheme 74. Hydrogenation of quinolines and isoquinolines catalyzed by $\mathrm{Co}(\text { stearate })_{2} \bullet \mathrm{AlEt}_{3}$.

\subsubsection{Iron}

Under water-gas shift conditions $\left(\mathrm{CO}+\mathrm{H}_{2} \mathrm{O} \rightarrow \mathrm{CO}_{2}+\mathrm{H}_{2}\right)$, Fish [61] found $\mathrm{Fe}(\mathrm{CO})_{5}$ catalyzed partial reduction of acridine to 9,10-dihydroacridine quantitatively (Scheme 75, top). Using similar conditions, Kaesz [106] also reported catalytic hydrogenation of quinoline to 1,2,3,4-tetrahydroquinoline and approximately stoichiometric reduction of 4,7- and 1,10-phenanthroline (Scheme 75, middle and bottom). As a probe of the system's homogeneity, Kaesz pyrolyzed $\mathrm{Fe}(\mathrm{CO})_{5}$ at $174{ }^{\circ} \mathrm{C}$ to form colloidal $\mathrm{Fe}^{0}$, and found the latter to be inactive in quinoline hydrogenation. 


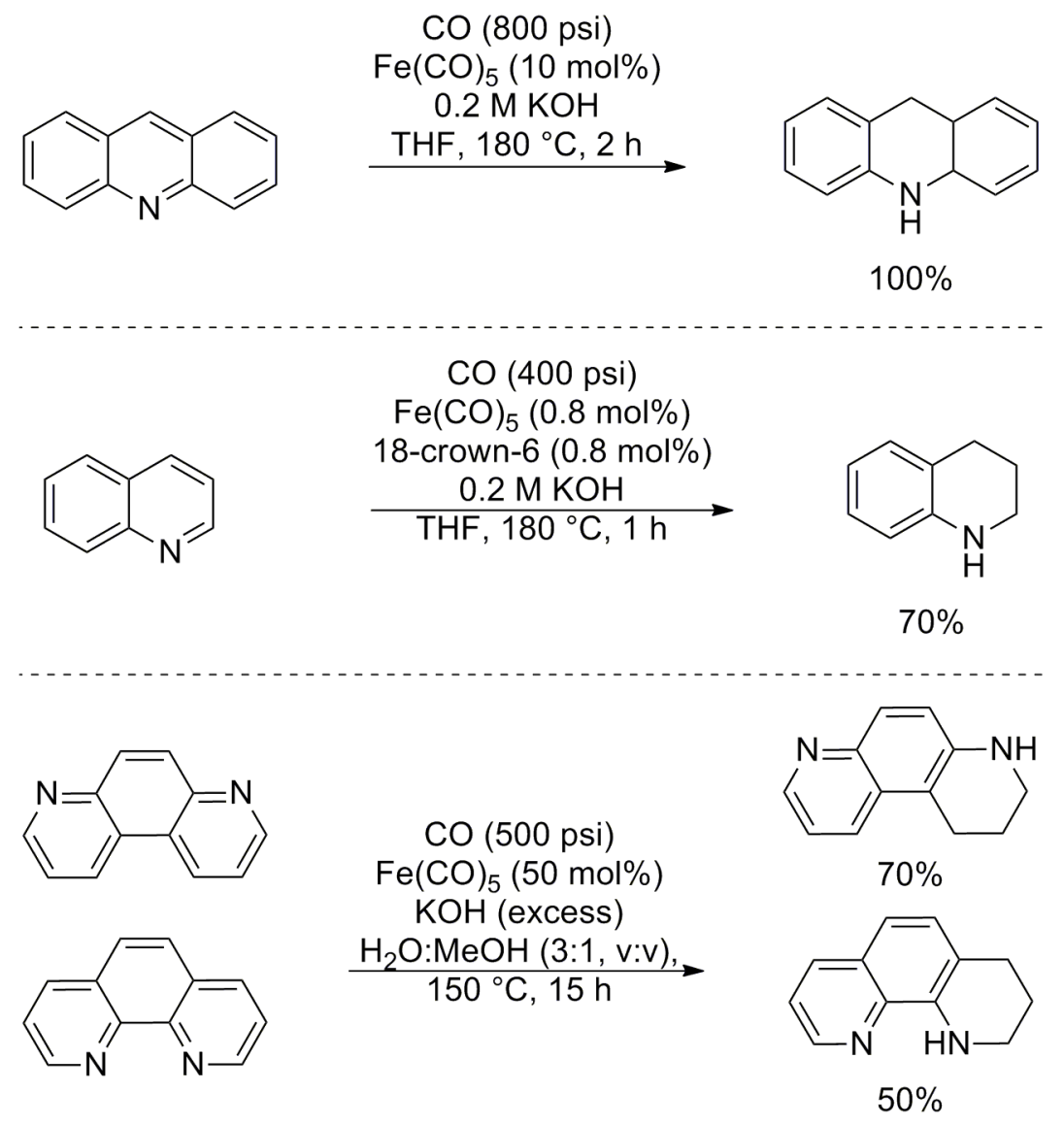

Scheme 75. Hydrogenation of $N$-heterocycles with $\mathrm{Fe}(\mathrm{CO})_{5}$ under water-gas shift conditions.

\subsubsection{Molybdenum}

Parkin reported $\eta^{6}$-complexes formed between $\mathrm{Mo}(\mathrm{PMe})_{6}$ and quinoline (71) [107] and isoquinoline (72) and quinoxaline (73) [108] undergo stoichiometric hydrogenation of the coordinated heterocyclic ring selectively (Scheme 76). The related $\eta^{6}$-complexes coordinated through the carbocyclic ring were notably resistant to hydrogenation under the same conditions; although in the case of quinoxaline, reduction primarily to 5,6,7,8tetrahydroquinoxaline was observed after prolonged reaction times (Scheme 77). The use of $\mathrm{Mo}\left(\mathrm{PMe}_{3}\right)_{4} \mathrm{H}_{4}$ rendered heterocyclic hydrogenation catalytic, but turnover numbers for all three substrates were low (Scheme 78).

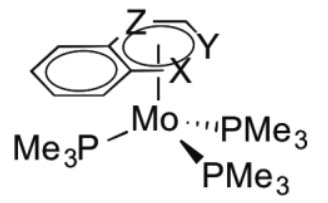

71: $X=N, Y=Z=C H$

72: $\mathrm{Y}=\mathrm{N}, \mathrm{X}=\mathrm{Z}=\mathrm{CH}$

73: $X=Z=N, Y=C H$

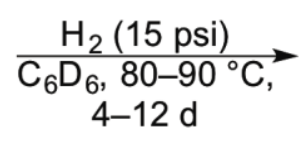

71: $95 \%$ (NMR conversion)

72: $84 \%$ (NMR conversion)

73: $91 \%$ (NMR conversion)

Scheme 76. Stoichiometric hydrogenation of molybdenum complexes 71, 72, and 73. 


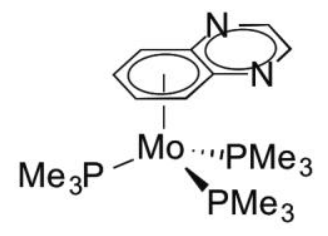

74

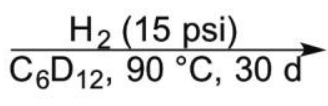<smiles>c1cnc2c(n1)CCCC2</smiles>

$\mathrm{C}_{6}$<smiles>c1ccc2c(c1)NCCN2</smiles>

$\mathrm{C}_{4} \mathrm{~N}_{2}$

$75 \%$ conv.

$\mathrm{C}_{6}: \mathrm{C}_{4} \mathrm{~N}_{2}=83: 17$

Scheme 77. Stoichiometric hydrogenation of $\eta^{6}-\mathrm{C}_{6}$-quinoxaline molybdenum complex $\mathbf{7 4}$.<smiles>[X]c1ccccc1-[Z]1ccccc1</smiles>

$\mathrm{H}_{2}$ (80 atm [1175 psi])

$\underset{\left.\mathrm{C}-\mathrm{C}_{6} \mathrm{H}_{12}, 11\right)^{\circ} \mathrm{C}, 7 \mathrm{~d}}{\longrightarrow}$<smiles>[Z]NC[Z]c1cccc[Y]1[H]</smiles>

$X=N, Y=Z=C H:$ TON $=21$

$\mathrm{Y}=\mathrm{N}, \mathrm{X}=\mathrm{Z}=\mathrm{CH}: \mathrm{TON}=24$

$\mathrm{X}=\mathrm{Z}=\mathrm{N}, \mathrm{Y}=\mathrm{CH}: \mathrm{TON}=8$

Scheme 78. Catalytic hydrogenation of heterocycles by $\mathrm{Mo}\left(\mathrm{PMe}_{3}\right)_{4} \mathrm{H}_{4}$.

\subsubsection{Palladium}

Palladium is often used in heterogeneous hydrogenation reactions of olefins and sometimes arenes. However, homogeneous palladium catalysis is not as common in the hydrogenation of heteroarenes. In 2010, Zhou and Zhang [109] reported an enantioselective palladium-catalyzed hydrogenation of substituted indoles in the presence of $L$-camphorsulfonic acid (Scheme 79, top). Based on deuterium labeling experiments, the authors proposed the reaction's stereoselectivity to arise from reversible protonation of the substrate; this process facilitates a dynamic kinetic resolution by which only the desired enantiomer of the protonated indole is hydrogenated. The requirement of a strong Brønsted acid limits the substrate scope to indoles substituted by simple alkyl and aryl groups. Nevertheless, in 2014, Fan and Zhou [110] found this method useful for the enantiopure synthesis of the biologically active indoline derivative 75 (Scheme 79, bottom). 


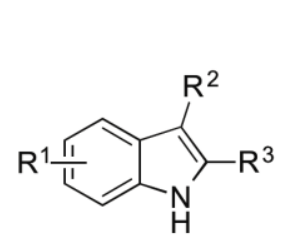

$\mathrm{R}^{1}=\mathrm{H}, \mathrm{Me}, \mathrm{F}$

$\mathrm{R}^{2}=\mathrm{H}$, alkyl

$\mathrm{R}^{3}=$ alkyl, benzyl

\section{$\mathrm{H}_{2}(700 \mathrm{psi})$}

$\mathrm{Pd}\left(\mathrm{OCOCF}_{3}\right)_{2}(2 \mathrm{~mol} \%)$

(R)-octahydro-BINAP (2.4 mol\%)

L-camphorsulfonic acid

$\mathrm{CH}_{2} \mathrm{Cl}_{2} / \mathrm{TFE}, \mathrm{RT}, 24 \mathrm{~h}$

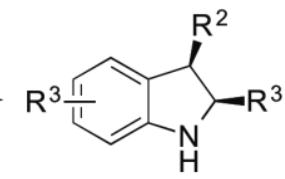

$78-99 \%$ yield $84-95 \%$ ee

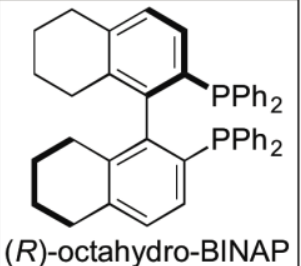

$(R)$-octahydro-BINAP<smiles>c1ccc2c3c([nH]c2c1)CCCC3</smiles>

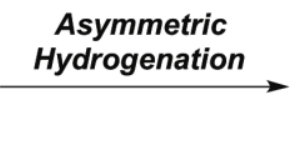

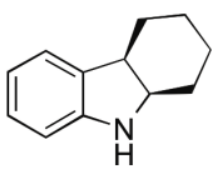

$95 \%$ yield $88 \%$ ee

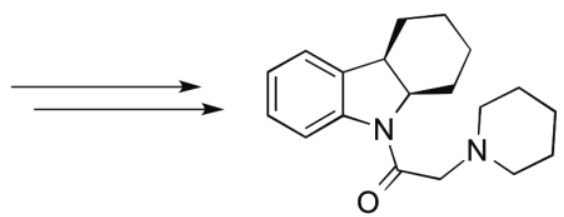

75

$>99 \%$ ee

Scheme 79. Asymmetric hydrogenation of substituted indoles by a palladium catalyst with $(R)$-octahydro-BINAP.

Combined experimental and theoretical efforts [110] led to a mechanistic proposal featuring significant ligand-metal cooperation (Scheme 80). Following phosphine coordination to bis-(trifluoroacetate)palladium(II), protonation of one of the TFA ligands (step i) leads to formation of a cationic $\sigma$-complex upon introduction of $\mathrm{H}_{2}$ and loss of TFA (step ii). The indole substrate undergoes outer-sphere protonation by the cationic complex (step iii), but becomes coordinated to the complex by hydrogen bonding with the carbonyl oxygen of the remaining TFA ligand. Intramolecular hydride addition and product dissociation (steps iv and $\mathrm{v}$ ) then facilitates regeneration of the bis-TFA Pdphosphine complex (step vi). 


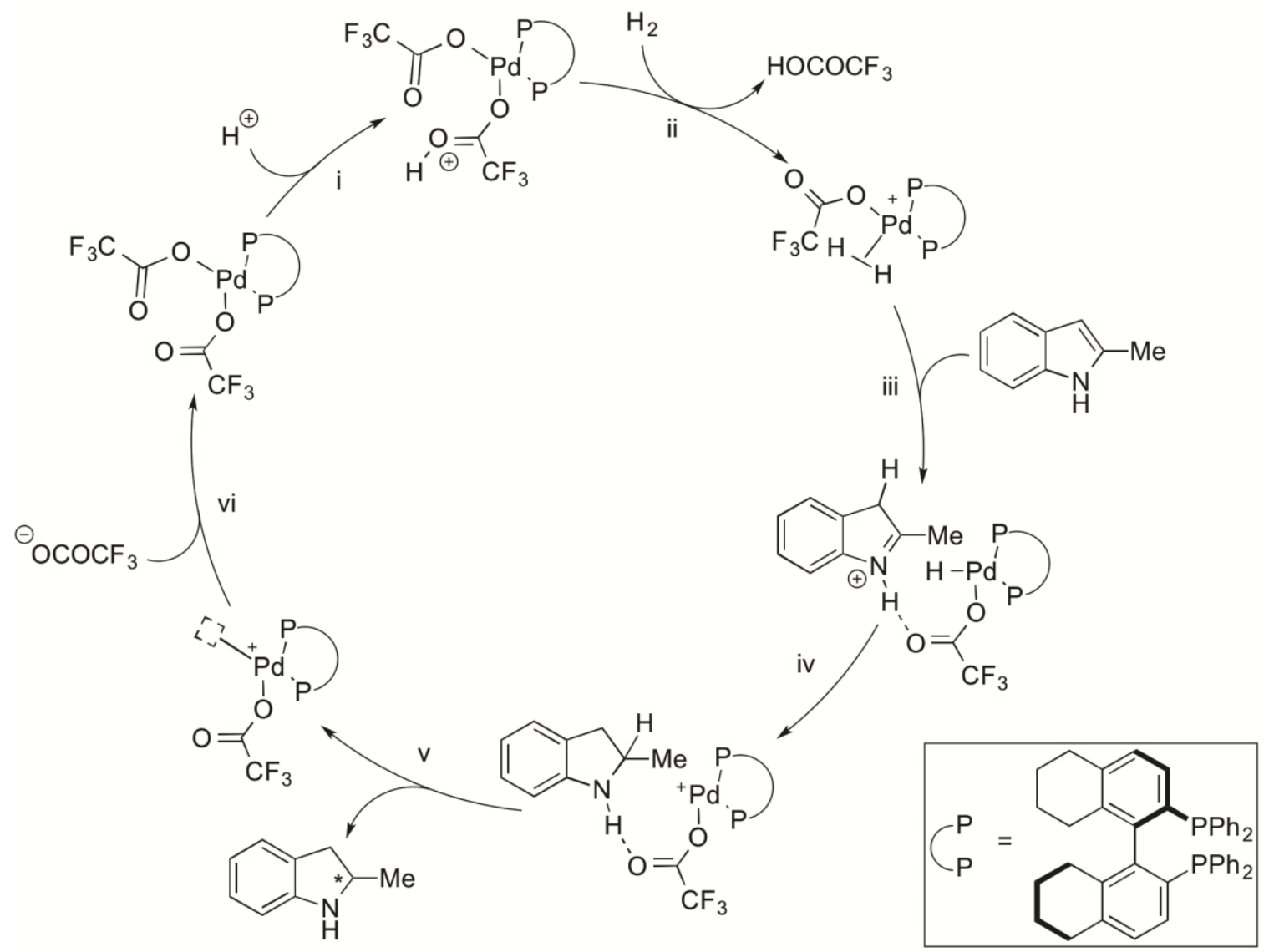

Scheme 80. Proposed catalytic cycle for palladium-catalyzed hydrogenation of substituted indoles.

Zhou [111] later reported enantioselective hydrogenation of 3-( $\alpha$-amino)indoles (Scheme 81). Under the acidic reaction conditions, elimination of the sulfonamide group ultimately resulted in 3-benzyl-substituted products. Zhou [112] also used a SEGPHOStype ligand to enantioselectively hydrogenate 2-substituted 3-phthalimidoquinolines. Notably, the substrate scope for this reaction included 2-E-styryl-3-phthalimidoquinoline, and the conjugated olefin was not reduced under the reaction conditions. The inert nature of the styryl moiety in this case stands in direct contrast to Zhou's asymmetric hydrogenation of indoles, where the styryl moiety stifled reactivity.

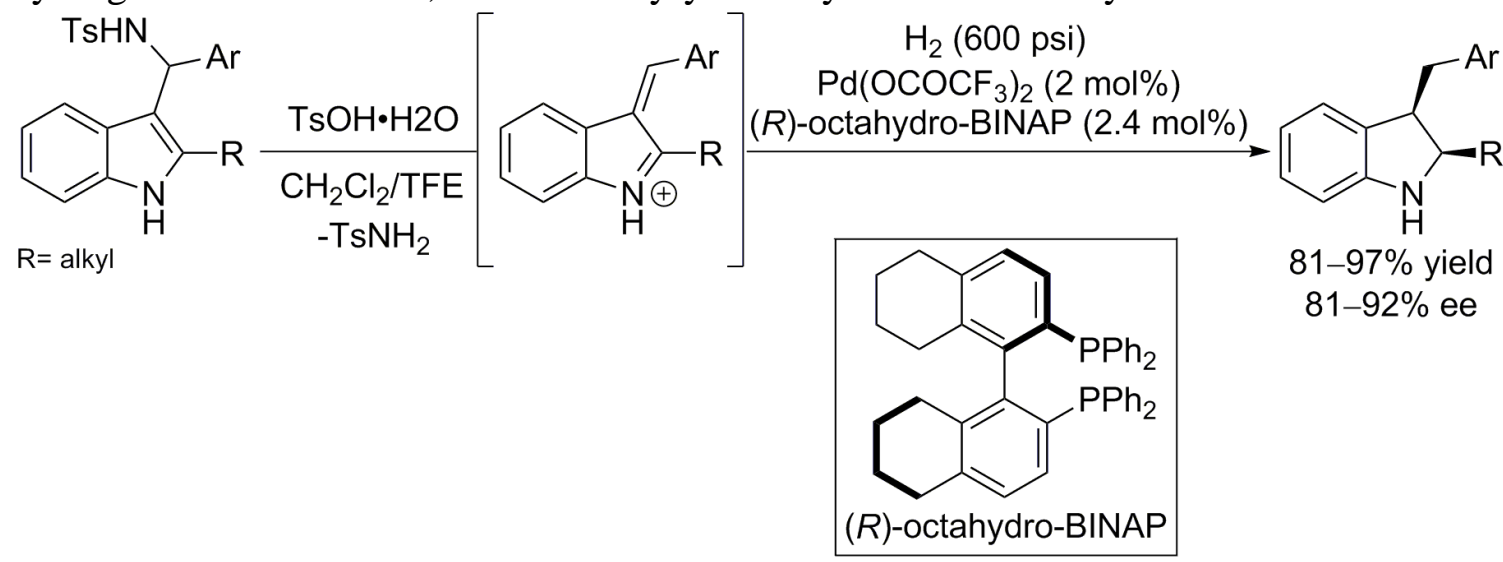


Scheme 81. Asymmetric hydrogenation of 3-( $\alpha$-amino)indoles to obtain enantioenriched 3-benzylindolines.

Most recently, Zhou [113] reported enantioselective hydrogenation of pyrazol-5ols using palladium catalysis (Scheme 82). This is another rare example of monocyclic heteroarene hydrogenation; these substrates were not appreciably hydrogenated by cationic rhodium or neutral ruthenium and iridium catalysts. Under the optimized reaction conditions, the anti-diastereomer was obtained with high enantioselectivity and with minimal $\mathrm{N}-\mathrm{N}$ bond cleavage.
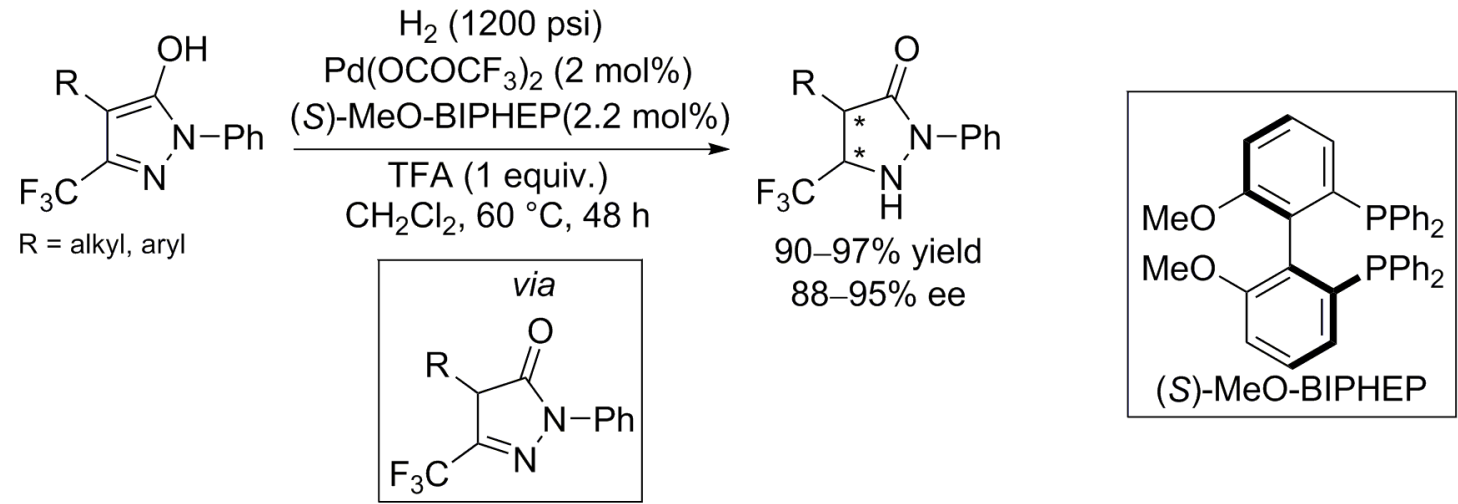

Scheme 82. Asymmetric hydrogenation of pyrazol-5-ols.

\subsubsection{Titanium}

In 1998, Harrod and Samuel [114] reported the titanocene complex $\mathrm{Cp}_{2} \mathrm{TiMe}_{2}$ catalyzed the hydrosilylation-hydrogenation of pyridines to produce the corresponding $\mathrm{N}$ silyl-1,2,3,4-tetrahydropyridines (Scheme 83). While the use of an excess of silane did not result in formation of the completely reduced piperidine products, a later study [115] revealed these species could be generated by performing the reactions under a hydrogen atmosphere (Scheme 84). In addition to substituted pyridines, the authors found $\mathrm{Cp}_{2} \mathrm{TiMe}_{2}$ also notably catalyzed the reduction of quinoline to a mixture of $N$-silyl-1,4dihydro- and 1,2,3,4-tetrahydroquinoline or the tetrahydro product exclusively in the absence or presence of $\mathrm{H}_{2}$ respectively (Scheme 85).<smiles></smiles>

$\mathrm{R}=\mathrm{H}, 3-\mathrm{Me}, 4-\mathrm{Me}$, $3,5-\mathrm{Me}_{2}$

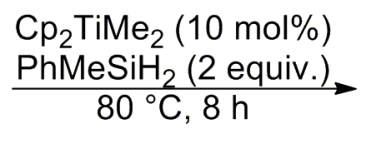

$80^{\circ} \mathrm{C}, 8 \mathrm{~h}$

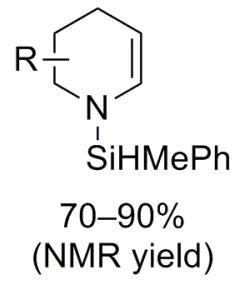

Scheme 83. $\mathrm{Cp}_{2} \mathrm{TiMe}_{2}$-catalyzed hydrosilylation-hydrogenation of pyridines to $\mathrm{N}$-silyl1,2,3,4-tetrahydropyridines. 


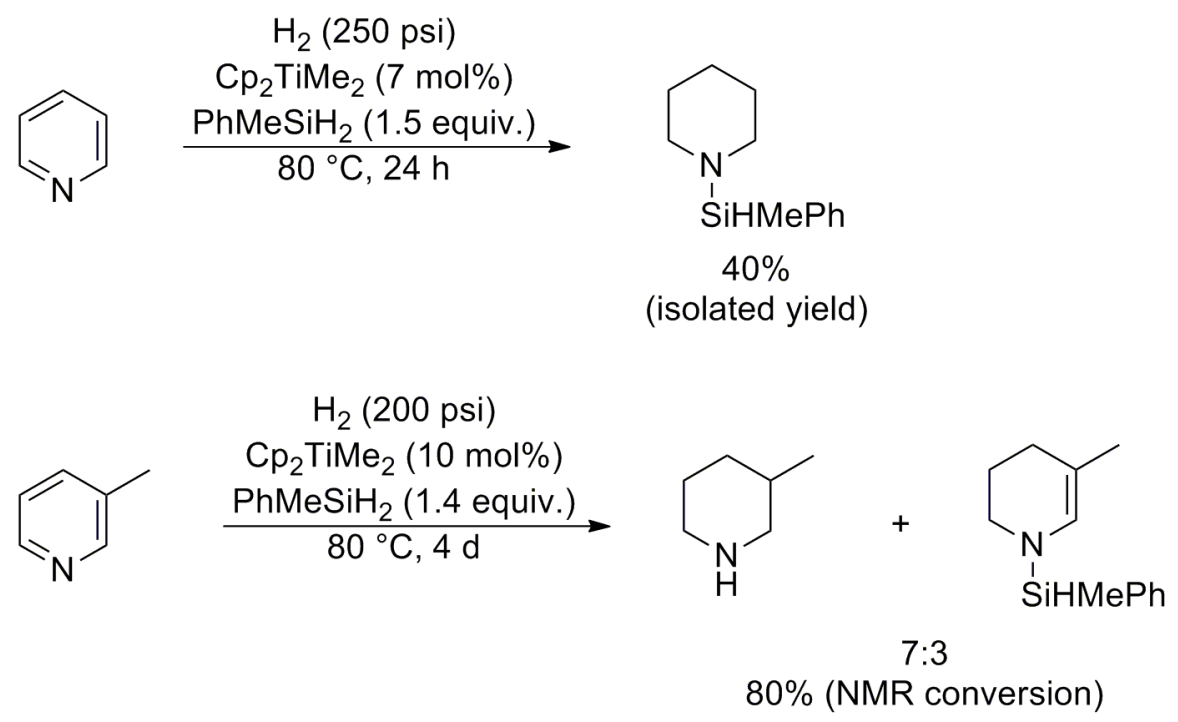

Scheme 84. $\mathrm{Cp}_{2} \mathrm{TiMe}_{2}$-catalyzed hydrosilylation-hydrogenation of pyridines to $\mathrm{N}$-silylpiperdines.
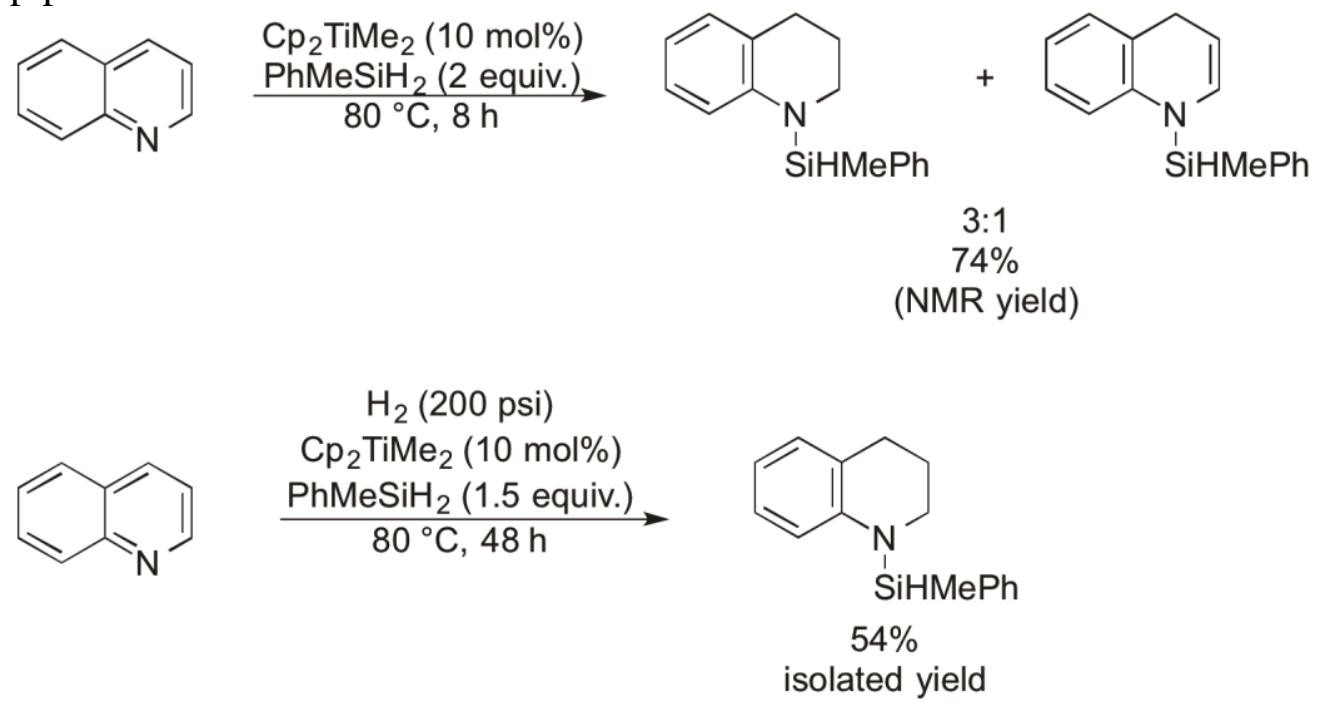

Scheme 85. $\mathrm{Cp}_{2} \mathrm{TiMe}_{2}$-catalyzed hydrosilylation-hydrogenation of quinolines in the absence (top) and presence (bottom) of $\mathrm{H}_{2}$.

While the precise nature of the catalytic cycle remains unelucidated, the authors have identified a number of potential intermediates. Specifically, the addition of $\mathrm{PhMeSiH}_{2}$ to $\mathrm{Cp}_{2} \mathrm{TiMe}_{2}$ in the presence of excess pyridine initially generated the pyridine-titanium(III) complex 76 (Scheme 86, top), which rapidly decomposed to the bimetallic species 77 (Fig. 9) [114]. This decomposition was proposed to proceed through the titanium hydride 78 and $\eta^{2}$-(2-pyridyl) complex 79 (Scheme 86, bottom). The former species was independently generated by the addition of pyridine to $\left[\mathrm{Cp}_{2} \mathrm{TiH}\right]_{2}$ at $-20{ }^{\circ} \mathrm{C}$; upon warming to room temperature, a signal highly suggestive of $\mathbf{7 9}$ was observed by EPR. Isotope labeling studies also provided evidence for the intermediacy of $\mathbf{7 8}$ and 79: under a hydrogen atmosphere in the presence of $10 \mathrm{~mol} \%\left[\mathrm{Cp}_{2} \mathrm{TiH}\right]_{2}$, pyridine- $d_{5}$ underwent complete $o$-H/D exchange (Scheme 87) [115]. Little hydrogenation to piperidine actually occurred under these conditions, however, leading the authors to suggest that a 
silyltitanium species such as $\mathbf{7 6}$, rather than a titanium hydride such as $\mathbf{7 8}$, may in fact be the active catalytic species.

$$
\mathrm{Cp}_{2} \mathrm{TiMe}_{2} \quad \stackrel{\mathrm{PhMeSiH}_{2} \text { (2 equiv.) }}{\text { pyridine (excess) }}
$$

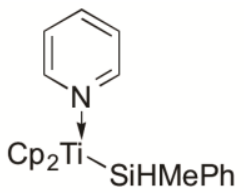

76

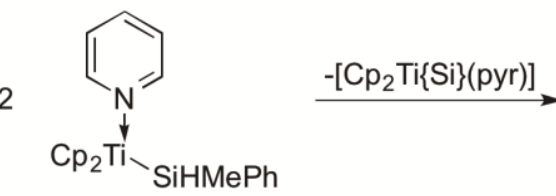

76<smiles>O=[Pt]c1ccccc1</smiles>

78

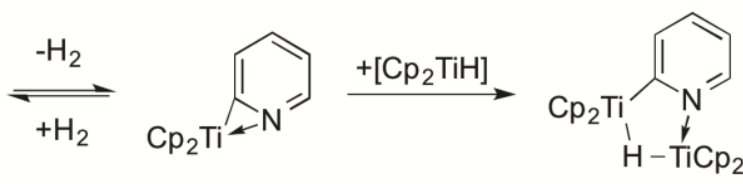

79 77

Scheme 86. Stoichiometric formation of 76 (top) and proposed decomposition pathway to 77 (bottom).

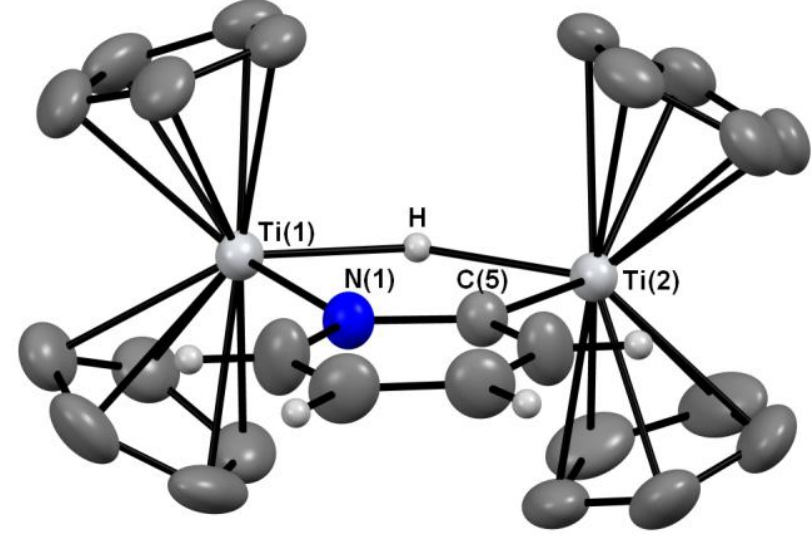

Fig. 9. ORTEP drawing of 77 generated with the program Mercury using crystallographic data retrieved from the Cambridge Crystal Structure Database (CCDC\# 102515); structure information originally provided in Ref. 114. Thermal ellipsoids are shown at 50\% probability; $\mathrm{Cp}$ ligand hydrogen atoms and pyridine solvate omitted for clarity. The $\mathrm{N}(1)$ and $\mathrm{C}(5)$ positions are mutually disordered with 0.52:0.48 occupancy.
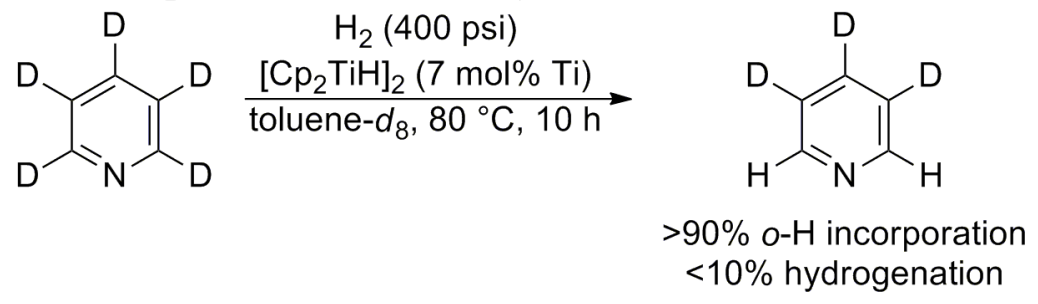

Scheme 87. $\left[\mathrm{Cp}_{2} \mathrm{TiH}\right]_{2}$-catalyzed H/D exchange of pyridine- $d_{5}$.

3. Carbocycle hydrogenation

\subsection{Cobalt}

Under high syngas pressures (2900-3200 psi), Friedman [116] found $\mathrm{Co}_{2}(\mathrm{CO})_{8}$ hydrogenated anthracene catalytically and also certain fused polycyclic aromatic compounds stoichiometrically (Scheme 88). Product selectivity appeared to be dictated 
by the formation of largely inert benzene, naphthalene, and phenanthrene units; likewise, substrates formally composed of these species, such as triphenylene, fluorene, and coronene, were essentially unreactive. As part of a mechanistic study, Orchin [117] found reduction of 9,10-dimethylanthracene with stoichiometric $\mathrm{Co}_{2}(\mathrm{CO})_{8}$ resulted in formation of an approximately 1:1 mixture of the cis and trans 9,10-dihydro products (Scheme 89). Additionally, Friedman [118] observed extensive H/D scrambling at the 9- and 10positions of anthracene when the reaction was performed using $\mathrm{D}_{2}$. Based on these results, Feder and Halpern [119] proposed a hydrogen atom transfer mechanism initiated by the in situ formation of $\mathrm{HCo}(\mathrm{CO})_{4}$ from $\mathrm{Co}_{2}(\mathrm{CO})_{8}$ and $\mathrm{H}_{2}$ (Scheme 90).

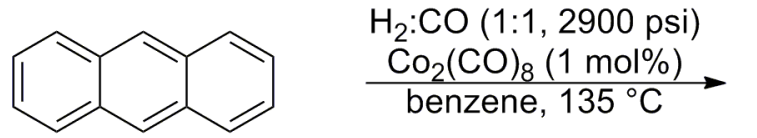<smiles>O=[N+]([O-])C1C=CC=CC2Cc3ccccc3CC21</smiles><smiles>c1ccc2cc3cc4ccccc4cc3cc2c1</smiles>

$\mathrm{H}_{2}: \mathrm{CO}(1: 1,3000 \mathrm{psi})$ $\underset{\text { benzene, } 140^{\circ} \mathrm{C}}{\stackrel{\mathrm{Co}_{2}(\mathrm{CO})_{8}(0.5 \text { equiv. })}{\longrightarrow}}$<smiles></smiles><smiles>c1cc2ccc3cccc4ccc(c1)c2c34</smiles>

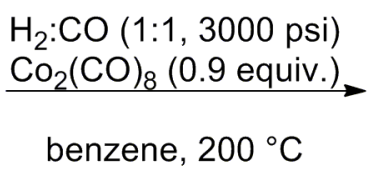<smiles>O=[N+]([O-])c1ccc2cccc3c2c1CCc1cccc-3c1</smiles><smiles>c1ccc2c(c1)-c1cccc3cccc-2c13</smiles>

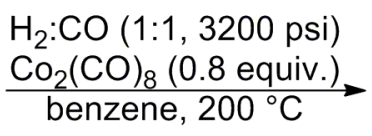<smiles>c1ccc2c(c1)-c1cccc3c1C2CCC3</smiles>
$54 \%$

Scheme 88. Hydrogenation of various polycyclic aromatic compounds catalyzed by $\mathrm{Co}_{2}(\mathrm{CO})_{8}$. Yields based on $\mathrm{GC}$ analysis.<smiles>Cc1c2ccccc2c(C)c2ccccc12</smiles>

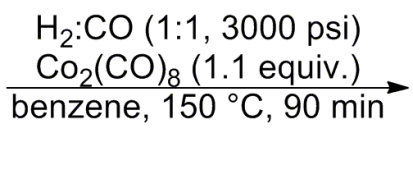<smiles>C[C@@H]1c2ccccc2[C@H](C)C2C=CC=CC21</smiles>

$+$<smiles>C[C@@H]1c2ccccc2[C@H](C)C2C=CC=CC21</smiles>

48:52

99\% (GC yield)

Scheme 89. Hydrogenation of 9,10-dimethylanthracene with stoichiometric $\mathrm{Co}_{2}(\mathrm{CO})_{8}$. 


$$
\mathrm{Co}_{2}(\mathrm{CO})_{8}+\mathrm{H}_{2} \rightleftharpoons 2 \mathrm{HCo}(\mathrm{CO})_{4}
$$<smiles></smiles><smiles>[R]C1c2ccccc2C([R])([R])C2C=C[CH+]C=CC12</smiles><smiles>[Z]C(=O)OC(=O)OC(=O)OC(=O)OC</smiles>

Scheme 90. Proposed catalytic pathway for hydrogenation of 9,10-substituted anthracenes by $\mathrm{Co}_{2}(\mathrm{CO})_{8}$.

In the 1970s, Muetterties published a series of studies of arene hydrogenation catalysts of the general form $\eta^{3}$-(allyl)CoL $\mathrm{CoL}_{3}[120,121]$. For the hydrogenation of benzene, the most active catalyst was formed when $\mathrm{L}=\mathrm{P}\left(\mathrm{O}^{i} \mathrm{Pr}\right)_{3}$ (Scheme 91); the lifetime of this species was notably limited, however, leading the authors to favor the more stable $\mathrm{P}(\mathrm{OMe})_{3}$ analogue $(\mathbf{8 0})$, which retained activity for up to $48 \mathrm{~h}$ [121]. While $\mathbf{8 0}$ achieved moderate turnover with benzene itself $(\mathrm{TON}=15)$ [121], hydrogenation of more sterically encumbered substrates was significantly slower, with 1,2,3,4tetramethylbenzene and hexamethylbenzene completely unreactive [122]. Substrates bearing electron-withdrawing substituents such $\mathrm{F}, \mathrm{CN}$, or $\mathrm{NO}_{2}$ were likewise unreactive.
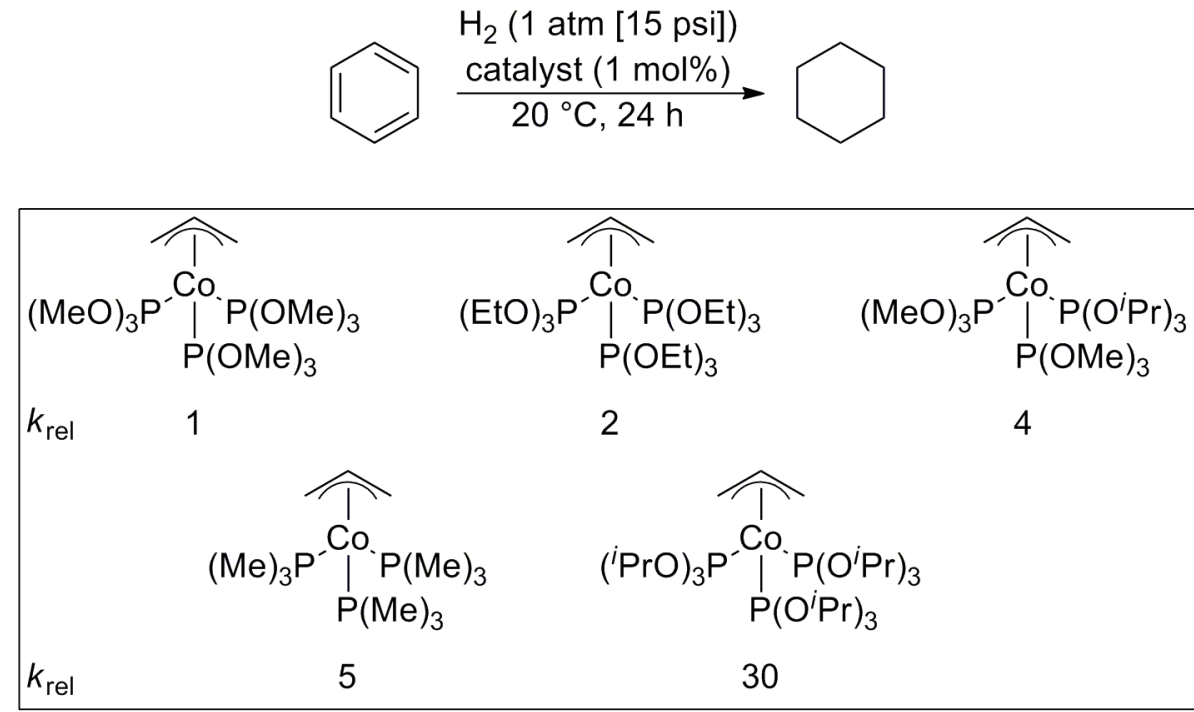

Scheme 91. Relative rates of hydrogenation catalyzed by $\eta^{3}$-(allyl) $\mathrm{CoL}_{3}$ catalysts.

In contrast to the $\mathrm{H} / \mathrm{D}$ scrambling reported by Friedman with $\mathrm{Co}_{2}(\mathrm{CO})_{8}$ (vide supra), Muetterties did not observe such exchange at aromatic positions with 80 [123]. 
Additionally, hydrogenation of benzene- $d_{6}$ yielded only all-cis cyclohexane- $d_{6}$ (Scheme 92, top) [124]; likewise, reactions of xylenes produced only cis-dimethylcyclohexanes, naphthalene, cis-decalin, and anthracene, cis-syn-cis-perhydroanthracene [122-124]. Finally, intermediary cyclohexene was not detected by GC analysis of the products of benzene hydrogenation [125]. Based on these results, the authors concluded that substrate-catalyst dissociation does not occur until generation of the final reduced product, which forms through a series of irreversible hydride additions (Scheme 93, steps vi and vii, ix and $x$, and xii and xiii).
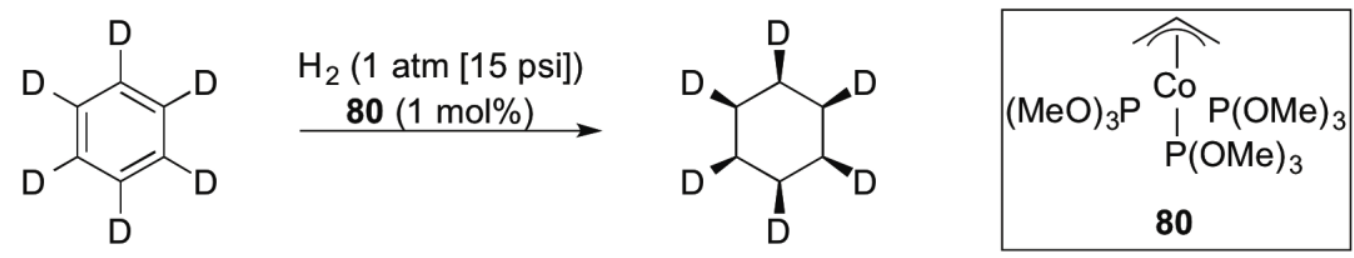<smiles>CC1CCCCC1C</smiles><smiles>CC1CCCC(C)C1</smiles><smiles>CC1CCC(C)CC1</smiles><smiles>C1CC[C@H]2CCCC[C@H]2C1</smiles><smiles>C1CC[C@@H]2C[C@@H]3CCCC[C@@H]3C[C@@H]2C1</smiles>

Scheme 92. Hydrogenation of $\mathrm{C}_{6} \mathrm{D}_{6}$ catalyzed by $\mathbf{8 0}$ to produce all-cis $\mathrm{C}_{6} \mathrm{H}_{6} \mathrm{D}_{6}$ (top), and other products formed stereoselectively (bottom) 


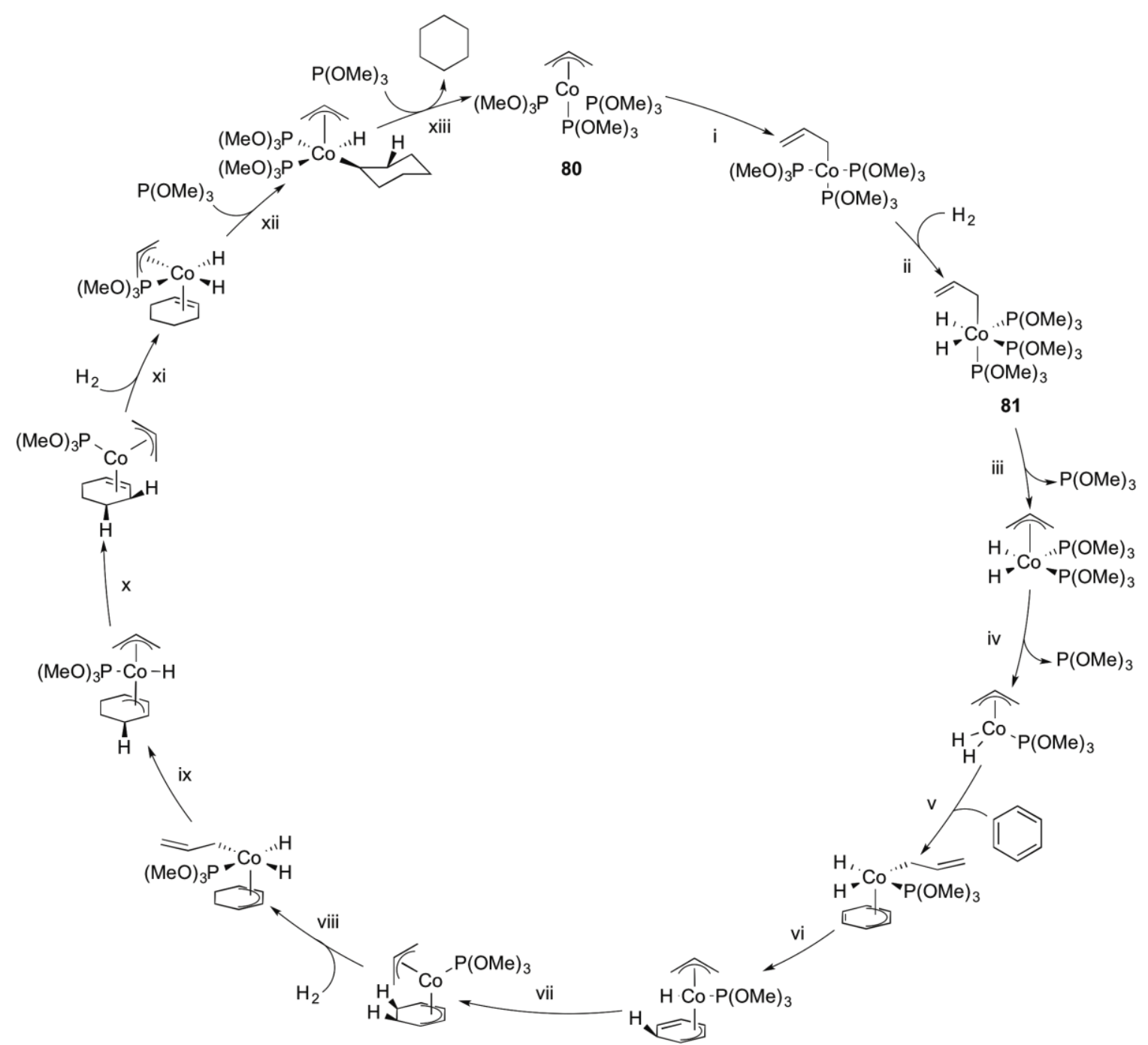

Scheme 93. Proposed catalytic cycle for hydrogenation of benzene with $\mathbf{8 0}$.

${ }^{1} \mathrm{H}$ NMR analyses of the starting complex $\mathbf{8 0}$ suggested the catalytic cycle initiates with a hapticity shift from $\eta^{3}$ - to $\eta^{1}$-allyl, followed by oxidative addition to $\mathrm{H}_{2}$ to form an octahedral cis-dihydride (81; Scheme 93, steps i and ii) [123,125]. ${ }^{20}$ Successive loss of two phosphite groups from $\mathbf{8 1}$ then facilitates $\eta^{4}$-coordination of the aromatic substrate (steps iii-v) [125]. Evidence for this initial coordination mode was provided by competition studies with linear dienes: the presence of equimolar amounts of 1,3- or 1,4hexadiene completely inhibited benzene hydrogenation, presumably through competitive $\eta^{4}$-coordination with the catalyst [122].

In the proposed catalytic cycle in Scheme 93, the allyl ligand notably remains bound to the metal center, in alternating $\eta^{3}$ and $\eta^{1}$ modes, throughout. Indeed, Muetterties reported nearly quantitative recovery of $\mathbf{8 0}$ from hydrogenation reactions after $24 \mathrm{~h}$ $[123,125]$. In the absence of aromatic substrates or after longer reaction times $(48 \mathrm{~h})$,

${ }^{20}$ Aromatic substrates were not observed to coordinate to the $\eta^{1}$-complex prior to oxidative addition to $\mathrm{H}_{2}$. 
however, the $\eta^{3}$-(allyl) $\mathrm{CoL}_{3}$ catalysts were observed to decompose by hydride migration to release propene and form either $\mathrm{HCo}\left(\mathrm{PR}_{3}\right)_{4}$ or $\mathrm{H}_{3} \mathrm{Co}\left(\mathrm{PR}_{3}\right)_{3}$ (the latter was isolated only in the case of $\mathrm{R}=\mathrm{O}^{i} \operatorname{Pr}[126]$ ) [121]. None of these cobalt hydrides exhibited catalytic hydrogenation activity.

\subsection{Nickel}

Klabunde and Radonovich [127] reported the $\eta^{6}$-nickel(II) catalyst 82 converts toluene to methylcyclohexane under relatively high hydrogen pressure at $25{ }^{\circ} \mathrm{C}$ (Scheme 94). However, 82 proved strongly susceptible to decomposition to $\mathrm{C}_{6} \mathrm{~F}_{5} \mathrm{H}$ and inactive $\mathrm{Ni}^{0}$; observed TONs were thus limited to $\leq 10$.

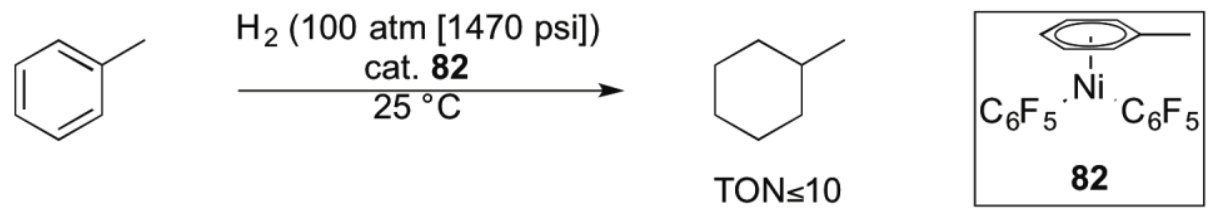

Scheme 94. Hydrogenation of toluene to methylcyclohexane catalyzed by $\mathbf{8 2}$.

\subsection{Niobium and Tantalum}

During the 1990s, Rothwell [128] conducted a series of studies of niobium- and tantalum-based arene hydrogenation catalysts. In general, these complexes consisted of $\mathrm{d}^{0}$ metal di- and trihydrides supported by bulky di- $O$-alkyl-substituted phenoxide ligands. While the tantalum trihydride $\mathbf{8 3}$ (Fig. 10) could be isolated and used directly [129], the phosphine-free niobium analogue was typically generated in situ by hydrogenolysis of the tribenzyl-ligated precursor 84 [130]. ${ }^{21,22}$

${ }^{21}$ Separate studies showed the accompanying hydrogenation of the phenoxide ligands' phenyl substituents occurred in an intramolecular fashion, and only for those at ortho positions, as in 84. For further details, see: B. D. Steffey, I. P. Rothwell, J. Chem. Soc., Chem. Commun. (1990), 213 and M. A. Lockwood, M. C. Potyen, B. D. Steffey, P. E. Fanwick, I. P. Rothwell, Polyhedron 14 (1995) 3293.

${ }^{22}$ Later iterations of this work also generated active niobium catalysts by reaction of the corresponding niobium chlorides with $n$-butyllithium prior to exposure to $\mathrm{H}_{2}$; see Ref. 133. 


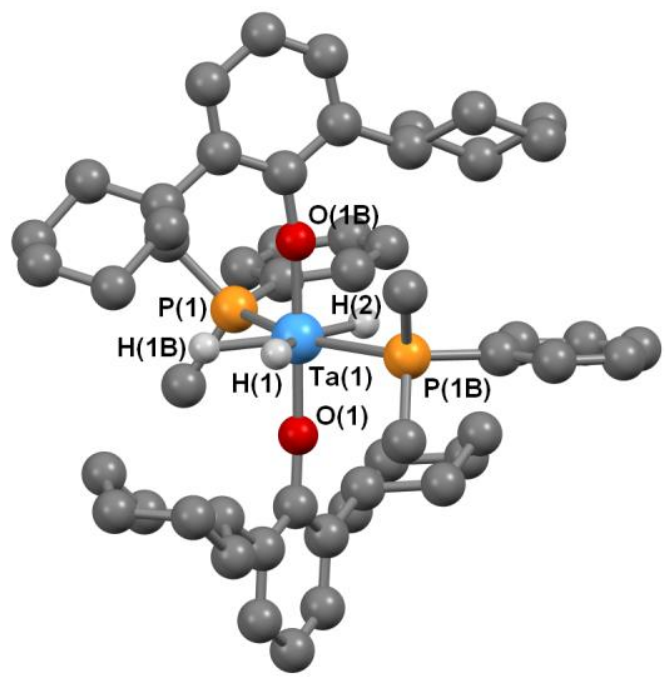

Fig. 10. Ball-and-stick representation of $\mathbf{8 3}$ generated with the program Mercury using crystallographic data retrieved from the Cambridge Crystal Structure Database (Refcode SODLAY); structure information originally provided in Ref. 129. Ligand hydrogen atoms have been omitted for clarity.

Both 83 and activated $\mathbf{8 4}$ catalyzed hydrogenation of naphthalene and anthracene in $>95 \%$ yield [131], although with different product selectivity for the latter substrate (Scheme 95). Phenanthrene was also reduced by 84 to a mixture of 9,10-

dihydrophenanthrene and 1,2,3,4,5,6,7,8-octahydrophenanthrene (Scheme 96, top); notably, 9,10-dihydrophenanthrene itself was resistant to further hydrogenation under the reaction conditions. Substrate steric effects were found to exert a significant influence on the reaction's regioselectivity, as exemplified by 1- and 2-methylnaphthalene, for which the unsubstituted ring was reduced exclusively (Scheme 96, bottom). Additional isotope labeling studies using perdeuterated substrates revealed both 83 and 84 to effect exclusively all-cis hydrogen addition (Scheme 97), a stereoselectivity notably also exhibited by Muetterties's $\eta^{3}$-allyl colbalt catalyst (see Section 3.1). 


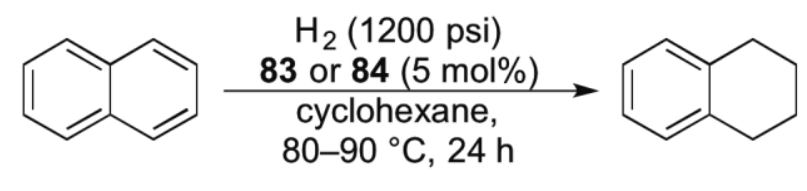

$>95 \%$

(NMR yield)<smiles>c1c2c(cc3c1CCCC3)CCCC2</smiles>

$>95 \%$

(NMR yield)
$\mathrm{H}_{2}$ (1200 psi)

$84(5 \mathrm{~mol} \%)$

cyclohexane,

$80^{\circ} \mathrm{C}, 24 \mathrm{~h}$

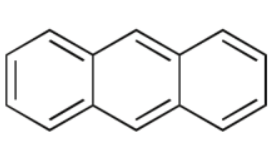

$\mathrm{H}_{2}(1200 \mathrm{psi})$
$83(5 \mathrm{~mol} \%)$<smiles>c1ccc2cc3c(cc2c1)CCCC3</smiles>

$>95 \%$

(NMR yield)
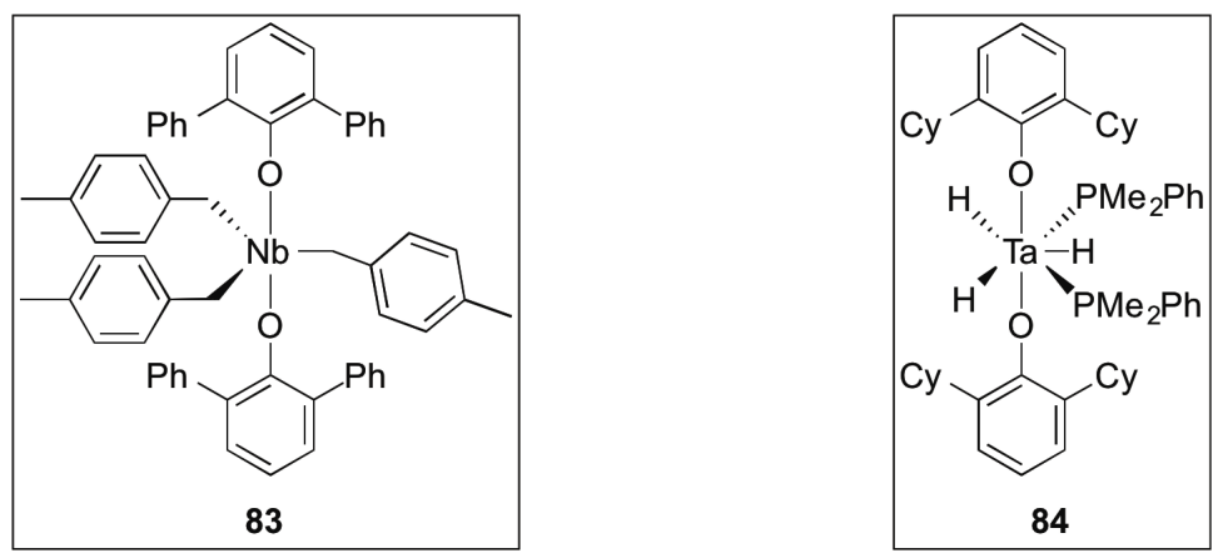

Scheme 95. Hydrogenation of naphthalene (top) and anthracene (bottom) catalyzed by $\mathbf{8 3}$ or 84.
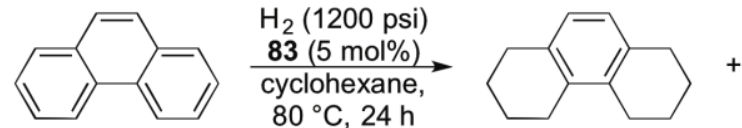

$78 \%$

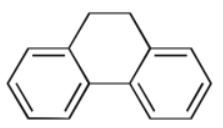

$22 \%$

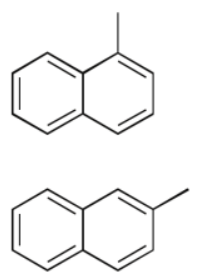

$$
\begin{aligned}
& \underset{\mathrm{H}_{2}(1200 \mathrm{psi})}{83(5 \mathrm{~mol} \%)} \\
& \underset{\mathrm{cyclohexane},}{80^{\circ} \mathrm{C}, 24 \mathrm{~h}}
\end{aligned}
$$<smiles>Cc1cccc2c1CCCC2</smiles>

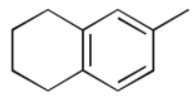

$>95 \%$

(NMR yield)

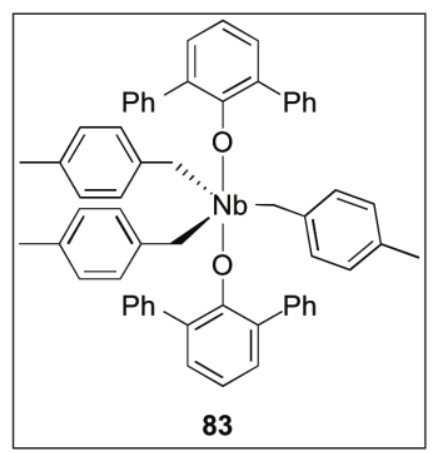

Scheme 96. Hydrogenation of phenanthrene (top) and 1- and 2-methylnaphthalene (bottom) catalyzed by $\mathbf{8 3}$. 


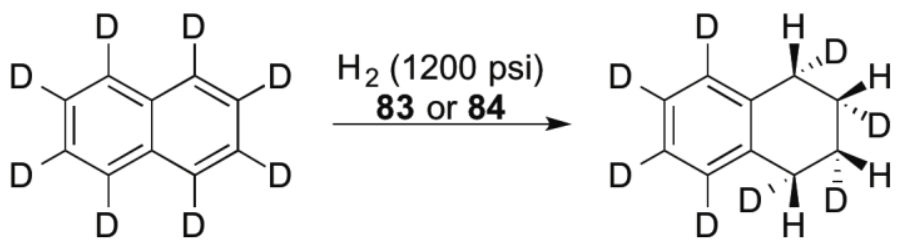<smiles>[2H]c1c([2H])c([2H])c2c([2H])c3c([2H])c([2H])c([2H])c([2H])c3c([2H])c2c1[2H]</smiles>

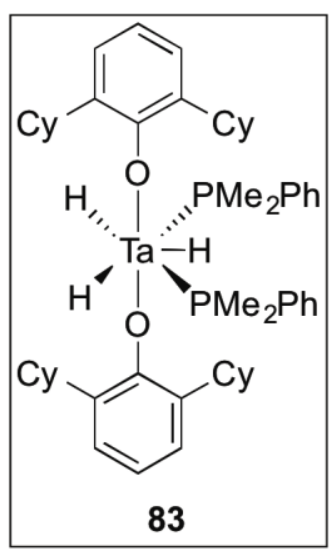<smiles>Cc1ccc(CN(Cc2ccc(-c3ccccc3)cc2)[N+](Cc2ccccc2)(Oc2c(-c3ccccc3)cccc2-c2ccccc2)c2ccccc2)cc1</smiles>

Scheme 97. Hydrogenation of perdeutero-labeled substrates catalyzed by $\mathbf{8 3}$ or $\mathbf{8 4}$ demonstrating all-cis hydrogen addition.

In addition to polycyclic arenes, $\mathbf{8 4}$ was also found to be remarkably effective for hydrogenation of aryl phosphines to their cycloalkyl counterparts (Scheme 98) [132]. In particular, the aryl groups of monodentate phosphines were reduced sequentially at successively slower rates; in contrast, those of bidentate substrates appeared to be jointly reduced to the final product through a single interaction with the catalyst [133]. 
<smiles>CP(c1ccccc1)c1ccccc1</smiles>

$\mathrm{Ph}_{2} \mathrm{P} \widehat{\mathrm{PPh}_{2}}$<smiles>CC(CP)(CP)CP(c1ccccc1)c1ccccc1</smiles>

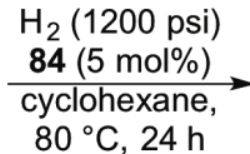

$\mathrm{H}_{2}$ (1200 psi)

$\underset{\text { cyclohexane, }}{\stackrel{84(4 \mathrm{~mol} \%)}{\longrightarrow}}$ $100{ }^{\circ} \mathrm{C}, 96 \mathrm{~h}$

$$
\begin{aligned}
& \mathrm{H}_{2}(1200 \mathrm{psi}) \\
& 84(21 \mathrm{~mol} \%) \\
& \hline \text { cyclohexane, } \\
& 100^{\circ} \mathrm{C}, 48 \mathrm{~h}
\end{aligned}
$$<smiles>CP(C1CCCCC1)C1CCCCC1</smiles>

$>99 \%$ (NMR yield)

$$
\begin{gathered}
\mathrm{Cy}_{2} \mathrm{P} \mathrm{PCy}_{2} \\
96 \% \\
\text { (isolated yield) }
\end{gathered}
$$<smiles>CCCCPCC(C)(CP)CP</smiles>

$85 \%$

(isolated yield)

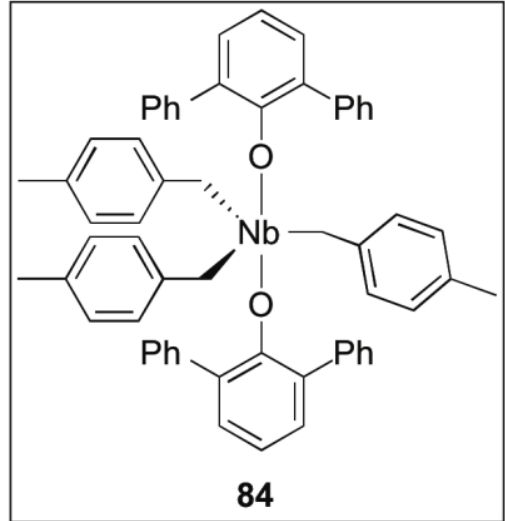

84

Scheme 98. Hydrogenation of various aryl phosphines catalyzed by 84 .

While the exact mechanism of hydrogenation by these niobium and tantalum hydride catalysts remains unelucidated, Rothwell has independently synthesized a number of potential catalytic intermediates or analogues thereof. These include $\eta^{4}$-complexes, such as 85 (Fig. 11), formed between the metal chlorides and 1,3-cyclohexadiene under reducing conditions $[134,135]$. Significantly, the cyclohexadiene ligand binds tightly to the metal center in these species; the authors attribute the strength of this interaction as the cause of the all-cis stereochemistry previously observed, as it largely prevents substrate-catalyst dissociation during hydrogen addition. Indeed, 85 was found to catalyze hydrogenation of 1,3-cyclohexadiene directly to cyclohexane without release of intermediary cyclohexene (Scheme 99).

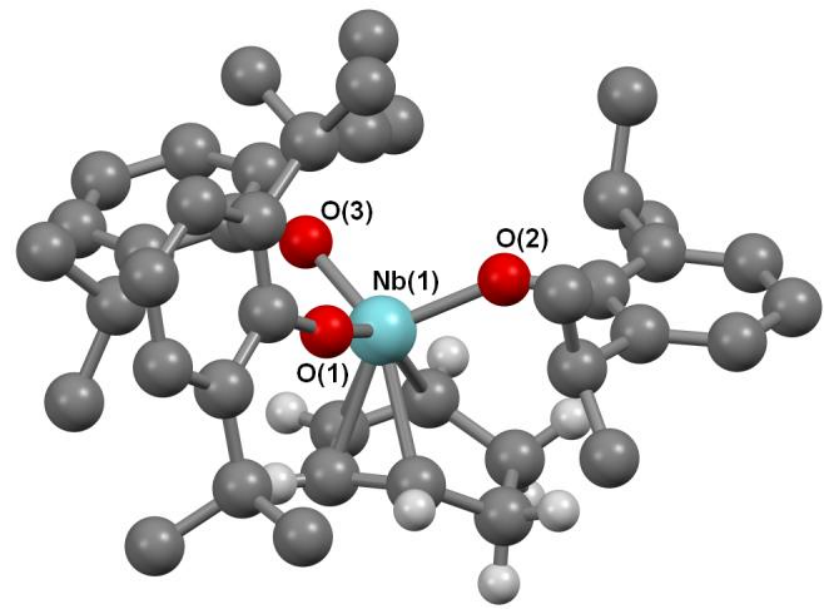

Fig. 11. Ball-and-stick representation of $\eta^{4}-1,3$-cyclohexadiene (triaryloxy)niobium complex 85, generated with the program Mercury using crystallographic data retrieved from the Cambridge Crystal Structure Database (Refcode ZOGYAV); structural 
information originally provided in Ref. 134. Aryloxy ligand hydrogen atoms omitted for clarity. The corresponding tantalum complex is isomorphous.<smiles>C1=CCCC=C1</smiles>

$$
\begin{gathered}
\underset{\mathrm{H}_{2}(900 \mathrm{psi})}{85(2 \mathrm{~mol} \%)} \\
\stackrel{\underset{\text { benzene }}{\longrightarrow}}{25^{\circ} \mathrm{C}, 5 \mathrm{~h}}
\end{gathered}
$$<smiles>C1CCCCC1</smiles>

$100 \%$

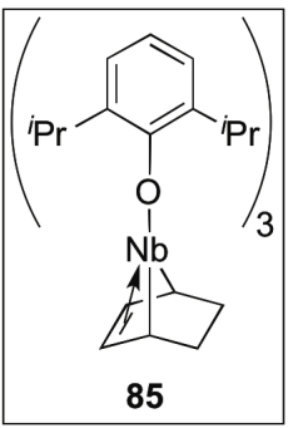

Scheme 99. Hydrogenation of 1,3-cyclohexadiene catalyzed by 85 .

While $\mathrm{Nb}$ or Ta complexes with cyclohexene itself have not been reported, an analogous $\eta^{2}$-styrenyl tantalum complex (86; Fig. 12) has been formed by addition of two equivalents of styrene to the tantalum dihydride 87 (Scheme 100) [136]. Notably, 86 released ethylbenzene and reformed $\mathbf{8 7}$ when placed under a hydrogen atmosphere, thus closing a potential catalytic cycle. Indeed, catalytic amounts of $\mathbf{8 7}$ were found to hydrogenate styrene to ethylbenzene with modest turnover frequencies.

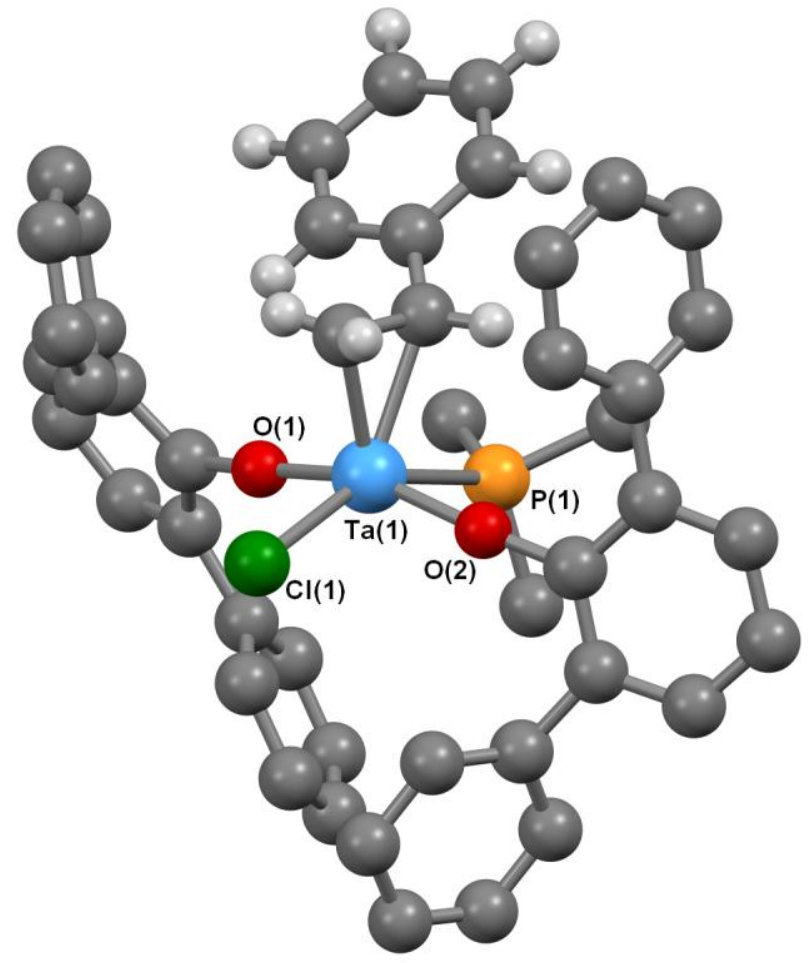

Fig. 12. Ball-and-stick representation of $\mathbf{8 6}$ generated with the program Mercury using crystallographic data retrieved from the Cambridge Crystal Structure Database (Refcode YIYWIM); structural information originally provided in Ref. 136. Phosphine and aryloxy ligand hydrogen atoms are omitted for clarity. 


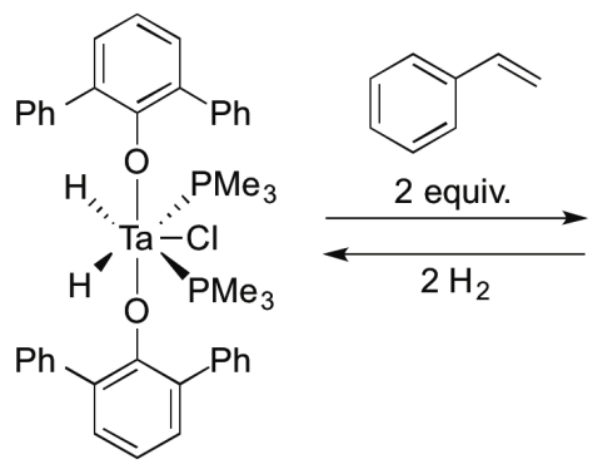

87

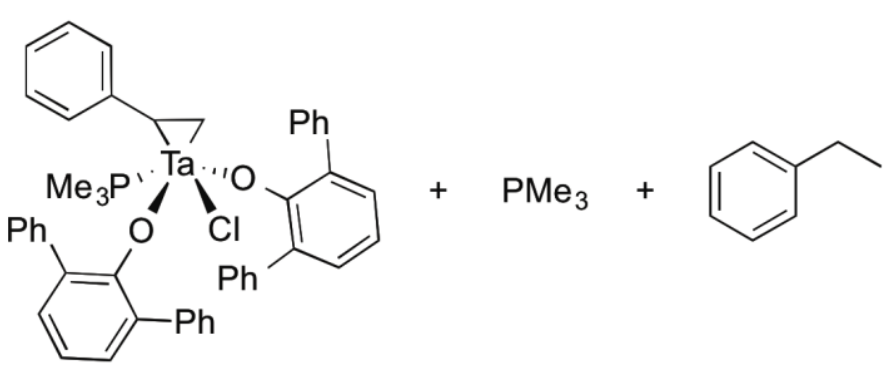

86

Scheme 100. Hydrogenation of styrene catalyzed by 86 .

Lastly, a cyclohexyl-tantalum complex (88) was synthesized by the stoichiometric reaction of a tantalum dihydride (89) with 1,3-cyclohexadiene (Scheme 101) [135]. Intriguingly, the third requisite hydride equivalent was produced by oxidative addition into the $\mathrm{C}-\mathrm{H}$ bond of a phenoxide ligand's tert-butyl substituent, ultimately resulting in cyclometallation.<smiles>CC(C)(C)c1cccc(C(C)(C)C)c1O[IH+](Cl)Oc1c(C(C)(C)C)cccc1C(C)(C)C</smiles>

89

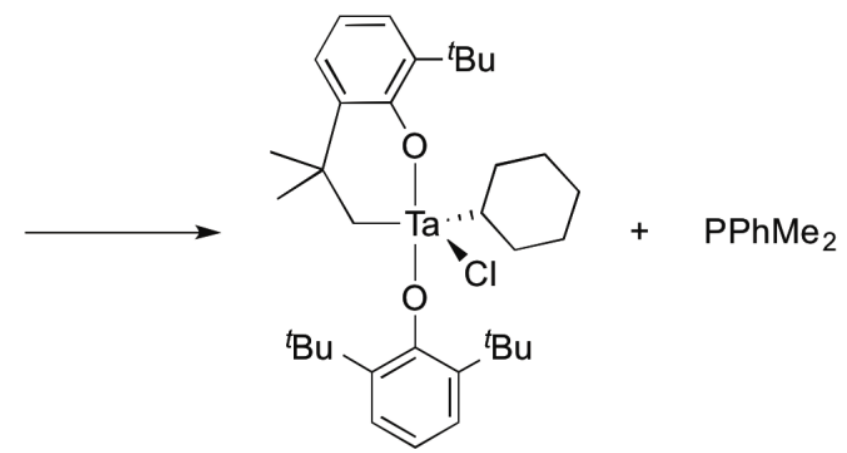

87

Scheme 101. Formation of a cyclohexyl-tantalum complex (88) from addition of 1,3cyclohexadiene to $\mathbf{8 9}$.

\subsection{Rhodium}

In 1983, Ziółkowski [137] reported the reduction of benzene by $\mathrm{Rh}(\mathrm{acac})\left[\mathrm{P}(\mathrm{OPh})_{3}\right]_{2}$ with moderate catalyst turnover (TOF $=294 \mathrm{~h}^{-1} ;$ Scheme 102). That same year, Halpern [138] demonstrated the cationic rhodium species $\left[\mathrm{Rh}(\mathrm{dppe})(\mathrm{MeOH})_{2}\right]^{+}(\mathbf{9 0})$ [139] could act as a precursor for polycyclic aromatic hydrogenation. Specifically, ${ }^{1} \mathrm{H}$ and ${ }^{31} \mathrm{P}$ NMR analyses revealed 90 in the presence of naphthalene and anthracene to form an equilibrium with the corresponding $\eta^{6}$-arene complexes (Scheme 103). Under hydrogen pressure, this equilibrium system catalyzed reduction of the coordinated aromatic ring to form 1,2,3,4-tetrahydro products.

$$
\frac{\begin{array}{c}
\mathrm{H}_{2}(10 \mathrm{~atm}[150 \mathrm{psi}]) \\
\left.\mathrm{Rh}(\mathrm{acac})\left[\mathrm{P}(\mathrm{OPh})_{3}\right)\right]_{2}(0.006 \mathrm{~mol} \%)
\end{array}}{80^{\circ} \mathrm{C}}
$$


Scheme 102. Hydrogenation of benzene catalyzed by $\mathrm{Rh}(\mathrm{acac})\left[\mathrm{P}(\mathrm{OPh})_{3}\right]_{2}$.

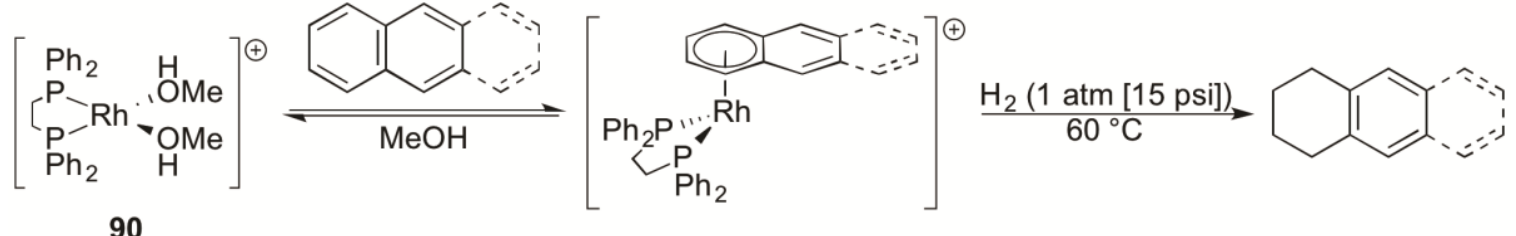

Scheme 103. Equilibrium formation of $\eta^{6}$-arene complexes from 90 and subsequent hydrogenation. Counteranions omitted for clarity.

Measurement of the initial rates of hydrogenation yielded the following rate equation [138]:

$$
-\frac{d[\text { arene }]}{d t}=k\left[\{\mathrm{Rh}(\mathrm{dppe})(\text { arene })\}^{+}\right]\left[\mathrm{H}_{2}\right]
$$

Based on these results, the authors proposed oxidative addition to $\mathrm{H}_{2}$ to be the ratedetermining step (Scheme 104, step iii). Notably, this process requires a preceding haptotropic shift of the arene ligand from $\eta^{6}$ to $\eta^{4}$; such a shift is expected to be more facile for anthracene than naphthalene, and indeed, the observed rate of anthracene hydrogenation is approximately nine times that of naphthalene $\left(k=5.3 \times 10^{-2}\right.$ versus 6.0 $\times 10^{-3} \mathrm{M}^{-1} \mathrm{~s}^{-1}$ respectively). The formation of free 1,2-dihydro intermediates (Scheme 104, step $\mathrm{v}$ ) is consistent with studies of diene hydrogenation by related $\left[\mathrm{Rh}(\mathrm{nbd}) \mathrm{L}_{2}\right]^{+}$catalysts [140]. As 90 is also significantly active for alkene hydrogenation $\left(k=2.2 \mathrm{M}^{-1} \mathrm{~s}^{-1}\right.$ for 1,2dihydronaphthalene), however, such partially reduced products were not actually isolated. 


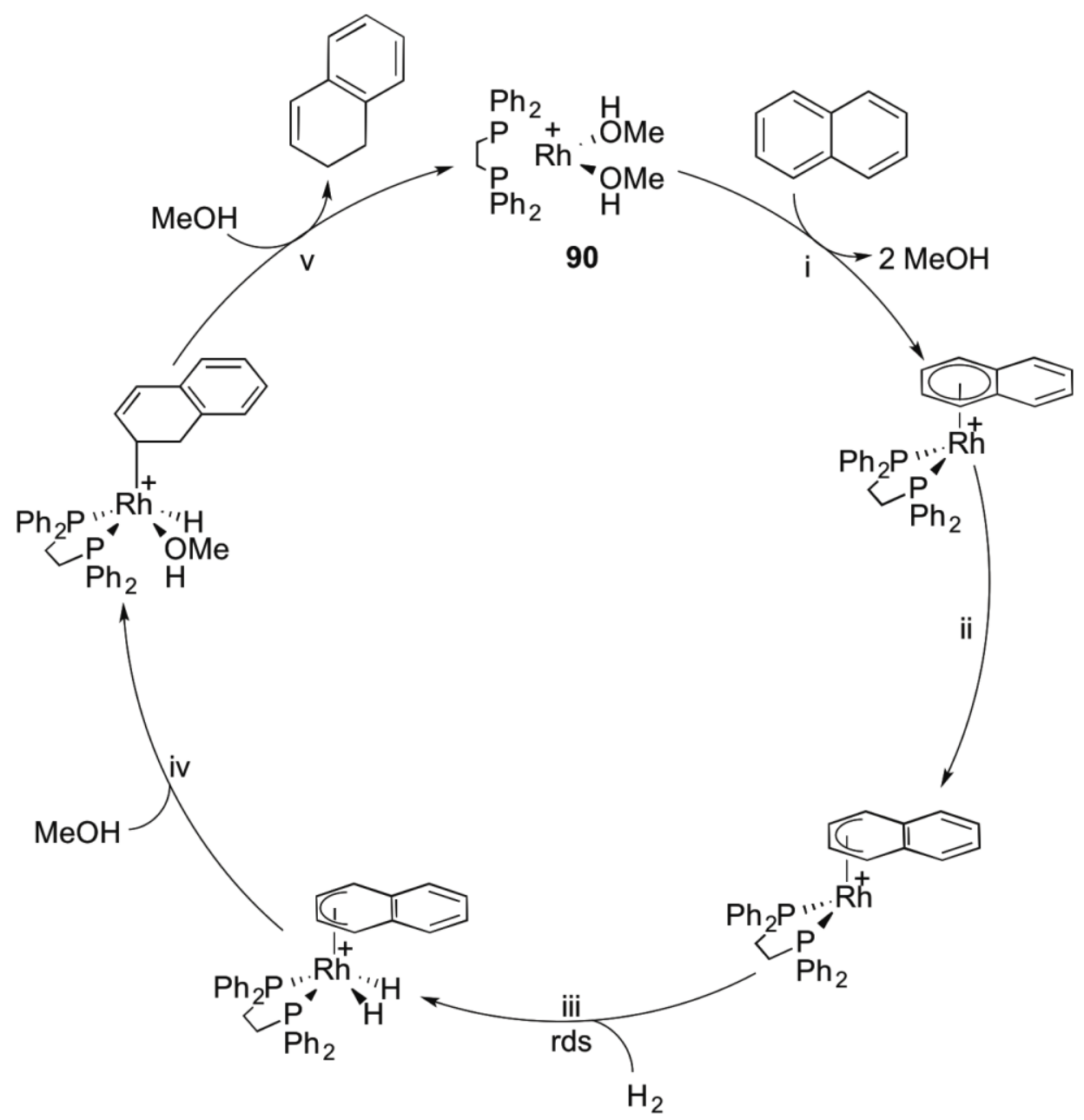

Scheme 104. Proposed catalytic cycle for initial hydrogen addition to polycyclic arenes catalyzed by 90 (shown for naphthalene to 1,2-dihydronaphthalene). Counteranions omitted for clarity.

\subsection{Ruthenium}

In 1977, Muetterties [141] discovered $\mathrm{Ru}\left(\mathrm{C}_{6} \mathrm{Me}_{6}\right)_{2}$ to serve as one of the first homogeneous catalysts for hydrogenation of benzene and certain other derivatives. Catalyst activity was admittedly low, exhibiting a maximum turnover frequency of $6 \mathrm{~h}^{-1}$. Cyclohexene formation was also significant (5-40\%). After 10 hours at $90{ }^{\circ} \mathrm{C}$ under mild hydrogen pressure (2-3 atm [30-45 psi]), the catalyst was recovered quantitatively, lending support to the assertion of homogeneity. Muetterties proposed a reaction mechanism similar to that devised for the allyl-cobalt catalyst 80 (Scheme 105) [142]. The initial $\eta^{6}-\eta^{4}$ mixed species first shifts hapticity to a coordinatively unsaturated bis $-\eta^{4}$ species. Oxidative addition to $\mathrm{H}_{2}$ followed by ligand exchange gives a mixed arene dihydridoruthenium(II) intermediate (91). Hydride addition followed by reductive elimination then gives the cyclohexadienyl-ligated complex 92. Repetition of these steps ultimately leads to the formation of the fully reduced cyclohexane products. 

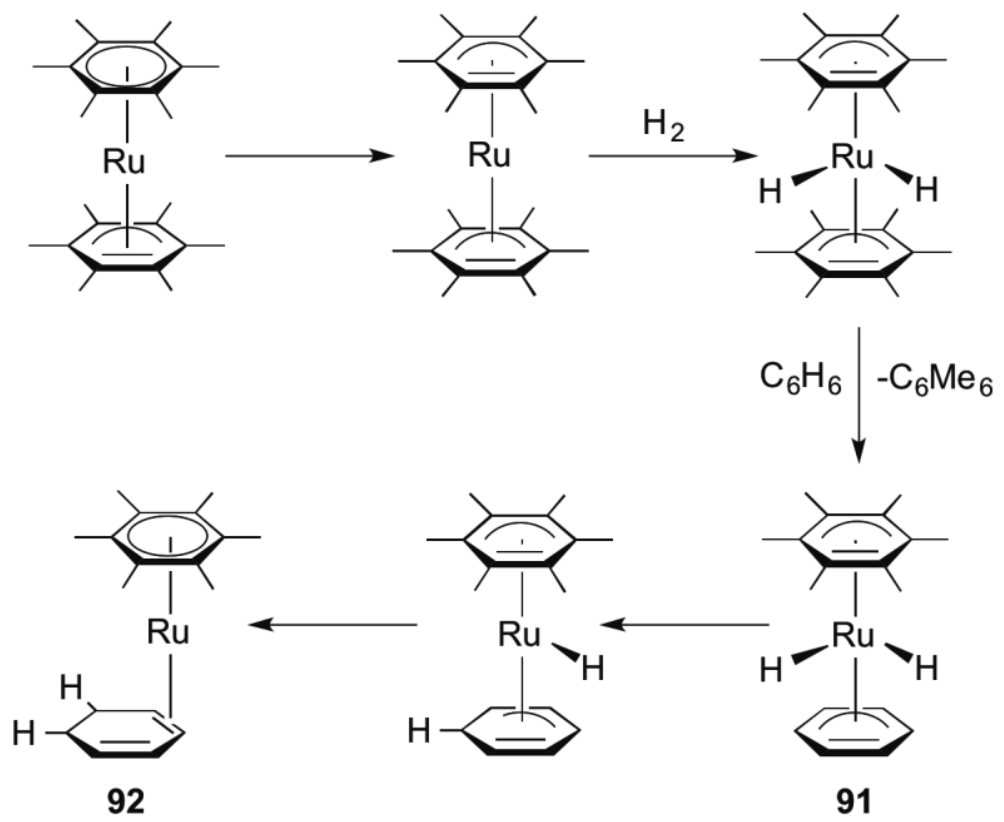

Scheme 105. Proposed reaction pathway for benzene hydrogenation catalyzed by $\mathrm{Ru}\left(\mathrm{C}_{6} \mathrm{Me}_{6}\right)_{2}$.

In 1983, Halpern [143] found that cyclometallated, anionic 93 and related trihydride 94 catalyzed hydrogenation of the outer rings of anthracene (Scheme 106). Stoichiometric experiments showed that treating the cyclometallated complex 93 with $\mathrm{H}_{2}$ produced ruthenium trihydride 94 . Starting from 94, the catalytic cycle presumably proceeds first through phosphine displacement by anthracene, hydride insertion, and reductive elimination to form a $\eta^{2}$-dihydroanthracene-ligated 95 (Scheme 106, step i). Oxidative addition to $\mathrm{H}_{2}$ and another hydride insertion-reductive elimination sequence then afford the 1,2,3,4-tetrahydroanthracene product. 
<smiles>[H][Y]([H])(P)[R](P)(c1ccccc1)c1ccccc1</smiles>

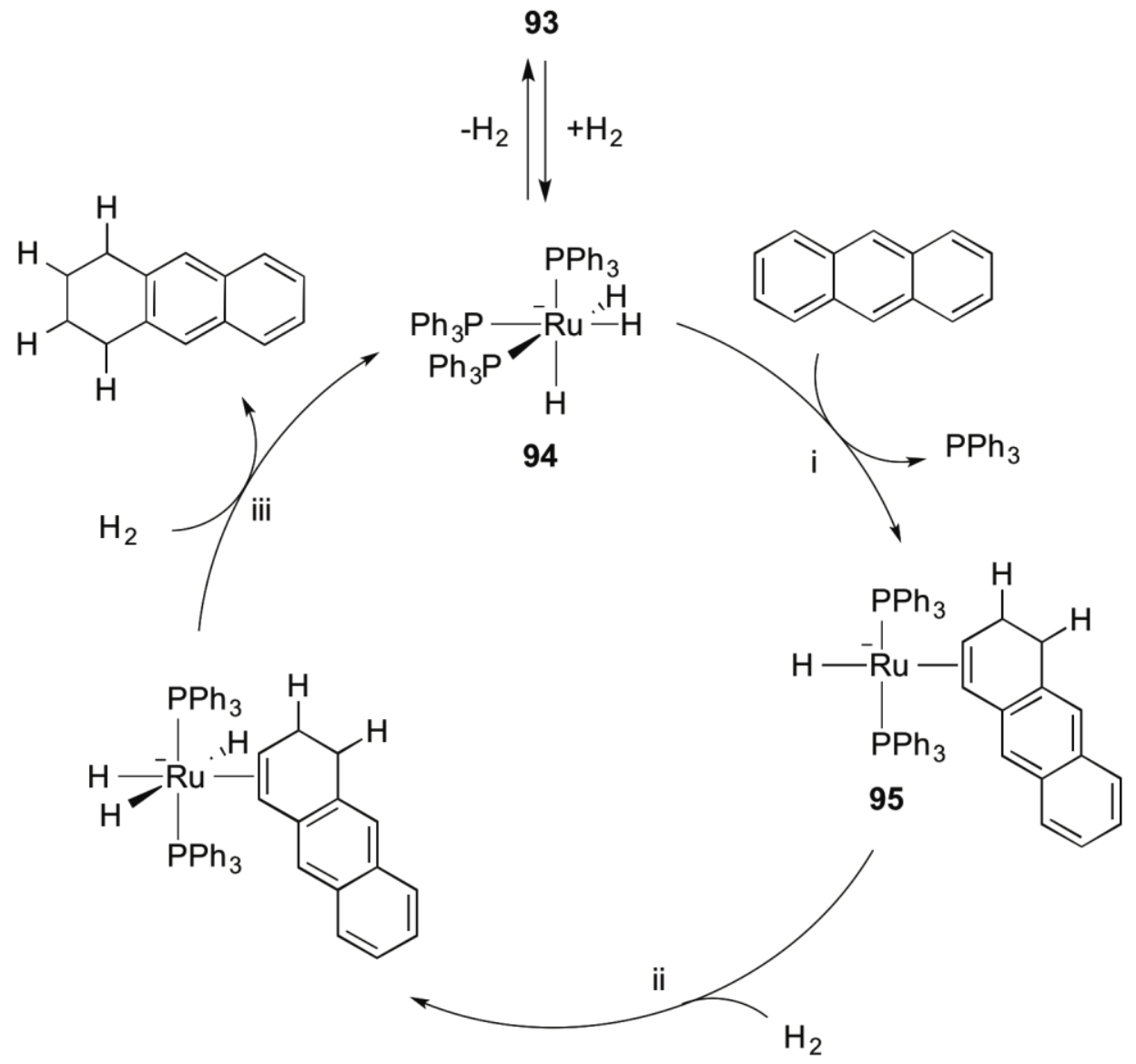

Scheme 106. Proposed catalytic cycle for hydrogenation of anthracene catalyzed by 94 . Counteranions omitted for clarity.

Halpern [144] also found neutral complex 96 effective in the hydrogenation of 9methylanthracene to produce both 9-methyl-1,2,3,4-tetrahydro- and 9-methyl$1,2,3,4,5,6,7,8$-octahydroanthracene (Scheme 107, top). As the ratio of these two products remained constant throughout the course of the reaction, Halpern concluded the tetrahydro product could not be an intermediate in the formation of the octahydro product [144]. In 2001, Borowski and Sabo-Etienne also hydrogenated the outer rings of anthracene using 97 (Scheme 107, bottom). ${ }^{23}$ In contrast to Halpern's observations, they found under their conditions that tetrahydroanthracene could indeed act as an intermediate toward formation of octahydroanthracene.

${ }^{23}$ Notably, this catalyst system was poisoned by mercury when used for benzene hydrogenation. A comparative poisoning experiment was not performed, however, for catalytic hydrogenation of naphthalene or anthracene. 
<smiles>Cc1c2ccccc2cc2ccccc12</smiles>
$\mathrm{H}_{2}, 96$ toluene, $55^{\circ} \mathrm{C}$<smiles>Cc1c2c(cc3ccccc13)CC1CCC2C1</smiles>

$+$

$5: 1$<smiles></smiles>
$\mathrm{PPh}_{3}$ $\mathrm{H}, \mathrm{PPP}_{3}$ $\mathrm{H}^{-\mathrm{Ru}} \boldsymbol{\nabla}_{\mathrm{H}_{2}}$ $\mathrm{PPh}_{3}$ 96
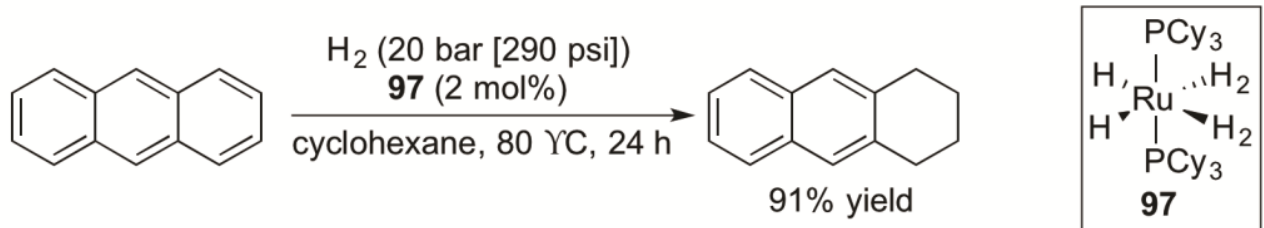

Scheme 107. Hydrogenation of 9-methylanthracene (top) and anthracene (bottom) catalyzed by 96 and 97 respectively.

Borowski and Sabo-Etienne [145] also used 97 to selectively hydrogenate the carbocyclic rings of acridine, quinoline, and isoquinoline (Scheme 108). In the case of acridine, carbocyclic hydrogenation occurred using either 97 or $\eta^{4}-\mathrm{C}_{4}$ acridine-ligated $\mathbf{9 8}$, leading the authors to propose the involvement of both species in the catalytic cycle (Scheme 109) [146]. Interestingly, reaction of indole [145] and benzothiophene [147] under the standard conditions resulted in hydrogenation of the heterocyclic rings (Scheme 108). Pyridine and pyrroles [145] and dibenzothiophene [147] could not be hydrogenated at all. 


$$
\text { Substrate } \frac{\mathrm{H}_{2}(3 \mathrm{bar}[45 \mathrm{psi}])}{97(2 \mathrm{~mol} \%)} \underset{\text { Products }}{\stackrel{\text { cyclohexane, } 80 \mathrm{YC}, 24 \mathrm{~h}}{\text { (GC Yield) }}}
$$<smiles>c1ccc2ncccc2c1</smiles><smiles>c1cnc2c(c1)CCCC2</smiles>

$(99 \%)$<smiles>c1ccc2cnccc2c1</smiles><smiles>c1cc2c(cn1)CCCC2</smiles>

(89\%)<smiles>c1ccc2nc3ccccc3cc2c1</smiles><smiles>c1ccc2nc3c(cc2c1)CCCC3</smiles>

$(50 \%)$<smiles>c1c2c(nc3c1CCCC3)CCCC2</smiles>

$(47 \%)$<smiles>c1ccc2[nH]ccc2c1</smiles><smiles>c1ccc2c(c1)CCN2</smiles><smiles>c1ccc2sccc2c1</smiles><smiles>c1ccc2c(c1)CCS2</smiles>

Unreactive substrates<smiles>c1ccncc1</smiles><smiles>c1ccc2c(c1)sc1ccccc12</smiles>

Scheme 108. Carbocyclic hydrogenation of various $N$-heteroarenes catalyzed by 97 and heterocyclic hydrogenation of indole and benzothiophene. 


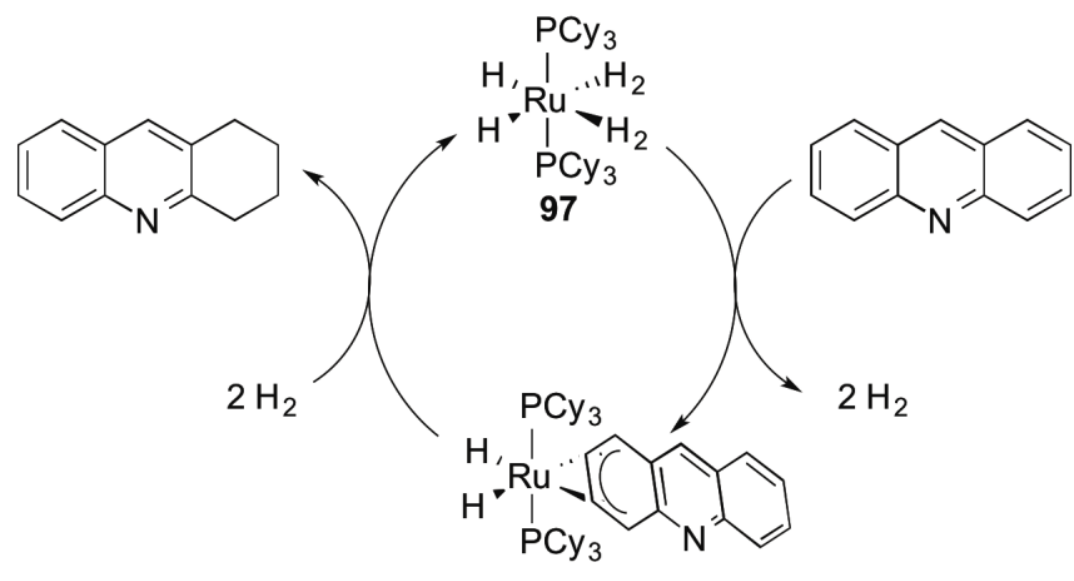

98

Scheme 109. Proposed catalytic cycle for carbocyclic hydrogenation of acridine catalyzed by 97.

In 2002, Dyson reported the hydrogenation of various alkyl-substituted benzenes with triphos-ligated ruthenium complex 99 (Scheme 110). Turnover frequencies were strongly affected by steric bulk (benzene TOF $=476 \mathrm{~h}^{-1}$ versus $n$-butylbenzene TOF $=84$ $\mathrm{h}^{-1}$ ). Non-conjugated olefins were unaffected by the reaction conditions; allylbenzene proved almost as reactive as benzene itself, with no hydrogenation of the exocyclic double bond observed. Styrene, however, was almost completely unreactive.

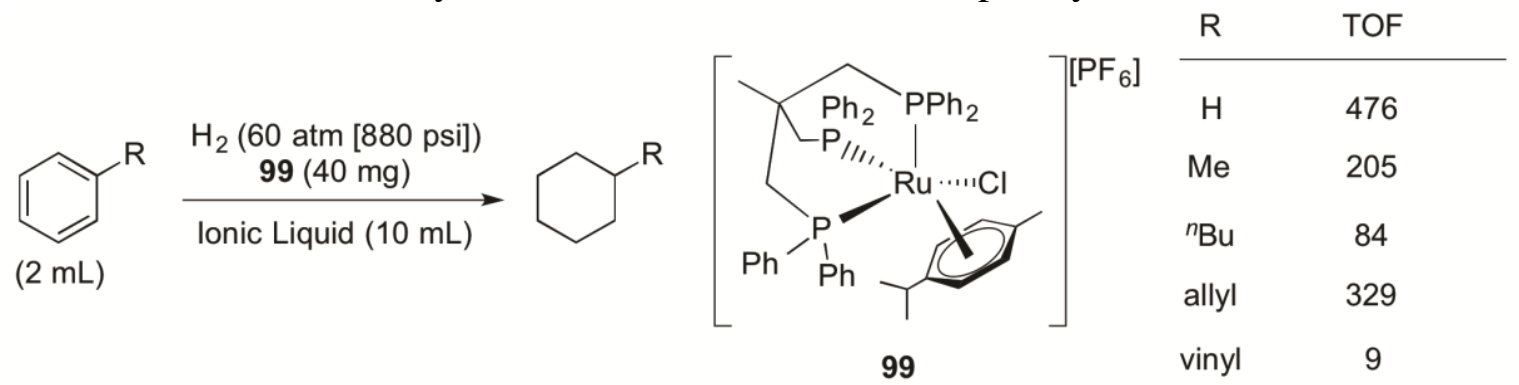

Scheme 110. Hydrogenation of substituted benzenes catalyzed by 99 in ionic liquid. TOF calculated as moles substrate converted per mole catalyst per hour.

In 2011, Glorius [148] demonstrated that the choice of ancillary NHC ligand could control the regioselectivity of ruthenium-catalyzed hydrogenation of quinoxalines; 2,6-(diisopropyl)phenyl-substituted NHC precursor 100 led to selective heterocyclic hydrogenation, while cyclohexyl-substituted NHC precursor 101 yielded carbocyclic hydrogenation (Scheme 111). Carbocyclic hydrogenation of quinoxalines is exceedingly rare; to our knowledge, Glorius's system represents the only homogeneous catalytic hydrogenation to produce exclusively the 5,6,7,8-tetrahydroquinoxaline. 


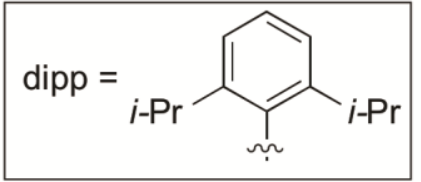<smiles>[O-][Mg]N1CCN(c2ccccc2)CC1</smiles>
100<smiles>Cc1ccc2nc(-c3ccccc3)c(-c3ccccc3)nc2c1</smiles>

101<smiles>[AlH2]</smiles><smiles>CC1CCc2nc(-c3ccccc3)c(-c3ccccc3)nc2C1</smiles>

$$
>99 \% \text { yield }
$$

Scheme 111. Regioselective carbo- and heterocyclic hydrogenation of quinoxalines using two different NHC-ligated ruthenium complexes.

Glorius further showed that chiral Ru-NHC catalysts could effect asymmetric hydrogenation of quinoxaline carbocyclic rings (Scheme 112). The enantioselectivity was reduced, however, when quinoxaline substituents were especially bulky, electron withdrawing, or in the 5-position instead of the 6-position.
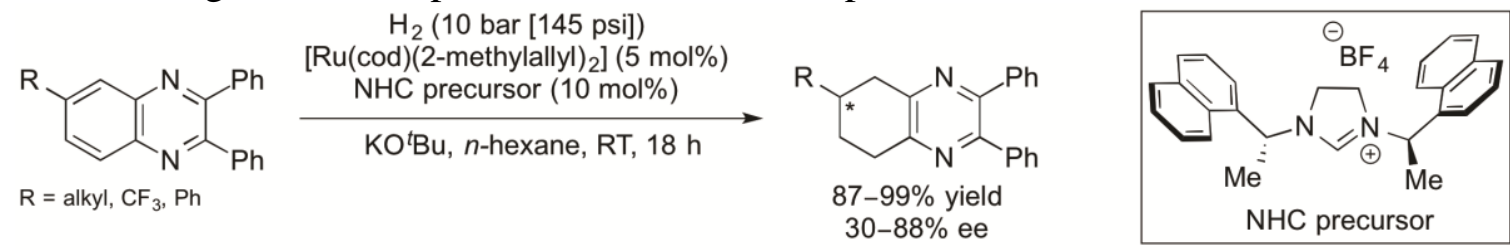

Scheme 112. Asymmetric carbocyclic hydrogenation of quinoxalines.

In 2012, Kuwano [149] used a Ru-PhTRAP catalyst in the asymmetric hydrogenation of 2,6- and 2,7-dialkoxy substituted naphthalenes (Scheme 113, top). Using the same catalyst system, Kuwano also used a similar catalyst system to selectively hydrogenated the carbocyclic ring in 8-substituted quinolines (Scheme 113, bottom) [150]. Hydrogenation of 5,6-dihydro-8-phenylquinoline proceeded with low stereoselectivity; Kuwano thus concluded that stereoinduction must accompany the disruption of aromaticity in the carbocyclic ring. 
<smiles>[R]Oc1ccc2cc([R20])ccc2c1</smiles>

$\mathrm{H}_{2}(50$ atm [735 psi])

[RuCl( $p$-cymene $)\{$ PhTRAP $\}[\mathrm{Cl}](2 \mathrm{~mol} \%)$

1,1,3,3-tetramethylguanidine (20 mol\%)<smiles>[R]Oc1ccc2ccc(O[R])cc2c1</smiles>

i- $\mathrm{PrOH}, 100^{\circ} \mathrm{C}, 48 \mathrm{~h}$

$\mathrm{R}=\mathrm{alkyl}$
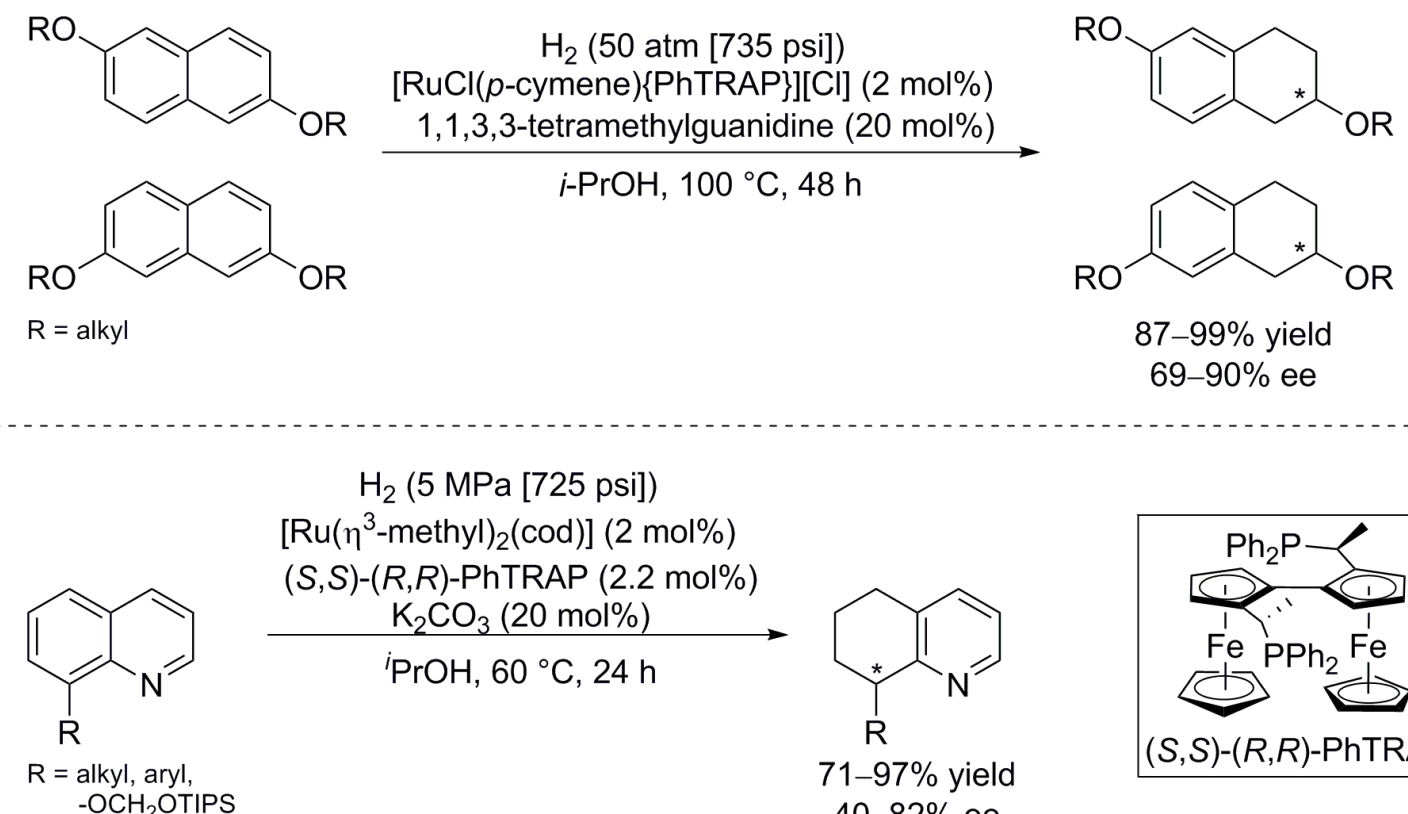

$\mathrm{H}_{2}$ (5 MPa [725 psi])

$\left[\mathrm{Ru}\left(\eta^{3} \text {-methyl }\right)_{2}\right.$ (cod)] (2 mol\%)

$(S, S)-(R, R)$-PhTRAP $(2.2 \mathrm{~mol} \%)$

$\mathrm{K}_{2} \mathrm{CO}_{3}(20 \mathrm{~mol} \%)$

${ }^{i} \mathrm{PrOH}, 60^{\circ} \mathrm{C}, 24 \mathrm{~h}$

alkyl, aryl,
$-\mathrm{OCH}_{2} \mathrm{OTIPS}$

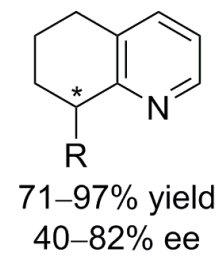

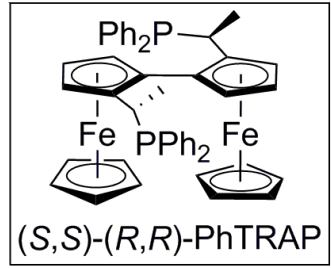

$(S, S)-(R, R)-P h T R A P$

Scheme 113. Asymmetric hydrogenation of 2,6-disubstituted naphthalenes (top) and asymmetric carbocyclic hydrogenation of quinoline (bottom) catalyzed by a Ru-PhTRAP catalyst.

\section{Dehydrogenation}

\subsection{Iridium}

The iridium PCP pincer fragment $\mathbf{1 0 2}$ was reported by Jensen and Kaska [151] in 1996 to perform catalytic transfer dehydrogenation of cycloalkanes such as cyclooctane using tert-butylethylene (TBE) as a hydrogen acceptor. In particular, the tridentate PCP pincer ligand serves to stabilize the catalyst's metal center at the elevated temperatures required for alkane (transfer) dehydrogenation. Soon after, Jensen and Kaska [152] were able to dehydrogenate saturated cyclic compounds such as tetrahydrofuran and cyclohexane to their aromatic homologues, although partially dehydrogenated compounds were also significant components of the product mixture (Scheme 114). Brookhart and Goldman were also able to drive the dehydrogenative cycloaromatization of $n$-alkanes using $\mathbf{1 0 3}$ as the catalyst and TBE as the hydrogen acceptor. $n$-Octane for example was cycloaromatized to a mixture of xylenes and ethylbenzene. Jensen [153] also later demonstrated transfer dehydrogenation as well as acceptorless dehydrogenation of perhydro- $N$-ethylcarbazole using 104 as the catalyst. 


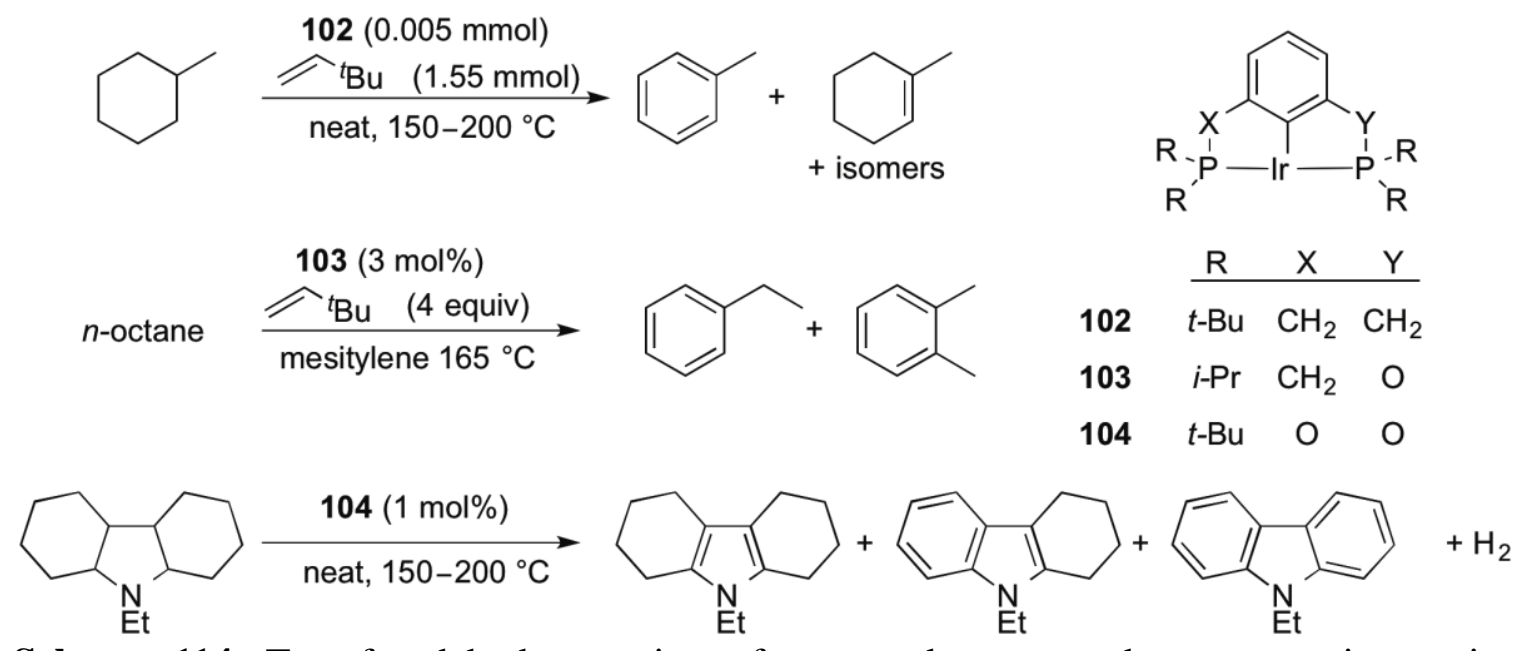

Scheme 114. Transfer dehydrogenation of saturated compounds to aromatic species catalyzed by Ir-PCP pincer catalysts.

The accepted mechanism of alkyl (transfer) dehydrogenation by iridium-PCPtype pincers is shown in Scheme 115 [154,155]. The active iridium(I) fragments 102-104 may be formed in situ from dihydrido or hydridochloride iridium(III) precatalysts, or else they may be generated from alkene-ligated iridium(I) species. The use of a hydrogen acceptor such as TBE or norbornene is often required as the reductive elimination of $\mathrm{H}_{2}$ from the dihydrido complex is generally slow and only occurs appreciably at high temperatures $\left(\sim 200^{\circ} \mathrm{C}\right)$. These high temperatures generally limit the applicability of these reactions to the synthesis of fine chemicals. In terms of creating value-added chemicals from alkane feedstocks though, this work serves as a considerable advancement. 


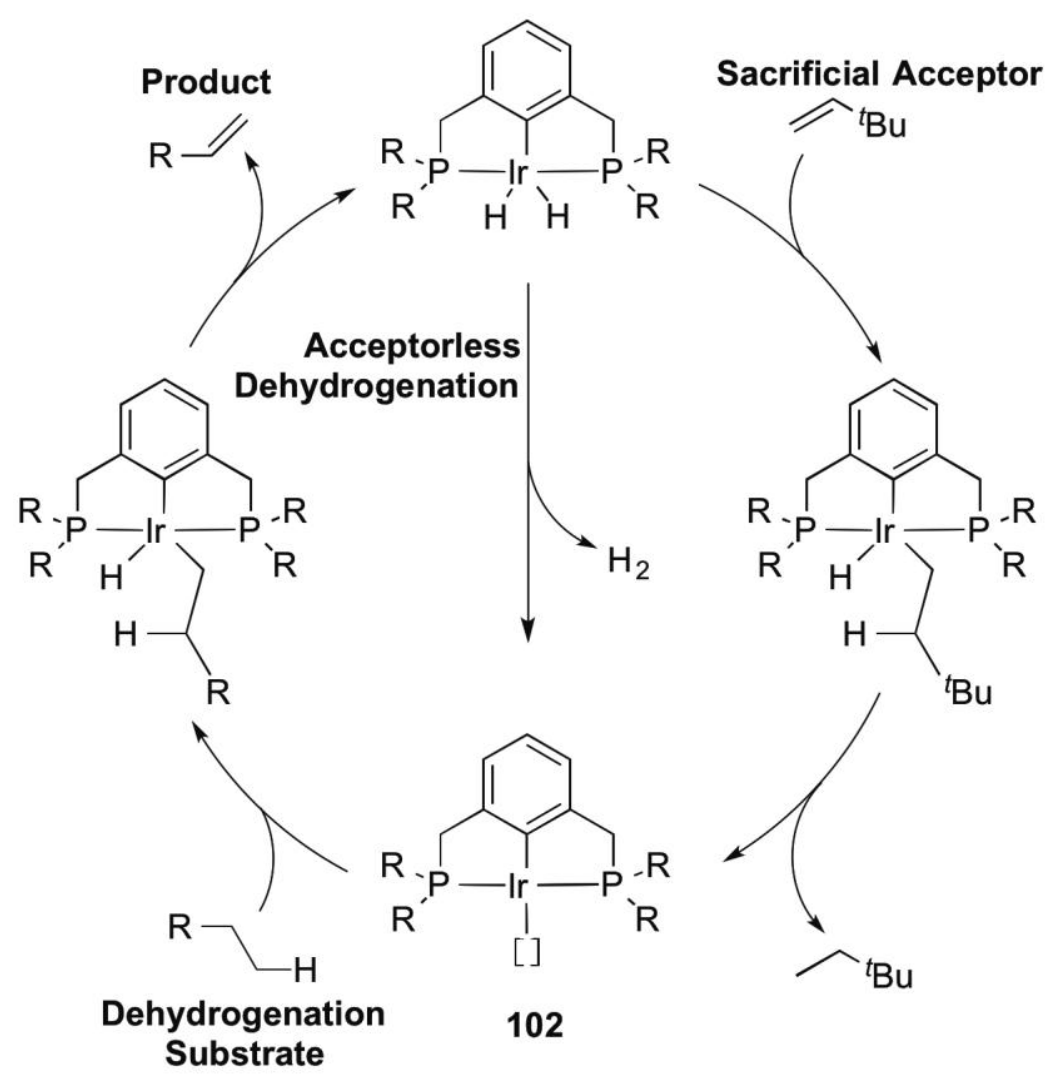

Scheme 115. Mechanism of Ir-PCP-catalyzed transfer dehydrogenation.

\subsection{Nickel}

In 2013, Crabtree [156] reported electrocatalytic dehydrogenation of 2-methyl1,2,3,4-tetrahydroquinoline (Scheme 116 , top) by an $\eta^{5}-\mathrm{CpNi}$ (II) catalyst (105) bearing a quinone-fused NHC ligand. Notably, the redox activity imparted by the quinone moiety was found to manifest independent of its incorporation into the catalyst structure, as the non-quinoid catalyst 106 exhibited comparable activity in the presence of free $p$ benzoquinone (Scheme 116, bottom). 
Pt electrode

$105(0.5 \mathrm{~mol} \%)$

$0.2 \mathrm{M}^{n} \mathrm{Bu}_{4} \mathrm{NF}$

$\mathrm{CH}_{3} \mathrm{CN}, 4 \mathrm{~h}$,

$1 \mathrm{~V}$ vs. NHE

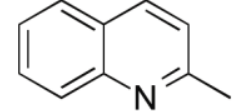

$78 \%$ isolated yield $80 \%$ Faradaic yield

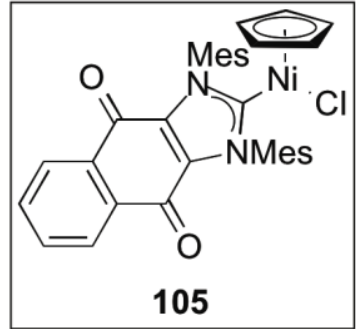

105

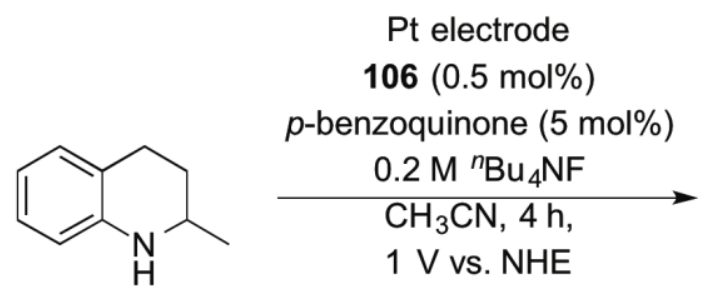<smiles>Cc1ccc2ccccc2n1</smiles>

$68 \%$ isolated yield $90 \%$ Faradaic yield

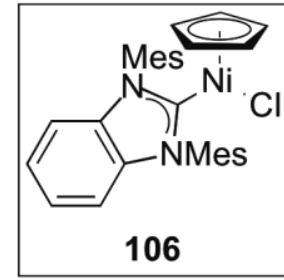

106

Scheme 116. Electrocatalytic dehydrogenation catalyzed by quinone-fused catalyst $\mathbf{1 0 5}$ (top) and non-quinoid catalyst $\mathbf{1 0 6}$ with free quinone (bottom).

5. Reversible systems

\subsection{Iridium}

In 2009, Yamaguchi and Fujita [157] reported reversible hydrogenationdehydrogenation of quinolines using a single iridium catalyst (107; Scheme 117). Hydrogenation proceeded under a single atmosphere of $\mathrm{H}_{2}$, while dehydrogenation required only heating to reflux in $p$-xylene without any hydrogen acceptors. The evolution of $\mathrm{H}_{2}$ was confirmed by the observed hydrogenation of 1-decene in a separate flask connected to the dehydrogenation vessel. The authors hypothesized the reactions occur through the action of a dinuclear, bridging hydride $\left[\mathrm{Cp}^{\star} \operatorname{Ir}(\mathrm{H})(\mathrm{Cl})\right]_{2}$ species as an on- or off-cycle intermediate, based on the observed expulsion of pyridine-2-ol from the catalyst in the presence of $\mathrm{H}_{2}$.
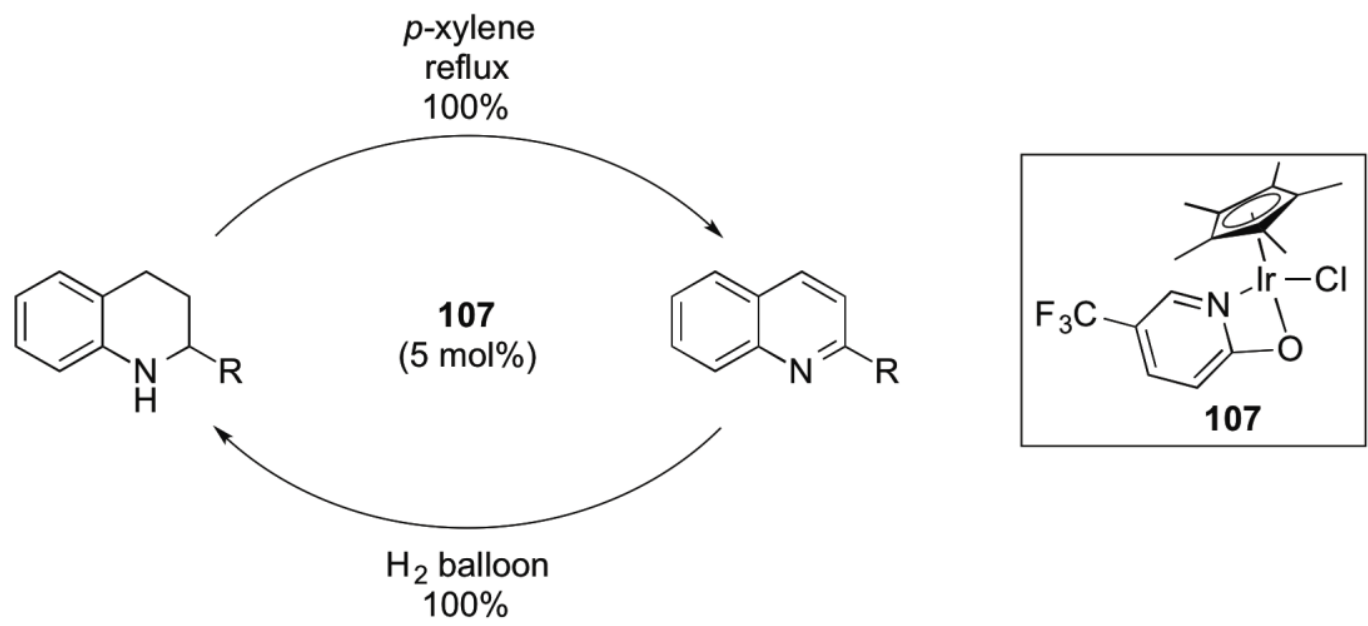

Scheme 117. Reversible hydrogenation-dehydrogenation of 2-substituted quinolines. 
The dehydrogenation cycle of the catalyst has been computationally explored by Zhang [158], whose findings are consistent with experimental observations. The proposed mechanism (Scheme 118) involves significant cooperation from the pyridinone ligand throughout the cycle. Initially, the pyridine-2-ol ligand tautomerizes to its non-aromatic keto-form. Then, the $\mathrm{NH}$ of the incoming tetrahydroquinoline engages in hydrogen bonding with the ligand through the ligand's carbonyl oxygen (step i). This places the adjacent $\mathrm{C}(2)-\mathrm{H}$ in close proximity to the iridium center, such that the simultaneous abstraction of hydride (by the metal) and proton (by the ligand) can occur (step ii). The now-weakly bound 3,4-dihydroquinoline intermediate then dissociates from the metal complex (step iii). Subsequent release of $\mathrm{H}_{2}$ from the complex occurs through combination of the metal hydride and ligand proton (step iv). This cooperative action presents a lower barrier to $\mathrm{H}_{2}$ release compared to that of reductive elimination from IrPCP catalysts (see Section 4.1).

The 3,4-dihydroquinoline intermediate re-enters the catalytic cycle via ligandassisted $\mathrm{C}-\mathrm{H}$ activation in which the hydride ends up on the pyridine-2-ol ligand (step v). The ligand then dissociates from the metal, and engages in hydrogen bonding with the iminic nitrogen atom of the substrate (step vi). This hydrogen bonding encourages $\beta$ hydride elimination (step vii). Subsequent dissociation of the product and re-association of the pyridine-2-ol ligand (step viii) produces an iridium complex that can again undergo cooperative elimination of $\mathrm{H}_{2}$.

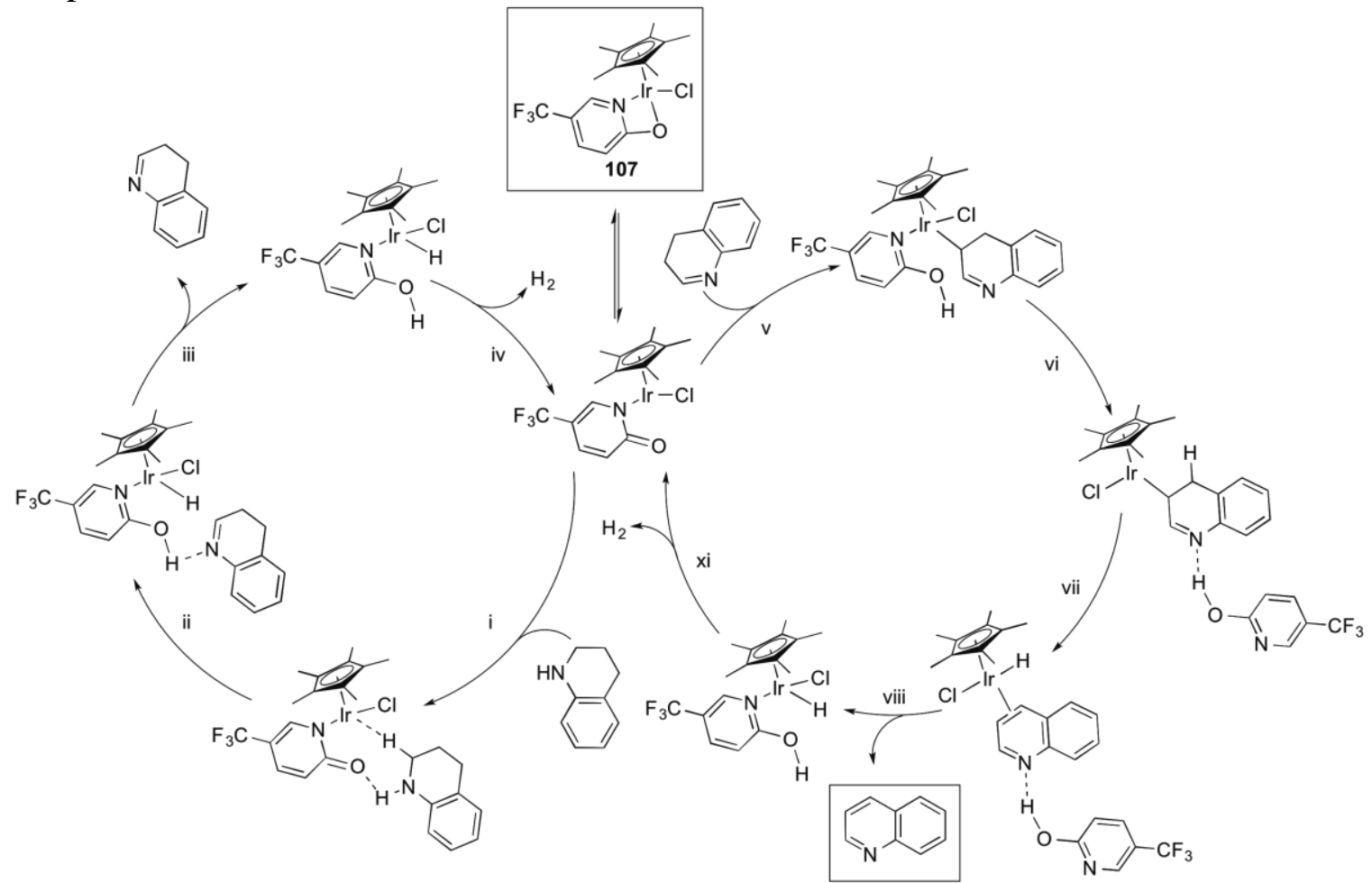

Scheme 118. Proposed catalytic cycle for dehydrogenation of tetrahydroquinoline catalyzed by $\mathbf{1 0 7}$ based on computations.

Yamaguchi and Fujita [159] also demonstrated perhydrogenation- 
perdehydrogenation of 1,5-naphthyridines using another iridium catalyst (108; Scheme 119). In contrast, perhydrogenation of 1,5-naphthyridines cannot be performed with Fan's ruthenium catalyst [101] (see Section 2.3.2). The hydrogenation product was obtained as a mixture of diastereomers, and the dehydrogenation of the mixture proceeded cleanly back to the fully aromatic product. The authors proposed the tetrahydride $\mathrm{Cp}^{\star} \mathrm{IrH}_{4}$ to serve as a possible active catalytic intermediate, since $\mathbf{1 0 8}$ converted to $\mathrm{Cp}^{*} \mathrm{IrH}_{4}$ when exposed to $\mathrm{H}_{2}$ in solution. Furthermore, $\mathrm{Cp}^{*} \mathrm{IrH}_{4}$ was found to be active in the hydrogenation reaction, albeit less so than 108 itself. When $\mathrm{Cp}^{*} \mathrm{IrH}_{4}$ was submitted to the reaction conditions with 2,9-dihydroxy-1,10-phenanthroline as an additive, however, the hydrogenation efficacy was restored.
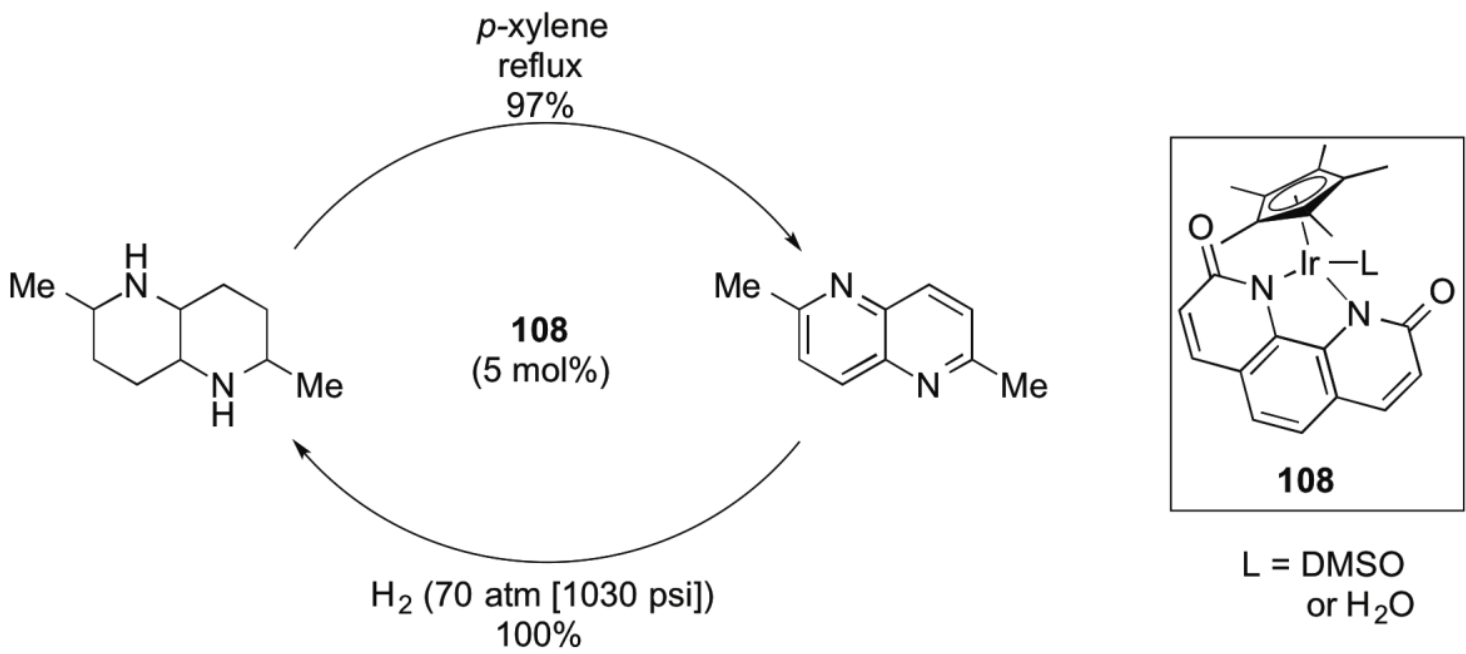

Scheme 119. Reversible hydrogenation-dehydrogenation of 1,5-naphthyridines catalyzed by 108 .

Xiao [160] developed a similarly structured catalyst system (109) for the dehydrogenation of benzofused $N$-heterocycles (Scheme 120). This catalyst could also hydrogenate 1-methylisoquinoline reversibly. The authors note that the mechanism must be distinct from Yamaguchi and Fujita's 107-type catalysts, since solvent $\mathrm{pH}$ was observed to exert a significant influence on activity. Specifically, a protic solvent was required for the reaction, with 2,2,2-trifluoroethanol proving optimal. In contrast, Yamaguchi and Fujita's catalysts $\mathbf{1 0 7}$ and $\mathbf{1 0 8}$ perform best in toluene or xylenes. In subsequent work, Xiao lowered the catalyst loading for the hydrogenation reaction to 1.0 mol\%. Furthermore, the use of a hydrogen-filled balloon was found sufficient to obtain high yields. The scope of the hydrogenation reaction was also expanded to include quinolines and acyclic imines [161]. 

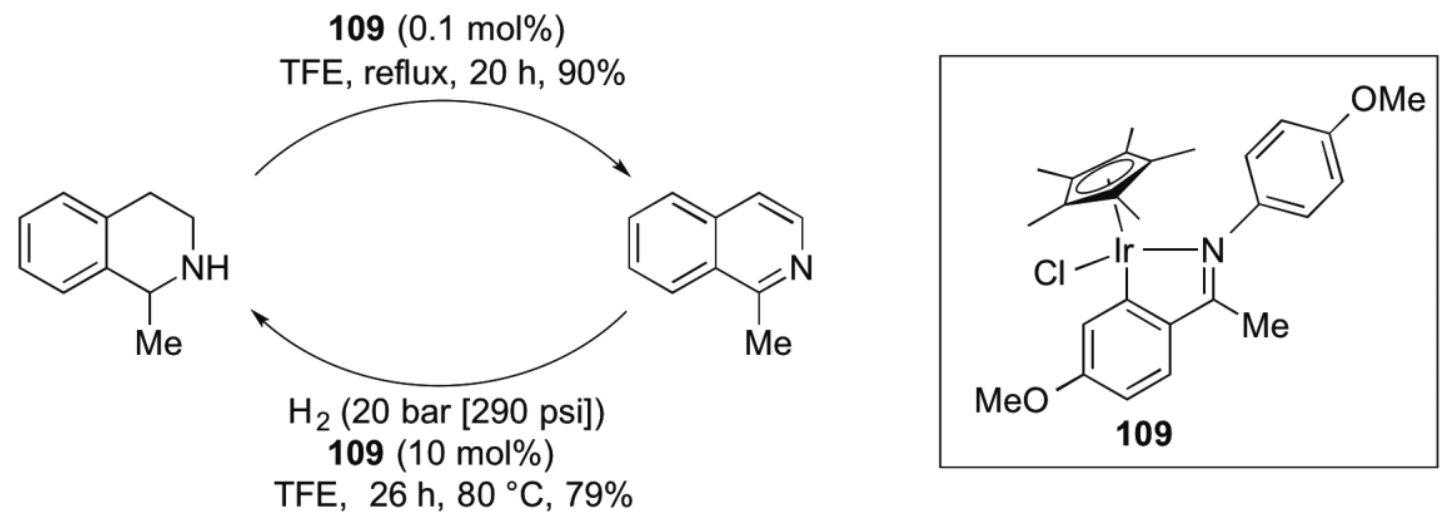

Scheme 120. Reversible hydrogenation-dehydrogenation of 1-methylisoquinoline catalyzed by 109.

Recently, Xiao [162] coupled the dehydrogenation of 2-methyl-1,2,3,4tetrahydroquinoline to an electrophilic $\mathrm{C}-\mathrm{C}$ bond-forming reaction. Specifically, treatment of the in situ-formed enamine with an electrophile such as ethyl 3,3,3trifluoropyruvate led to functionalization of the $\mathrm{C}(2)$ methyl group (Scheme 121).

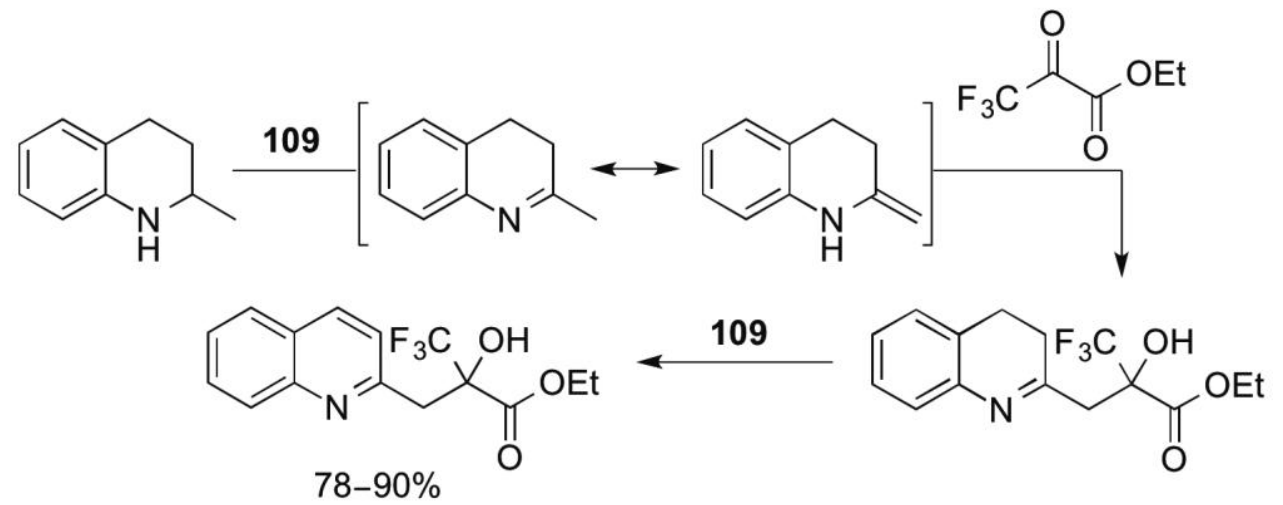

Scheme 121. Dehydrogenative coupling strategy

\subsection{Iron}

In a notable advance, Jones [163] recently reported a single iron-based catalytic system for similarly reversible hydrogenation-dehydrogenation reactions of $\mathrm{N}$ heterocycles. Specifically, the known [164-166] PNP-ligated iron(II) hydride complexes 110 and 111 were found to catalyze dehydrogenation and hydrogenation respectively of (iso)quinoline-, indole-, and pyridine-based substrates (Scheme 122). Product selectivity of both the dehydrogenation and hydrogenation reactions were high, with no partial oxidation observed in the former and no reduction of bicyclic substrates' all-carbon rings in the latter. 

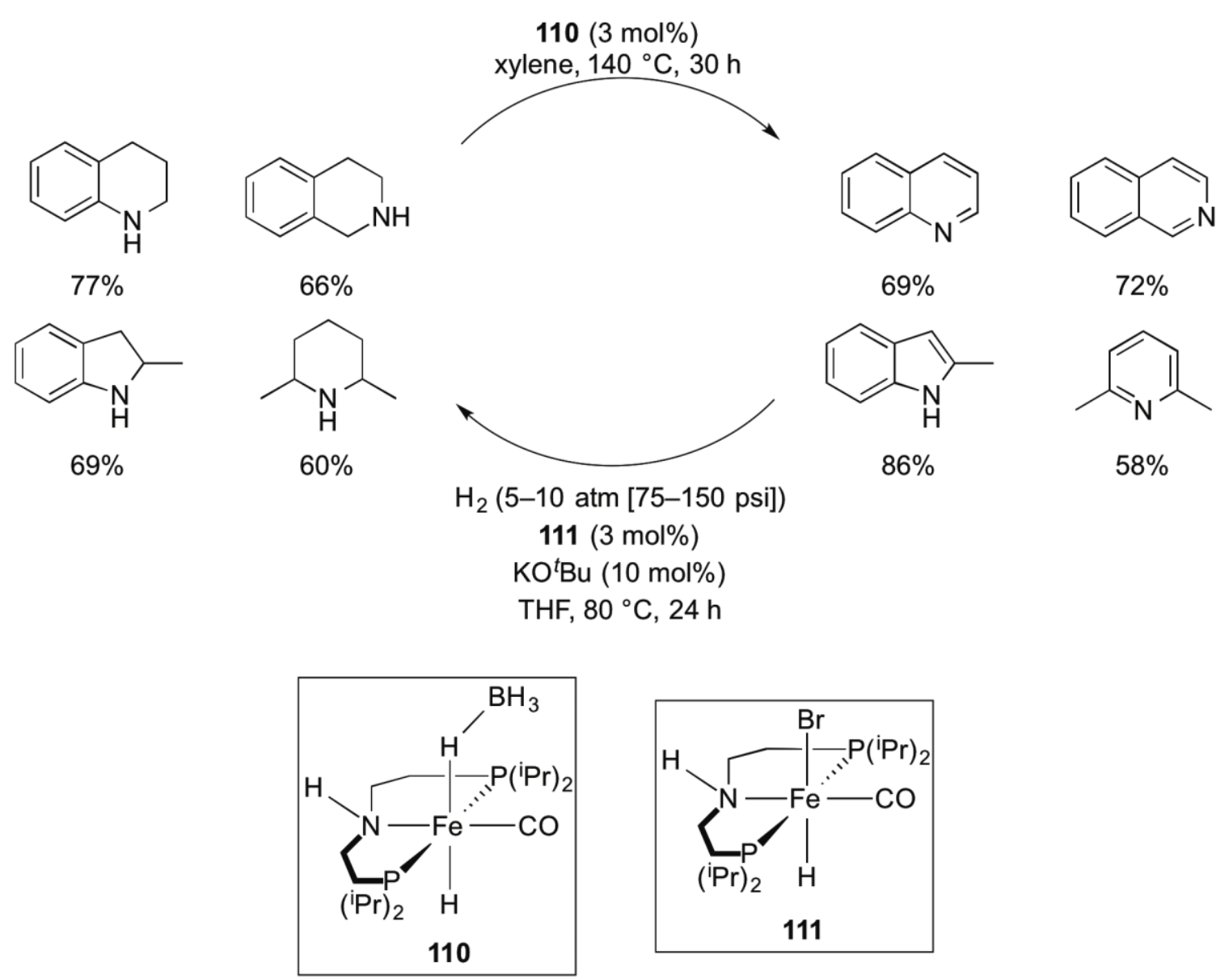

Scheme 122. Dehydrogenation and hydrogenation of $N$-heterocycles with $\mathbf{1 1 0}$ and $\mathbf{1 1 1}$ respectively.

The iron(II) hydride complex 112 (Fig. 13) was proposed as the active catalytic species for dehydrogenation; upon independent synthesis, 112 was found to exhibit activity comparable to that of $\mathbf{1 1 0}$ (Scheme 123, top). The corresponding active species for hydrogenation (113; Fig. 14.) could not be isolated, but was observed by ${ }^{1} \mathrm{H}$ NMR when 112 was placed under a hydrogen atmosphere. Indeed, 113 was found to also effectively catalyze the hydrogenation of 2-methylquinoline (Scheme 123, bottom). 


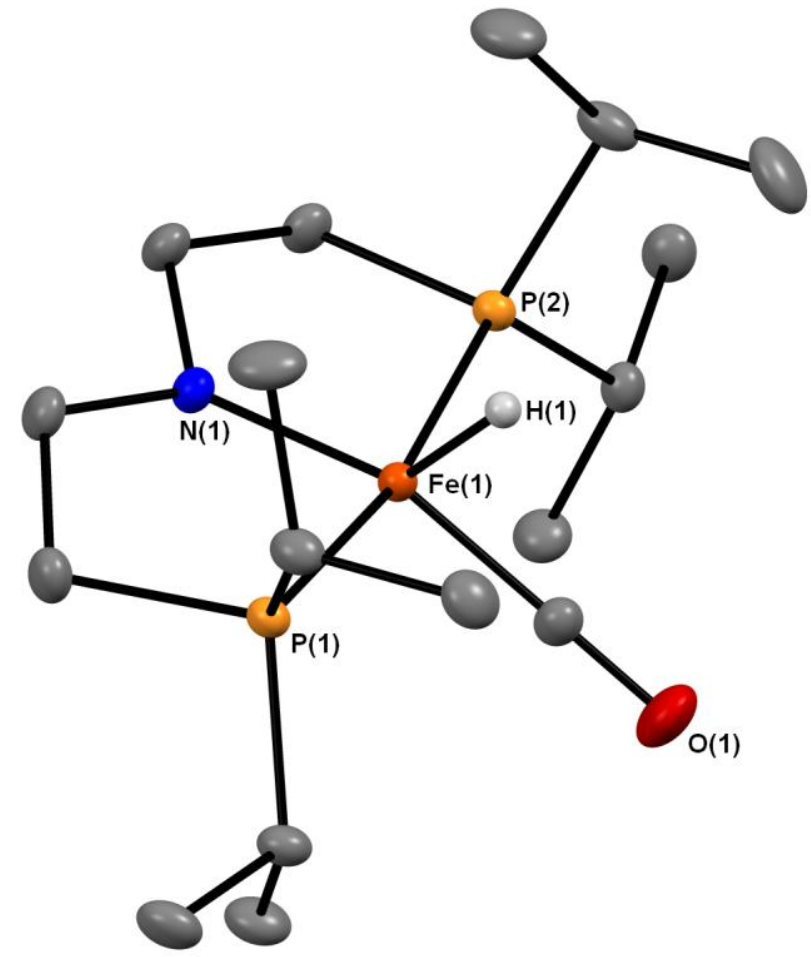

Fig. 13. ORTEP drawing of $\mathbf{1 1 2}$ generated with the program Mercury using crystallographic data made available in the Supporting Information of Ref. 163. Thermal ellipsoids are shown at $50 \%$ probability; ligand hydrogen atoms have been omitted for clarity.

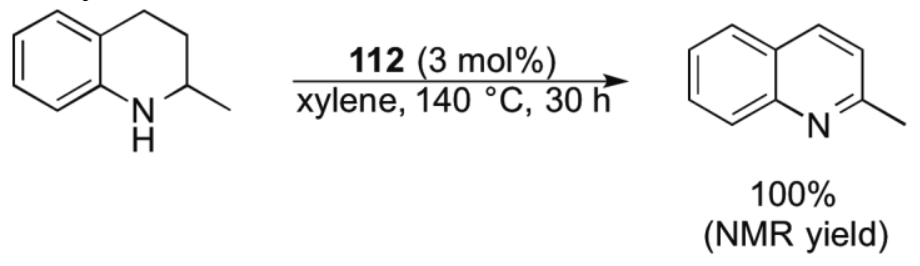<smiles>Cc1ccc2ccccc2n1</smiles>

112 (3 mol\%) $\frac{\mathrm{H}_{2}(5 \mathrm{~atm}[74 \mathrm{psi}])}{\mathrm{THF}, 80^{\circ} \mathrm{C}, 24 \mathrm{~h}}$<smiles>CC1CCc2ccccc2N1</smiles>

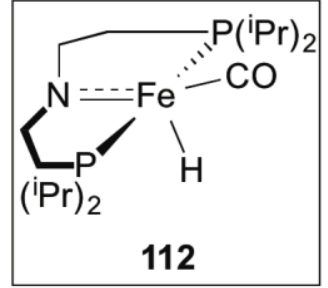

$100 \%$

(NMR yield)

Scheme 123. Reversible dehydrogenation-hydrogenation catalyzed by $\mathbf{1 1 2}$.

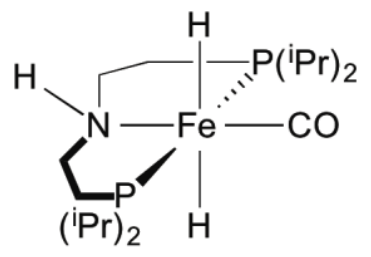

113

Fig. 14. Proposed active species 113 for iron-catalyzed hydrogenation. 


\section{Summary and Outlook}

Homogeneous metal-catalyzed heteroarene reduction has advanced to the point that highly enantioselective hydrogenation has been realized for nearly all major classes of bicyclic and monocyclic $N$-heterocycles, although only limited examples exist for some substrate types. The effective asymmetric hydrogenation of oxygen and sulfur heterocycles has likewise been reported, but to a considerably lesser extent. Indeed, Glorius [93] has provided the only example for the latter group, although racemic hydrogenation of benzothiophene has also been reported by Sánchez-Delgado [52] and Borowski and Sabo-Etienne [147].

Catalytic hydrogenation of mixed bicyclic heteroarenes, e.g. quinoline, has been found to proceed almost exclusively with regioselectivity for the heteroatom-containing ring; Borowski and Sabo-Etienne's [146], Glorius's [148], and Kuwano's [150] ruthenium catalysts provide the only known exceptions. Indeed, the homogeneous metal-catalyzed reduction of arenes has proven far more difficult than that of heteroarenes, with those catalysts reported typically suffering from either low activity or short lifetimes. Overcoming these current shortcomings will likely require new catalyst designs, both in terms of structure and mode of operation. Such innovation may also lend itself to achieving enantioselective, monocyclic arene hydrogenation, a transformation as yet unrealized (to our knowledge) by any form of catalysis.

In comparison to the number of homogeneous arene and heteroarene hydrogenation catalysts, those developed for the related dehydrogenation of cycloalkanes and saturated heterocycles are relatively few, with most based on iridium. As Jones [163] has recently demonstrated, however, there remains significant opportunity for advancement of this field, particularly with respect to the as yet untapped potential of first-row transition metals such as iron, cobalt, and nickel. Notably, such earth-abundant metals are also largely absent among the most recent generations of homogeneous arene and heteroarene hydrogenation catalysts. Indeed, Jones's iron-based hydrogenation-dehydrogenation catalyst was reported as the first of its kind. Further development of such reversible single catalyst systems is also of particular interest for their potential to facilitate greater chemical interrelation between aromatic and saturated cyclic compounds.

\section{Acknowledgement}

We are grateful to the US Department of Energy (DE-EE-0005658) for funding. 


\section{References}

[1] Y.-G. Zhou, Acc. Chem. Res. 40 (2007) 1357.

[2] D.S. Wang, Q.A. Chen, S.M. Lu, Y.-G. Zhou, Chem. Rev. 112 (2012) 2557.

[3] Q.-A. Chen, Z.-S. Ye, Y. Duan, Y.-G. Zhou, Chem. Soc. Rev. 42 (2013) 497.

[4] F. Glorius, Org. Biomol. Chem. 3 (2005) 4171.

[5] R. Kuwano, Heterocycles 76 (2008) 909.

[6] Y.-M. He, Q.-H. Fan, Org. Biomol. Chem. 8 (2010) 2497.

[7] P.J. Dyson, Dalton Trans. (2003) 2964.

[8] J.A. Widegren, R.G. Finke, J. Mol. Catal. A Chem. 191 (2003) 187.

[9] J. Schwartz, Acc. Chem. Res. 18 (1985) 302.

[10] Y. Lin, R.G. Finke, Inorg. Chem. 33 (1994) 4891.

[11] K.S. Weddle, J.D. Aiken, R.G. Finke, J. Am. Chem. Soc. 120 (1998) 5653.

[12] C.M. Hagen, L. Vieille-Petit, G. Laurenczy, G. Süss-Fink, R.G. Finke, Organometallics 24 (2005) 1819.

[13] C.M. Hagen, J.A. Widegren, P.M. Maitlis, R.G. Finke, J. Am. Chem. Soc. 127 (2005) 4423.

[14] M.J. Russell, C. White, P.M. Maitlis, J. Chem. Soc. Chem. Commun. (1977) 427.

[15] R.A. Sánchez-Delgado, M. Rosales, Coord. Chem. Rev. 196 (2000) 249.

[16] C. Bianchini, A. Meli, F. Vizza, Eur. J. Inorg. Chem. 2001 (2001) 43.

[17] C. Bianchini, A. Meli, Acc. Chem. Res. 31 (1998) 109.

[18] C. Bianchini, A. Meli, F. Vizza, J. Organomet. Chem. 689 (2004) 4277.

[19] H.-U. Blaser, C. Malan, B. Pugin, F. Spindler, H. Steiner, M. Studer, Adv. Synth. Catal. 345 (2003) 103.

[20] M. Heitbaum, F. Glorius, I. Escher, Angew. Chem. Int. Ed. 45 (2006) 4732. 
[21] M. Studer, H.-U. Blaser, C. Exner, Adv. Synth. Catal. 345 (2003) 45.

[22] H.-U. Blaser, Top. Catal. 53 (2010) 997.

[23] H.-U. Blaser, F. Spindler, M. Struder, Appl. Catal. A Gen. 221 (2001) 119.

[24] H.-U. Blaser, B. Pugin, F. Spindler, M. Thommen, Acc. Chem. Res. 40 (2007) 1240 .

[25] G.B. Kistiakowsky, J.R. Ruhoff, H.A. Smith, W.E. Vaughan, J. Am. Chem. Soc. 58 (1936) 137.

[26] G.B. Kistiakowsky, J.R. Ruhoff, H.A. Smith, W.E. Vaughan, J. Am. Chem. Soc. 58 (1936) 146.

[27] S.W. Slayden, J.F. Liebman, Chem. Rev. 101 (2001) 1541.

[28] M.J.S. Dewar, A.J. Holder, Heterocycles 28 (1989) 1135.

[29] C.W. Bird, Tetrahedron 48 (1992) 335.

[30] A.R. Katritzky, K. Jug, D.C. Oniciu, Chem. Rev. 101 (2001) 1421.

[31] A.T. Balaban, D.C. Oniciu, A.R. Katritzky, Chem. Rev. 104 (2004) 2777.

[32] A. Moores, M. Poyatos, Y. Luo, R.H. Crabtree, New J. Chem. 30 (2006) 1675.

[33] E. Clot, O. Eisenstein, R.H. Crabtree, Chem. Commun. (2007) 2231.

[34] R.-F. Lu, G. Boëthius, S.-H. Wen, Y. Su, W.-Q. Deng, Chem. Commun. (2009) 1751.

[35] W. Wang, S. Lu, P. Yang, X. Han, Y. Zhou, J. Am. Chem. Soc. 125 (2003) 10536.

[36] D.-W. Wang, X.-B. Wang, D.-S. Wang, S.-M. Lu, Y.-G. Zhou, Y.-X. Li, J. Org. Chem. 74 (2009) 2780.

[37] Z.-S. Ye, M.-W. Chen, Q.A. Chen, L. Shi, Y. Duan, Y.-G. Zhou, Angew. Chem. Int. Ed. 51 (2012) 10181.

[38] L. Shi, Z.-S. Ye, L.-L. Cao, R.-N. Guo, Y. Hu, Y.-G. Zhou, Angew. Chem. Int. Ed. 51 (2012) 8286.

[39] Z.-S. Ye, R.-N. Guo, X.-F. Cai, M.-W. Chen, L. Shi, Y.-G. Zhou, Angew. Chem. Int. Ed. 52 (2013) 3685. 
[40] M. Chang, Y. Huang, S. Liu, Y. Chen, S.W. Krska, I.W. Davies, X. Zhang, Angew. Chem. Int. Ed. 53 (2014) 12761.

[41] V. Dragan, J.C. McWilliams, R. Miller, K. Sutherland, J.L. Dillon, M.K. O’Brien, Org. Lett. 15 (2013) 2942.

[42] J.L. Núñez-Rico, H. Fernández-Pérez, A. Vidal-Ferran, Green Chem. 16 (2014) 1153.

[43] W.-X. Huang, C.-B. Yu, L. Shi, Y.-G. Zhou, Org. Lett. 16 (2014) 3324.

[44] R. Kuwano, Y. Hashiguchi, R. Ikeda, K. Ishizuka, Angew. Chem. Int. Ed. 54 (2015) 2393.

[45] K. Fujita, C. Kitatsuji, S. Furukawa, R. Yamaguchi, Tetrahedron Lett. 45 (2004) 3215.

[46] D.W. Wang, W. Zeng, Y. Zhou, Tetrahedron Asymmetry 18 (2007) 1103.

[47] J. Tan, W. Tang, Y. Sun, Z. Jiang, F. Chen, L. Xu, Q.-H. Fan, J. Xiao, Tetrahedron 67 (2011) 6206.

[48] C. Wang, C. Li, X. Wu, A. Pettman, J. Xiao, Angew. Chem. Int. Ed. 48 (2009) 6524.

[49] G.E. Dobereiner, A. Nova, N.D. Schley, N. Hazari, S.J. Miller, O. Eisenstein, R.H. Crabtree, J. Am. Chem. Soc. 133 (2011) 7547.

[50] R.A. Sánchez-Delgado, V. Herrera, C. Bianchini, D. Masi, C. Mealli, Inorg. Chem. 32 (1993) 3766.

[51] C. Bianchini, A. Meli, M. Peruzzini, F. Vizza, V. Herrera, R.A. Sánchez-Delgado, Organometallics 13 (1994) 721.

[52] V. Herrera, A. Fuentes, M. Rosales, R.A. Sánchez-Delgado, C. Bianchini, A. Meli, F. Vizza, Organometallics 16 (1997) 2465.

[53] D. Cartigny, F. Berhal, T. Nagano, P. Phansavath, T. Ayad, J.-P. Genêt, T. Ohshima, K. Mashima, V. Ratovelomanana-Vidal, J. Org. Chem. 77 (2012) 4544.

[54] Y. Kita, A. Iimuro, S. Hida, K. Mashima, Chem. Lett. 43 (2014) 284.

[55] Y. Kita, K. Yamaji, K. Higashida, K. Sathaiah, A. Iimuro, K. Mashima, Chem. Eur. J. 21 (2015) 1915.

[56] S.E. Lyubimov, D. V Ozolin, V.A. Davankov, Tetrahedron Lett. 55 (2014) 3613. 
[57] S.E. Lyubimov, D. V Ozolin, P.Y. Ivanov, A. Melman, V.S. Velezheva, V.A. Davankov, Chirality 26 (2014) 56.

[58] L. Pauli, R. Tannert, R. Scheil, A. Pfaltz, Chem. Eur. J. 21 (2015) 1482.

[59] A.M. Voutchkova, D. Gnanamgari, C.E. Jakobsche, C. Butler, S.J. Miller, J. Parr, R.H. Crabtree, J. Organomet. Chem. 693 (2008) 1815.

[60] R.H. Fish, J.L. Tan, A.D. Thormodsen, J. Org. Chem. 49 (1984) 4500.

[61] R.H. Fish, J.L. Tan, A.D. Thormodsen, Organometallics 4 (1985) 1743.

[62] S. Murata, T. Sugimoto, S. Matsuura, Heterocycles 26 (1987) 763.

[63] R. Kuwano, K. Sato, Y. Ito, Chem. Lett. (2000) 428.

[64] Y. Alvarado, M. Busolo, F. López-Linares, J. Mol. Catal. A Chem. 142 (1999) 163.

[65] U.E. Bucher, A. Currao, R. Nesper, H. Rüegger, L.M. Venanzi, E. Younger, Inorg. Chem. 34 (1995) 66.

[66] V. Parekh, J.A. Ramsden, M. Wills, Tetrahedron Asymmetry 21 (2010) 1549.

[67] R.H. Fish, H.S. Kim, J.E. Babin, R.D. Adams, Organometallics 7 (1988) 2250.

[68] R.H. Fish, E. Baralt, S.J. Smith, Organometallics 10 (1991) 54.

[69] E. Baralt, S.J. Smith, J. Hurwitz, I.T. Horvpth, R.H. Fish, J. Am. Chem. Soc. 6114 (1992) 5187.

[70] R.A. Sánchez-Delgado, E. González, Polyhedron 8 (1989) 1431.

[71] R.A. Sánchez-Delgado, D. Rondon, A. Andriollo, V. Herrera, G. Martin, B. Chaudret, Organometallics 12 (1993) 4291.

[72] C. Bianchini, P. Barbaro, M. Macchi, A. Meli, F. Vizza, Helv. Chim. Acta 84 (2001) 2895.

[73] P. Barbaro, C. Bianchini, A. Meli, M. Moreno, F. Vizza, Organometallics 21 (2002) 1430.

[74] M. Rosales, R. Vallejo, J.J. Soto, G. Chacón, Á. González, B. González, Catal. Letters 106 (2006) 101. 
[75] M. Rosales, R. Vallejo, J.J. Soto, L.J. Bastidas, K. Molina, P.J. Baricelli, Catal. Letters 134 (2009) 56.

[76] M. Studer, C. Wedemeyer-Exl, F. Spindler, H.-U. Blaser, Monatshefte Fur Chemie $131(2000) 1335$.

[77] P. Feiertag, M. Albert, U. Nettekoven, F. Spindler, Org. Lett. 8 (2006) 4133.

[78] R. Kuwano, K. Sato, T. Kurokawa, D. Karube, Y. Ito, J. Am. Chem. Soc. 122 (2000) 7614.

[79] R. Kuwano, K. Kaneda, T. Ito, K. Sato, T. Kurokawa, Y. Ito, Org. Lett. 6 (2004) 2213.

[80] N. Mršić, T. Jerphagnon, A.J. Minnaard, B.L. Feringa, J.G. de Vries, Tetrahedron Asymmetry 21 (2010) 7.

[81] M. Yamashita, N. Negoro, T. Yasuma, T. Yamano, Bull. Chem. Soc. Jpn. 87 (2014) 539.

[82] P. Frediani, L. Rosi, L. Cetarini, M. Frediani, Inorg. Chim. Acta 359 (2006) 2650.

[83] J.D. Miller, F.D. Oliver, J. Chem. Soc. Dalt. Trans. (1972) 2473.

[84] J. Wu, C. Wang, W. Tang, A. Pettman, J. Xiao, Chem. Eur. J. 18 (2012) 9525.

[85] R.H. Fish, A.D. Thormodsen, G.A. Cremer, J. Am. Chem. Soc. 104 (1982) 5234.

[86] P. Frediani, V. Pistolesi, M. Frediani, L. Rosi, Inorg. Chim. Acta 359 (2006) 917.

[87] M. Rosales, Y. Alvarado, M. Boves, R. Rubio, H. Soscún, R.A. Sánchez-Delgado, Transit. Met. Chem. 20 (1995) 246.

[88] M. Rosales, M. Boves, H. Soscún, F. Ruette, J. Mol. Struct. THEOCHEM 433 (1998) 319.

[89] M. Rosales, J. Navarro, L. Sánchez, A. González, Y. Alvarado, R. Rubio, C. Cruz, T. Rajmankina, Transit. Met. Chem. 21 (1996) 11.

[90] S. Urban, B. Beiring, N. Ortega, D. Paul, F. Glorius, J. Am. Chem. Soc. 134 (2012) 15241.

[91] J. Wysocki, N. Ortega, F. Glorius, Angew. Chem. Int. Ed. 53 (2014) 8751.

[92] N. Ortega, D.T.D. Tang, S. Urban, D. Zhao, F. Glorius, Angew. Chem. Int. Ed. 52 (2013) 9500. 
[93] N. Ortega, S. Urban, B. Beiring, F. Glorius, Angew. Chem. Int. Ed. 51 (2012) 1710 .

[94] N. Ortega, B. Beiring, S. Urban, F. Glorius, Tetrahedron 68 (2012) 5185.

[95] H. Zhou, Z. Li, Z. Wang, T. Wang, L. Xu, Y. He, Q.-H. Fan, J. Pan, L. Gu, A.S.C. Chan, Angew. Chem. Int. Ed. 47 (2008) 8464.

[96] T. Wang, L.-G. Zhuo, Z. Li, F. Chen, Z. Ding, Y. He, Q.-H. Fan, J. Xiang, Z.-X. Yu, A.S.C. Chan, J. Am. Chem. Soc. 133 (2011) 9878.

[97] Z.Y. Ding, T. Wang, Y.M. He, F. Chen, H.F. Zhou, Q.-H. Fan, Q. Guo, A.S.C. Chan, Adv. Synth. Catal. 355 (2013) 3727.

[98] O. Eisenstein, R.H. Crabtree, New J. Chem. 37 (2013) 21.

[99] J. Qin, F. Chen, Z. Ding, Y.-M. He, L. Xu, Q.-H. Fan, Org. Lett. 13 (2011) 6568.

[100] T. Wang, F. Chen, J. Qin, Y.M. He, Q.-H. Fan, Angew. Chem. Int. Ed. 52 (2013) 7172 .

[101] J. Zhang, F. Chen, Y.-M. He, Q.-H. Fan, Angew. Chem. Int. Ed. 54 (2015) 4622.

[102] R. Kuwano, M. Kashiwabara, M. Ohsumi, H. Kusano, J. Am. Chem. Soc. 130 (2008) 808.

[103] L. Perrin, E.L. Werkema, O. Eisenstein, R.A. Andersen, Inorg. Chem. 53 (2014) 6361.

[104] L. Maron, E.L. Werkema, L. Perrin, O. Eisenstein, R.A. Andersen, J. Am. Chem. Soc. 127 (2005) 279.

[105] A. Alvanipour, L.D. Kispert, J. Mol. Catal. 48 (1988) 277.

[106] T.J. Lynch, M. Banah, H.D. Kaesz, C.R. Porter, J. Org. Chem. 49 (1984) 1266.

[107] G. Zhu, J.M. Tanski, D.G. Churchill, K.E. Janak, G. Parkin, J. Am. Chem. Soc. 124 (2002) 13658.

[108] G. Zhu, K. Pang, G. Parkin, J. Am. Chem. Soc. 130 (2008) 1564.

[109] D.S. Wang, Q.A. Chen, W. Li, C. Bin Yu, Y.-G. Zhou, X. Zhang, J. Am. Chem. Soc. 132 (2010) 8909.

[110] Y. Duan, L. Li, M.-W. Chen, C. Bin Yu, H.J. Fan, Y.-G. Zhou, J. Am. Chem. Soc. 136 (2014) 7688. 
[111] Y. Duan, M.-W. Chen, Q.-A. Chen, C.-B. Yu, Y.-G. Zhou, Org. Biomol. Chem. 10 (2012) 1235.

[112] X.-F. Cai, W.-X. Huang, Z.-P. Chen, Y.-G. Zhou, Chem. Commun. 50 (2014) 9588.

[113] Z.-P. Chen, M.-W. Chen, L. Shi, C.-B. Yu, Y. Zhou, Chem. Sci. 6 (2015) 3415.

[114] L. Hao, J.F. Harrod, A.M. Lebuis, Y. Mu, R. Shu, E. Samuel, H.-G. Woo, Angew. Chem. Int. Ed. 37 (1998) 3126.

[115] J.F. Harrod, R. Shu, H.-G. Woo, E. Samuel, Can. J. Chem. 79 (2001) 1075.

[116] S. Friedman, S. Metlin, A. Svedi, I. Wender, J. Org. Chem. 24 (1959) 1287.

[117] P.D. Taylor, M. Orchin, J. Org. Chem. 37 (1972) 3913.

[118] T.A. Weil, S. Friedman, I. Wender, J. Org. Chem. 39 (1974) 48.

[119] H.M. Feder, J. Halpern, J. Am. Chem. Soc. 97 (1975) 7186.

[120] E.L. Muetterties, F.J. Hirsekorn, J. Am. Chem. Soc. 96 (1974) 7920.

[121] M.C. Rakowski, F.J. Hirsekorn, L.S. Stuhl, E.L. Muetterties, Inorg. Chem. 15 (1976) 2379.

[122] L.S. Stuhl, R. Dubois, F.J. Hirsekorn, J.R. Bleeke, a E. Stetens, E.L. Muetterties, J. Am. Chem. Soc. 100 (1978) 2406.

[123] E.L. Muetterties, F.J. Hirsekorn, J. Am. Chem. Soc. 96 (1974) 4063.

[124] E.L. Muetterties, M.C. Rakowski, F.J. Hirsekorn, W.D. Larson, V.J. Basus, F.A.L. Anet, J. Am. Chem. Soc. 97 (1975) 1266.

[125] F.J. Hirsekorn, M.C. Rakowski, E.L. Muetterties, J. Am. Chem. Soc. 97 (1975) 237.

[126] M.C. Rakowski, E.L. Muetterties, J. Am. Chem. Soc. 99 (1977) 739.

[127] K.J. Klabunde, B.B. Anderson, M. Bader, L.J. Radonovich, J. Am. Chem. Soc. 100 (1978) 1313.

[128] I.P. Rothwell, Chem. Commun. (1997) 1331.

[129] B.C. Ankianiec, P.E. Fanwick, I.P. Rothwell, J. Am. Chem. Soc. 113 (1991) 4710. 
[130] R.W. Chesnut, G.G. Jacob, J.S. Yu, P.E. Fanwick, I.P. Rothwell, Organometallics 10 (1991) 321.

[131] J.S. Yu, B.C. Ankianiec, I.P. Rothwell, M.T. Nguyen, J. Am. Chem. Soc. 114 (1992) 1927.

[132] J.S. Yu, I.P. Rothwell, J. Chem. Soc. Chem. Commun. (1992) 632.

[133] M.C. Potyen, I.P. Rothwell, J. Chem. Soc. Chem. Commun. (1995) 849.

[134] V.M. Visciglio, M.T. Nguyen, J.R. Clark, P.E. Fanwick, I.P. Rothwell, Polyhedron 15 (1996) 551.

[135] V.M. Visciglio, J.R. Clark, M.T. Nguyen, D.R. Mulford, P.E. Fanwick, I.P. Rothwell, J. Am. Chem. Soc. 119 (1997) 3490.

[136] J.R. Clark, P.E. Fanwick, I.P. Rothwell, J. Chem. Soc. Chem. Commun. 44 (1995) 553.

[137] D. Pieta, A.M. Trzeciak, J.J. Ziółkowski, J. Mol. Catal. 18 (1983) 193.

[138] C.R. Landis, J. Halpern, Organometallics 2 (1983) 840.

[139] J. Halpern, D.P. Riley, A.S.C. Chan, J.J. Pluth, J. Am. Chem. Soc. 99 (1977) 8055.

[140] R.R. Schrock, J.A. Osborn, J. Am. Chem. Soc. 98 (1976) 4450.

[141] J.W. Johnson, E.L. Muetterties, J. Am. Chem. Soc. 99 (1977) 7395.

[142] E.L. Muetterties, J.R. Bleeke, Acc. Chem. Res. 12 (1979) 324.

[143] R. Wilczynski, W.A. Fordyce, J. Halpern, J. Am. Chem. Soc. 105 (1983) 2066.

[144] D.E. Linn Jr., J. Halpern, J. Am. Chem. Soc. 109 (1987) 2969.

[145] A.F. Borowski, S. Sabo-Etienne, B. Donnadieu, B. Chaudret, Organometallics 22 (2003) 1630.

[146] A.F. Borowski, L. Vendier, S. Sabo-Etienne, E. Rozycka-Sokolowska, A. V Gaudyn, Dalton Trans. 41 (2012) 14117.

[147] A.F. Borowski, S. Sabo-Etienne, B. Donnadieu, B. Chaudret, Organometallics 22 (2003) 4803.

[148] S. Urban, N. Ortega, F. Glorius, Angew. Chem. Int. Ed. 50 (2011) 3803. 
[149] R. Kuwano, R. Morioka, M. Kashiwabara, N. Kameyama, Angew. Chem. Int. Ed. 51 (2012) 4136.

[150] R. Kuwano, R. Ikeda, K. Hirasada, Chem. Commun. 51 (2015) 7558.

[151] M. Gupta, C. Hagen, R.J. Flesher, W.C. Kaska, C.M. Jensen, Chem. Commun. 36 (1996) 2083.

[152] M. Gupta, C. Kaska, C.M. Jensen, Chem. Commun. (1997) 461.

[153] Z. Wang, I. Tonks, J. Belli, C.M. Jensen, J. Organomet. Chem. 694 (2009) 2854.

[154] C.M. Jensen, Chem. Commun. 3 (1999) 2443.

[155] J. Choi, A.H.R. MacArthur, M. Brookhart, A.S. Goldman, Chem. Rev. 111 (2011) 1761.

[156] O.R. Luca, D.L. Huang, M.K. Takase, R.H. Crabtree, New J. Chem. 37 (2013) 3402 .

[157] R. Yamaguchi, C. Ikeda, Y. Takahashi, K. Fujita, J. Am. Chem. Soc. 131 (2009) 8410.

[158] X.-B. Zhang, Z. Xi, Phys. Chem. Chem. Phys. 13 (2011) 3997.

[159] K. Fujita, Y. Tanaka, M. Kobayashi, R. Yamaguchi, J. Am. Chem. Soc. 136 (2014) 4829.

[160] J. Wu, D. Talwar, S. Johnston, M. Yan, J. Xiao, Angew. Chem. Int. Ed. 52 (2013) 6983.

[161] J. Wu, J.H. Barnard, Y. Zhang, D. Talwar, C.M. Robertson, J. Xiao, Chem. Commun. 49 (2013) 7052.

[162] D. Talwar, A. Gonzalez-de-Castro, H.Y. Li, J. Xiao, Angew. Chem. Int. Ed. 54 (2015) 5223.

[163] S. Chakraborty, W.W. Brennessel, W.D. Jones, J. Am. Chem. Soc. 136 (2014) 8564.

[164] E. Alberico, P. Sponholz, C. Cordes, M. Nielsen, H.J. Drexler, W. Baumann, H. Junge, M. Beller, Angew. Chem. Int. Ed. 52 (2013) 14162.

[165] I. Koehne, T.J. Schmeier, E. a. Bielinski, C.J. Pan, P.O. Lagaditis, W.H. Bernskoetter, M.K. Takase, C. Würtele, N. Hazari, S. Schneider, Inorg. Chem. 53 (2014) 2133. 
[166] S. Chakraborty, H. Dai, P. Bhattacharya, N.T. Fairweather, M.S. Gibson, J.A. Krause, H. Guan, J. Am. Chem. Soc. 136 (2014) 7869. 
Scheme 1. Heterogeneous hydrogenation of benzene (left) and homogeneous hydrogenation of cyclohexene (right) using the same catalyst precursor $\left[\mathrm{Cp}^{*} \mathrm{RhCl}_{2}\right]_{2}$.

Scheme 2. Asymmetric imine hydrogenation by an Ir-xyliphos catalyst used in production of $(S)$ metolachlor by Ciba-Geigy (now Solvias).

Scheme 3. Calculated (B3PW91/aug-cc-pVDZ) enthalpies of dehydrogenation (kcal/mol substrate) for cyclohexane and a series of six-membered $N$-heterocycles.

Scheme 4. Asymmetric hydrogenation of quinolines catalyzed by $[\operatorname{Ir}(\operatorname{cod}) \mathrm{Cl}]_{2}$ in the presence of $(R)$-MeO-BIPHEP.

Scheme 5. Proposed pathway for formation of $\mathbf{3}$ from $[\operatorname{Ir}(\operatorname{cod}) \mathrm{Cl}]_{2}$.

Scheme 6. Proposed catalytic cycle for asymmetric hydrogenation of quinolines starting with $\mathbf{3}$ (shown for 2-methylquinoline).

Scheme 7. Asymmetric hydrogenation of 5 as a model for 3,4-dihydroquinoline intermediates.

Scheme 8. Asymmetric hydrogenation of pyridinium salts using $[\operatorname{Ir}(\operatorname{cod}) \mathrm{Cl}]_{2}$ as a precatalyst and (R)-SynPhos.

Scheme 9. Asymmetric hydrogenation of 3,4-disubstituted isoquinolines (top) and 1,2disubstituted isoquinolinium salts (bottom). $(\mathrm{BCDMH}=1$-bromo-3-chloro-5,5dimethylhydantoin)

Scheme 10. Asymmetric hydrogenation of $N$-substituted 2-arylpyridinium salts using $[\operatorname{Ir}(\operatorname{cod}) \mathrm{Cl}]_{2}$ as a precatalyst and $(R)-\mathrm{MP}^{2}-$ SEGPHOS.

Scheme 11. Asymmetric hydrogenation of an advanced intermediate in the synthesis of Vabicaserin. (DtBP = 2,6-di-t-butylpyridine)

Scheme 12. Asymmetric hydrogenation of free indoles using $[\operatorname{Ir}(\operatorname{cod}) \mathrm{Cl}]_{2}$ as a precatalyst and a $\mathrm{P}-\mathrm{OP}$ ligand.

Scheme 13. Asymmetric hydrogenation of pyrrolopyrazinium salts using $[\operatorname{Ir}(\operatorname{cod}) \mathrm{Cl}]_{2}$ as a precatalyst and TunePhos.

Scheme 14. Asymmetric partial hydrogenation of pyrimidines using $[\mathrm{Ir}(\operatorname{cod}) \mathrm{Cl}]_{2}$ as a precatalyst and $(R)-(S)-\mathrm{Ph}_{2} \mathrm{PF}-\mathrm{P}\left({ }^{t} \mathrm{Bu}\right)_{2}$.

Scheme 15. Proposed catalytic cycle for transfer hydrogenation of quinoline catalyzed by $\left[\mathrm{Cp}^{\star} \mathrm{IrCl}_{2}\right]_{2}$.

Scheme 16. Asymmetric transfer hydrogenation of quinolines using Hantzsch esters as the hydrogen source. 
Scheme 17. Transfer hydrogenation of quinoxalines using formic acid as the hydrogen source.

Scheme 18. Hydrogenation of quinolines catalyzed by 7 .

Scheme 19. Proposed catalytic cycle for hydrogenation of 2-methylquinoline catalyzed by 8 . Counteranions omitted for clarity.

Scheme 20. Addition of $S$-heterocycles to $\left[\operatorname{Ir}(\operatorname{cod})\left(\mathrm{PPh}_{3}\right)_{2}\right]\left[\mathrm{PF}_{6}\right]$ in the presence of $\mathrm{H}_{2}$ (shown for benzothiophene).

Scheme 21. Proposed pathway for formation of $\mathbf{1 1}$ from $\mathbf{1 0 .}$

Scheme 22. Proposed catalytic cycle for hydrogenation of benzothiophene catalyzed by 15 . Counteranions omitted for clarity.

Scheme 23. Asymmetric hydrogenation of quinoxalines (top), pyridinium salts (middle), and isoquinolinium hydrochlorides (bottom) catalyzed by 19.

Scheme 24. Asymmetric hydrogenation of 2-methylindole using $\left[\operatorname{Ir}(\operatorname{cod})_{2}\right][\mathrm{BArF}]$ as a precatalyst and $\mathbf{2 0}$ as a chiral ligand.

Scheme 25. Asymmetric hydrogenation of benzofurans and furans catalyzed by 21.

Scheme 26. Transfer hydrogenation of pyrazine catalyzed by 22.

Scheme 27. Hydrogenation of quinoxaline and 2-methylquinoxaline catalyzed by $\left[\mathrm{RhCl}(\mathrm{CO})_{2}\right]_{2}$ in the presence of $(S, S)$-DIOP and $\mathrm{KBH}_{4}$.

Scheme 28. Hydrogenation of indoles and other heterocycles catalyzed by $\mathrm{Rh}(\mathrm{acac})(\mathrm{cod})$ in the presence of $\mathrm{PPh}_{3}$.

Scheme 29. Hydrogenation of quinoline catalyzed by $[\mathrm{RhCl}(\operatorname{cod})]_{2}$ in the presence of NaTp.

Scheme 30. Proposed formation of $\mathbf{2 4}$ starting from $[\mathrm{RhCl}(\mathrm{cod})]_{2}$.

Scheme 31. Asymmetric transfer hydrogenation of 2-alkyl (top) and 2-aryl (bottom) quinolines catalyzed by pre-formed $\mathrm{Cp}^{\star} \mathrm{RhCl}(\mathrm{TsDPEN})$ complex 25a and in situ generated $\mathbf{2 5 b}$ respectively.

Scheme 32. Asymmetric transfer hydrogenation of 2-substituted quinolines catalyzed by tethered-TsDPEN Rh and Ru complexes 26 and 27 (generated in situ from the corresponding dimeric precursors).

Scheme 33. Relative activities of hydrogenation of quinoline (top) and benzothiophene (bottom) catalyzed by various complexes.

Scheme 34. Formation of $\mathbf{3 5}$ from 34 under hydrogenation conditions. 
Scheme 35. Proposed catalytic cycle for hydrogenation of quinoline catalyzed by 35 . Counteranions omitted for clarity.

Scheme 36. Formation of $\mathbf{3 8}$ and 39 from 37.

Scheme 37. Hydrogenation of quinoline catalyzed by either $\mathbf{3 7}$ or $\mathbf{3 8 .}$

Scheme 38. Deuterium-labeling of quinoline reduction by 37 with $\mathrm{D}_{2}$.

Scheme 39. Proposed catalytic cycle for hydrogenation of quinoline catalyzed by 38 . Counteranions omitted for clarity.

Scheme 40. Hydrogenation of indole catalyzed by 37 .

Scheme 41. Proposed catalytic cycle for hydrogenation of indole starting with 42. Counteranions omitted for clarity.

Scheme 42. Formation of $\mathbf{4 1}$ and $\mathbf{4 2}$ from 37 under acidic conditions in the presence of $\mathrm{H}_{2}$.

Scheme 43. Initial rates of hydrogenation of quinoline (top) and acridine (bottom) using various Rh- and Ir-based catalysts.

Scheme 44. Proposed generation of active catalytic species 44 from $\left[\mathrm{MCl}(\mathrm{coe})_{2}\right]_{2}(\mathrm{M}=\mathrm{Rh}, \mathrm{Ir})$ precatalysts.

Scheme 45. Asymmetric hydrogenation of picolinic acid and its ethyl ester using $\left[\mathrm{Rh}(\mathrm{nbd})_{2}\right]\left[\mathrm{BF}_{4}\right]$ as a precatalyst.

Scheme 46. Attempted asymmetric hydrogenation of 2-substituted furans using $\left[\mathrm{Rh}(\mathrm{nbd})_{2}\right]\left[\mathrm{BF}_{4}\right]$ as a precatalyst.

Scheme 47. Asymmetric hydrogenation of 2,5-disubstituted furan 45 catalyzed by $[\mathrm{Rh}(\mathrm{cod})($ ligand $)]\left[\mathrm{BF}_{4}\right] \quad$ (ligand $\quad=\quad 2,3-\mathrm{bis}[(2 R, 5 R)-2,5$-di-isopropylphospholano $]$ benzo[b]thiophene).

Scheme 48. Asymmetric hydrogenation of 2- and 3-substituted indoles using $\left[\mathrm{Rh}(\mathrm{nbd})_{2}\right]\left[\mathrm{SbF}_{6}\right]$ as a precatalyst and $(S, S)-(R, R)$-PhTRAP as a chiral ligand.

Scheme 49. Asymmetric hydrogenation of methyl $N$-acetylindole-2-carboxylate using $\left[\mathrm{Rh}(\operatorname{cod})_{2}\right]\left[\mathrm{BF}_{4}\right]$ as a precatalyst and $(S)$-PipPhos as a chiral ligand.

Scheme 50. Asymmetric hydrogenation of 46 using $\left[\mathrm{Rh}(\operatorname{cod})_{2}\right][\mathrm{OTf}]$ as a precatalyst and $(S, S)$ Et-FerroTANE as a chiral ligand.

Scheme 51. Transfer hydrogenation of quinoline and pyridine catalyzed by pre-activated cis$\left[\mathrm{Rh}(\text { bipy })_{2} \mathrm{Cl}_{2}\right][\mathrm{Cl}] \cdot 2 \mathrm{H}_{2} \mathrm{O}$. Preactivation conditions: $0.0125 \mathrm{M} \mathrm{NaOH},{ }^{i} \mathrm{PrOH}, 80{ }^{\circ} \mathrm{C}, 3 \mathrm{~h}, \mathrm{~N}_{2}(1$ 
$\operatorname{MPa}[145 \mathrm{psi}])$.

Scheme 52. Proposed formation of 49 from $c i s-\left[\mathrm{Rh}(\text { bipy })_{2} \mathrm{Cl}_{2}\right][\mathrm{Cl}] \cdot 2 \mathrm{H}_{2} \mathrm{O}$ and catalytic cycle for first net addition of hydrogen to quinoline.

Scheme 53. Reductive hydrosilylation of quinoline and other $N$-heterocycles catalyzed by $\left[\mathrm{Rh}(\mathrm{cod})\left(\mathrm{PPh}_{3}\right)_{2}\right]\left[\mathrm{PF}_{6}\right] \mathbf{5 0}$. Reaction time $=12 \mathrm{~h}$ for isoquinoline, acridine, and indole.

Scheme 54. Attempted asymmetric transfer hydrogenation of $N$-methyl-2-methylquinolinium iodide with 52 (top) and transfer hydrogenation of 2-methylquinoline catalyzed by $\left[\mathrm{Rh}\left(\mathrm{Cp}^{*}\right) \mathrm{Cl}_{2}\right]_{2}$ with and without iodide additives (bottom).

Scheme 55. Proposed mechanistic pathway for transfer hydrogenation of 2-methylquinoline starting from 53.

Scheme 56. Transfer hydrogenation of quinolines, isoquinolines, and quinoxalines catalyzed by $\left[\mathrm{Rh}\left(\mathrm{Cp}^{*}\right) \mathrm{Cl}_{2}\right]_{2}$ in the presence of $\mathrm{KI}$.

Scheme 57. Hydrogenation of various $N$-heterocycles catalyzed by $\mathrm{RuCl}_{2}(\mathrm{CO})_{2}\left(\mathrm{PPh}_{3}\right)_{3}$.

Scheme 58. Hydrogenation of quinoline catalyzed by $\mathrm{RuH}_{2}\left(\mathrm{PPh}_{3}\right)_{3}$

Scheme 59. Proposed catalytic cycle for quinoline hydrogenation catalyzed by $\mathbf{5 6}$. Counteranions omitted for clarity.

Scheme 60. Proposed mechanistic pathway for hydrogenation of acridine catalyzed by 60 .

Scheme 61. Asymmetric hydrogenation of benzothiophenes and thiophenes (top) and other heterocycles (bottom) using a Ru-NHC catalyst.

Scheme 62. Asymmetric hydrogenation of 2-substituted benzofurans using a Ru-NHC catalyst.

Scheme 63. Asymmetric hydrogenation of quinolines catalyzed by Noyori-type catalyst $\mathbf{6 1}$.

Scheme 64. Proposed catalytic cycle for asymmetric quinoline hydrogenation using Noyori-type catalysts.

Scheme 65. Asymmetric hydrogenation of quinoxalines catalyzed by 63 and 64 .

Scheme 66. Asymmetric hydrogenation of 1,10-phenanthrolines catalyzed by $(R, R)-61$.

Scheme 67. Catalyst-controlled enantio- and diastereoselective hydrogenation of tetrahydrophenanthroline $\mathbf{6 5}$.

Scheme 68. Catalyst-controlled enantioselective hydrogenation of 1,5-naphthyridines (top) and subsequent substrate-controlled diastereoselective hydrogenation (bottom). 
Scheme 69. Asymmetric hydrogenation of $N$-Boc-pyrroles.

Scheme 70. Formation of $\eta^{2}$-(2-pyridyl) cerium complex 67 by addition of pyridine to [Ce]'H.

Scheme 71. Hydrogenation of 67 in the absence (top) and presence (bottom) of [Ce]'H.

Scheme 72. Proposed reaction cycle for hydrogenation of 67 to 69 based on DFT (B3PW91) calculations.

Scheme 73. Hydrogenation of $N$-heterocycles catalyzed by $\mathrm{Co}_{2}(\mathrm{CO})_{6}\left(\mathrm{PPh}_{3}\right)_{2}$ under syngas.

Scheme 74. Hydrogenation of quinolines and isoquinolines catalyzed by $\mathrm{Co}(\text { stearate })_{2} \cdot \mathrm{AlEt}_{3}$.

Scheme 75. Hydrogenation of $N$-heterocycles with $\mathrm{Fe}(\mathrm{CO})_{5}$ under water-gas shift conditions.

Scheme 76. Stoichiometric hydrogenation of molybdenum complexes 71, 72, and $\mathbf{7 3 .}$

Scheme 77. Stoichiometric hydrogenation of $\eta^{6}-\mathrm{C}_{6}$-quinoxaline molybdenum complex $\mathbf{7 4}$.

Scheme 78. Catalytic hydrogenation of heterocycles by $\mathrm{Mo}\left(\mathrm{PMe}_{3}\right)_{4} \mathrm{H}_{4}$.

Scheme 79. Asymmetric hydrogenation of substituted indoles by a palladium catalyst with $(R)$ octahydro-BINAP.

Scheme 80. Proposed catalytic cycle for palladium-catalyzed hydrogenation of substituted indoles.

Scheme 81. Asymmetric hydrogenation of 3 -( $\alpha$-amino)indoles to obtain enantioenriched 3 benzylindolines.

Scheme 82. Asymmetric hydrogenation of pyrazol-5-ols.

Scheme 83. $\mathrm{Cp}_{2} \mathrm{TiMe}_{2}$-catalyzed hydrosilylation-hydrogenation of pyridines to $\mathrm{N}$-silyl-1,2,3,4tetrahydropyridines.

Scheme 84. $\mathrm{Cp}_{2} \mathrm{TiMe}_{2}$-catalyzed hydrosilylation-hydrogenation of pyridines to $N$-silylpiperdines.

Scheme 85. $\mathrm{Cp}_{2} \mathrm{TiMe}_{2}$-catalyzed hydrosilylation-hydrogenation of quinolines in the absence (top) and presence (bottom) of $\mathrm{H}_{2}$.

Scheme 86. Stoichiometric formation of $\mathbf{7 6}$ (top) and proposed decomposition pathway to $\mathbf{7 7}$ (bottom).

Scheme 87. $\left[\mathrm{Cp}_{2} \mathrm{TiH}\right]_{2}$-catalyzed H/D exchange of pyridine- $d_{5}$. 
Scheme 88. Hydrogenation of various polycyclic aromatic compounds catalyzed by $\mathrm{Co}_{2}(\mathrm{CO})_{8}$. Yields based on GC analysis.

Scheme 89. Hydrogenation of 9,10-dimethylanthracene with stoichiometric $\mathrm{Co}_{2}(\mathrm{CO})_{8}$.

Scheme 90. Proposed catalytic pathway for hydrogenation of 9,10-substituted anthracenes by $\mathrm{Co}_{2}(\mathrm{CO})_{8}$.

Scheme 91. Relative rates of hydrogenation catalyzed by $\eta^{3}$-(allyl) $\mathrm{CoL}_{3}$ catalysts.

Scheme 92. Hydrogenation of $\mathrm{C}_{6} \mathrm{D}_{6}$ catalyzed by $\mathbf{8 0}$ to produce all-cis $\mathrm{C}_{6} \mathrm{H}_{6} \mathrm{D}_{6}$ (top), and other products formed stereoselectively (bottom).

Scheme 93. Proposed catalytic cycle for hydrogenation of benzene with $\mathbf{8 0}$.

Scheme 94. Hydrogenation of toluene to methylcyclohexane catalyzed by $\mathbf{8 2}$.

Scheme 95. Hydrogenation of naphthalene (top) and anthracene (bottom) catalyzed by 83 or 84 .

Scheme 96. Hydrogenation of phenanthrene (top) and 1- and 2-methylnaphthalene (bottom) catalyzed by 83 .

Scheme 97. Hydrogenation of perdeutero-labeled substrates catalyzed by 83 or 84 demonstrating all-cis hydrogen addition.

Scheme 98. Hydrogenation of various aryl phosphines catalyzed by 84 .

Scheme 99. Hydrogenation of 1,3-cyclohexadiene catalyzed by 85 .

Scheme 100. Hydrogenation of styrene catalyzed by $\mathbf{8 6}$.

Scheme 101. Formation of a cyclohexyl-tantalum complex (88) from addition of 1,3cyclohexadiene to $\mathbf{8 9}$.

Scheme 102. Hydrogenation of benzene catalyzed by $\mathrm{Rh}(\mathrm{acac})\left[\mathrm{P}(\mathrm{OPh})_{3}\right]_{2}$.

Scheme 103. Equilibrium formation of $\eta^{6}$-arene complexes from 90 and subsequent hydrogenation. Counteranions omitted for clarity.

Scheme 104. Proposed catalytic cycle for initial hydrogen addition to polycyclic arenes catalyzed by $\mathbf{9 0}$ (shown for naphthalene to 1,2-dihydronaphthalene). Counteranions omitted for clarity.

Scheme 105. Proposed reaction pathway for benzene hydrogenation catalyzed by $\mathrm{Ru}\left(\mathrm{C}_{6} \mathrm{Me}_{6}\right)_{2}$. 
Scheme 106. Proposed catalytic cycle for hydrogenation of anthracene catalyzed by 94. Counteranions omitted for clarity.

Scheme 107. Hydrogenation of 9-methylanthracene (top) and anthracene (bottom) catalyzed by 96 and 97 respectively.

Scheme 108. Carbocyclic hydrogenation of various $N$-heteroarenes catalyzed by 97 and heterocyclic hydrogenation of indole and benzothiophene.

Scheme 109. Proposed catalytic cycle for carbocyclic hydrogenation of acridine catalyzed by 97 .

Scheme 110. Hydrogenation of substituted benzenes catalyzed by 99 in ionic liquid. TOF calculated as moles substrate converted per mole catalyst per hour.

Scheme 111. Regioselective carbo- and heterocyclic hydrogenation of quinoxalines using two different NHC-ligated ruthenium complexes.

Scheme 112. Asymmetric carbocyclic hydrogenation of quinoxalines.

Scheme 113. Asymmetric hydrogenation of 2,6-disubstituted naphthalenes (top) and asymmetric carbocyclic hydrogenation of quinoline (bottom) catalyzed by a Ru-PhTRAP catalyst.

Scheme 114. Transfer dehydrogenation of saturated compounds to aromatic species catalyzed by Ir-PCP pincer catalysts.

Scheme 115. Mechanism of Ir-PCP-catalyzed transfer dehydrogenation.

Scheme 116. Electrocatalytic dehydrogenation catalyzed by quinone-fused catalyst $\mathbf{1 0 5}$ (top) and non-quinoid catalyst 106 with free quinone (bottom).

Scheme 117. Reversible hydrogenation-dehydrogenation of 2-substituted quinolines.

Scheme 118. Proposed catalytic cycle for dehydrogenation of tetrahydroquinoline catalyzed by 107 based on computations.

Scheme 119. Reversible hydrogenation-dehydrogenation of 1,5-naphthyridines catalyzed by 108 .

Scheme 120. Reversible hydrogenation-dehydrogenation of 1-methylisoquinoline catalyzed by 109.

Scheme 121. Dehydrogenative coupling strategy

Scheme 122. Dehydrogenation and hydrogenation of $N$-heterocycles with 110 and 111 respectively.

Scheme 123. Reversible dehydrogenation-hydrogenation catalyzed by 112 . 
Fig. 1. Comparison of the measured heat of hydrogenation of 1,3-cyclohexadiene (left) and benzene (right) with that of cyclohexene.

Fig. 2. Ball-and-stick representations of 7 (left) and 8 (right) generated with the program Mercury using crystallographic data made available in the Supporting Information of Ref. 49. $\mathrm{PF}_{6}$ counteranions and hydrogen atoms are omitted for clarity.

Fig. 3. Ball-and-stick representation of $\mathbf{1 0}$ (left) and $\mathbf{1 1}$ (right) generated with the program Mercury using crystallographic data retrieved from the Cambridge Crystal Structure Database (Refcodes HAKLEK and HAKLIO respectively); structural information originally provided in Ref. 50. $\mathrm{PF}_{6}$ counteranion, dichloromethane solvate, and ligand hydrogen atoms omitted for clarity. The metal hydride ligands could not be located for $\mathbf{1 1}$.

Fig. 4. Ball-and-stick representation of $\mathbf{1 6}$ generated with the program Mercury using crystallographic data retrieved from the Cambridge Crystal Structure Database (Refcode RUPHOZ); structural information originally provided in Ref. 52. $\mathrm{PF}_{6}$ counteranion and ligand hydrogen atoms are omitted for clarity.

Fig. 5. Relative rates of product formation from hydrogenation of heterocycles catalyzed by $\mathrm{RhCl}\left(\mathrm{PPh}_{3}\right)_{3}$. Conditions: $10 \mathrm{~mol} \%$ catalyst, $310 \mathrm{psi} \mathrm{H}_{2}$, benzene, $85{ }^{\circ} \mathrm{C}$.

Fig. 6. Complexes formed between $\left[\mathrm{Cp}{ }^{\star} \mathrm{Rh}\left(\mathrm{CH}_{3} \mathrm{CN}\right)_{2}\right]\left(\mathrm{BF}_{4}\right)_{2}$ and various quinoline derivatives.

Fig. 7. Relative rates of product formation from hydrogenation of heterocycles catalyzed by $\left[\mathrm{Cp}^{\star} \mathrm{Rh}\left(\mathrm{CH}_{3} \mathrm{CN}\right)_{2}\right]\left[\mathrm{BF}_{4}\right]_{2}$. Conditions: $5 \mathrm{~mol} \%$ catalyst, $500 \mathrm{psi}_{2}, \mathrm{CH}_{2} \mathrm{Cl}_{2}, 40{ }^{\circ} \mathrm{C}$.

Fig. 8. ORTEP drawing of 68 (left) and 69 (right) generated with the program Mercury using crystallographic data made available in the Supporting Information of Ref. 103. Cp' ligand hydrogen atoms are omitted for clarity.

Fig. 9. ORTEP drawing of 77 generated with the program Mercury using crystallographic data retrieved from the Cambridge Crystal Structure Database (CCDC\# 102515); structure information originally provided in Ref. 114. Thermal ellipsoids are shown at 50\% probability; Cp ligand hydrogen atoms and pyridine solvate omitted for clarity. The $\mathrm{N}(1)$ and $\mathrm{C}(5)$ positions are mutually disordered with $0.52: 0.48$ occupancy.

Fig. 10. Ball-and-stick representation of $\mathbf{8 3}$ generated with the program Mercury using crystallographic data retrieved from the Cambridge Crystal Structure Database (Refcode SODLAY); structure information originally provided in Ref. 129. Ligand hydrogen atoms have been omitted for clarity.

Fig. 11. Ball-and-stick representation of $\eta^{4}-1,3$-cyclohexadiene (triaryloxy)niobium complex $\mathbf{8 5}$, generated with the program Mercury using crystallographic data retrieved from the Cambridge Crystal Structure Database (Refcode ZOGYAV); structural information originally provided in Ref. 134. Aryloxy ligand hydrogen atoms omitted for clarity. The corresponding tantalum complex is isomorphous. 
Fig. 12. Ball-and-stick representation of $\mathbf{8 6}$ generated with the program Mercury using crystallographic data retrieved from the Cambridge Crystal Structure Database (Refcode YIYWIM); structural information originally provided in Ref. 136. Phosphine and aryloxy ligand hydrogen atoms are omitted for clarity.

Fig. 13. ORTEP drawing of $\mathbf{1 1 2}$ generated with the program Mercury using crystallographic data made available in the Supporting Information of Ref. 163. Thermal ellipsoids are shown at 50\% probability; ligand hydrogen atoms have been omitted for clarity.

Fig. 14. Proposed active species 113 for iron-catalyzed hydrogenation. 

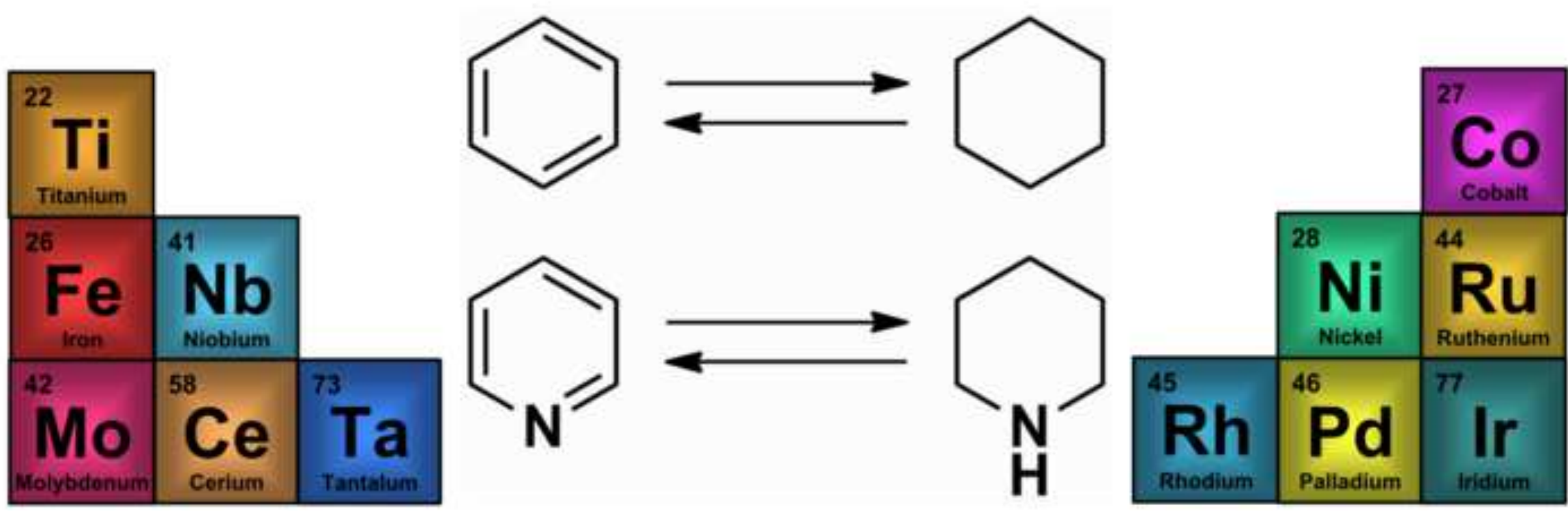